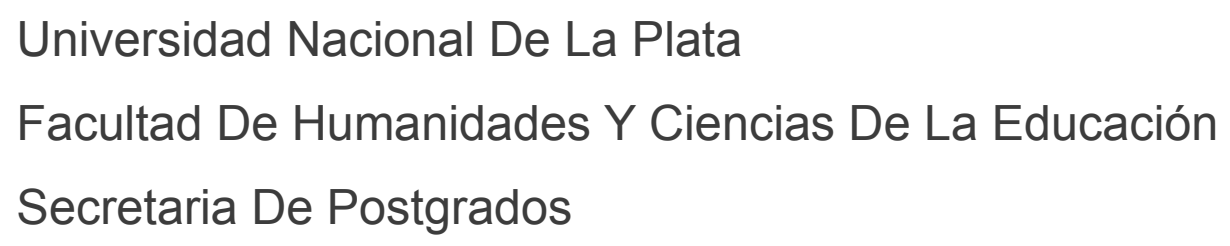

\title{
La Construcción de Sentido de la Desaparición Forzada en el Proceso de Memoria de Hijos e Hijas en Colombia
}

\author{
Andrea Guatavita Garzón
}

Tesis para optar por el grado de Magíster en Historia y Memoria

Director: Daniel Kersner, UBA

Codirectora: Sandra Raggio, UNLP

La Plata, 28 de mayo de 2014 


\section{Resumen}

La desaparición forzada es una práctica sistemática en Colombia. Ha sido reconocida a lo largo de las últimas cuatro décadas, definida legalmente y penalizada como una acción ejecutada por grupos de seguridad del Estado.

Genera impactos y pérdidas en personas, familias y grupos sociales. Frente a esas pérdidas las personas han optado por adelantar acciones de memoria con distintos objetivos y características, y en distintos escenarios.

Gracias a esas diferencias es posible construir una noción de la memoria en Colombia teniendo en cuenta que se desarrolla mientras avanza el proceso de represión. Pero también es posible conocer cómo la memoria de hijos e hijas de las personas desaparecidas es nutrida y promueve debates sobre temas como: el trauma, la transmisión familiar o generacional, la política, los potenciales de transformación de la memoria, las enseñanzas y los vacíos del pasado.

Esta tesis fue elaborada desde una perspectiva psicológica vinculándola con distintos discursos sociales para dar un marco amplio de comprensión al proceso subjetivo. En consecuencia, es posible decir que el sentido que hijos e hijas dan a la memoria es complejo y no está por fuera de su momento histórico y de la ideología que lo atraviesa.

Esos elementos externos a la disciplina así como algunas reflexiones sobre el acompañamiento psicológico a hijos e hijas, buscan ser un aporte novedoso al abordaje de la desaparición forzada. 
A los ausentes

y a quienes los mantienen siempre presentes en su rostro, en su lucha y en su corazón.

A Joaquín, a Diego y a Ana por que su solidaridad afectuosa fue fundamental en la realización de esta tesis. A mi mamá y mi hermano por su cariño y apoyo. 


\section{Índice de contenido}

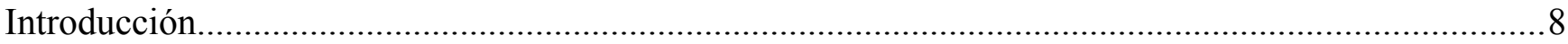

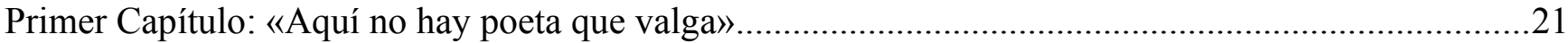

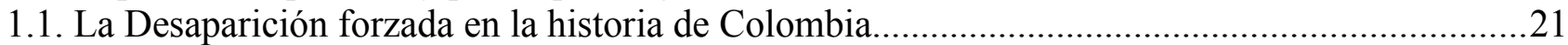

1.2. Elementos que constituyen la seguridad nacional y las estrategias de contrainsurgencia...........26

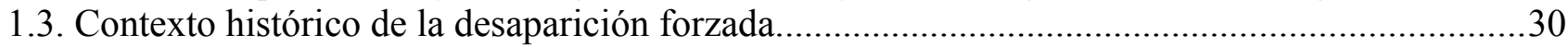

1.3.1. Huelga del '77 y reconocimiento oficial de la desaparición forzada.....................................30

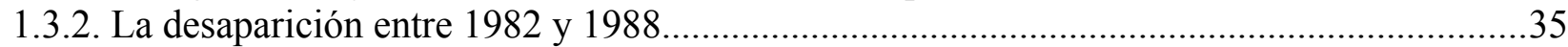

1.3.3. La Desaparición durante un giro en el desarrollo militar y la operatividad paramilitar (1988

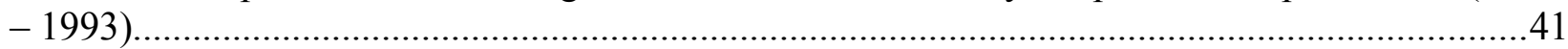

1.3.4. Establecimiento de una política de represión paralela a una política de memoria para la

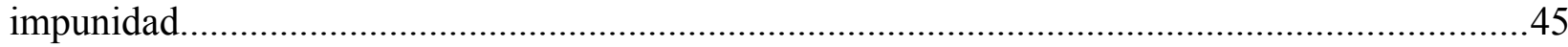

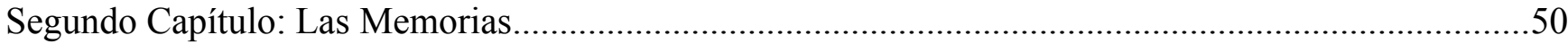

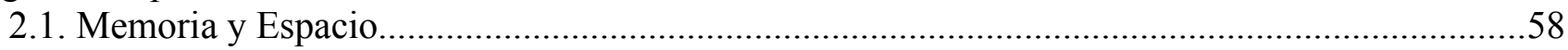

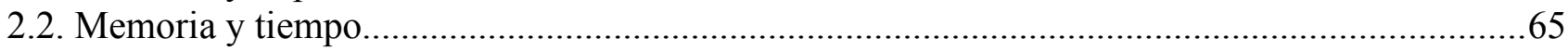

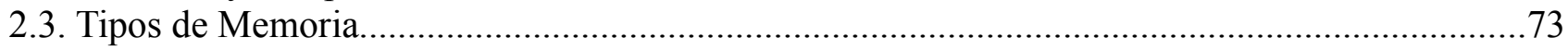

2.4. Trabajadores de estas memorias......................................................................................74

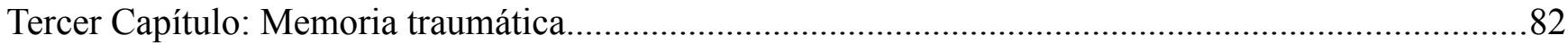

3.1. Procesos subjetivos frente a la desaparición forzada...............................................................91

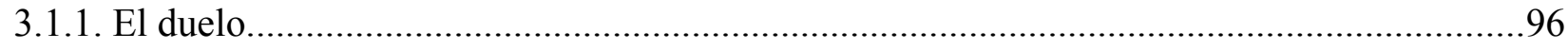

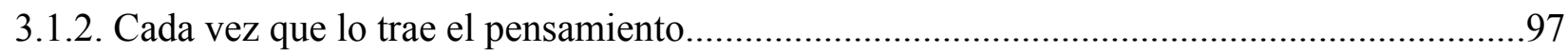

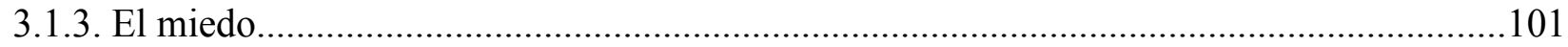

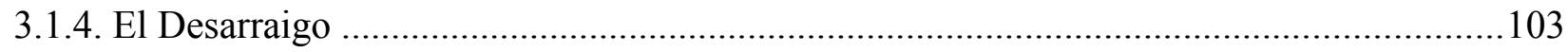

3.2. El dispositivo clínico en esta reconstrucción..........................................................................111

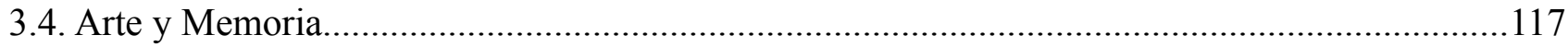

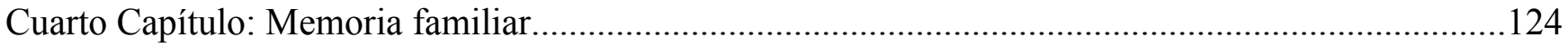

4.1. Organizaciones de familias de personas desaparecidas de manera forzosa................................127

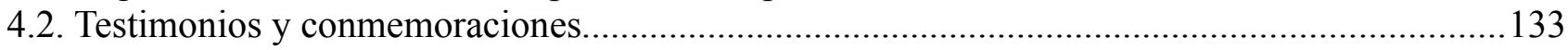

4.3. Transmisión entre generaciones y subjetividad......................................................................143

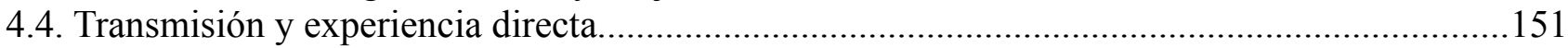

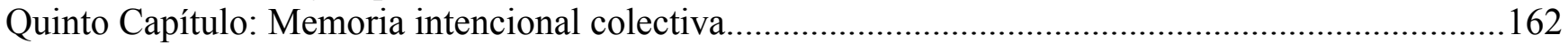

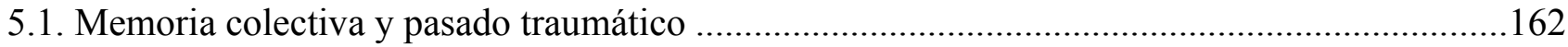

5.2. Disputas por el establecimiento de la memoria..........................................................................166

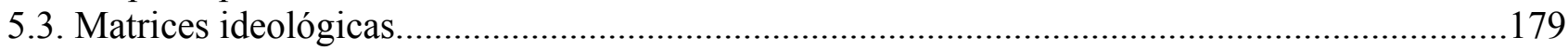

5.4. La memoria y su incidencia en el Estado...…………...........................................................182

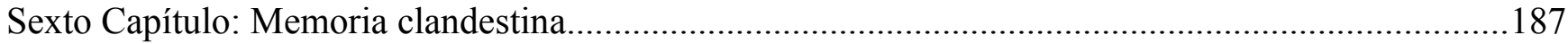

6.1. Marcos de memoria y márgenes de omisión.........................................................................187

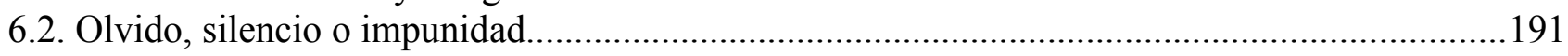

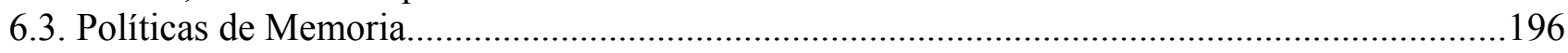

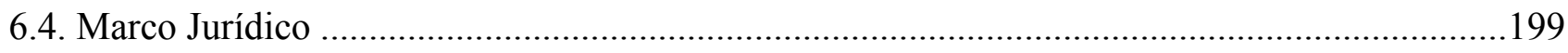

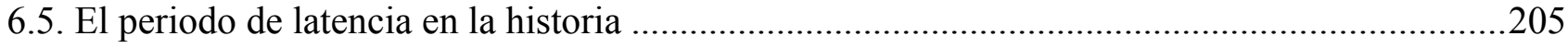

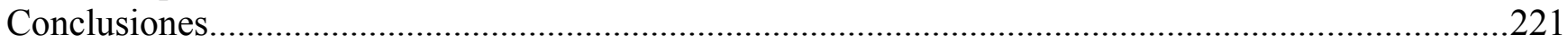

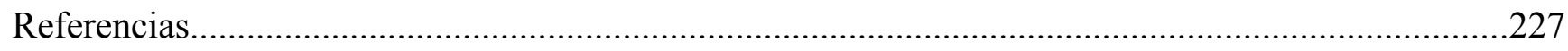




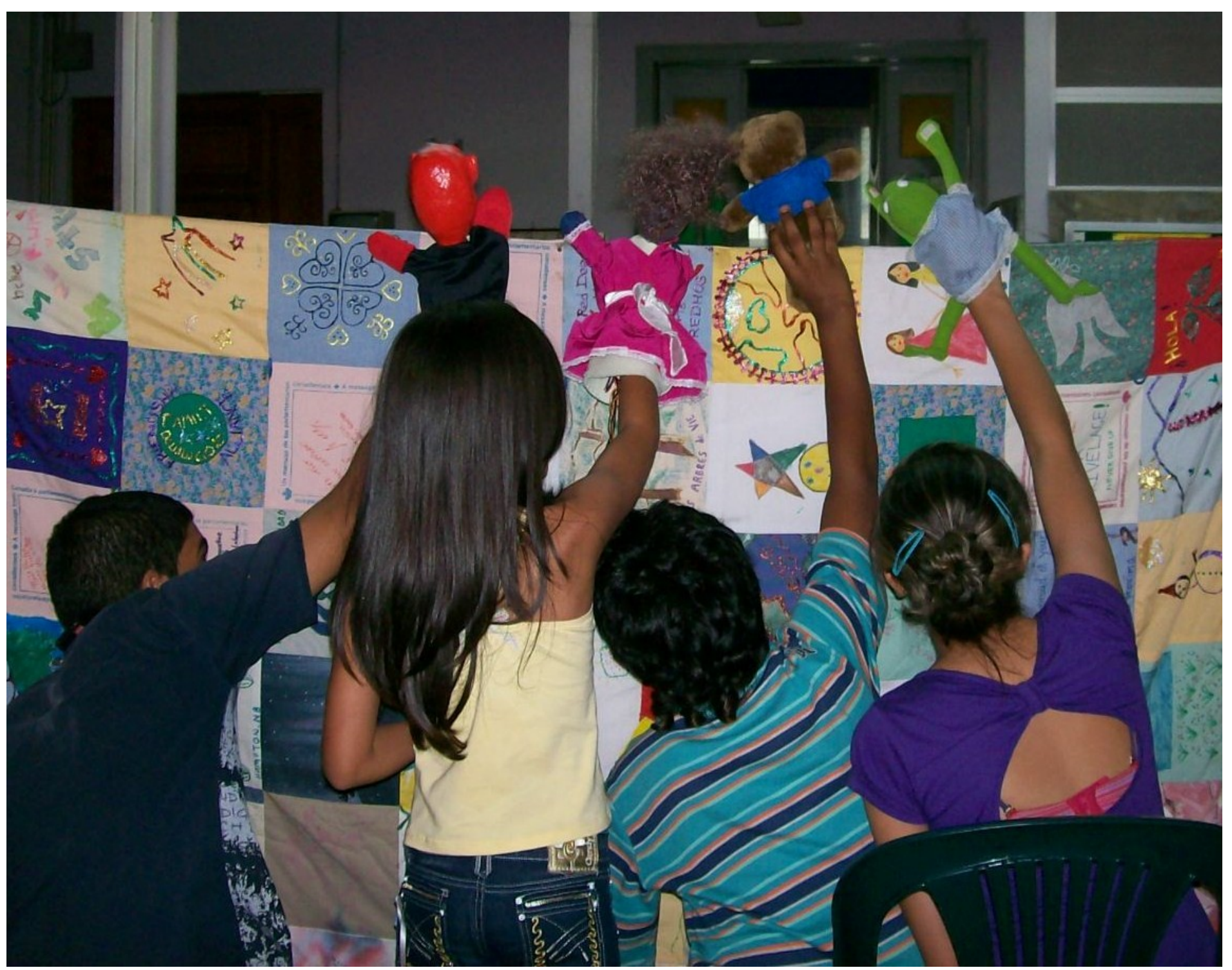

Medellín. Asfaddes. 2008. Fotografía: Andrea Guatavita 


\section{Introducción}

Hay varias experiencias que tengo presentes a la hora de pensar la tesis: La primera es la de un relato sobre un campesino de Tierralta $^{1}$ que se quitó las botas pantaneras (de caucho) que usaba sin medias y las entregó a una psicóloga para comprobar que podía ponerse en sus zapatos, como un ejercicio práctico ante el idealismo que ella impartía al hablar de convivencia. En otra ocasión, en un panel realizado en la Universidad de los Andes ${ }^{2}$ sobre los asesinatos realizados por el ejército en donde las víctimas son pasadas por muertas en combate, un espectador le preguntó a una "Madre de Soacha" ${ }^{3}$ cómo ayudarle a resolver esa situación por la que estaba pasando, sin caer en la situación por la que él mismo estaba pasando al escucharla, siendo parte del mismo contexto social. Sin relación dialéctica.

Ahora como sé que solo puedo intuir la situación de precariedad o de explotación de otro o de otra, o la experiencia de un familiar de alguien desaparecido, tengo que reconocer mi propia condición, al menos ponerme en mis zapatos.

Pensé primero en mi papel como psicóloga en el trabajo con familiares de personas desaparecidas, me pregunté a cerca de cuál era la manera o qué debía tener en cuenta para hacer bien el trabajo que creía que tenía que hacer: "Ayudar a los familiares a transitar el dolor y retomar o construir nuevos espacios de lucha" y me encontré con que la memoria colectiva era fundamental en el trabajo.

Le propuse a unas mujeres de la Comuna 13 un ejercicio llamado "la línea imaginaria" en donde unas argumentaban y otras contra argumentaban al rededor de premisas, ideas 0

\footnotetext{
${ }^{1}$ Municipio perteneciente a la provincia de Córdoba, ubicada en la Zona Caribe de Colombia y colindante con el municipio de Antioquia.

${ }^{2}$ La Universidad de los Andes, es una universidad privada con sede en Bogotá. Fundada en 1948 por el intelectual Mario Laserna, vinculado al partido conservador.

${ }^{3}$ Luz Marina Porras Bernal, Carmenza Gómez Romero, María Ubilerma Sanabria López, Blanca Nubia Monroy, Edilma Vargas Riojas y Flor Hilda Hernández son un grupo de mujeres habitantes de Soacha, municipio conurbanado con Bogotá y uno de los mayores centros de recepción de población desplazada de todo el país.
} 
imaginarios que son comunes en el grupo social al que pertenecen y pertenecemos. Les leí: "Es importante hacer memoria". Luego les propuse: "Las que estén de acuerdo se hacen de un lado de la línea y las que no están de acuerdo se hacen del otro". Y la mayoría se ubicaron del lado del desacuerdo. Les pregunté a estas mujeres que vivieron la experiencia de los tres operativos militares en la Comuna $13^{4}$, el por qué de cada posición. Una de ellas afirmó que era mejor olvidar y que recordar era muy doloroso. Mientras, silenciosamente, yo estaba de acuerdo pues las había escuchado cuando querían hablar de lo que le había ocurrido a sus familiares y era siniestro.

Teniendo en cuenta lo anterior pensé hacer este trabajo con personas que habían vivido experiencias que pueden sobrepasar las capacidades de elaboración de un sujeto, experiencias traumáticas de tipo político, que hubiesen adelantado sus propios procesos de memoria para que me enseñaran desde su experiencia "qué pasa con la memoria" ¿Cómo se hace? ¿Qué lugar tienen los sentimientos?

Esa pregunta por los sentimientos puede ser perversa si se expresa como: ¿Te dolió? ¿Qué tanto te dolió? Porque siempre duele. Por eso no dirijo la investigación por este camino. En cambio, si pensamos en los sentimientos dentro del campo social, con la ideología que dicta qué duele y qué no, "quiénes pueden ser llorados y quiénes no" (Buttler, 2010), la pregunta es distinta y no está dirigida a un familiar sino al colectivo: “¿Por qué a los hijos e hijas les duele y a otros no?". Por ejemplo, en la tesis sobre Mapiripán ${ }^{5}$ (Guatavita y Rozo, 2003) la pregunta era sobre si la masacre y desaparición de las personas que fueron victimizadas, en tanto crímenes de lesa humanidad, ofendían a todos los miembros de la nación colombiana. Ahora la cuestión es si la desaparición forzada en Colombia si lo hace. Yo siento que no, que sigue siendo un drama privado que no encuentra asiento en el relato del Estado porque este

\footnotetext{
${ }^{4}$ En la comuna 13 tuvieron lugar tres operaciones militares con apoyo de distintas instituciones de seguridad del estado: Orión (16 de octubre de 2002), Mariscal (21 de mayo de 2002), y otras menos reconocidas como Otoño, Contrafuego, Potestad y Antorcha bajo el principio de la lucha contra grupos subversivos y de control de drogas en la zona. Como resultado cientos de personas entre ellas, miembros de organizaciones sociales, fueron victimizadas, detenidas, asesinadas, desaparecidas y torturadas frente a la comunidad; por otro lado, los grupos paramilitares quedaron instalados como autoridades de la zona.

${ }^{5}$ Mapiripán es un municipio en el departamento de Guaviare al que ingresaron los paramilitares de las Autodefensas Unidas de Córdoba y Urabá en el año de 1997 y en el que ejecutaron una masacre. El Estado Colombiano fue sentenciado por parte de la Corte Interamericana de Derechos Humanos por su responsabilidad.
} 
aún no reconoce su ejecución generalizada desde hace, por lo menos, cuarenta años.

Qué mandato ideológico y en qué momento cubrió gran parte de las posibilidades de sentir que alguien es explotado y vulnerado y no responder de inmediato al hecho, de la misma manera que respondería alguien si lo pinchan con una aguja y en respuesta grita o retira la mano. ¿Por qué algunos son capaces de seguir la vida sin ningún cambio después de escuchar que el país sigue gobernado por ladrones y asesinos?

Los hijos e hijas guardan emociones y conocimientos que intentan reintegrar a la memoria colectiva. Esa idea es clara para mí después de una conversación con Diana Gómez, una de las hijas que participó en la investigación. Ella me hablaba con convicción de la necesidad de repensar las estrategias, las ideas políticas y no repetir o conservar los errores de la vieja izquierda de Colombia y yo desde una ignorancia bastante consciente de sí misma y atacada desde mi inquietud le pregunté: ¿Cuales errores de la izquierda? Y le recordé que yo no soy heredera de ese legado, que a mi pesar el olvido fue eficaz y no entendía bien de qué me estaba hablando.

Siempre que inicio un trabajo de investigación - todos han sido sobre Colombia y su realidadpienso en mis abuelos. Ellos son recordados en la familia por su pensamiento político, las acciones que realizaron y las consecuencias que esas acciones les generaron. Mi abuelo materno fue un campesino de ideología liberal, en la época de la "violencia" fue un perseguido Gaitanista, y después fue convocado por Tirofijo en el nacimiento de las guerrillas liberales para pelear, pero él ya estaba a cargo de once hijos y decidió otro camino.

Mi abuelo paterno, tenía ideología conservadora, sirvió como baquiano a la policía en la época de la violencia. Pero por eso no cambio su condición de vida ni tuvo protección. La guerrilla en retaliación le quemó la casa y la camioneta con la que trabajaba. Después de eso se desplazó a la periferia de Bogotá y su vida estuvo signada por la pobreza. Gracias a ellos recibí muchos elementos de algunas de las cosas que ocurrieron hace más de medio siglo y que marcaron la historia del país. Entre ellas el olvido y la marginación del discurso 
comunista. A pesar de que la política marcó la historia familiar, ni mi padre, ni mi madre o mis tíos tuvieron ninguna relación con la vida política de sus regiones ni de su país.

Los hijos y las hijas que participaron en este trabajo, me transmitieron relatos sobre la vida política de la generación anterior, la generación que creció después de "la violencia", que reaccionó ante el Frente Nacional y que vio su vida entera atravesada por el conflicto armado, la política generada por Julio Cesar Turbay durante la aplicación de la doctrina de Seguridad en Colombia. Posteriormente las políticas de neoliberalismo y el exterminio ejecutado por Álvaro Uribe Vélez, al igual que mis padres. A diferencia de ellos, una generación influenciada por los propuestas comunistas que surgieron a nivel global.

Estos hombres y mujeres cuentan con un conocimiento del pasado de estas ideologías del que estamos desprovistos muchos y muchas interesadas en la transformación del país, y mi consciencia de esto se dio gracias a este trabajo de indagar el poder terapéutico de la memoria. Esto me permitió reflexionar sobre su potencialidad de transformación y su carácter político, y por lo tanto, cambió mi propia visión del individuo y la clínica.

Tracé cuáles podrían ser las preguntas o la ruta que debía seguir para no desviar mi propósito: Cuál es el efecto de la historia de una generación en la que la continua, cuáles son las condiciones subjetivas de la construcción de la memoria en hijos e hijas de padres y madres desaparecidos, para encontrar los elementos que podrían guiar un posible acompañamiento psicosocial para aquellos y aquellas que participaran del proceso: El duelo, el miedo y los pactos de silencio.

En segundo lugar, para pensar este problema en un marco histórico, indagué el entretejido social que envuelve el ejercicio de memoria de hijos e hijas: Cuáles son las condiciones sociales para la construcción de la memoria en hijos e hijas de padres y madres desaparecidos. En consecuencia, hay unas vivencias que reconocí a través de las entrevistas, vivencias individuales que se tocan o que me dejan ver condiciones sociales. En resumen este un trabajo sobre el cómo de la memoria, sobre la experiencia de 
reconstrucción no sólo en el escenario público de difusión sino en el proceso que moviliza la emoción y el conocimiento del pasado en un marco social determinado.

El enfoque de la investigación fue etnográfico. Articula una acción hermenéutica a la antropología para centrarse en el significado de los hechos culturales y no en la observación de ciertas conductas (Cairo, 2008), se refiere a la transformación del mundo social a través de la transformación de la narración que se construye de él. Cuenta con una perspectiva subjetivista en tanto "la selección, planificación y aplicación de técnicas están ligadas al conocimiento que el investigador produce de sí mismo y que producen los informantes" (Gubert, 2004:118). Pero teniendo en cuenta algunos aportes del enfoque de la Investigación Acción Participativa, metodología endémica de latinoamérica, reconozco en la investigación una acción de intercambio en donde aquellas personas que participan no son informantes, sino que a través de este trabajo construyen conocimiento y pueden reflexionar. Lo que hace particular mi trabajo es que como investigadora inserto conocimientos previos y categorías para la lectura y desarrollo del proceso de investigación.

Con respecto a mi decisión de hablar del cómo de la memoria resalto, como lo señala Visakovsky, que la memoria se circunscribe a las formas de producción social de interpretaciones publicas del pasado para constituir el presente. Por lo tanto, su abordaje involucra procesos de interpretación y condiciones de producción y uso. La articulación de los eventos pasados se funda en esquemas de interpretación anteriores, gracias a que el pasado guarda relación con el presente y esa relación lo legitima (Visakovsky, 2007). La investigación busca esa continuidad más que los elementos que separan históricamente una versión del pasado con el presente.

Esta investigación plantea la posibilidad de hablar de la vida de los familiares de desaparecidos desde su propia visión (Geertz, 1997), no espera contrastar sus afirmaciones con sus prácticas, reflexión que está más acorde con un análisis antropológico del ejercicio de la memoria y su significado desde las experiencias de hijos e hijas ${ }^{6}$. Para esto ubica las

6 La Psicóloga María Paula Gómez que hizo parte del proceso de hijos e hijas desarrolló su trabajo de tesis sobre esa relación entre la memoria y la práctica como eje sostén de la noción de buenas prácticas. Su hipótesis fundamental es que 
entrevistas al rededor de un momento histórico que se sigue hasta hoy, que no termina de hacerse pasado, pero que se origina en momentos de los cuales ya se construye historia y por lo cual, entrevisté a personas y busqué bibliografía que me explicara algunas expresiones sociales y acontecimientos históricos que tuvieron importancia tanto para el Estado y el historiador como para las personas que participaban de la investigación.

"Conocer para actuar bien y transformar mejor" (Orlando Fals Borda)

Esta investigación tiene la influencia determinante del marco ideológico y conceptual de la investigación y las experiencias previas en el campo, por parte de la investigadora. Sin embargo, teniendo en cuenta que mi objetivo es conocer esta realidad para aportar al proceso de transformación en Colombia, me exige también una posición crítica frente a la información y muy rigurosa de elaboración para encontrar elementos novedosos.

Este proceso de investigación implica la comprensión del contenido emocional del tema, la introducción en un nivel muy importante de todos los sentimientos que emergen en el proceso de investigación. Este reconocimiento ético me implicó también poner en juego elementos a los que llamo herramientas de contención y que están dirigidas a mantener la escucha, reconocer la realidad de la desaparición y sus impactos, e indagar los recursos de elaboración activados en el pasado por los familiares (Pérez -Sales, 2008) aunque no fueran centrales en la elaboración de la tesis.

Para mantener el cuidado del grupo y la investigadora, se planteó como estrategia el encuentro regular con quienes guían la investigación y la devolución del proceso por parte de la investigadora al grupo. Para finalizar es necesario aclarar que esta investigación busca la creación de un conocimiento novedoso y válido, en ese sentido y teniendo en cuenta los anteriores principios éticos, se comprometió a la implementación de una metodología rigurosa que ayude a dar cuenta de esta problemática. En consecuencia se hizo registro muy

la disminución entre la brecha que define lo que se espera o se propone y las prácticas reales del colectivas mejora la situación colectiva y la salud mental de las personas que hacen parte de la organización. 
preciso del trabajo de campo y el análisis de los resultados con relación a la teoría para señalar algunos espacios de trabajo y explorar el campo sin denunciar premisas universales.

Según autores como Robben (1989) el trabajo con personas que han vivido una experiencia de victimización, permite una mínima neutralidad, pues ellos requieren un gesto de acuerdo de parte del investigador para crear vínculos de confianza, esto a razón de que "sus relatos han sido enfrentados con incredulidad". La experiencia analítica, por ejemplo, a través de la cual es un requisito que el terapeuta crea en las palabras de su paciente, ilustra las condiciones del trabajo de campo con estos sujetos desde otras líneas $y$, por lo tanto, la necesidad de escuchar desde otro lugar el relato, entendiendo que el reconocimiento de la verdad es fundamental para el vínculo de confianza.

Esta confianza en la versión de los familiares parte no sólo del hecho de crear condiciones de trabajo para el investigador y del reconocimiento de que los testigos, son fuente efectiva de la reconstrucción fáctica de la desaparición. Viene de la necesidad de conocer la versión del familiar y su construcción subjetiva. En consecuencia, se discute la distancia propuesta al investigador como parte de un colectivo que atraviesa por situaciones de crisis social profunda. Martín Baró plantea sobre este tema:

Toda la psicología, deseosa de adquirir estatuto científico y reconocimiento académico, tendió a desprenderse demasiado radicalmente de sus raíces filosóficas, a someterse con excesiva estrechez a los limitados márgenes del método experimental y a pretender una asepsia científica que la ubicaba por encima de las preocupaciones y conflictos concretos de la vida social, ahorrándole al psicólogo la dolorosa necesidad de tener que optar por unos u otros valores (...) se va a insistir por un lado en la necesidad urgente de volver a teorizar y no sólo a elaborar modelos de corto alcance, así como a someter los métodos a la teoría y las técnicas a los problemas, no al contrario. (Martín Baró, 1983:44).

En este caso la teoría sometida, es aquella que se refiere a la memoria como dadora de sentido, la hipótesis de carácter psicosocial que dicta que la reconstrucción de la memoria implica pasar la frontera entre el sufrimiento guardado en la familia y el ámbito social. El objetivo en este caso, es repensar la memoria como requisito para la comprensión o 
construcción de la realidad de personas afectadas por la desaparición forzada desde su propia experiencia.

Las técnicas usadas para la recolección de la información en campo fueron las siguientes:

- Seguimiento y revisión de documentos y distintas expresiones de memoria Recolección de fotografías tomadas a los padres y madres desaparecidos y compartidos en la investigación, fotografías de carteles y otros símbolos usados durante conmemoraciones o marchas, canciones, videos del documental NN elaborado por Chico Bauti, escritos tomados de páginas y blogs que los hijos y las hijas compartieron conmigo o del libro de poesía "Tránsito de un Hijo al Alba" de Chico Bauti, distintas representaciones que los y las jóvenes han usado en el proceso de memoria.

- Observación participante

La transformación del medio por la presencia de la investigadora, su acción de conocimiento a través de la construcción del campo, elecciones y categorizaciones, son asumidas en esta investigación. Por lo tanto se desarrolló un diario de campo que narra la experiencia y permite el descubrimiento de emergentes en campo así como de variantes promovidas por ella, la investigación y su metodología.

- Entrevistas para el reconocimiento del pasado transmitido

Aunque las entrevistas tuvieron variaciones se movieron al rededor de los siguientes temas:

1. Noción de memoria.

2. Cambios surgidos con la desaparición.

3. Cambios experimentados durante la reconstrucción de la memoria.

4. Escenarios para la reconstrucción de la memoria

5. Dificultades de la memoria.

6. Quiénes aportan en la reconstrucción de la memoria.

7. Acciones validadas por los y las hijas para lidiar con el dolor.

8. Concepto de generación. 
9. Condiciones generales de los hijos y las hijas, edad, ocupación, educación, entre otras.

10. El papel de la memoria en la vida de hijos e hijas.

Todas las preguntas fueron abordadas en términos de conocer o indagar las acciones, reacciones, ideas, actitudes que los hijos e hijas construyeron al rededor de los eventos que iban narrando en términos de valorarlos como caminos de transformación personal y resistencia por dos motivos: No profundizar en núcleos traumáticos pues la investigadora no planeaba continuar procesos terapéuticos; buscar nuevas herramientas o acciones para desarrollar el acompañamiento realizado por profesionales de la psicología o trabajadores del área psicosocial.

Cuando se realizan estas entrevistas se puede optar por proponer a los participantes firmar un consentimiento informado y disponerse a usar la información que ellos y ellas conocerán con suerte al final del trabajo de la investigación, puesto que en términos legales el compromiso queda saldado. Por otro lado, por recomendación legal se guarda confidencialidad de los datos de las personas entrevistadas. Con respecto a estos puntos se realizaron dos reflexiones: La primera tras la lectura de un texto de Daniel Kersner llamado Consentimiento informado o informando con sentimiento que termina de la siguiente manera:

Le pregunta a Caín si sabe de Abel. “¿Acaso soy yo el guardián de mi hermano?” Responde culposo Caín, proponiendo por la negativa una ética de la responsabilidad -él debe saber sobre su hermano-, del involucramiento -él debe cuidar de su hermano, ya que aquí la palabra guardián equivale a cuidador-, y de la igualdad -ya que se trata de su hermano, un par-. Responsabilidad, compromiso o involucramiento y trato igualitario, deben estar siempre presentes en la relación médico-paciente, en cualquier especialidad (Kersner: 4).

Este documento sobre consentimiento informado reflexiona sobre cómo un instrumento de importancia dentro del mundo médico se torna una herramienta burocrática despersonalizada que no asegura el cuidado que el médico le debe a su paciente. Aunque este trabajo no se realizó desde el establecimiento de una relación médica las preguntas que realicé tocan el 
mundo emocional de las personas y requirieron el uso del consentimiento informado para formalizar acuerdos con los y las participantes de la investigación. Les anuncié en qué participaban, asumí su decisión autónoma de permitirme usar la información después de leer la transcripción.

En segundo lugar, y gracias a este ejercicio, una de las participantes me planteó que mantener su nombre anónimo sirve a un proceso ideológico por parte de la academia de hacer invisible al "sujeto" de la investigación y que el proceso de investigación debe ser amplio y permitirles dar a conocer su versión de la historia. En consecuencia la identidad de las y los participantes del proceso es explícita, en todos los casos después de su aprobación.

Teniendo en cuenta que he planteado pocos casos y que estos no son representativos de una población, propongo el reconocimiento de las significaciones que van surgiendo en cada relato para delimitar un campo y reconocer elementos importantes en el análisis del tema sin llegar a generalizar. Seguramente las personas que lean el documento encontrarán elementos en común con los casos conocidos, así como me ocurrió leyendo las investigaciones del cono sur sobre daño transgeneracional. Pero es importante resaltar que el foco del debate está en el análisis del trabajo de la memoria, sus implicaciones psicosociales y la comprensión del marco social. A razón de que no se ha divulgado y profundizado en la ejecución de la desaparición forzada en Colombia, le dedico gran parte de la tesis a exponer la problemática.

Para poder desarrollar mi propuesta organicé el texto de la siguiente manera: En el primer capítulo expongo un contexto general de la desaparición, algunos antecedentes de su realización antes de su reconocimiento oficial en 1977. En el segundo capítulo presento un análisis sobre las memorias, dividido según distintas categorías que reconocí gracias a las entrevistas realizadas en el trabajo de campo. Estas categorías se diferencian si se tienen en cuanta las preguntas que guían a los y las hijas al momento de encarar y reconstruir el pasado, el tipo de acciones y su motivación más o menos intencional, la diferencia en el eje o en el centro de las problemáticas que cada reconstrucción propone y la diferencia de 
escenarios que dan lugar a estos procesos. Estas categorías son: memoria traumática, memoria familiar, memoria colectiva.

La memoria traumática es desarrollada en el tercer capítulo e incluye algunas reflexiones sobre el concepto de trauma en relación con la memoria, y una profundización en las cuestiones del duelo, el miedo y los pactos de silencio. En el cuarto capítulo se expone la idea de memoria familiar en donde toma un importante lugar el concepto de transmisión y la pregunta sobre qué se transmite de una generación a otra, una historia, un proceso de lucha, o un daño. Cuáles son las limitaciones de esa memoria y algunos de sus escenarios.

La memoria colectiva es propuesta en el cuarto capítulo, aunque se construye con base en reflexiones anteriores sobre la transmisión toma un lugar fundamental el análisis de las luchas de la memoria y las preguntas sobre cuales son los nuevos elementos que se introducen con la nueva generación, qué intentan recuperar. Esta memoria colectiva se contrapone de alguna manera con la idea de impunidad y por lo tanto, se introduce una reflexión sobre las condiciones políticas para la reconstrucción de la memoria en Colombia.

En el quinto capítulo se recogen elementos que se escapan de todas estas producciones y que pueden considerarse, más que olvidados, silenciados y transmitidos a través de algunos grupos o escenarios por la necesidad de conservarlos y a la espera de una transformación del contexto que permita que ciertos recuerdos puedan instalarse e incluirse en la memoria colectiva. La tesis finaliza con un conjunto de conclusiones que intentan dar cuenta de algunas nuevas preguntas para la investigación y de los elementos que lograron aclararse gracias al desarrollo de este trabajo.

Agradezco especialmente a las personas que participaron de la investigación por sumarse una vez más a esta tarea y poner al servicio de la reflexión académica un trozo de su experiencia de vida para colectivizar su pasado y encontrar en él trozos de la historia política del país y de una generación que propuso un camino para la transformación. Su conocimiento sigue siendo vital para explicar el presente y encontrar otros caminos de lucha. 


\section{SIGLAS}

ACCU

Autodefesas de Córdoba y Urabá (Estructura Paramilitar)

AUC Autodefensas Unidas de Colombia (Estructura Paramilitar)

$\mathrm{CIDH}$ .Comisión Interamericana de Derechos Humanos

ColDH .Corte Interamericana de Derechos Humanos CINTRAS. .Centro de Salud Mental y Derechos Humanos (Chile)

$\mathrm{CNMH}$ .Centro Nacional De Memoria Histórica

CONVIVIR Cooperativas de Vigilancia y Seguridad Privada CUT Central Unitaria de Trabajadores

DSMIV. Manual Diagnóstico y Estadístico de Desórdenes Mentales, 4th Edición EATIP Equipo Argentino de Trabajo e Investigación Psicosocial EPL .Ejército Popular del Pueblo (Organización de Izquierda Armada)

FARC - EP Fuerzas Armadas Revolucionarias De Colombia - Ejercito Del Pueblo (Organización de Izquierda Armada) FEDEGAN .Federación Nacional de Ganaderos FFMM .Fuerzas Militares De Colombia GTNM/RJ. Grupo Tortura Nunca Mais do Río de Janeiro

$\mathrm{M}-19$ Movimiento 19 de Abril (Organización de Izquierda Armada) MAS. Muerte A Secuestradores (Estructura Paramilitar) MTDF Mesa De Trabajo Sobre Desaparición Forzada

PCNM Proyecto Colombia Nunca Más PRT Partido Revolucionario de los Trabajadores (Organización de Izquierda Armada) SAC Sociedad de Agricultores de Colombia (Agricultores Latifundistas) SERSOC Servicio de Rehabilitación Social (Uruguay) UP. ..Unión Patriótica (Partido político de izquierda)

CONADEP. .Comisión Nacional sobre la Desaparición de Personas (Argentina) ESMA. Escuela de Mecánica de la Armada (Argentina) 


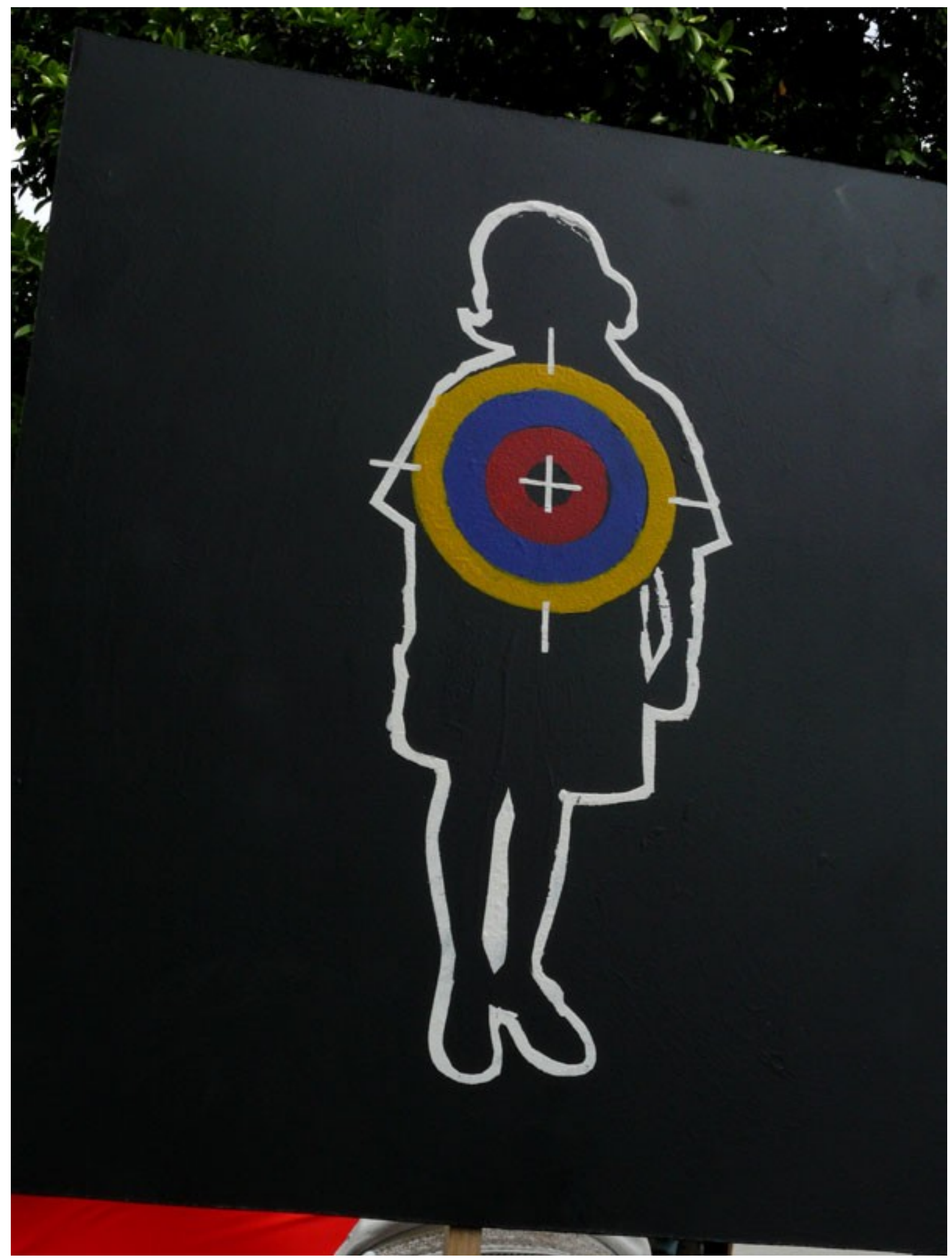

"Blanco". Marcha por la dignidad de las víctimas de crímenes de estado. Bogotá. 6 de marzo de 2008. Fotógrafo: Jaime Gómez. 


\title{
Primer Capítulo: «Aquí no hay poeta que valga»
}

\subsection{La Desaparición forzada en la historia de Colombia}

\author{
Párese el río y cesen sus rumores; \\ no dé el rosal su rosa conversada; \\ no hable la bandera sus colores, \\ quédese la estación estacionada. \\ Muera el árbol. No se alcen los alcores \\ y el sabio ruiseñor no diga nada; \\ la luz no rectifique sus fulgores, \\ desembárquese el agua ya embarcada. \\ El sol suspenda su divina serie; \\ endurézcase el viento, y no lo diga \\ y el ancho cielo deje la intemperie. \\ No hable la voz sus altas soledades \\ ique la patria dejó de ser amiga \\ y están sin libertad sus libertades! \\ (A La Libertad, Luis Vidales. 1948. ${ }^{7}$ )
}

En La cambiante memoria de la dictadura. Discursos públicos, movimientos sociales y legitimidad democrática, Daniel Lvovich y Jacquelina Bisquert (2008) presentan un recorrido en torno a la representación que se fue transformando, según las coyunturas, de lo que significó la última dictadura militar y en particular del terrorismo de estado en Argentina. La memoria configurada a partir del esfuerzo de los organismos de los derechos humanos es la representación predominante una vez que fue asumida casi por completo por el Estado. Esta novedad permitió establecer a los derechos humanos como fundamento de la legitimidad democrática y los convirtió en una señal de identidad partidaria, aunque estas representaciones difundidas a través de distintas herramientas comunicativas no se plasmen de manera uniforme sobre el conjunto social.

En Colombia no hay un corte histórico o reconocimiento público de la acción criminal del Estado. La comunidad internacional y los historiadores hablan de una guerra prolongada y una violencia generalizada. Al mismo tiempo, el Grupo de Memoria Histórica oficial,

\footnotetext{
${ }^{7}$ Poeta nacido en 1904. Secretario nacional del partido comunista colombiano, líder en la lucha de tierras adelantada por los campesinos y miembro del movimiento de Jorge Eliécer Gaitán. Exiliado en Chile en 1953 en donde residió durante once años. Fue detenido por el ejercito Nacional durante el gobierno de Julio César Turbay Ayala y torturado en "las caballerizas de Usaquén" en 1979. Fue condecorado en 1983 con el premio Lenin de la Paz por la URSS. Falleció en 1990.
} 
reconoció la responsabilidad del Estado en la perpetración de algunos hechos. La convivencia de las dos ideas es el núcleo de una confusión permanente.

Colombia ha vivido las últimas décadas en luto permanente. Masacres y otras formas de violencia colectiva con diversas magnitudes, intencionalidades y secuelas han ensangrentado la geografía nacional. Entre 1982 y 2007, el Grupo de Memoria Histórica ha establecido un registro provisional de 2.505 masacres con 14.660 víctimas. Colombia ha vivido no sólo una guerra de combates, sino también una guerra de masacres. Sin embargo, la respuesta de la sociedad no ha sido tanto el estupor o el rechazo, sino la rutinización y el olvido. El municipio de Trujillo, en el norte del departamento del Valle, ha sido escenario de esa violencia múltiple y continuada, y también de nuestra amnesia. No sólo sus vecinos del orden regional desconocen o han olvidado lo sucedido, sino que más aún, respecto a esos eventos existe lo que pudiéramos llamar una desmemoria nacional, como en efecto lo han resentido las víctimas. Volver la mirada a Trujillo es entonces un primer ejercicio en la misión de convocar la solidaridad ciudadana y mostrarle al país que los hechos de Trujillo pertenecen al pasado nacional. Trujillo es, en más de un sentido, Colombia (...) (Sánchez, 2008:12).

Una de las mayores dificultades es que hechos como las que menciona este informe en donde se establece la participación del estado y la existencia de escuelas de tortura y acciones sistemáticas de terror por parte de este se llaman la Violencia o toman el nombre de conflicto armado, por la existencia innegable de dos grupos guerrilleros, ante lo cual algunos dudan hasta de la posibilidad de la aplicación de las normas de Derechos Humanos o del reconocimiento de los Crímenes de Lesa Humanidad. Estos crímenes son generados por el estado cuando de la misma manera y en términos formales es un estado democrático, que ha firmado los distintos acuerdos internacionales de los Derechos Humanos.

Se debe su especial arraigo, como su desenvolvimiento, renovación y ocultamiento, a esa lógica de conservar a toda costa e ininterrumpidamente la apariencia de unas formas exteriores del régimen jurídico-político, y por otro lado a la intencional explotación adecuada o utilidad planeada de esa imagen de democracia, supuestamente nunca quebrantada por ocupaciones militares o cesiones del Estado Democrático, tras la que se esconde eficazmente ese aterrador expediente y el actual panorama de políticas y mecanismos con los que se ha desarrollado el genocidio en Colombia (PCNM, 2000).

La existencia de un régimen constitucional, la inscripción de todos los derechos liberales y los discursos de los distintos gobiernos así como su integración a los tratados 
internacionales, no han servido de garantía para la prevención o judicialización de los crímenes de Lesa Humanidad.

Colombia es una excepción altamente costosa de la denominada doctrina de seguridad nacional, no por estar fuera del historial de esa teoría, sino por constituirse gradualmente en este país un refinado paradigma práctico de la misma, creado por civiles y militares, que ha probado eficazmente hasta la actualidad su alcance estratégico como en ningún otro país de América Latina. Superarlo es acabar con algunas de las premisas o supremos fundamentos de validez de la guerra sucia y el terrorismo de Estado (PCNM, 2008).

Las organizaciones participantes en el proceso de documentación adelantado por el Proyecto Colombia Nunca Más (en adelante PCNM) consensuaron que el ciclo de violencia que se mantiene hasta la actualidad tiene perfiles muy claros que lo diferencian de ciclos anteriores. Inicia a mediados de la década del sesenta y continua hasta hoy.

\begin{abstract}
Muchas circunstancias históricas de Colombia, de América Latina y del mundo, contribuyeron a que la violencia, durante este período, se ubicara fundamentalmente sobre el eje de un conflicto social en el que se enfrentan proyectos antagónicos de sociedad. La violencia anterior, de las décadas de los cuarentas y los cincuentas, tuvo un perfil declaradamente policlasista, enfrentando a dos sectores económico-políticos de intereses opuestos, que buscaban cada uno la hegemonía, y que se proyectaba, mediante banderas partidistas que explotaban los sentimientos populares, a todo el espectro de capas sociales (PCNM, 2000).
\end{abstract}

Eso en términos de otros casos nacionales sería definir un intervalo de tiempo reconocido como pasado traumático, pero sin desarticularlo del resto del proceso histórico puesto que se consolida gracias a antecedentes de la violencia y elementos políticos y económicos de mediados de siglo. En consecuencia podríamos preguntar cual es el intervalo más duro en cuanto al ejercicio de la violencia de estado y en términos generales podríamos afirmar que pudo ser el periodo de la presidencia de Julio César Turbay Ayala entre 1978 y 1982. Sin embargo, teniendo en cuenta el análisis del proceso de fortalecimiento militar y paramilitar es más interesante ver cómo se da la transformación de una estructura de estado establecida para la criminalidad más que detenerse sólo en el tipo de gobierno que se gestó en el 
periodo mencionado. Algunas de las características con que Gonzalo Sánchez describe el terror de esa época, podrían aplicarse también al actual ciclo de violencia:

En una sociedad en donde los contendores políticos y sociales no pueden ser pensados en términos de rivalidad sino de desviación de una verdad o creencia originaria — de ortodoxia y herejía, como en las guerras de religión-, la regeneración social y política no puede lograrse sino por medio de la proscripción o el aniquilamiento de quienes, según los parámetros histórico-culturales dominantes, se encuentran en estado de transgresión. A este tipo de representaciones de la sociedad se aproximaba la Colombia de los años cincuentas. Desde el poder se urdían verdaderas estrategias de homogenización dentro de las cuales la guerra y la política no podían pensarse simplemente en términos de victoria sobre el enemigo sino de eliminación física del mismo. La diferencia se había hecho incompatible con el orden" (Sánchez, 2004).

Hay otros elementos que son particulares a los dos periodos estudiados, en la década de los 50', después del asesinato de Jorge Eliécer Gaitán", la violencia se ejerció "como instrumento de una guerra inter-partidista que suprimía las expresiones sociales"; mientras que la violencia en el segundo ciclo "se ejerce como instrumento de militarización de la polarización social" (PCNM, 2000) y se reconoce la incidencia del narcotráfico potenciando el nivel de terror. Dentro de esa documentación del PCNM, después de escoger ese periodo histórico que aun no se ha cerrado se establece la necesidad de documentar tan sólo los crímenes de Derechos Humanos y no del Derecho Internacional Humanitario.

EI DIH no tuvo en cuenta, pues, la racionalidad propia de la Guerra de Guerrillas, cuyos manuales más elaborados comenzaron a ser conocidos en los años sesentas. Este modelo de guerra, diseñado para dirimir conflictos de legitimidad dentro de un mismo Estado, y desde los intereses del polo más pobre de la población, se sale de los marcos más clásicos de la guerra regular entre Estados, sobre cuyo modelo se redactó el DIH.

En efecto, la Guerra de Guerrillas se funda en una primera realidad: que debe enfrentar una estructura estatal, detentora de medios muy poderosos de guerra (como aviones y tanques de guerra, ejércitos bien financiados y armados gracias al presupuesto del Estado) sin tener acceso a los recursos del Estado,

\footnotetext{
${ }^{8}$ Esas intervenciones se mantuvieron y se concretaron en momentos históricos para la historia del país: Jorge Eliécer Gaitán, abogado defensor del movimiento obrero, miembro del partido liberal, investigador del caso de las bananeras, encabezó un movimiento social de grandes dimensiones en Colombia. El 9 de abril de 1948, dos décadas después de las bananeras, el abogado fue asesinado al parecer con apoyo de la CIA (Sánchez Torres, 2001).
} 
dado que el motivo fundamental de la guerra es justamente el no acceso de las capas empobrecidas a los recursos del Estado. La racionalidad de ese tipo de guerra implica, entonces, adoptar métodos de camuflaje entre la población civil y de acciones ofensivas de sorpresa, y jamás de acciones defensivas, pues estas últimas conllevarían a una desventaja militar evidente frente al enemigo. Este elemento fundamental de la racionalidad propia de la Guerra de Guerrillas entra ya en contradicción con uno de los principios básicos del $\mathrm{DIH}$, como es la distinción neta entre combatientes y no combatientes.

Muchos Estados, y entre ellos el colombiano, han tomado pie en esta característica de la Guerra de Guerrillas o "irregular", para justificar su agresión sistemática contra la población civil, o para camuflar a los combatientes del Estado bajo fachadas de ejércitos irregulares o paramilitares que se presentan como "no estatales". Pero mal podría justificar un Estado el asumir métodos característicos de fuerzas guerrilleras, métodos cuya única justificación descansaría precisamente en la imposibilidad de acceso a los recursos que tiene el Estado (PCNM, 2000).

El anterior criterio del PCNM es altamente conflictivo y problemático en el contexto actual porque evidencia la desigualdad de estrategias y cuestiona como entender los crímenes cometidos por la guerrilla en un contexto que más que igualarla al Estado prioriza su imagen de crueldad. La documentación se hace en clave del tipo y la intención política del crimen según el contexto político y económico de cada región documentada, no se construye sólo en términos humanitarios.

Ahora bien, para establecer las características de cada modelo de represión construido por el PCNM se tienen en cuenta diversos aspectos que en su interacción y dinámica configuran un modelo de control social y político más o menos determinado, tales como el tratamiento jurídico del delito político y el conflicto social en materia de violaciones graves en los procedimientos (allanamientos, detenciones, interrogatorios, proceso judicial y derecho de defensa); las modalidades y cuantificación de Crímenes de Lesa Humanidad; la identificación de los sectores sociales criminalizados; los mecanismos de impunidad, de hecho y de derecho, implementados; y la operatividad represiva (operativos y planes militares, operaciones encubiertas y paramilitarismo) (Giraldo, 1998). 


\subsection{Elementos que constituyen la seguridad nacional y las estrategias de contrainsurgencia}

Las estrategias de contrainsurgencia están basadas en manuales que definen según el $\mathrm{PCNM}^{9}$ :

La noción de enemigo, o gestor de una alternativa ilegal de nacionalidad y sociedad que surge por la desatención del Estado a múltiples necesidades de la población. El conflicto es consecuencia de conflictos de otro nivel que generan el choque entre fuerzas de seguridad y grupos subversivos organizados con apoyo de extranjeros con el objetivo de tomar el poder y con participación activa de distintos sectores sociales ${ }^{10}$ (PCNM, 2008).

Población civil como objeto de la estrategia contrainsurgente, según los manuales estadounidenses y franceses las fuerzas irregulares dependen de la sociedad civil y la identifican como parte de estas fuerzas junto con el grupo armado; los paros y huelgas se identifican como acciones de guerra; se reconocen como organizaciones sociales "en lucha revolucionaria": estudiantes, obreros, etc; y se asigna al movimiento obrero como forma de organización primordial del sector simpatizante. Insurgencia se define como "todo intento de parte de una organización disciplinada de hombres para efectuar una reestructuración socio económica de la sociedad en nombre de aquellos amplios sectores económicamente necesitados y que no participan en la vida política de su propio país"11. En todo caso no es siempre armada y no tiene un campo de batalla limitado (PCNM, 2008).

\footnotetext{
9 "Operaciones Contra Las Fuerzas Irregulares", editado por el Ejército Nacional en septiembre de 1962, como traducción del manual FM-31-15 del Ejército de los Estados Unidos; "La Guerra Moderna", texto elaborado por el francés Roger Trinquier, en el cual sistematiza la experiencia contra insurgente en las guerras de Argelia y de Vietnam, traducido y editado por el Ejército colombiano en 1963 y usado desde entonces en el adoctrinamiento militar. Muchas de sus directrices se retoman en los manuales posteriores; "Reglamento de Combate de Contraguerrillas" (EJC 3-10, Reservado) aprobado en la Ayudantía General del Comando del Ejército en 1979; "Combate contra Bandoleros o Guerrilleros", (EJC-3-101), aprobado por la Disposición № 00014 del 25 de junio de 1982 del Comandante del Ejército; "Reglamento de Combate de Contraguerrillas" (EJC-3-10), aprobado por la Disposición № 036 del 12 de noviembre de 1987, del Comandante General de las Fuerzas Militares (PCNM).do por la Disposición No 005 del 9 de abril de 1969 del Comandante General de las Fuerzas Militares; "Instrucciones Generales para Operaciones de Contraguerrillas", impreso en la Ayudantía General del Comando del Ejército en 1979; "Combate contra Bandoleros o Guerrilleros", (EJC-3-101), aprobado por la Disposición Nº 00014 del 25 de junio de 1982 del Comandante del Ejército; "Reglamento de Combate de Contraguerrillas" (EJC-3-10), aprobado por la Disposición № 036 del 12 de noviembre de 1987, del Comandante General de las Fuerzas Militares (PCNM, 2008).

${ }^{10}$ Cita de la página 29 del "Reglamento de Combate de Contraguerrillas" (EJC-3-10), aprobado por la Disposición № 036 del 12 de noviembre de 1987, del Comandante General de las Fuerzas Militares. Recuperado por el proyecto Colombia Nunca Más y publicado en http://www.movimientodevictimas.org

11 Documento de "Instrucciones Generales para Operaciones de Contraguerrillas", impreso en la Ayudantía General del Comando del Ejército en 1979. Recuperado por el proyecto Colombia Nunca Más y publicado en http://www.movimientodevictimas.org
} 
Métodos repulsivos de control social sobre la población, operaciones para desaparecer el virus del proceso "insurgente", en actividades policiacas, es común el uso de agentes de civil para conocer las actividades y el perfil psicológico de las personas organizadas, entendidas siempre como un sujeto colectivo. Se establecen los principios de la guerra psicológica:

"Influir en las opiniones, emociones, actitudes y comportamientos de grupos hostiles, de tal manera que apoyen la realización de los objetivos nacionales" $(\ldots)^{12}$, y se debe "tener en cuenta que toda operación psicológica busca: (...) crear unidad nacional"13. La población debe ser sometida a análisis rigurosos para descubrir "sus actitudes, el origen de las mismas, los factores externos que las gobiernan, las vulnerabilidades y susceptibilidades que puedan ser explotadas psicológicamente y las necesidades humanas que originan problemas políticos, sociales y económicos"14 (PCNM, 2000).

Ignorar las normas imperativas de humanidad de la civilización, que supone que aquel que no se detiene frente al horror tiene ventaja frente a su adversario y que conlleva la aplicación de la tortura, niega la filiación política de la víctima, neutraliza los principios éticos de los soldados, a través de estructuras encargadas de este trabajo (PCNM, 2008).

De la "limpieza política e ideológica" a la "limpieza" social, sostenida desde la idea de que hay sectores de la sociedad discriminados, que pueden ser exterminados sin un juicio social, miembros de grupos sospechosos que rompen con el paisaje homogeneizado de sistemas totalitaristas, expresiones de nazismo. Entre estos sectores los adolescentes y jóvenes son reconocidos por su vulnerabilidad ante nuevas ideologías por la etapa de su desarrollo psicosocial (PCNM, 2008).

Por otro lado los modelos de represión reconocidos por el PCNM son:

- La Implementación de la Doctrina Contra insurgente (1966 - 1981)

- Para militarismo y control social (1982 - 1987)

- Desarrollo Militar y Operatividad paramilitar (1988 - 1993)

12 Instrucciones generales para operaciones de Contraguerrillas. p.174. Citado por el PCNM (2000).

13 Ibid. p.176.

14 Ibid. p.177. 
- Reingenieria Militar, legalización y legitimación del paramilitarismo (1994 - ） 


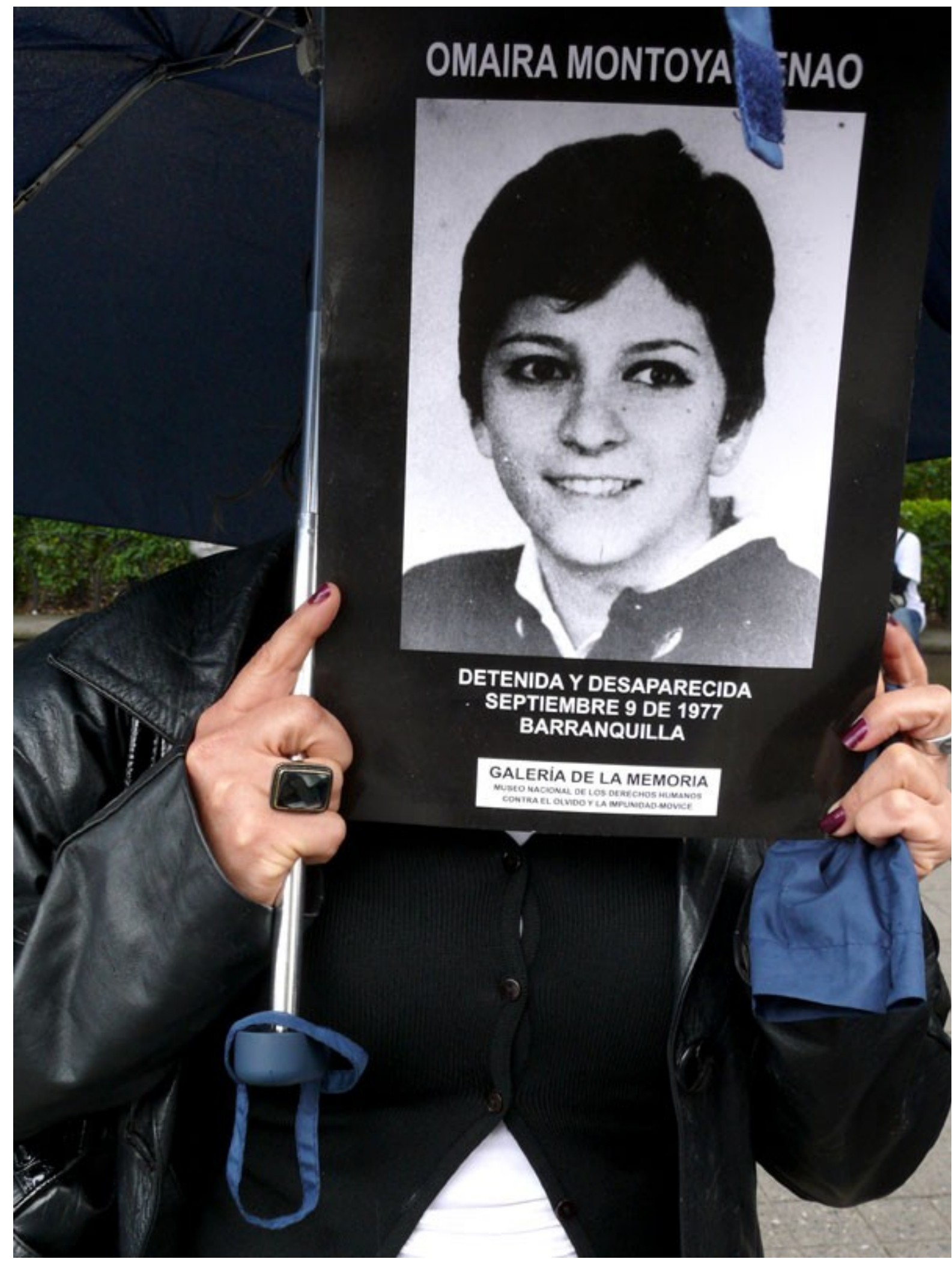

Fotografía: Jaime Gómez. Marcha por la dignidad de las víctimas de crímenes de estado. 
Bogotá. 6 de marzo de 2008.

\subsection{Contexto histórico de la desaparición forzada}

Este contexto se basa en la definición de los modelos de represión mencionados en el apartado anterior, reordenados al rededor de la pregunta sobre la ejecución de la desaparición forzada.

\subsubsection{Huelga del '77 y reconocimiento oficial de la desaparición forzada}

...recuerdas hermano que nos marginaron, por creer despiertos en el hombre nuevo, por ser espejo del gran desconcierto, y por romperle el cuello a la indiferencia, recuerdas hermano que aprendí mi entrega, viviendo a Colombia tras muchas cervezas, y en un rojo trasfondo de frases y emblemas, oro negro y tinto eran nuestra mezcla... (Jaime Valencia)

El Frente Nacional se instauró entre 1958 hasta 1974 para que los partidos liberal y conservador lograran compartir su estancia en el poder. Para el siguiente periodo es elegido como presidente Alfonso López Michelsen.

En septiembre de 1977 una gran huelga nacional frente a la política económica, resultado de la vinculación de los sectores obreros más conservadores y los sectores de izquierda. Se trató de un paro de orden cívico que convocó marchas rurales hacia las ciudades más importantes de Colombia: Bogotá, Cali, Medellín, Barranquilla y Tunja; y que asumieron expresiones propias de la idiosincrasia de los pueblos de la movilización, ollas comunitarias y carnavales. Este acontecimiento es un punto común de rememoración de los testigos de la época.

Me concentraré en una: el Paro Cívico de 1977. Las condiciones de pobreza, el proceso de refeudalización del campo, las recurrentes masacres contra sindicalistas, el bajísimo nivel salarial, la falta de solución a vivienda, educación, salud, la permanente intención de implementar el Plan ATCON ${ }^{15}$ de privatización de la educación pública (eso lo hacía Galán, ministro de educación en aquél entonces), generaban un clima de descontento justo y necesario, y la capacidad para organizarlo sin frenarse en los debates ideológicos a ultranza, y logrando una buena coordinación de fuerzas, permitió una respuesta contundente, fue un frenazo a los planes gubernamentales. Recuerdo que el barrio en el que vivíamos

\footnotetext{
${ }^{15}$ Rudolph Atcon desarrolló entre 1950 y 1970 un plan integrado para las universidades de América Latina ligado con el proyecto de modernización y desarrollo económico de la escuela de Chicago. Introdujo la privatización, y la eliminación de la conciencia política entre estudiantes y maestros por "retrasar" los proyectos del estado. (Atcon, 2009).
} 
era tan depresivo, todas las personas luchando por su subsistencia, era tan oscuro y gris, la rutina de ir a trabajar, y de repente se hizo la luz de la lucha popular; ollas comunitarias; las tanquetas de la policía recibidas con agua hirviente, miles de ladrillos llovían en sus cortinas metálicas, hasta un policía se bajó en la calle 27 sur con caracas, apagó, se quitó el uniforme y se fue corriendo.

Ese día caminamos todos hacia el centro de la ciudad, en la Caracas con 6 sur, frente al monasterio, un militar en su Mercedes, saca una Lugger, y una señora de muy avanzada edad se le para al frente, el tipo la mira sin dejar el arma, la señora le dice que la retire o que ella no responde, el milico inicia un ademán de pretender bajar la pistola hacia la señora, pero la viejita, bella, con una velocidad y fuerza que sólo razones profundas en el alma de los humildes, genera, saca un ladrillo y se lo pone en la cara, el tipo cae, sangrante, humillado, los señores de edad controlan a la gente que quería lincharlo, simplemente lo atan a un poste debajo de la caracas y le pisotean el keppis y le arrancan esas maricadas que se ponen en el pecho, el arma desaparece rápidamente, se voltea el mercedes, se prende una tea en el tanque, queda quemándose. Seguimos hacia la calle primera, se une los estudiantes de medicina, le dan agua a las personas, continuamos hacia la Estación 100 de Policía, nos esperan chorros de agua. Corremos hacia la calle 8tva, que después se convirtió en El Cartucho, las prostitutas nos permiten guarecernos en sus casas. Baja la marea policial y salimos por la Calle 6, hacia la décima, los vendedores ambulantes tienen acorralados a los policías. Llegamos al centro de Bogotá, las marchas de estudiantes, Centrales Obreras (en ese entonces no estaba corporativizado el sindicalismo como ahora) los choferes, los profesores, y la marcha campesina que llegaba ese día. Visto en perspectiva, faltó liderazgo para tomar el Poder (Vaca, entrevista 16 de marzo de 2013).

En ese clima de agitación, el descontento por la crisis económica, la imposibilidad de participación política, el nivel de politización de la gente, la rápida urbanización producto de un proceso obligado de migración a la ciudad, las ideas cubanas, rusas y chinas, la respuesta del gobierno de Alfonso López fue el fortalecimiento o surgimiento de nuevas estructuras armadas apoyadas por sectores rurales, obreros, académicos y artísticos (Gómez, 2007).

En ese proceso se reconoció "oficialmente" la desaparición forzada de personas. La primera detención desaparición fue la de Omaira Montoya Henao el 9 de septiembre, quien tenía tres meses de embarazo junto con su novio, un militante del Ejército de Liberación Nacional (ELN).

En Colombia, la historia de las desapariciones forzadas data de 1977, fecha en que se registró el primer 
caso durante el gobierno de Alfonso López Michelsen. Ocurrió el 9 de septiembre de ese año, en el aeropuerto de la ciudad de Barranquilla cuando Omaira Montoya Henao, bacterióloga y militante de izquierda, fue detenida junto con su compañero, Mauricio Trujillo Uribe, por el servicio secreto de la Policía de entonces, conocido como F2, cuando ambos intervenían en el cobro de un rescate por el secuestro de un industrial. Los dos fueron esposados y trasladados fuera de la ciudad, en donde los sometieron a un intenso interrogatorio bajo tortura. Luego fueron separados y desde entonces no se tiene noticia sobre el paradero de Omaira. Ese caso inauguró la práctica sistemática de las desapariciones forzadas como mecanismo para perseguir la oposición política, la cual era identificada por los manuales de operaciones de la Fuerza Pública como la base social de las guerrillas (MTDF, 2012)

De 1966 a 1981, se implementó la Doctrina Contrainsurgente. Este periodo estuvo marcado por la implementación de las propuestas proferidas por EEUU y la escuela francesa bajo las estrategias de contrainsurgencia fue llamado por algunos militantes y analistas, la "guerra sucia” durante la formación de militares en la Escuela de las Américas ${ }^{16}$. El gobierno de Estados Unidos, a través de la Alianza para el Progreso, definió una política para Latinoamérica en donde los países se abrían al libre comercio y combatían al comunismo que triunfaba en $\mathrm{Cuba}^{17}$.

Para ello se favoreció la elección de representantes políticos, se hicieron tareas de control en la zona urbana y obstaculizaron las movilizaciones populares. Se creó una legislación de excepción en 1965 que otorgó atribuciones judiciales en contra de civiles a las FFMM.

\footnotetext{
${ }^{16}$ La Escuela de las Américas es un complejo militar creado en 1946 con la herramienta ideológica de la guerra fría. Existe hasta la actualidad y ha cambiado su ubicación y nombre en distintas ocasiones: (Panamá) Centro de Adiestramiento Latinoamericano del Ejército de los EE.UU. Fuerte Amador. Escuela de Fuerzas de Tierra de América Latina. Escuela del Caribe del Ejercito de los EE.UU. Escuela de las Américas (Fuerte Benning, Georgia, EE.UU). Instituto de Cooperación y Seguridad del Hemisferio Occidental (Whinsec, en inglés). Al parecer Colombia es el país que más efectivos militares envía al año y como consecuencia de sus acciones se reconoció la ejecución de los crímenes llamados "falsos positivos". (Defensores en Línea, 2012).

17 La Alianza para el progreso (ALPRO) fue propuesta por John F. Keneddy para demostrar que el capitalismo progresista impulsaría el desarrollo de los países latinoamericanos para prevenir que fueran seducidos por la revolución cubana. En este pacto Colombia estuvo representada por el presidente Alberto Lleras Camargo y su implementación se realizaría a través del BID, el Fondo Panamericano para el Desarrollo, entre otras. En Colombia su introducción fue después del tiempo valorada por la prensa. El Tiempo en sus segmentos históricos plantea que: "Se consiguió que uno de cada cuatro niños latinoamericanos obtuviera una comida adicional, y que muchos de ellos fueran beneficiados con nuevas escuelas o libros de texto. Además, un millón de familias de toda Latinoamérica se beneficiaron de las reformas agrarias" (El tiempo, 2012). Entre ese millón de familias ninguna vivía en Colombia.
} 
...el 21 de mayo de 1965 por medio del Decreto 1290 del Gobierno del presidente Guillermo León Valencia, en el que, tras la declaratoria de estado de sitio reconocido por el Decreto 1288 del mismo año, "se le dio competencia a la justicia penal militar para investigar y sancionar, por el procedimiento de los Consejos de Guerra Verbales, varios delitos y conductas antisociales definidos y castigados por la ley penal común, con miras a reprimir rápida y severamente estos ilícitos cuya frecuente comisión ha producido grave y justa alarma social”, como señaló el Decreto 1886, también del año 1965. Este último estableció medidas para asegurarle a la justicia penal militar suficientes investigadores especializados para poder realizar el encargo que le había asignado el precitado Decreto 1290 (CNMH, 2013:206).

\section{Hasta 1966 las FFMM adquirieron un perfil anticomunista. El Estado conformó una estructura o estrategia nueva, un esquema legislativo y militar para armar civiles que apoyaran la guerra contrainsurgente (PCNM, 2008).}

TITULO I. DEFINICIONES. ARTÍCULO 10. "Defensa nacional es la organización y previsión del empleo de todos los habitantes y recursos del país, desde tiempo de paz, para garantizar la independencia nacional y la estabilidad de las instituciones" (...)ARTíCULO 4o. Todas las personas naturales y jurídicas del país están obligadas a cooperar en la defensa nacional y sus actividades estarán supeditadas a los fines de ella.

El Proyecto Colombia Nunca Más reconoce que después de esta legislación los manuales de las Fuerzas Armadas centran su papel en la lucha contrainsurgente.

Bajo estado de sitio en 1968 se le da carácter permanente a este decreto por medio de la Ley 48 de 1968. A pesar de su carácter defensivo, su papel se centró en la lucha contrainsurgente al amparo y bajo la dirección de las Fuerzas Armadas, que proporcionaban el entrenamiento, armamento y adoctrinamiento necesarios a los civiles. Algunos de los manuales entregados a las Fuerzas Armadas contenían expresamente la orden de armar y entrenar civiles, es el caso del Reglamento de Combate de Contraguerrillas, que incluye en su bibliografía cinco Manuales Militares de Campo y tres Textos Militares estadounidenses. En el Reglamento, los comandantes de campo reciben instrucciones sobre como "organizar en forma militar a la población civil para que se proteja contra la acción de las guerrillas y apoye la ejecución de operaciones de combate." (PCNM, 2000). 
El Estado adoptó la Doctrina de Seguridad Nacional. "El Decreto 1573 fue la primera norma en mencionar de manera específica el concepto de seguridad nacional" (PCNM, 2000).

\begin{abstract}
La Doctrina de Seguridad Nacional se sustenta en dos postulados básicos: el de la bipolaridad, entendido como la división existente entre Occidente capitalista y Oriente comunista, cuya influencia podría sentirse en Latinoamérica por medio de la insurrección revolucionaria, y por eso cada Estado debería prepararse para afrontar conflictos en diversas manifestaciones. El segundo postulado es el de la guerra generalizada que parte de la idea de un conflicto de carácter permanente, en el que los límites de la política interna y externa se desvanecen, y la lucha atraviesa todos los campos y emplea todos los recursos a su alcance. El enfrentamiento estará siempre latente, en la medida en que el espectro comunista amenace con desestabilizar el orden interno de cada uno de los Estados (PCNM, 2008).
\end{abstract}

A través de la Doctrina de Seguridad este y otros conflictos no sólo de Latinoamérica sino del mundo, mezcla de distintas ideologías, historias étnicas, luchas económicas, fueron reducidos y explicadas desde el enfrentamiento de Estados Unidos de América Vs Comunismo internacional, y combatidos bajo esquemas de represión muy similares. Sin embargo, es necesario decir que en el balance sobre lo que cada uno de esos conflictos buscaba y el contexto en el que se desarrollaba era importante reconocer ese enfrentamiento como un motor ideológico pero no como un proceso de auge del comunismo internacional. La realidad de los otros países era mucho más compleja (Halliday, 1989).

Posteriormente, bajo la presidencia de Julio César Turbay, presidente del partido liberal, se creó el Estatuto de Seguridad (Calderón, 1999) y se delegó por completo el control de la seguridad nacional al ejército (Bitár, 2007). En consecuencia se multiplicaron los casos de desaparición conocidos antes de su gobierno y aumentó la prisión política. "El estado de sitio, complementado con la adopción del Estatuto de Seguridad, creaba un marco jurídico de excepción, destinado a restringir libertades democráticas y derechos políticos y civiles" (Cuesta, 2007:36). Por otro lado el secuestro de Marta Nieves Ochoa hermana de Jorge Luis Ochoa (narcotraficante), por parte del M-19, fue la excusa para la creación de un cuerpo privado en contra de la "amenaza guerrillera", constituyéndose el grupo paramilitar Muerte A Secuestradores conocido como MAS (PCNM, 2008). 
Los grupos paramilitares superaron su formación como grupos al mando de civiles para controlar las acciones de campesinos contra el latifundio, por ejemplo, y se convierten en una estructura con acciones políticas que determinan escenarios de gran importancia nacional (PCNM, 2000).

\subsubsection{La desaparición entre 1982 y 1988}

Para 1982 las Farc realizan su séptima conferencia y toman el nombre de Ejército Popular (Farc - EP). Esta decisión se toma durante el VII Congreso en un ambiente en el que consideraban que por el fortalecimiento y politización de la población a nivel nacional, la lucha armada podía tomar carácter insurreccional (Pizarro Leongomez, 2006). Al mismo tiempo hay un cambio en el modelo represivo, se desmontan algunas estructuras de represión del Estado y el gobierno comienza a hablar de Derechos Humanos. El grupo paramilitar MAS, se consolida y los grupos de narcotraficantes se vinculan con las estructuras de seguridad del Estado para lograr sus intereses, el primero de ellos: no ser extraditados. El paramilitarismo se convierte en mecanismo fundamental de la "guerra sucia".

El Paramilitarismo llega a ser, entonces, piedra angular de una estrategia de guerra sucia, donde las acciones sucias no puedan ser atribuidas a personas que comprometan al Estado a través de su accionar visible, sino que se deleguen, se traspasen o se proyecten en cuerpos confusos de civiles armados, anónimos y fácilmente definibles como delincuentes comunes que actúan y luego se esfuman en la niebla (Giraldo, 2004).

En el desarrollo de esa estrategia de impunidad de las Fuerzas Militares, y el fortalecimiento de sus propias estructuras con apoyo de una legislación que hace legales las violaciones a los derechos humanos se desarrolló la práctica de la desaparición forzada en Colombia.

De varias personas, algunos profesores míos; mi primo por el que nos tocó dedicarnos días enteros a averiguar y averiguar hasta dar con su paradero (casi dos semanas), luego los Lalinde, Gustavito (le fritaron una pata), él y mi primo tienen la mala honra de haber inaugurado el sistema de informes de Amnesty International en Colombia. El método radicaba en capturar sin informes y en horas inverosímiles, a Pedrito lo cargaron a las 3:50 am, a la nena a las 12 de la noche, a Tavo dentro del 
Colegio donde era Proferoso (profesor), poner al reo o prisionera a rodar por entre cuarteles y comisarias, hasta llevarlo a un sitio y allí negar su presencia, a mi primo y a mi prima las metieron en el Cantón Norte, allá los torturaban, nosotros buscábamos dinero, corríamos "borrando" bibliotecas, cartas, periódicos, pasquines, cuartillas; octavillas, diapositivas, eso, todo el material y hasta la ropa que creíamos que ellos habían usado en algún mitin, sus gafas (lástima, tocó moler las del maestro Oriol Rangé $\left.\right|^{18}$. Ellos fueron torturados, luego de haberlos rastreado por todos lados pudimos lograr (con la ayuda de ASONAPRO) que los fichara oficialmente, estaban hechos mierda; la nena lloraba mucho, ella siempre fue mi prima querida; "guipa" (pequeña) le decíamos, a veces nos habíamos encontrado "en las mismas" (comprando ropa interior para los muchachos, y jabón y esas cosas) y nos tocaba no saludarnos, eso era en San Victorino, en los sótanos de las casetas, allá estaba todo lo necesario, jajaja. De esa misma ASONAPRO nacería el Colectivo de Abogados y de esas organizaciones desaparecerían a Alirio Pedraza, un abogado genial y amoroso (Vaca, entrevista 16 de marzo de 2013).

A manos del $\mathrm{MAS}^{19}$ y de las fuerzas legítimas del Estado desaparecieron en 1982 a un grupo importante de la organización estudiantil, un campesino, un obrero y un mecánico: Pedro Pablo Silva, Orlando García Villamizar, Samuel Humberto, Alfredo Rafael San Juan, Edgar Helmut García, Rodolfo Espirita, Gustavo Campos Guevara, Hernando Ospina Rincón, Rafael Guilermo Prado Useche, Edilbrando Joya, Francisco Antonio medina, Bernardo Heli Acosta Rojas, Manuel Dario Acosta Rojas. En la memoria de las organizaciones y familiares este fue llamado el Colectivo 82 (Cuaderno de Campo, martes 13 de septiembre).

Después de "la <<Operación Colombia>> acción militar que le permitió al M - 19 sustraer de las bodegas de un centro militar llamado el Cantón Norte ${ }^{20}$ cinco mil fusiles, fueron retenidas miles de personas por estar presuntamente implicadas con esta guerrilla; el Nobel de literatura Gabriel García Márquez, por ejemplo, partió en marzo de 1981 para la ciudad de México anticipándose a un allanamiento (Cuesta, 2007:37).

\section{En 1982 Belisario Betancour comenzó su gobierno y estableció las condiciones para el} diálogo de paz con la creación de una propuesta de amnistía y un conjunto de instituciones

\footnotetext{
${ }^{18}$ Oriol Rangel fue un músico, pianista, compositor y arreglista nacido en el departamento (provincia) de Pamplona en 1917.

${ }^{19}$ Rasgo esencial del funcionamiento del grupo paramilitar Muerte A Secuestradores, en este segundo modelo represivo es la libertad de acción en las zonas más militarizadas del país. Había paramilitares organizados con el nombre de MAS en al menos ocho de los treinta y dos departamentos colombianos, incluidos Antioquia, Boyacá, Caquetá, Córdoba, Cundinamarca, Meta, Putumayo, y Santander (PCNM, 2008).

${ }^{20}$ Base Militar del Ejército Nacional perteneciente a la Quinta Brigada y ubicada en la zona norte de la ciudad de Bogotá.
} 
dedicadas a intervenir en los procesos sociales de mayor conflicto, entre ellos el conflicto agrario (PCNM, 2000). Pero el proceso conllevó el reconocimiento político de los grupos subversivos.

El proceso de paz conlleva a un acelerado crecimiento del protagonismo de las Farc, al reafirmamiento del EPL y del ELN en varias zonas del país y a la consolidación del M-19. Esta situación genera la idea extendida entre ganaderos, terratenientes y militares de que los acuerdos de paz eran desventajosos, puesto que desarticulaban las dinámicas de poder existentes y otorgaban un estatus político a las guerrillas (PCNM, 2000).

En esta coyuntura fue secuestrada en Bogotá la señora Gloria Lara Echeverry el 23 de junio 1982 y asesinada el 28 de noviembre del mismo año, miembro de una importante familia y representante de las Juntas de Acción Comunal ${ }^{21}$. Este delito mereció el repudio de la sociedad e inauguró una de las polémicas más complejas con respecto al conflicto armado, el uso del secuestro dentro de las estrategias de los grupos armados y el manejo mediático que el Estado ha hecho de ese crimen. Para el desaparecido Jaime Gómez (2007), este secuestro fue realizado por el mismo Estado para llevar a la opinión pública al desconocimiento del estatus de beligerancia y posterior negociación con los grupos guerrilleros.

Durante la investigación la Brigada de Institutos Militares de Bogotá detuvo a un grupo de personas como los autores intelectuales y materiales de este hecho y en su retención ejecutó detenciones arbitrarias, desapariciones forzosas, torturas para obligar a los sindicados a inculparse y finalmente estos se vieron obligados al exilio. Este secuestro en el que se vieron involucrados distintos miembros de las FFMM y el MAS, se hizo usando el nombre de la organización de izquierda Organización Revolucionaria Popular (ORP) y tenía por objeto deslegitimar la negociación de paz (Gómez, 2007).

En la construcción del relato hegemónico sobre estos hechos participaron según la investigación de Gómez (2007) altos representantes del ejército y medios de comunicación.

${ }^{21}$ Las Juntas de Acción Comunal son los órganos administrativos de base más importantes según la división política del territorio en la zona rural de Colombia. 
Se buscaba la deslegitimación de la imagen de la guerrilla pues la culpaban de crímenes deplorables para hacer fracasar el proceso de paz. Según la hija de Jaime Gomez, se dejó de difundir al rededor de dos cientas desapariciones forzadas realizadas desde finales de los años $70^{\prime}$ por organismos de inteligencia del Estado. $Y$ se desconoció por ejemplo, la desaparición de la Señora Patricia Rivera y sus dos hijas, así como la del anciano Marco Antonio Crespo. Ocurridas durante el proceso de investigación y al parecer causadas por una posible relación familiar entre las tres primeras y uno de los detenidos.

Durante los procesos de negociación "se estima que para 1983 en pleno desarrollo del proceso de paz, existieron 1.325 detenciones, un número de desapariciones mayor a cien y unos 600 asesinatos con connotación política. La acción represiva paramilitar lleva a cabo casi un $70 \%$ de las desapariciones y asesinatos políticos en ese mismo año (PCNM, 2008).

En este y otros relatos se conoce la detención de niños y niñas y de mujeres en estado de embarazo como Omaira Montoya, pero sobre el tema no existe ninguna investigación en Colombia. En el relato de un hijo aparece la desaparición como una amenaza a su propia seguridad, por un conocimiento previo de la desaparición de menores.

Entonces pues a mí me fueron a preguntar directamente al colegio donde estaba estudiando para llevarme para torturar a Nydia. Pero bueno por suerte en el colegio eran un poco habidos de la historia que estaba pasando porque ya les habían desaparecido a un muchacho de ese colegio, a Antonio... y ellos me negaron y desde siempre pensaba que podían venir por mí y siempre ha sido así (Chico Bauti, entrevista realizada en Septiembre de 2011).

El 27 de febrero de 1980, el M-19 tomó la embajada de la República Dominicana e hizo rehenes a los embajadores de Estados Unidos, México, Venezuela y Perú. La toma duró dos meses y como resultado el M-19 recibió un pago importante por parte del estado, se desplazó a Cuba junto con los rehenes y logró la visita de organismos internacionales para realizar una veeduría sobre las desapariciones y las condiciones de los detenidos. De este procesos dejó constancia la visita que la Comisión Interamericana de Derechos Humanos realizó a Colombia como respuesta a las exigencias políticas del grupo guerrillero. La visita buscó verificar la situación de Derechos Humanos durante el estado de Sitio y bajo el 
Estatuto de Seguridad.

Aunque el libro Tras las Huellas de la Verdad narra cómo la Brigada de Institutos Militares fue lugar de detención de los implicados en el secuestro de Gloria Lara, el informe de la CIDH solo confirmó como lugares de detención, junto con las cárceles nacionales: el Batallón Baraya, la Escuela de Artillería y la Escuela de Caballería. En el informe sin embargo, aparecen en el apartado $\mathrm{D}$ del Capítulo IV treinta y un centros de detención en donde se denunció "apremios ilegales" 22 , estos últimos ocurrían también en las cárceles visitadas. A través de esta investigación no puedo definir el nivel de clandestinidad de estos centros pero si el uso de centros de detención que junto con las cárceles, estuvieron dedicados a la tortura $^{23}$. La CIDH expuso las prácticas de tortura, entre las que se cuentan: ahogamientos, aplicación del 'submarino', ataduras y vendajes, golpes en diversas partes del cuerpo con palos y patadas, simulacro de dispararles en la cabeza, tortura de otras personas cerca de la celda para que se escucharan los gritos, aplicación de energía y choques eléctricos en diferentes partes del cuerpo, permanencia desnudos y de pie, provocación de asfixia, lavadas, caminar de rodillas, quemaduras con cigarrillos, sacar al detenido a los allanamientos y utilizarlo como 'chaleco anti-balas', simulacros de fusilamientos, introducción de armas en la boca, rotura de nervios como consecuencia de colgamientos, negativa de asistencia médica para embarazo, contemplación de las torturas a otras personas, advertencias de delación entre los detenidos, pinchazos en varias partes del cuerpo con

\footnotetext{
${ }^{22}$ Los centros o lugares de detención y tortura denunciados fueron: Batallón Nueva Granada de Barrancabermeja; Batallón Pichincha de Cali; Escuela Suboficial Inocencio Chinca de Popayán; Quinta Brigada de Bucaramanga;Escuela de Caballería de Bogotá; Sitio La Remonta; Brigada de Institutos Militares; Batallón Rook de Ibagué; Batallón Bolívar en Tunja, Boyacá; Batallón de Sogamoso; Cuevas de Sacromonte; Batallón Cisneros de Armenia; Batallón Codazzi de Palmira; Batallón Tarqui, Sogamoso, Boyacá; Sitio La Raya en Antioquia; Sitio Polvorines en Río Meléndez; Cárcel de Villanueva; Batallón San Mateo; Batallón de Policía Militar № 4 de la Cuarta Brigada en Medellín; Localidad de Santa Elena; Departamento Administrativo de Seguridad; Penitenciaría San Isidro de Popayán; Batallón № 1 de la Policía Militar de Bogotá; Penitenciaría Nacional de Palmira; Puesto Militar de Yacopí; Puesto de Policía de La Palma en Bucaramanga; Puesto Militar de Cimitarra; Puesto Militar de Bucaramanga; Puesto Militar de La Victoria en Boyacá; Batallón Boyacá; Batallón H-1 de la policía militar de Puente Aranda en Bogotá.

${ }^{23}$ La CONADEP definió los centros clandestinos de detención gracias a que" los testimonios presentados ante la Comisión por las personas que estuvieron detenidas clandestinamente y recuperaron su libertad, se pueden establecer dos grandes categorías de centros clandestinos de detención: "Según la clasificación utilizada por las Fuerzas Armadas, en la mayor parte de las zonas del país hubo: Lugar de Detención de Detenidos:: (LRD). Centros donde los detenidos eran mantenidos en general por períodos considerables de tiempo hasta que se decidía su destino definitivo. Lugar transitorio : (LT) EI tiempo de detención era - salvo excepción - corto. A estos lugares el detenido llegaba inmediatamente después del secuestro o, así se determinaba, en el periodo previo a su liberación o a su puesta a disposición del Poder Ejecutivo Nacional" (CONADEP, 1984).
} 
alfileres, violencia sexual, interrogatorios continuos y escritos obligados en que decía que había participado en el asalto, entre otros. En las cárceles había un número importante de estudiantes de los cuales casi la totalidad pertenecían a la Universidad Nacional de Colombia. Una de las mujeres presentaba signos de aborto ( $\mathrm{CIDH}, 1981$, cinta on line).

Con Belisario Betancour las Farc - EP entraron en negociación y sus militantes desmovilizados constituyeron en mayo de 1984, junto con militantes de otros procesos populares, al Partido Unión Patriótica y durante las elecciones en las que participaron, lograron curules en el senado, presentaron dos candidatos presidenciales, y más de cuatro cientos cargos en administraciones regionales. El segundo proceso en agosto del mismo año, se realizó con el M - 19 y el Ejército Popular de Liberación. Ninguno de los grupos terminó la negociación y este fracaso se dio en la memoria de sobreviventes como José Cuesta (2007), por intervención de la elite nacional inserta en el congreso; las fuerzas militares: y grupos económicos como la Sociedad de Agricultores de Colombia - SAC-, la Federación Nacional de Ganaderos- FEDEGAN-, y los gremios de industriales (Cuesta, 2007). Durante este periodo las FFMM y los grupos paramilitares atacaron e intentaron exterminar varios movimientos políticos.

Después del fracaso en la negociación con el M-19 este grupo ejecutó la toma del Palacio de Justicia el 6 de noviembre de 1985. El ejército respondió con la retoma y fueron desaparecidos: Carlos Augusto Rodríguez Vera, Cristina del Pilar Guarín Cortes, David Suspes C., Bernardo Beltrán Hernández, Hector Jaime Beltrán, Lucy Amparo Oviedo de Arias, Ana Rosa Castiblanco, Gloria Estela Lizarazo Figueroa, Luz Mary Portela León, Norma Constanza Esguerra, Gloria anzola de Lanao e Irma Franco.

Para los familiares hacer visible el crimen de la desaparición forzada como estrategia de esa guerra sucia, era una labor imposible pues se consideraba que la desaparición era propiedad de las dictaduras. Después de la desaparición de su hijo Luis Fernando Lalinde, Fabiola Lalinde afirmaba, que a pesar de estar en democracia las fotos no podían salir, no podían llevarse a la visita del papa para hacer visible el hecho (Cuaderno de campo, abril de 2011). 
Mientras tanto los jóvenes miembros de distintos partidos de izquierda, como Luis Fernando del partido Marxista Leninista iban desapareciendo. Parte de ellos nunca aparecieron, de otros se encontraron cadáveres en los botaderos de basura, montañas cercanas a las ciudades o en centros militares. Algunos desparecidos, lo estuvieron por un período y aparecieron nuevamente después de vivir la tortura. Como es el caso de José Cuesta Novoa, estudiante de filosofía, de la Universidad Nacional y militante del Movimiento 19 de Abril, quien fue dejado en libertad veinte días después de su desaparición, y que según sus captores fue detenido a causa del secuestro de Álvaro Gómez Hurtado (Cuesta, 2007).

El fracaso definitivo del proceso de paz con Belisario Betancour fue uno de los sucesos más costosos para la historia del país. Por el asesinato de miles de militantes de la UP, por ejemplo, el Estado afronta un proceso en la jurisdicción internacional por genocidio político. Los militantes del M-19 fueron objeto de una gran persecución por el alcance de sus golpes políticos y fue durante esa época que desaparecieron entre muchas de sus militantes a Nydia Erika Bautista. Por otro lado, la confrontación armada se recrudeció llevando a los grupos beligerantes a la desesperanza frente al diálogo.

Lo que nos preocupa es que de pronto los guerreristas, los que con relativa facilidad hacen las declaraciones formales de guerra, de pronto, decimos, no vayan a los campos de batalla a respaldar con acciones de guerra sus asertos o sus planteamientos y nos toque a la gente pobre y sencilla de este país matarnos bajo las órdenes de potenciales enfermos de reacción como lo dejó dicho para la historia 12 días antes de caer asesinado Guillermo Cana Isaza (Arenas, 24 de febrero de 1987:271).

\subsubsection{La Desaparición durante un giro en el desarrollo militar y la operatividad paramilitar (1988 - 1993)}

Según la Mesa de Trabajo sobre Desaparición Forzada (En adelante MTDF) (2012) de la Coordinación Colombia Europa Estados Unidos, en este periodo se consolidó una segunda forma o modus operandi de la desaparición forzada, que se ejecutaría de manera colectiva, como herramienta de terror y control de grandes poblaciones para despojarlas de su territorio 
o ponerlas bajo autoridad de los grupos paramilitares. Fueron ejecutadas en su mayoría por estos grupos en alianza con fuerzas de seguridad del Estado y acompañadas por desmembramientos, torturas y otras expresiones de sevicia. El destino de los cuerpos al parecer fueron las fosas comunes, los ríos y los hornos crematorios.

En el análisis de la intervención de los grupos paramilitares, por ejemplo, a zonas de producción de coca, el PCNM (2000) reconocería que inició una represión brutal contra los "eslabones débiles de las cadenas de producción y comercialización". Sobre el tema el jefe paramilitar Carlos Castaño afirmó cómo el paramilitarismo había seguido tres momentos: autodefensa, control de territorio y formalización de lo ganado. Para él sería ubicado en el segundo momento el uso de las estrategias de terror generalizadas y acciones contra la población para el control de poblaciones que se salían del margen de una conducta social deseada. Estos momentos sin embargo, son la forma en la que el paramilitarismo buscó legitimarse, primero como forma de defensa contra la guerrilla por encima de hacer visible la estrategia de las fuerzas militares y otros sectores para adelantar un proyecto económico, social y político (Guatavita y Rozo, 2003). El número de masacres se elevó, tan sólo en 1988 fueron ejecutadas sesenta de estas y sus objetivos se ampliaron hasta los organismos judiciales, pero se centraron en gran parte en los miembros de la Unión Patriótica y otros partidos de izquierda (PCNM, 2000).

A pesar de esto a final de la década de los $80^{\prime}$ el movimiento estudiantil y social organizado movilizó la séptima papeleta y la creación de una asamblea constituyente que sumó la participación de tres grupos armados en proceso de desmovilización: El Ejército Popular del Pueblo (EPL), el Comando Quintín Lame y el Partido Revolucionario de los Trabajadores (PRT). La asamblea se constituyó por un número amplio de representantes de distintos sectores y desembocó en la declaración en 1991 de la nueva constitución. El cambio constitucional se caracterizó por la introducción de adelantos jurídicos que para su momento fueron novedosos en Latinoamérica como el reconocimiento de la desaparición forzada, o el reconocimiento legal de territorios de propiedad colectiva. 
Después de la creación de la constitución de 1991 y gracias a la persistencia de las familias, la desaparición comenzó a tener lugar en la jurisdicción nacional; primero se creó el artículo 12 de la Constitución que prohibió la desaparición forzada; luego la Ley 589 de 2000 que tipificó el crimen y posteriormente otras normas regularon los procedimientos de las fuerzas de seguridad, la búsqueda, los procesos de identificación, judicialización y entrega de restos, apropiando distintas normas internacionales con respecto a los deberes del Estado en la prevención del crimen y a los principios de reparación a las víctimas de violaciones a los derechos humanos. A pesar de la normativa la desaparición continua de manera sistemática.

El gobierno nacional se ampara en los estados de excepción y presenta en octubre de 1992 la declaratoria de Guerra Integral, que se complementa en noviembre del año siguiente con la formulación de la segunda fase de la "Estrategia Nacional contra la Violencia". Los efectos de estas medida y las modalidades represivas a las que abre paso se irán revelando paulatinamente y adquiriendo una fisonomía reconocible en 1993 cuando: "Por una parte, el presupuesto militar aumentó en forma exorbitante; fueron creadas unidades contra insurgentes en todas las Brigadas militares; el arsenal bélico fue modernizado; los soldados profesionales aumentaron de 2.000 a 23.000; se desplazaron del combate a reclutas temporales; la remuneración de las Fuerzas Armadas se elevó considerablemente. Los medios de comunicación promocionaron intensamente el nuevo profesionalismo militar así como los avances en la tecnología bélica (PCNM, 2008).

Al mismo tiempo, el estado evidenció el mantenimiento de la lucha armada, y sumó a su inconformidad frente al cambio constitucional después de un siglo de haberse mantenido la constitución de Rafael Uribe. EI PCNM reconoció que desde 1994 se ejecuta una reingenieria militar, legalización y legitimación del paramilitarismo. En ese año se realizó la primera cumbre de las Autodefensas Unidas de Colombia y se conoció a la organización paramilitar como un cuerpo articulado con una estructura de mando tras la legalidad que el gobernador Álvaro Uribe Vélez y el presidente César Gaviria les proporcionaron a través de la existencia de las Convivir :

\footnotetext{
...Empresa asociativa sin ánimo de lucro en la cual los trabajadores son simultáneamente los aportantes y los gestores de la empresa, creada con el objeto de prestar servicios de vigilancia en forma remunerada a terceros y el desarrollo de servicios conexos, como los de asesoría, consultoría e
} 
investigación y seguridad (PCNM, 2008).

Después de ese proceso de legalidad y fortalecimiento, las Convivir perdió su legalidad. Pero se fortalecieron por la consolidación definitiva de la relación entre los narcotraficantes que vivieron el auge de sus ingresos en el contexto de la apertura económica, y el paramilitarismo.

... para 1998 ya se habían presentado tres "Cumbres del movimiento de autodefensas", cuyo objetivo se puede inferir como una "política" de coordinación y solidez de una estructura paramilitar de carácter nacional. En 1997 se hacen públicos algunos comunicados del grupo dirigente de la estructura paramilitar Autodefesas de Córdoba y Urabá - ACCU que reafirman la coordinación y la creación de un estado mayor a nivel nacional, tratando de trascender los límites regionales. A partir de estas "cumbres" se considera que las "Autodefensas Unidas de Colombia", AUC, son una organización política de alcance nacional, teniendo como base un programa político y económico, pretendiendo representar una tercera vía entre la guerrilla y el establecimiento. Estos ingentes esfuerzos por amalgamar una coalición de grupos locales y regionales de paramilitares dan continuidad a las acciones criminales en contra de la población civil, más no en la confrontación directa con la guerrilla (PCNM, 2008:23).

En 1998 el presidente Andrés Pastrana inició el proceso de negociación en el que participaron las Farc - EP y a las que se les adjudicó el control de cinco municipios del sur oriente del país: Vista Hermosa, Macarena, San Vicente del Caguán, La Uribe y Mesetas. Se implementaron audiencias de participación para la sociedad civil.

Mientras este diálogo se desarrolló la violencia paramilitar se extendió por el territorio nacional. Durante ese proceso el presidente Andrés Pastrana firmó con Estados Unidos el Plan Colombia, como un programa de ayuda contra el narcotráfico financiado por ese país y que acarrearía un aumento en las acciones contrainsurgentes del ejército colombiano. Durante su aplicación las cifras de desaparición (sin información o forzosa) se mantuvieron generalmente al rededor de las cuatro mil víctimas.

El resultado del proceso fue el fracaso del diálogo acompañado por el descrédito a la salida negociada al conflicto, la persecución contra personas y organizaciones que hicieron parte 
del proceso y la intervención militar a los municipios despejados sin ninguna mediación o respeto por las normas internacionales.

\subsubsection{Establecimiento de una política de represión paralela a una política de memoria para la impunidad}

En el 2003 comenzó el proceso de desmovilización de los grupos paramilitares propuesto por Álvaro Uribe bajo el título de "proceso de paz" que consistió en la entrega de algunos combatientes del paramilitarismo y su integración a la vida civil en programas de vigilancia privada. En términos generales las estructuras de control territorial quedaron intactas y no se reconoció la responsabilidad del Estado en la creación y mantenimiento de estas fuerzas. Cambió la nominación de los grupos regionales, continuó la ejecución de desapariciones forzadas, y se ofrecieron penas máximas de ocho años para los responsables de crímenes de Lesa Humanidad. Teniendo en cuenta que estos procesos siempre se realizan por la difusión de la verdad se legitimó el número de crímenes y la forma de su realización tuvo justificación en que las víctimas pertenecían a grupos guerrilleros y se conocieron también algunas formas macabras del crimen.

'El Iguano', ex comandante del bloque Fronteras, contó que los mandos medios de las AUC tuvieron que acudir en 2001 a la incineración para "desaparecer los cadáveres de los asesinados", porque Carlos Castaño y Mancuso ordenaron no dejar rastro de los cuerpos. Dijo que la idea fue suya y que construyó uno en Puerto Santander. 'Hernán' hizo lo mismo en Villa del Rosario. "Había varios hombres encargados de prender los hornos, otros metían los cuerpos y estaban siempre vigilando -relató ante Justicia y Paz-. Cada vez que había una cremación inmediatamente se lavaba el horno para que no quedara huella". También reveló que los cuerpos que no eran cremados en el horno o quemados en hogueras improvisadas con llantas, los tiraban a los ríos Táchira, Zulia y Catatumbo. Y dijo que como no bastaba con desaparecer los cadáveres, había que hacerlo con las cenizas y que éstas iban a una quebrada que conectaba con el río Táchira. Según él, mientras estuvo al frente de esa tenebrosa tarea en 2001, las víctimas fueron casi 100 (Revista Cambio, 6 de marzo de 2003).

Los paramilitares crearon campos de exterminio que funcionaron como lugares de entrenamiento. Este último punto es fundamental como hipótesis para explicar, entre otras 
cosas, la reproducción de su ejército y las prácticas paramilitares a través de la victimización sistemática de niños y niñas.

En el 2001, 'Martín Llanos' decidió hacer fuerte su ejército. En un solo curso, de los varios que hizo en el 2002, entrenó a 220 muchachos. Se veían niños hasta de 13 años. A muchos los recogían de los pueblos y fincas de la zona, a otros los sacaron de correccionales como la de Villavicencio, se llevaron niños de la calle de Bogotá, muchachos en las esquinas de Ciudad Bolívar, del Tolima y hasta algunos incautos que caían con avisos que invitaban a ir a un "centro de rehabilitación especial para la drogadicción".

"A muchos les decían que iban a recoger arroz, y cuando llegaban y se daban cuenta, se veía mucho hombre llorar", recuerda uno de ellos.

Y lloraban porque los entrenamientos eran campos de exterminio: muchos se quedaban a mitad de camino destrozados por sus mismos compañeros. El método 'pedagógico' era macabro: se deshacían de los débiles o los que no parecían estar convencidos de la causa y con sus crueles asesinatos le daban al resto lecciones de barbarie (Sierra, 2007).

Junto con la ejecución de la desaparición en zona rural y de población marginal o estigmatizada en la sociedad colombiana: trabajadoras sexuales, jóvenes que trabajan en la calle, miembros de la comunidad LGTB, consumidores de drogas, habitantes de calle, personas con discapacidad, entre otros, continuó la desaparición contra militantes de izquierda como en el caso de Guillermo Rivera; Jaime Gómez; Evelio del Socorro Valle Lopera, hombre de 75 años, miembro del Partido Comunista, sobreviviente de la Unión Patriótica, miembro del Polo Democrático Alternativo ${ }^{24}$, editor y formador de las nuevas generaciones dentro del Partido Comunista Colombiano en Antioquia, desaparecido el 2 de febrero de 2011; y Sandra Viviana Cuellar, joven ambientalista vinculada al movimiento social en Cali, desaparecida el 17 de febrero de 2011; entre otros. La desaparición se extendió a población que se encuentra en territorios estratégicos económicamente, corredores de drogas o armamento, territorios con movimientos sociales organizados (Gómez, 2011) ${ }^{25}$.

\footnotetext{
${ }^{24}$ Partido de izquierda democrática que vincula al Polo democrático independiente con Alternativa democrática. Estos a su vez, surgieron en una colisión de los partidos ANAPO y Vía Alterna, el Movimiento "Frente de Esperanza" , el Frente Social y Político (FSP), el Movimiento Obrero Independiente y Revolucionario (MOIR), Unidad Democrática, Movimiento Ciudadano, Autoridades Indígenas de Colombia y Opción Siete.

${ }^{25}$ Análisis realizado por Gloria Gómez el 13 de septiembre durante la conmemoración del colectivo 82 en el auditorio "Hermanos San Juan" de la Facultad de ciencias de educación en la Universidad Distrital Francisco José de Caldas.
} 
Actualmente se hizo importante la figura del "falso positivo", ejecutado por el ejército como otro crimen que incluye la desaparición forzada de personas, bajo una premisa de lucha contra el terrorismo. Para su ejecución se desaparece a los jóvenes, se le asesina y se legaliza su muerte con el supuesto de que se trata de un guerrillero caído en combate y enterrado como No Identificado. Con su presentación el militar gana un beneficio. Sin poner en cuestión la legitimidad del "positivo" y el uso de esas expresiones que oscurecen la ejecución de una desaparición o un asesinato.

\begin{abstract}
De manera general un "positivo" en la jerga militar es la consecución de un resultado contra la delincuencia y/o la insurgencia. El término se usa de manera amplia entre las diferentes fuerzas que componen el ámbito militar para designar todo tipo de acciones como incautaciones, detenciones, desmantelamiento de estructuras criminales, así como quienes son "dados de baja" en combate" (...) De manera reiterada y sin distinción entre ámbitos urbanos o rurales, el término "legalización" resulta especialmente escabroso porque encierra un significado profundamente cercano a lo permitido mediante una regulación legal. El homicidio como tabú desaparece en cuanto la condición de la víctima como "guerrillero" o "terrorista" de alguna forma justifica su aniquilamiento" (Sierra, 2009: 25).
\end{abstract}

Este proceso fue motivado por una directiva del entonces Ministro de Defensa Camilo Ospina que definía "la política para el pago de recompensas por captura o abatimiento en combate de cabecillas de organizaciones al margen de la ley" (Sierra, 2009:54). Estas políticas se establecen a pesar de lo que significó para el estado y las fuerzas armadas el establecimiento de pago por combatientes y dentro de las políticas contra insurgentes, con sus consecuencias en el lazo social: la divulgación de que matar paga.

De la misma manera se reconoce que hay un conjunto de acciones propias o comunes en la ejecución de la desaparición forzada que constituyen en sí mismas mecanismos de impunidad para facilitar la negación por parte del estado y sus agentes de su actuación y que se ejecutan desde la primera desaparición hasta ahora: Ocultamiento de la identidad de los victimarios, así como el uso de capuchas por parte de estos o de los detenidos; utilización de personal civil al servicio de la fuerza pública u organismos de seguridad para Impedir la vinculación de entidades estatales y borrar pistas; ejecución de los crímenes a altas horas de 
la noche, en fines de semana o días festivos, utilizando parajes solitarios; trasladar a los detenidos a guarniciones militares e incomunicarlos; etc (PCNM, 2008). Lo que permanece en mayor desconocimiento es en dónde están los desaparecidos, a dónde fueron llevados, pues si hay cuarteles usados para tales fines ninguno ha sido investigado y mucho menos desmantelado.

A noviembre de 2011, el Registro Nacional de Desaparecidos, reportaba un total de 50.891 casos (24\% mujeres y $17 \%$ niñas y niños). De ese total, se presume que 16.907 corresponden a desapariciones forzadas. Por su parte, la Unidad de Justicia y Paz de la Fiscalía General de la Nación reportó a mayo de 2011, un total de 32.000 casos de desapariciones forzadas cometidas por grupos paramilitares, recibidos a través de los formatos de registro que llenaron las víctimas de hechos atribuibles a grupos armados al margen de la ley. Por impresionantes que puedan parecer esas cifras, constituyen un subregistro en relación con la magnitud del fenómeno en el país. Evidencia de este subregistro es que de las 22.689 personas que fueron registradas como N.N en los diferentes cementerios públicos de todo el país a fines del 2011, tan solo 440 habían sido reportadas por sus familias como desaparecidas ante el Registro Nacional de Personas Desaparecidas. Tampoco se incluyen las miles de personas que han sido arrojadas a los ríos o que fueron incineradas en hornos crematorios, o enterradas en cementerios clandestinos, según han confesado algunos de los paramilitares dentro del proceso de la ley 975/05 (MTDF, 2012).

Se conoce un porcentaje en la desaparición de menores, pero de su destino se habla con frecuencia de fosas y ríos. El caso del reclutamiento forzado en campos paramilitares también ha sido mencionado. Por otro lado, del número de desapariciones registradas en el Instituto de Medicina Legal y Ciencias Forenses - IMLCF el $25 \%$ de la cifra total fueron ubicadas en Bogotá. Según el análisis de una muestra de novecientos casos por parte de la MTDF (2012), en la mitad de los casos las víctimas fueron trabajadores del campo, le siguen estudiantes, líderes, docentes, defensores de derechos humanos, militantes de algún partido político y sindicalistas. 


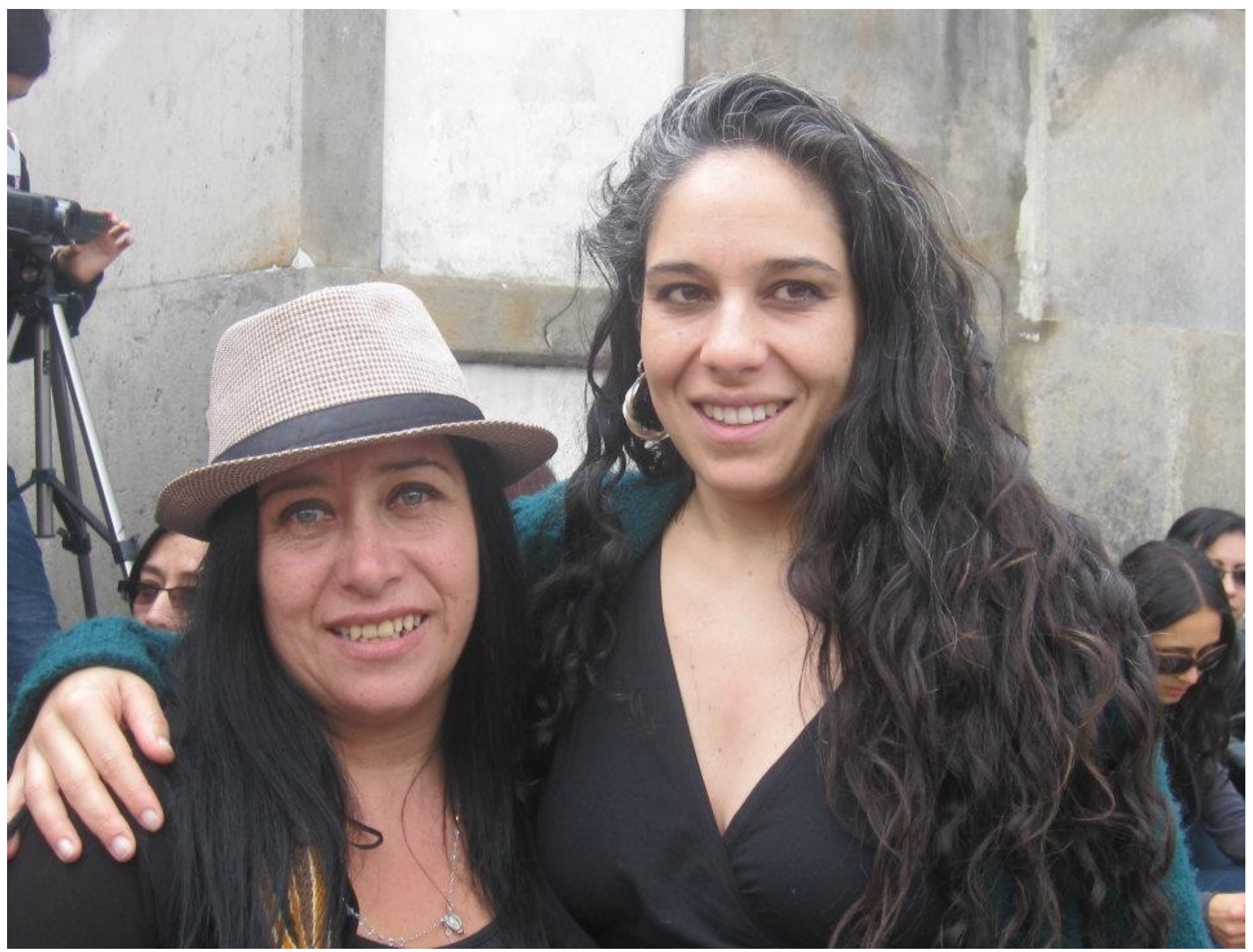

A la derecha María José Pizarro hija de Carlos Pizarro comandante del grupo guerrillero M-19, responsable de la toma del Palacio de Justicia. A la Izquierda Pilar Navarrete esposa de Héctor Jaime Beltrán, trabajador en la cafetería del Palacio y desaparecido el día de la toma de la embajada, durante la retoma del edificio realizada por parte del Ejército Nacional. Lugar: Conmemoración de la Muerte de Carlos Pizarro. Cementerio Central. Bogotá. 2012. Fotografía donada por Pilar Navarrete. 


\section{Segundo Capítulo: Las Memorias}

La memoria se consolida tímidamente como parte de las otras historias, desde las consideraciones post modernas del otro, como relatos paralelos que se mueven en frecuencias dispares y concurrentes en los

mismos espacio - tiempos sobre los cuales se expresa y pontifica la historia oficial, coronada como la única verdad gracias al método científico historiográfico detentado por historiadores oficiales y academias autorizadas venidas a más con los abolengos de otros siglos.

(Nadiezhda Henríquez Chacín, 2000)

El primer capítulo intentó ser un panorama de la manera como se puede entender la desaparición forzada y ubicar en un periodo histórico. Este apartado es un análisis del proceso de memoria relacionado con algunos hechos presentados y está construido con el objetivo de reconocer ciertos elementos del proceso de memoria: introducirnos en el o los tipos de memoria que están siendo elaborados y quiénes lo adelantan, intentando armar una historia amplia y compleja, y al mismo tiempo, seguir la recomendación de uno de los entrevistados:

(...) en ese debate que no está saldado decimos: "Bueno habría que construir más que una visión subalterna, una versión compleja de la historia, una visión más de subversiones que se tejen, que se mezclan, de hecho ahí hay un personaje -No sé si es Octavio Paz porque ya se me olvidó- que dice que no hay nada más mentiroso que la verdad, la verdad es una versión sobre una serie de hechos que pueden ser narrados de distinta manera, el reto sería construir nociones complejas de las verdades, de las realidades (...) (Camilo, entrevista 18 de octubre de 2011).

Para la construcción compleja de ese pasado incluyo a personas que vivieron directamente la experiencia de la desaparición y sus relatos, no como únicas fuentes para explicar la desaparición forzada pero sí como fuentes fundamentales de lo que quiero entender: el proceso de reconstrucción de la memoria de hijos e hijas de personas desaparecidas. Es decir, en el primer capítulo se describió un momento histórico pero al rededor de él emergen ahora experiencias y pensamientos sobre cómo el significado de ese pasado, cuáles son sus huellas y cómo se transmiten. Tal vez en esas mismas narraciones se encuentren diferencias con respecto a los relatos iniciales. 
Sin embargo, los relatos y experiencias de hijos e hijas no son las únicas que aparecen en este apartado. En primer lugar, participaron hijos e hijas de personas desaparecidas que no hacen parte de la misma organización, y otro conjunto de personas miembros de organizaciones que se sumaron para aportar su percepción sobre la reconstrucción.

En primer lugar, en este trabajo de definir qué memoria se está construyendo es necesario el reconocimiento del papel que cumplen los lazos de afecto en el contexto del trabajo memorístico, los lazos de afecto con los padres y madres, los lazos de afecto con el campo popular, con la lucha social y con la vida.

-¿Qué es memoria para ti?

- Esa pregunta siempre me la hacen y siempre me quedo pensando y creo que no respondo siempre lo mismo porque no me acuerdo qué respondo.

- ¿La memoria es una cosa que no recuerdo?... ¿y el olvido?

- No, te voy a responder qué es la memoria pero lo voy a responder cómo es desde lo que ha significado para mí este momento de mi vida, es algo vital en mi existencia, es mi herramienta para construir para pelear, para empoderar, para solucionar cosas que tengo pendientes por solucionar, para conocer, para acercarme a mis padres, a sus luchas, para caminar, es algo muy vital en este momento de mi vida. Y el olvido es la otra cara es contra lo que yo lucho desde la memoria (Shaira, entrevista realizada el 26 de julio de 2011).

La memoria supera un ejercicio cognitivo de reconstrucción de momentos e implica al mundo emocional, la construcción de poder popular que pertenece al campo político, las capacidades de pensar y aprender, de relacionarse con los seres queridos y de vivir.

En segundo lugar, aparece la relación entre la memoria que deviene en práctica social y en nuevas representaciones sociales ${ }^{26}$. Aparece un análisis al rededor de las relaciones entre el

\footnotetext{
${ }^{26}$ El concepto de memoria en la reflexión social tiene un antecedente filosófico en Luckacs quien planteaba la existencia de una subjetividad de clase o una propia visión del mundo desde la pertenencia al grupo social (Duvignan, 1968). Avanza a inicios del siglo veinte en el pensamiento sociológico de Halbwachs quien reconoce en la memoria un vínculo entre la historia, centrada en hechos y cronologías, y la subjetividad, o reconocimiento de la experiencia de los individuos según los grupos que conforman (Duvignan, 1968). La creación del campo de la memoria vinculando la historia y la subjetividad aparece en los análisis de Halbwachs quien se remite al conocimiento sobre la conservación o transmisión de las experiencias de un pueblo desde su propia perspectiva y al estudio de los marcos que lo hacen posible. Allí se pone en juego el recuerdo individual relacionado con el grupo por lazos de afecto y la existencia de contextos que le dan sentido (Halbwachs, 1950).
} 
tiempo pasado y los fenómenos sociales actuales, el análisis histórico con procesos e interacciones que quedan marcadas y a través de las cuales se generan nuevas representaciones sociales ${ }^{27}$.

(...) Yo te voy a conceptualizar la memoria como la he entendido y la he ido construyendo en hijos. Para mi la memoria es una práctica que te trae del pasado cosas que tú seleccionas para hacer una reconstrucción de ese pasado, pero para mí la memoria tiene sentido en la medida que sea una memoria crítica (Diana, 21 de septiembre de 2011).

En ese sentido, la relación entre la memoria, la sensibilidad, la acción nos hace una pregunta obligatoria por la ideología. Es decir que hay algo en el contenido de la memoria que puede determinar sentires y haceres sociales que pueden estar relacionados también con el mantenimiento de formas de transmisión de su contenido que son específicas. En tanto la memoria define sensibilidad, acciones y formas de ver la realidad puede ser definida como

\footnotetext{
${ }^{27}$ Con respecto a esto, Bloch (1925), quien se dedica en su trabajo historiográfico inicial a hacer un estudio de la memoria social, introduce no sólo reflexiones sobre la memoria colectiva, o conservación de recuerdos comunes a todo un grupo humano y su influencia sobre la vida de las sociedades (Bloch,1925:223), sino que afirma que cualquier explicación de la memoria en su dimensión puramente individual queda corta por la existencia del lenguaje, que es social, y atraviesa al recuerdo. Según Halbwachs, la memoria colectiva proviene de acontecimientos y experiencias que tocan a la mayoría de los miembros del grupo, resultan de él o de la relación con otros cercanos. La salida de un miembro del grupo y su presencia en uno nuevo le genera sentimientos nuevos. Su posibilidad de recordar depende de que otros le ayuden a su acción de memoria por ello los recuerdos más difíciles son los que parecen más propios o individualizados. "La memoria colectiva obtiene su fuerza y duración al apoyarse en un conjunto de hombres" (Halbwachs, 1950) , sin embargo, cada uno tendrá una percepción de ella según su posición dentro del grupo y su punto de vista. En consecuencia, la memoria depende de las relaciones sociales y aparece en el encuentro entre distintos grupos sociales relacionados y al tiempo hace posible la interacción pues conserva las herramientas para que esta sea posible. "Olvidar un periodo de la propia vida es perder contacto con aquellos que nos rodeaban y olvidar un idioma extranjero es no ser ya capaz de comprender a quienes se dirigían a nosotros en dicho idioma, ya fuesen personas vivas y presentes o autores cuyas obras leíamos" (Halbwachs, 1950). Para Joel Candou (2002), antropólogo francés, la memoria no se desvincula del carácter cultural, identitario, lingüístico de un colectivo. Candau resalta que gracias a la memoria se construye la relación social, desde elementos básicos: unir dos ideas para superar la inmediatez y por lo tanto, hacer posible cualquier contrato o convención. Para él, el recuerdo no es una copia fiel del pasado sino que, a largo plazo, permite el procesamiento de la información con profundidad o el trabajo de memoria: atribución de sentido producida por la categorización de las sensaciones y percepciones con el correr del tiempo. Esta "historia con protagonistas" reconoce entonces que no se refiere a individuos sino a sujetos relacionados en un contexto en donde cada uno recuerda, según distintos elementos, parte de las experiencias que vivió conjuntamente y de igual manera le dan un sentido. Para Yerushalmi, "la memoria colectiva no tiene ninguna herencia vagamente genérica, ni una estructura psíquica innata análoga a los arquetipos junguianos" (Yerushalmi, 1981:XXXV) o una forma de psicolamarkismo de Freud, que propone identidades esenciales de los grupos sociales. Él plantea que la memoria es posible gracias a la transmisión, siguiendo a Halbwachs. La memoria está atravesada por unos marcos y es una realidad transmitida a través de ciertas prácticas e instituciones. Para algunos antropólogos, la memoria incide de manera efectiva en distintas cuestiones propias del sujeto social: "la aprehensión y clasificación del mundo, en la constitución de la personalidad, la construcción de la subjetividad, la elaboración de conocimiento, la transmisión de herencias y saberes" (Da Silva Catela, 2008, 10). A su vez la memoria define experiencias, perspectivas y sentimientos de pertenencia que generan una imagen colectiva y aportan a la definición y reconocimiento de quién soy yo y el otro. "Sin memoria la identidad se desvanece. Solo produce un sucedáneo de pensamiento, un pensamiento sin duración, sin el recuerdo de su génesis, condición necesaria para la conciencia y para la conciencia de uno mismo" (Candau, 2002: 4).
} 
una ideología y de la misma manera requiere aparatos de reproducción que se construyen desde su propio contenido. El Edificio de la Escuela de Mecánica de la Armada Argentina es hoy una institución de conservación de la memoria que tomó su forma por que es ella misma contenido del pasado reconstruido.

En términos de cómo la describe Zizek: La ideología como estructura reflejada sobre sí misma funciona a través de presupuestos que determinan la estructura de la práctica económica y actitudes "espontáneas" que constituyen un momento de la reproducción de prácticas no ideológicas. Como ejemplo "los medios estructuran de antemano nuestra percepción de la realidad y hacen la realidad indistinguible de su imagen "estetizada"” (Zizek, 2003). Según Zizek el contenido de la ideología crea la forma y tiene las mismas características mencionadas: está articulada a un sujeto en una lógica cínica, se trasmite gracias a situaciones concretas que le dan existencia y se reactiva en presupuestos que parecen ajenos a los Aparatos ideológicos. En cuanto a Zizek, la ideología no deja de ser reproductiva y constituyente de sujetos. El valor verdadero o falso de lo real y su legitimidad depende de su relación con un sujeto para mantener una dominación.

Como que si hay una hipótesis ahí de base y es que los movimientos sociales -digamos que esto es un tema de este año para atrás porque ya llevo un tiempito como alejada- en los movimientos sociales como que están muy pendientes de todo el mundo menos de ellos mismos en su interioridad, en su emoción y cómo esa emoción termina afectando mucho esa acción pero pareciera que no. Entonces hay un sujeto público y privado muy dividido pero nosotros lo que planteábamos con mi compañera de tesis es eso está totalmente unido no hay un sujeto público y privado y el que está saliendo afuera es el de la emoción... (María Paula, entrevista realizada el 5 de octubre de 2011).

Es justamente la relación entre cada sujeto y el otro el objeto de análisis de la tesis de María Paula, psicóloga que hizo parte de hijos. El lugar en el que comienzan a revisar una ideología que se antepone y marca la distancia entre un pensamiento emancipatorio y las acciones cotidianas de los miembros del grupo. La relación entre esas acciones y el pasado de dolor de cada una y cada uno de los integrantes. Es justamente este trabajo psicosocial el que permite revisar hacia atrás la consecuencia entre el ideal político y las acciones llevadas a 
cabo por la organización, tras la conciencia de que las emociones hacen parte fundamental del proceso político aunque parezcan ajenas.

Si usamos una metáfora para explicar la relación entre la ideología y el campo de la memoria, podríamos imaginar un aparato de impresión en tercera dimensión: el elemento reproducido fue diseñado con anterioridad y su contenido define la forma del aparato reproductor que aparece como producto. El nuevo aparato es la representación en el presente que emerge e interviene nuevas prácticas sociales para continuar el proceso y mantener al fin y al cabo una imagen verídica y legitima de la realidad, en este caso del pasado, para lograr como fin último el mantenimiento de una estructura económica, que en este caso sigue siendo a pesar del tiempo. La impresora es aquella institución que solidifica una práctica social que decide sostenerse sobre un recuerdo, un principio, un enunciado transmitido a través de su propia reproducción y toma la forma del contenido que reproduce.

Este primer elemento es fundamental para profundizar en el análisis del tipo de memoria que se está construyendo. Si Diana afirma en su testimonio, así como Camilo que intentan hacer una memoria transformadora están apuntando a lo que múltiples discusiones ${ }^{28}$ sobre la

\footnotetext{
${ }^{28}$ La ideología en este apartado es comprendida como una condición subjetiva y eficaz, que no es propiedad solo de la clase dominante. La ideología pasa de ser falsa conciencia o interpretación equivocada de las relaciones de producción en Marx (1845) a ser una realidad, en términos de Althusser (2003) en la cual se representa una relación imaginada que en el proceso constituye un sujeto. Este proceso va de reconocerla como negativa y falsa y luego como positiva o eficaz en la realidad. Finalmente gracias a Zizek (2003) como una articulación particular alrededor de lo real, en donde su valor verdadero o falso y adquiera legitimidad depende de su relación con un sujeto para mantener una dominación. La ideología se constituye por la lucha de clases y puede ser definida como propiedad única de la clase dominante o como propiedad posible también, de la clase explotada, según la construcción de Gramsci (1948) y Bordieu (2006). Esto deja por delante el reconocimiento de la ideología en su función de enmascaradora de las relaciones de dominación o continente de la lucha de clases que constituye al sujeto, sin ser propiedad de la clase dominante. Retomando la ideología alemana, la existencia del comunismo como el borramiento de la lucha de clases propone la eliminación la ideología y el conflicto social. Por otro lado, con Althusser (2003) y según la crítica de Ípola (2007), surge la imposibilidad de un sujeto no atravesado por la ideología, en tanto esta se reproduce en prácticas ideológicas problematiza el punto que definió Marx (1845), lo que puede derivarse es la comprensión de una ideología diferente no dirigida a la reproducción de las relaciones de producción, una ideología emancipadora constituyendo sujetos pero dirigida al cambio en las relaciones de producción. Entonces la ideología puede interpelar sujetos sin reproducir las relaciones sociales, puede constituirse una sociedad sin ideología, sin lucha de clases, como lo plantea Marx (1845) en la ideología alemana, o es posible la reproducción de otras formas de relación productiva que no sea la establecida hasta ahora, en consecuencia con la idea de que todas las ideologías no son dominantes.

La discusión sobre el cambio o no en las formas económicas se refiere a la función política de la ideología y depende de la relación que mencionaba al inicio, entre esta forma y un sujeto, pero no todos los planteamientos sobre ideología lo suponen. Geertz (1995) por ejemplo, se centra en la eficacia simbólica y en cómo produce una unidad emotiva, punto en el que muchos autores coinciden. Pero la función política se sostiene en tanto se vincula a un sujeto o un lugar de poder o no como una búsqueda consciente o propia de la acción de unos sujetos para mantener un orden establecido.

La opción planteada por Geertz (1995) tiene que ver con profundizar en la comprensión de la ideología y sus intereses o de su carga psicológica para definir el mecanismo simbólico que permite que se construya. Así que tanto en él como en Bordieu (2006) el tema simbólico toma un lugar fundamental. Sin embargo en el segundo caso el lugar del sujeto es más importante
} 
ideología vienen señalando y es la doble condición de la ideología, la de ser una herramienta de reproducción de estructuras o la de al mismo tiempo ser la herramienta que a través del análisis y transformación de ciertas clases sociales pueden promover la transformación de esas estructuras, llevando más allá el análisis de Ipola sobre la ideología (2007).

En segundo lugar, las entrevistas no lo introducen directamente pero en el caso de teóricos como Zizek la estructura de dominación a reproducirse es alienante. $Y$ esa reproducción puede ocurrir cuando se transmite por los aparatos ideológicos reconocidos medios de comunicación, colegios, entidades de la memoria. Y pueden tomar la forma de representaciones sensibles que dicen reconocer la historia de las víctimas y su sufrimiento pero ser recogidas por "especialistas" que alienan a sus productores originales de la comprensión del para qué de esa memoria y la capitalizan para el bien del estado, aun cuando sean historias de sus propias víctimas.

Pero aquellos que buscan en la memoria un dispositivo ideológico de transformación plantean que hay un proceso de identidad y reconstrucción crítica, es decir de análisis y conciencia frente al contenido de su recuerdo y su estética de lucha o sufrimiento.

La identidad, ese es un fortalecimiento porque en la medida en que yo me miro, me reconozco, escribo, identifico mi historia y me identifico con otros potencio la lucha eso es lo que hace que hijos tuviera tal fuerza son varios con la misma historia, se conectan, se unen, y buscan un objetivo común entonces ya no era uno hablando de me desaparecieron a mi papá entonces: "Ay pobrecito que vaina". O mentiras silencio, muchos de ellos estaban muy silenciados y hay unos que son más silenciados que otros porque tienen historias más difíciles que contar que otros y eso marca una diferencia también dentro de ese plano de memoria (María Paula, entrevista realizada el 5 de octubre de 2011).

En el caso de "Hijos e Hijas por la memoria y contra la impunidad" la historia compartida está relacionada con la militancia de los padres y la identidad se basa en eso más que en el perfil de violación de Derechos Humanos. Es decir que hay un elemento ideológico previo que es consciente en muchos de los casos y que nos pide preguntarnos, ¿es la memoria por si

que en el primero. Y esto no es menor en tanto el vínculo entre el sujeto y el sistema simbólico previene de la relación entre la ideología y la sociedad en términos de poder. 
misma ideología o la experiencia ideológica previa de los padres es la matriz que moldea los recuerdos que se transmiten?

El problema es que estamos abordando la noción de justicia con las herramientas de justicia y con los sistemas de justicia del victimario". Y casi que la respuesta es: "Es que estamos llenando de contenido esa justicia". El problema no es llenar de contenido el problema es recuperar la matriz ideológica que habla de una justicia popular o de una noción de justicia comunitaria si se quiere (Camilo, entrevista 18 de octubre de 2011).

Es decir que el sentimiento y el anhelo de transformación política puede recuperar a través de la memoria ideales propios del movimiento social o ser usados y empacados en categorías y nombres de nuevos sujetos según las políticas de estado. Es decir un nuevo elemento ideológico cuando la reconstrucción de la memoria no se dedica a reconocer esos principios ideológicos que les dio lugar.

Con relación a eso, podemos volver a ejemplificar la comprensión del proceso ideológico a través del análisis de un objeto que enmarca al recuerdo en un elemento identitario fundamental: la fotografía. Esta trae un enunciado del pasado al presente. Puede convertirse en una mercancía, en tanto objeto aislado del sujeto que la produjo, o puede relacionarse a través del análisis crítico, a través de la reconstrucción del proceso que lo generó, en un producto de su época. ¿Cual es el eje de esa mirada hacia atrás? La construcción colectiva que integra las dimensiones emocionales, políticas, económicas de la conciencia de un grupo.

El Centro Clandestino de Detención "Olimpo" por ejemplo, está dedicado al análisis de la memoria del pasado reciente y gracias a esto se demostró que fue un lugar usado para la detención clandestina de presos que está en manos de quienes lo deconstruyen y entienden su sentido. Pero podría haberse usado como lo fue la Isla Gorgona ${ }^{29:}$ como lugar turístico

\footnotetext{
${ }^{29} \mathrm{La}$ isla Gorgona está ubicada en el océano pacífico y hace parte del departamento del Valle en el sur occidente de Colombia. Allí se construyó la cárcel de máxima seguridad más importante de la historia del país. Los métodos y el aislamiento del lugar fue justificado por el nivel de peligrosidad de sus reclusos pero de las pocas investigaciones que se han realizado sobre el tema se conoce que fue una herramienta fundamental para la represión ejercida durante la aplicación de la doctrina de seguridad. "A través del Decreto 0012 de 1959 se creó la Isla Prisión de Gorgona, producto, de acuerdo con el historiador, del "peligrosismo", un concepto jurídico según el cual se vulneran los derechos fundamentales; "eliminaba
} 
aprovechando el paisaje natural y el halo de misterio que deja la vieja estructura penitenciaria; olvidando que esta estructura alojó a detenidos que fueron torturados y en muchos casos asesinados por su supuesta peligrosidad durante un periodo histórico que cayó bajo la niebla: el gobierno de Julio César Turbay.

Si la memoria está definida por las condiciones de producción del grupo que la construye, puede tener distintas características y toma distintas formas. Por eso este apartado se denomina memorias y presenta una tipología que viene primero de la relación entre estas y el grupo de pertenencia. Por ejemplo, podríamos decir que no es igual la memoria del trabajador asalariado y más aún sindicalizado, que hace un esfuerzo por cuidar su historia como sujeto político y a través de ella reconstruye formas específicas de dominación para la explotación de su trabajo, que la del desempleado que en general está desprovisto del grupo de pertenencia laboral, pero está incluido en la barrial, o familiar ${ }^{30}$.

Por otra parte, la creación de una tipología también viene del hecho de que la memoria está afectada o definida por el momento histórico y el contexto en el que se reconstruye, gracias al diálogo y al trabajo entre personas que la discuten, es así que la memoria de la década de los $70^{\prime}$ marcada por análisis y categorías relacionadas con la vida de los trabajadores, la pobreza o las clases sociales, es distinta a la que se puede realizar hoy, por la inserción de los discursos sobre la ciudadanía, la pluralidad, la etnicidad, el feminismo, propios de otras formas de pensamiento que constituyen o transforman la matriz ideológica y la elección de cosas a transmitir y reproducir.

... el movimiento social de izquierda crítico tiene propuestas muy fuertes y reivindicativas con nociones de

cualquier posibilidad de rehabilitación pues disfrazaba la represión con prevención". Entre algunas de las disposiciones se encontraba la posible detención por parte de las autoridades militares y de policía a personas "que se encuentren en 'evidente' estado antisocial", criterio que se prestó para todo tipo de interpretaciones subjetivas" (Unimedios, 2006).

${ }^{30}$ Según el Departamento Administrativo Nacional de Encuestas, en Colombia la condición de desempleo aumentó un 12,5 por ciento durante el último año y el índice de subempleo fue del 11 por ciento. El sector que sumó trabajadores fue el del comercio y decayeron principalmente la construcción y la industria. En Colombia no existen movimientos ni organizaciones sociales de desocupados y en cambio si distintos móviles de violación de derechos se han aprovechado de esta condición para seleccionar a sus víctimas. Se acercan a barrios marginados y ofrecen trabajo en los campos, se llevan a los jóvenes y los desaparecen, en algunas ocasiones aparecen sus cuerpos en alguna otra región del país enterrados como no identificados muertos en combate a manos de las fuerzas armadas. Por otro lado, del porcentaje de personas vinculadas laboralmente solo el $4 \%$ están organizadas sindicalmente. 
sujeto desde las diferentes manifestaciones de los sujetos todos pero la política de estado social demócrata que está basada en una política garantista, en un asunto asistencial y en un asunto de discriminación positiva lo que hace es fragmentar al sujeto, yo no estoy diciendo que sea un problema de las feministas, estoy diciendo es que cuando el Estado construye una idea de discriminación positiva en donde tú vales más por ser mujer sin tener en cuenta variables como la de clase, como la historia del Estado, variables como la constitución de las mismas regiones o de las comunidades pues te está fragmentando (Camilo, entrevista 18 de octubre de 2011).

Este proceso es distinto al de la construcción de una conciencia de clase, aunque no la excluye, porque integra el reconocimiento del papel histórico y la opresión de los grupos indígenas, afro descendientes, las mujeres así como el papel que en esta opresión han jugado el estado y el capitalismo. En consecuencia reconoce otros elementos determinantes en la opresión como el patriarcado y el racismo.

\subsection{Memoria y Espacio}

Otro elemento importante en la definición de la memoria y por lo tanto en la diferenciación de distintas formas de reconstrucción del pasado es el del espacio. Según Halbwachs (1950), los espacios se habitan según la particularidad de cada individuo, lo reflejan. Los objetos ubicados en esos espacios son un vínculo con grupos sociales diversos. "Las cosas son parte de la sociedad". No se trata de concordancias entre cosas y personas sino de lo que dicen estas de lo común entre varias. El espacio es transformado por el grupo y este cede y se adapta.

La imagen que el grupo tiene del ambiente que lo rodea y de su estable relación con ese ambiente, es fundamental para la idea que el grupo se forma de sí mismo, y penetra cada elemento de su conciencia, moderando y gobernando su evolución (Halbwachs, 1950:13).

Como muestra de esa relación hay un conjunto de acciones que se centran en la construcción de la memoria poniendo como eje el espacio. Chico Bauti, por ejemplo, se ha dedicado a esta reflexión. Teniendo en cuenta su trabajo y para aclarar otra de las características del análisis de la memoria que estoy realizando quiero resaltar la categoría 
que él construye de memoria ancestral de grupos indígenas. Categoría relacionada con distintas tradiciones y reflexiones sobre el territorio como medio de producción y como sostén simbólico. En donde prácticas sociales como el trueque, el trabajo colectivo y la economía solidaria juegan un papel fundamental porque apuntan a la necesidad de la conservación de ciertos conocimientos y prácticas al rededor del trabajo y la cotidianidad. A su vez están relacionados con formas de ver el mundo y explicar el mundo, la salud, la educación, marcadas directamente por esa relación con el territorio. Esta conservación se vería como una forma de resistencia frente a la pérdida del territorio y como consecuencia ante el etnocidio por la desaparición de líderes espirituales y estandartes de la tradición oral:

La memoria ancestral se trabajará en relación a otro territorio; proveniente como lo indica el profesor Juan Arturo Echeverri de un -territorio indígena, aunque puede llegar a demarcarse y limitarse, se define no tanto por sus fronteras y límites como por marcas geográficas que señalan la ligazón de un grupo humano a un paisaje y una historia-. Esta memoria emerge en una relación entre la naturaleza y la cultura muy diferente a la que se establece en el espacio urbano. Es una memoria que tiene un pasado milenario, fragmentado/segmentado por toda la violencia en la que se ha enmarcado el proceso de colonización hasta nuestros días. Esta memoria cuestionará las demás memorias, brindándoles elementos que pierden centros de la modernidad y de la sociedad red, estableciendo otras relaciones con el pasado que práctica la gente de la tierra (Geomalla).

El concepto de memoria ancestral no es idéntico al de memoria que nos ocupa en este trabajo, fundamentalmente por la importancia que tiene la reproducción y conservación de las tradiciones y los saberes, mientras que la memoria moderna es una memoria para la no repetición (aunque definitivamente el pasado no pueda repetirse idéntico), para la innovación y la transformación. Es una yuxtaposición entre la valoración de procesos anteriores y la necesidad de recuperarlos y el deseo de transformar ese pasado para afectar el presente, en un esfuerzo por no guiarse solo de lo que antecedió y recuperarlo sin denegarlo, sin impunidad. Entonces la memoria se convierte en transformación pero también en legado del pasado que se contradice con la impunidad generada por expresiones "fascistas" del estado, similares a las que describió en su momento Primo Levi, dedicadas a "una guerra obsesiva contra la memoria ya que practicaba una falsificación de la memoria digna de Orwell, una negación de la realidad. Prácticas que no terminaron con el régimen (Huyssen, 2002). 
Por otro lado, hay una relación entre esta memoria ancestral tan estrechamente relacionada con el territorio porque hay vínculos muy fuertes entre las militancias pasadas y presentes y la lucha por la tierra.

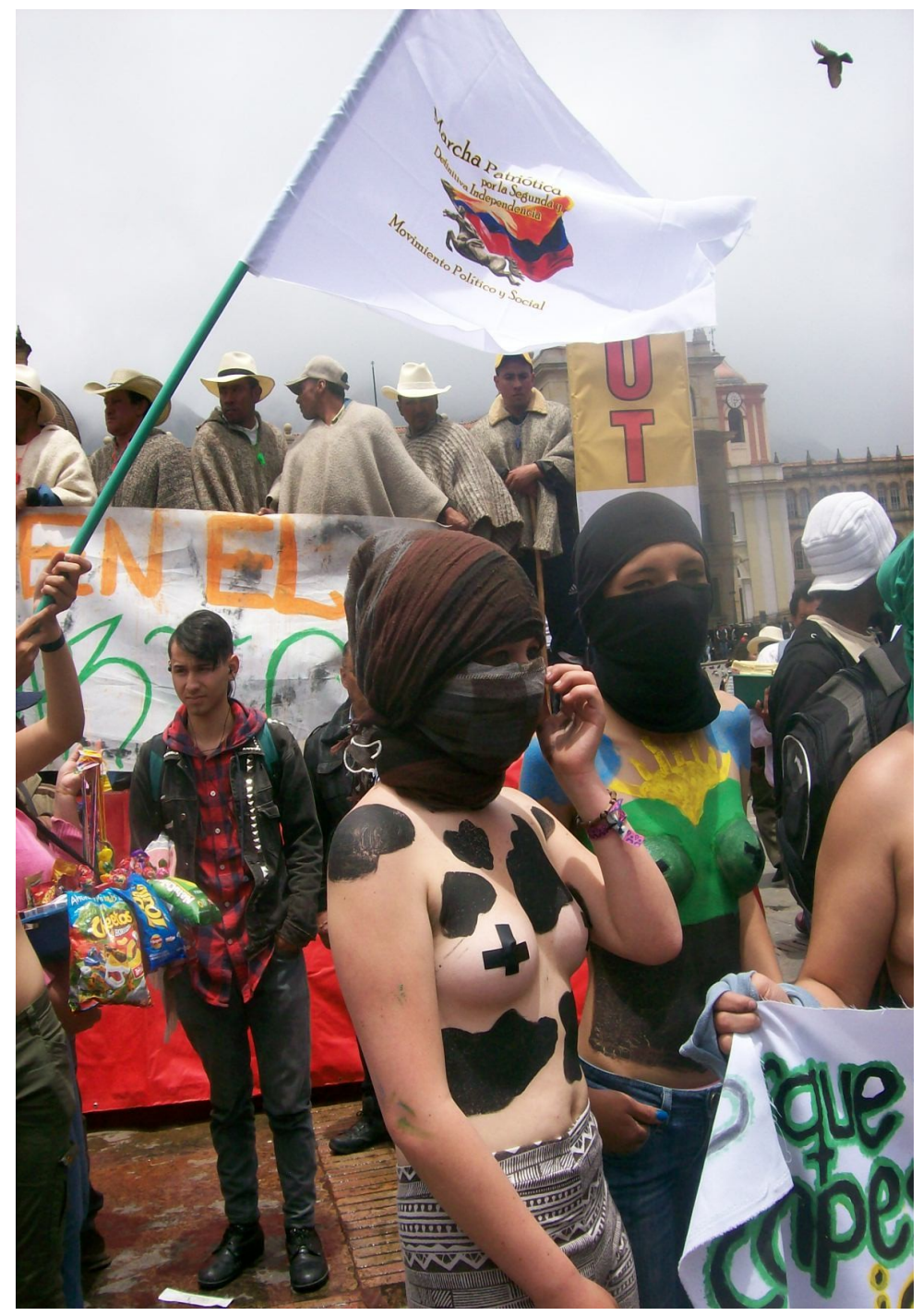

Paro agrario nacional. Arriba líderes campesinos de la zona rural de Usme - Bogotá, a la derecha banderas de la central obrera de corte marxista leninista CUT (Central Unitaria de Trabajadores); a la izquierda bandera del movimiento social y político Marcha Patriótica y abajo representantes de la ruta de mujeres. Plaza de Bolívar de Bogotá. Septiembre de 2013. Fotografía: Andrea Guatavita.

Gracias a una experiencia personal en un ejercicio de memoria con la comunidad indígena Wiwa de la Sierra Nevada de Santa Marta identifico en las formas que alcancé a reconocer 
de investigación y socialización de la memoria realizada por parte de estos hijos e hijas que fundamentalmente usan estrategias urbanas de memoria. Estrategias que por ejemplo para estas comunidades no son idóneas porque sus formas de transmisión son distintas y dependen del trabajo sobre la tierra, la música regional y el tejido, por ejemplo.

¿Qué son formas de construcción de memoria urbana? Una reconstrucción que usa para la investigación herramientas de las ciencias sociales como entrevista o etnografía, que se basa en el lenguaje verbal y cuando incluye expresiones artísticas incluye practicas como el mural, el performance, que se construye en espacios de debate cerrados y no en medio del ambiente natural. Esa forma de hacer memoria urbana que parece casi inmaterial, marcada por la velocidad, la preeminencia del tiempo sobre el proceso y la fragmentación de la ciudades generalizadas. Se ve afectada por la influencia que tienen en su arquitectura y su cultura la zona rural como característica específica de las ciudades latinoamericanas (Romero, 2013).

En la ciudad los lugares de memoria "tradicionales" como edificios y monumentos se mezclan con murales y grafittis que nacen todos los días, con música y otras expresiones más temporales, perecederas, como punto medio entre la memoria de cemento y la que se construye en las regiones sobre los ríos, en medio de paisajes naturales que van transformándose. También implica una transmisión que ocurre en espacios de debate y el movimiento social: las asambleas, las marchas, como espacios de acción en donde las acciones aprendidas en la reconstrucción del pasado se ponen en práctica.

Además de la caracterización urbana de esta memoria que aparece reconstruida en la tesis, y de estar llena de referencias de lugares en Colombia, localidades, barrios, ciudades, hay un lugar más complejo y que fue mencionado durante el primer capítulo pero que no ha sido tan significado en Colombia como en Argentina ha sido el de los centros de detención de las personas que han sido desaparecidas forzadamente. Investigaciones pasadas dieron lugar al reconocimiento de estos espacios pero en tanto son edificios dedicados aún al ejercicio de seguridad del estado y no se ha podido comprobar que funcionen como circuitos de 
detención como lo fue en Argentina no han tomado la importancia necesaria. Sin embargo, como lugares no lugar, que deben existir porque alguna respuesta debe darse a la pregunta ¿en dónde están los desaparecidos? son heterotípias ${ }^{31}$, cárceles, batallones, cuevas, en donde los derechos no son respetados y se desarrollan torturas y retenciones ilegales. Estos lugares que no tienen cabida aún en la memoria colectiva pero son buscados eternamente y nombrados como posibilidad o fin de la búsqueda.

Otro lugar, quizás el más importante para la memoria traumática, "no lugar" presente en algunos de los relatos es el cuerpo. El cuerpo del desaparecido es un lugar de reflexiones infinitas. En dónde está, qué hicieron de él. El cuerpo que se vuelve centro de investigaciones ya que justamente los lugares de detención son invisibles. Entonces el resto, la fosa común y el trabajo que con esos lugares hacen los antropólogos forenses se vuelve central. Lugares que son leídos a través del discurso científico y de esa manera se hacen extraños e incomprensibles para los familiares. Fundamentales porque contienen entre otros elementos la identidad del desaparecido.

"... encontrar a Nidia fue un hecho histórico porque no se encuentran desaparecidos todos los días, y después de tantos años nosotros no teníamos esperanzas pudimos hacer honores en el cementerio, pudimos devolverle el nombre, devolverle la familia, la dignidad, porque la querían volver una cosa y nosotros la volvimos un ser humano con derechos. Se hizo la identificación de los restos, allí estaban las ropas, el zapato, el arete, un Cristo, el saco, todo... Todo lo reconocimos, era Nidia..." (Hermana, Bogotá, $1987)^{32}$

El encuentro, se convierte en el aparente fin de un proceso pero es en realidad un paso dentro de un gran proceso, porque los procesos de identificación se entorpecen. Porque los familiares buscan usando los rastros de las acciones realizadas sobre ese cuerpo que se haga justicia, porque tienen que elaborar lo que significan esos rastros y porque con el proceso jurídico aumentan las persecuciones.

31 Concepto acuñado por Foucault (1997): Tierra de nadie, espacios que están fuera de todos los espacios pero localizables. Lugares comparables con el espejo real gracias al cual se tiene la experiencia de estar en un lugar irreal. No se entra o sale de ellos sin problema. Hay un inicio y fin que los aísla y abre. Se es obligado o se pasa por un ritual gracias a alguien que autoriza cumpliendo algunos actos.

${ }^{32}$ Extraído del libro Veinte años de historia y lucha. Asfaddes con todo el derecho (2003). 
El cuerpo emerge como referencia inevitable cuando algunas obras artísticas o performance se dedican a reconstruirlo y llenarlo de significado para rebatir las huellas que dejan en el cuerpo cuando este aparece. O como continente de significados cuando de él sólo queda una silueta para llenar o una fotografía.

El cuerpo se convierte en una expresión del desorden o la convivencia entre vivos y muertos, algunas veces por un misterio de ritual mortuorio repetitivo que es leído simbólicamente como lo hace Alejandro Castillejo (2006), del cual poco se conocen sus razones objetivas o sus culpables, convertidos no en grupos paramilitares específicos sino en "escuadrones de la muerte". Todo es ominoso, oscuro, siniestro y misterioso. Es decir la expresión del terror y de su objetivo pues no permite ver más allá la lógica de las acciones porque constituyen su parte más irracional. Parte del territorio visible e imagen de "este país" como dice Adriana Lalinde $^{33}$, en donde casi todo parece posible y en donde todo tiene que ser aceptado. Es decir que las acciones sobre el cuerpo se extienden a la imagen del territorio que por no estar delimitado como en el caso de los centros clandestinos consolidan en regiones enteras espacios de exterminio. Así se habló de las bananeras, del Urabá, del magdalena medio, de la zona esmeraldera. Lugares peligrosos que al servir de morada explican aparentemente que sobre sus pobladores se de algún tipo de victimización. Y esta simbolización supera las fronteras y genera que a la hora de hablar de violencia, si se menciona a Colombia el tema no sea nuevo ni genere sorpresa porque en Colombia (de manera generalizada) la gente muere todos los días. Por eso sigue siendo una tarea pendiente delimitar los lugares, quiénes desaparecen y en dónde se encuentran los desaparecidos.

${ }^{33}$ Hermana del desaparecido militante del Partido Marxista Leninista Luis Eduardo Lalinde. 


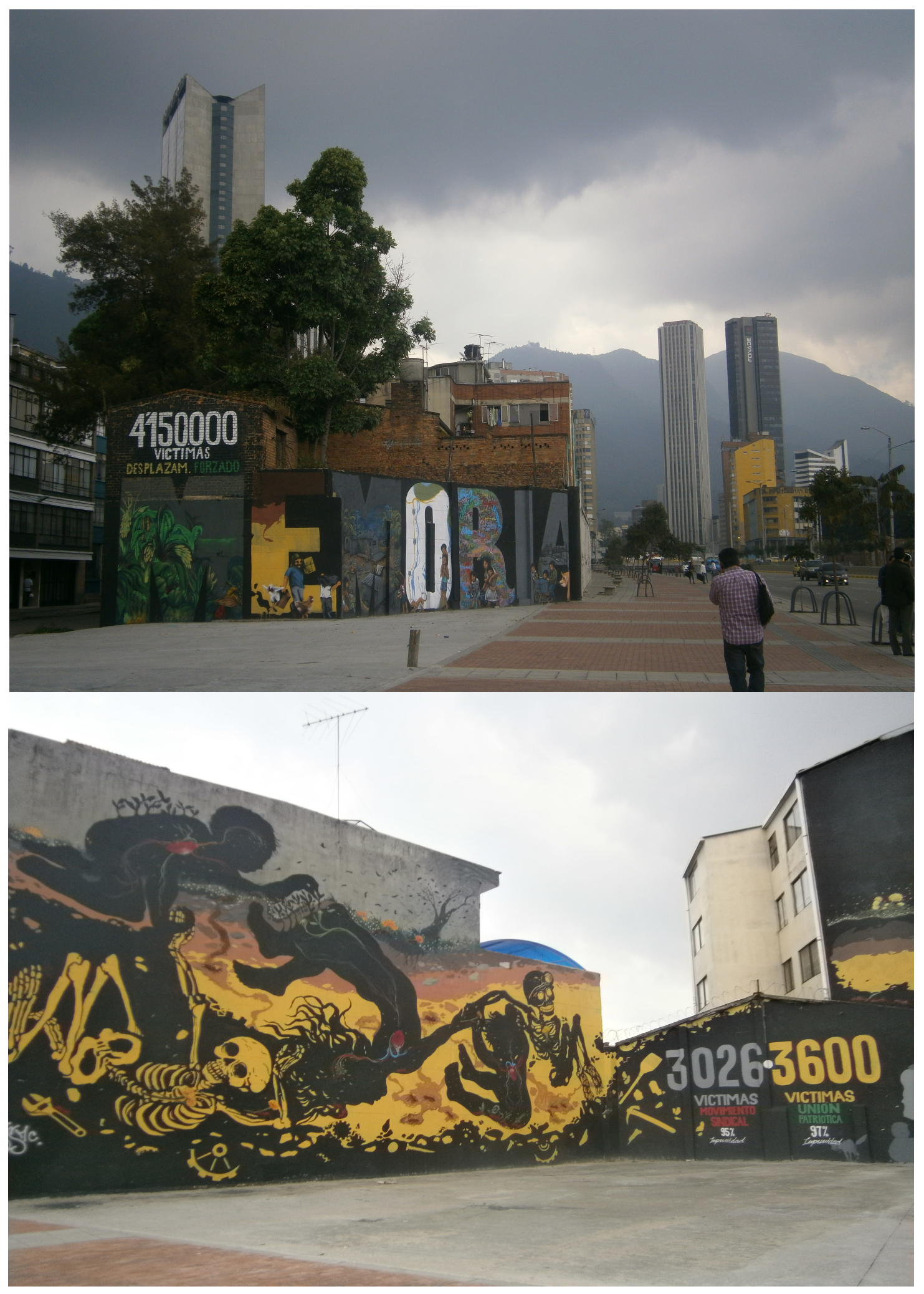

Autopista El Dorado. Bogotá. 2013. Fotografías: Andrea Guatavita. 


\subsection{Memoria y tiempo}

Con respecto a la memoria y su relación con el tiempo ${ }^{34}$, se plantea que esta se construye apenas se constituye el sujeto social, gracias a una corriente de pensamiento invisible e inconsciente que lo atraviesa y los niños en contacto con otras generaciones se conectan con pasados más lejanos (Halbwachs, 1950). Al construir vínculos vivos entre las generaciones ${ }^{35}$ se construyen marcos colectivos para la memoria, no centrados en las fechas sino guiados por corrientes de pensamiento que permiten encontrar el pasado. Este vector tiempo funda la generación unida, entre otras cosas, por los lazos de identidad.

-Es difícil porque yo creo que hay tres tipos de entrada (a la memoria) ahí: Una más individual, personal,

\footnotetext{
${ }^{34}$ La relación entre memoria y tiempo es indisoluble. Retoma la división antes/ ahora. Hay que tener en cuenta la noción de tiempo de cada sociedad. Hay un tiempo, inmemorial, anónimo (ancestros), fundado en eventos significativos para la familia o colectividad (Sociedades rurales) y no fundado en hechos históricos. El daño neuronal genera una memoria de los hechos con los cuales el sujeto tuvo implicación directa. Cosa que evidencia la relación entre sujeto individual y social. La sociedad provee al individuo de herramientas para facilitar la memoria, medidas de tiempo que cargan una información local y hacen parte de la cultura popular. (memoria-popular). La capacidad de la memoria es notable y evidente en las sociedades de tradición oral, que son capaces de un conocimiento basto según Strauss en la ciencia de lo concreto sostenido por mitos y ritos. El primer intento de memorizar, dejar huella fue las pinturas prehistóricas. Que son la primera expresión de una preocupación por inscribir algo y muestra la relación entre la historia y la escritura. La escritura motivada por la voluntad de conservar la memoria genera la posibilidad de generar acuerdos, convenios económicos, una representación de la muerte. "herodoto escribió "para impedir que lo que hicieron los hombres se borrara con el tiempo, con el proyecto de que ingresara en la memoria no solamente el tiempo de los orígenes, sino también el de los acontecimientos más cercanos.

Pareciera que responde al miedo que genera la acción contraria o intención de borrar la memoria de lo más cercano. Es un intento de conservación que refuerza y da verosimilitud a la memoria oral pero la transforma sumándole periodicidad y una distancia crítica. Pero que puede generar según los textos platónicos un olvido en el alama de aquello contenido en la escritura, que el un medio para "recordar afuera".

La diferencia entre memoria viva o muerta depende de la posibilidad de nuevas inscripciones. Así la escritura de la memoria está viva en tanto puede inscribirse nuevamente y sobre todo si llega a reforzar la tradición oral en una localidad o recupera los mitos para conservarlos y expandirlos, pues lo que diferencia las dos memorias es su actitud hacía el olvido. La memoria genérica permite una interpretación que incluye el olvido, signo de vida y dinámica. En ella la palabra es fundamento de intercambio y la transmisión. Gran diferencia con la escritura a menos que esta llegue a reforzar la oralidad. El olvido en esta es consentido en la primera, involuntario. Si la escritura genera una nueva discusión no deja de hacerlo también el uso de nuevas tecnologías. "la ausencia de fuentes escritas permite una verdadera interpretación de la memoria transmitida, interpretación que puede pasar por el borramiento puro y simple de una parte de esta memoria. "(...) la sociedades de memoria son aquellas en las que la palabra es el fundamento esencial de los intercambios y de la transmisión social, en tanto que las sociedades de lo escrito" (Candau, 2002).

${ }^{35}$ La generación es una categoría distinta a la genealogía. Según Candau (2002) La genealogía es una categorización arbitraria que se refiere a la dimensión utilitaria que fundamenta la legitimidad de la transmisión y devolución de bienes, reconstruye linajes, oralmente alcanza a la séptima generación pero desde la tercera tiene lagunas. Se vuele imprecisa. Selectiva o ficticia. Investigaciones muestran diferencias: hay mayor memoria en comunidades nómadas como si solventaran la no territorialidad, como si así se compensara la ausencia de anclaje territorial. El entorno popular, las tradiciones aseguran la memoria de los ausentes, disminuyen la angustia. Esto depende del conocimiento mutuo durante un tiempo. La memoria generacional en cambio, es la conciencia de pertenecer a varias generaciones que tienen peso sobre las nuevas y que da lugar a la memoria colectiva. Es intrageneracional, pertenece a una generación. Según el autor la preeminencia de esta memoria deja a las otras generaciones sin memoria, sin nada que transmitir.
} 
si se quiere subjetiva, si se quiere, que necesita romper ese escenario privado que ha sido privado, que ha sido cerrado, que necesita diálogo, que necesita diálogo con los iguales, creo que esa es una entrada. Por eso hay tanta tensión con eso de la identidad, la identidad como en todo grupo es un factor fundamental de arranque o del desenvolvimiento de los escenarios entonces pensar en cuáles son tus iguales en un escenario marcado como el que nos tocó lleva a que mis iguales son aquellas personas que han sufrido vulneraciones similares a las mías, es que la palabra no me gusta, o que han tenido historias de vida similares no necesariamente traumáticas tampoco, esa es una entrada (Camilo, entrevista 18 de octubre de 2011).

Esos lazos de identidad como lo indica el párrafo anterior tienen que ver con una condición subjetiva privada que va siendo colectivizada y a través de la cual se comparten experiencias bajo un marco o intervalo de tiempo específico. Lo primordial es la posibilidad de identificarse en la interpretación de un pasado común más que por tener rangos de edad similares.

La generación se define para Arostegüi (2006) según el lugar de un grupo social con respecto a ciertos hechos históricos, el efecto de ser testigo o víctima directa de un hecho violento o de no tener ninguna relación con el hecho estudiado y el lazo filial. En España por ejemplo se pueden reconocer tres generaciones, la que vivió la guerra civil, los hijos de esas personas, que vivieron durante el franquismo y los nietos.

En el caso de la segunda guerra mundial la primera generación estuvo definida por todos sin importar su etapa de vida, en el campo de concentración adultos o niños y la segunda generación por aquellos hombres y mujeres que nacieron fuera de los campos de concentración (CINTRAS, EATIP, GTNM/RJ, SERSOC, 2009). La comprensión y definición de las generaciones estaría dada por la relación temporal con la experiencia traumática.

En las investigaciones sobre las dictaduras en el cono sur, la primera generación fue constituida por aquellos hombres y mujeres víctimas directas de la represión, desaparecidos, torturados, exiliados y la segunda generación por sus descendientes a pesar de haber vivido persecución y pérdida directa de sus familiares (CINTRAS, EATIP, GTNM/RJ, SERSOC, 2009). 
Con frecuencia, la segunda generación incluyó a descendientes de quienes vivieron directamente la represión, y ha sido común, al menos en países como Guatemala, México, Colombia, Argentina y Uruguay, que se creen grupos de pares que reconstruyen la memoria al rededor del vínculo filial para dar cuenta de su experiencia desde las particularidades de cada país. En el caso de Argentina por ejemplo, la organización Hijos se formó con hijos e hijas de personas desaparecidas forzosamente por la dictadura ocurrida entre 1976 y 1982.

Ser Hijo no supone haber vivido de modo único la ausencia de sus padres. Una primera diferencia se
establece entre quienes tenían a sus padres desaparecidos, sin conocer qué destino habían tenido, y
quienes sabían que sus padres estaban muertos. La desaparición fue un hecho que necesitó de una
traducción particular para esos niños que debían explicarse qué había sucedido. Pero, así como a partir
del surgimiento de la agrupación, a mediados de los años noventa, todos pasaron a nombrarse como
"Hijos", o "HIJOS" - porque la identidad "hijo de desaparecidos" ya iba cobrando por entonces una
referencia social que no requería demasiadas explicaciones-, la infancia había significado para ellos y sus
familias la necesidad de construir diversas estrategias para comprender, soportar y explicar las ausencias (Cueto, 2008:36).

En este ejemplo se demuestra como hijos tiene que ver con la relación filial con una persona que ha vivido una experiencia de represión específica. Aunque más adelante, en este trabajo se reconozca cómo la organización va transformando su perfil es fundante la idea de que la segunda generación en Argentina se define por la relación con respecto a las víctimas de la desaparición forzada.

En el caso de las investigaciones realizadas por el Grupo Tortura Nunca Mais do Río de Janeiro la segunda generación está constituida por familiares con distintas filiaciones que no vivieron la desaparición directa, nacidos fuera de la dictadura (CINTRAS, EATIP, GTNM/RJ, SERSOC, 2009). El grupo brasilero de manera novedosa señaló con esta definición que el trauma no se ubica en la familia y en los hijos, sino en los herederos generacionales de un momento histórico. Esta aproximación se relaciona con lo concebido por las siguientes personas entrevistadas.

1.

- ¿Qué papel juega la memoria en la recuperación de los hijos? 
- (...) Yo personalmente creo que muchas familias hacen este ejercicio para dignificar, por que los hijos, en los casos donde quedaron muy pequeños, no alcanzan a recordar ni a visibilizar quien era la persona, no solamente los hijos porque recuerde que hay muchos desparecidos que no dejaron hijos pero dejaron sobrinos que se criaron con ellos. Dejaron menores de edad que compartían un entorno, que habían lazos de afecto. Creo y es una posición muy mía, que en todos los espacios, en la vida de las familias que vivimos la desaparición forzada así haya aparecido el cuerpo o no haya aparecido hay una tendencia a desconocer eso, que no solamente son los hijos los afectados y que en el caso de muchos desaparecidos en el núcleo familiar habían menores de edad que generaron lazos de afecto muy fuertes, y solo se habla del daño para los hijos (Gloria, entrevista realizada el 22 de septiembre de 2011).

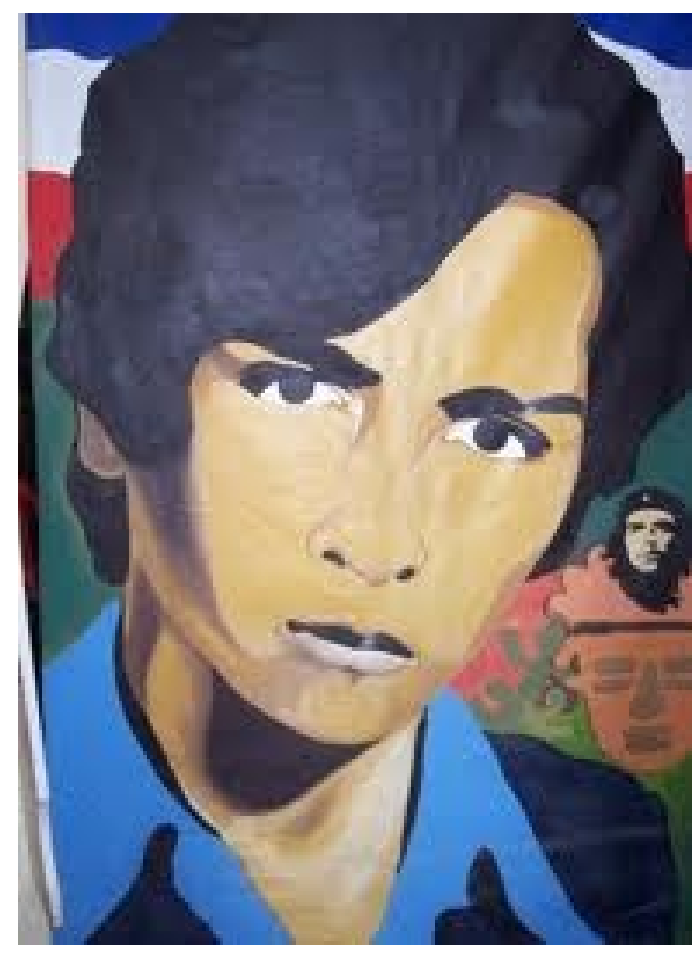

Leonardo Gómez. Fotografía donada por la Asociación de Familiares de Detenidos Desaparecidos Forzadamente - ASFADDES

El problema del daño supera el vínculo filial hijo o hija y se refiere a una generación que vivió una ausencia inexplicable en su grupo familiar. Entonces es necesario superar el límite generacional puesto sobre los descendientes directos. En primer lugar, por el reconocimiento de un vínculo y un efecto en miembros de la segunda o tercera generación que no fueron propiamente hijos. En segundo lugar, porque si la transmisión no sólo trae vacíos o malestares emocionales sino formas de lucha, los herederos no son sólo los hijos de padres y madres desaparecidos, sino exiliados o desplazados, en todos los casos perseguidos y 
estigmatizados, vinculados con luchas que en Colombia no se han cerrado y que en un punto pueden continuar, replantearse y redirigirse.

- Una pregunta, ahora que hablabas sobre los hijos entonces el movimiento de hijos no se está planteando desde la noción de víctima.

- Nunca, habemos o hay compañeros que tenemos la condición de víctima como condición pero siempre se ha pensado como un movimiento generacional que convoca a través de la memoria y la lucha por la justicia a un llamado generacional a construir un nuevo país (Camilo, entrevista 18 de octubre de 2011).

La segunda generación se reconoce, en este caso, en el decir de personas que hacen parte de la organización de hijos e hijas como una generación que heredó un momento histórico de la izquierda y asumió el presente tras el análisis de esa memoria. Este es un tema crítico pues abre una discusión con respecto a las dimensiones del daño transgeneracional que abordaré más adelante. Por otro lado, esta definición generacional refleja un cambio de momentos históricos que es necesario limitar.

Para la definición de la primera generación es necesario reconocer un intervalo histórico que puede ser llamado momento o acontecimiento histórico traumático, desde el marco de análisis de la historiografía que se refiere a historias de violencia de algunas naciones. Teniendo en cuenta que lo que se hizo en el primer capítulo fue un recorrido de la desaparición en distintos momentos o formas de gobierno no se señaló un proceso traumático específico. ¿Entonces cómo definimos la segunda generación de colombianos con respecto a qué "pasado" traumático?

Hijas e hijo participaron, en dos de los casos, de la búsqueda y se encargaron directamente de las denuncias junto con sus familiares, así que según la edad que tenían en el momento de la desaparición recibieron en más o menos medida la transmisión o directa del impacto, la imagen y la historia social y política de sus padres. Sin embargo, entre ellos se guardan diez años o más de diferencia ¿Qué los ubica dentro del mismo intervalo o dentro de la misma generación? 
Las duraciones de los diversos grupos en los que se descompone la sociedad implican divisiones [temporales] diferentes, no se podría establecer ninguna correspondencia entre sus movimientos. Precisamente porque estos grupos están separados el uno del otro, porque cada uno de ellos tiene su movimiento propio, y porque los hombres individuales pasan, no obstante, de uno a otro" (Halbwachs [1998]:12).

Esas generaciones definidas desde la filiación y la existencia de un pasado "traumático", o tan sólo desde la herencia de ese pasado, requieren una mirada crítica a su definición: la necesidad de un corte temporal con el pasado y, por lo tanto, reconocimiento de hechos que marcan un antes y un ahora en la historia de un pueblo, la introducción de la noción de trauma en el campo de la historiografía.

En el caso de Colombia no es tan fácil aceptar un intervalo definido o pasado traumático por parte de la historiografía por la longitud y magnitud del momento de "violencia". Por lo tanto, la delimitación generacional me ha sido más compleja y será planteada de la siguiente manera: La primera generación para este trabajo está conformada por aquellos y aquellas que vivieron y con frecuencia militaron durante el primer intervalo histórico en Colombia en el que se reconoce oficialmente la ejecución del delito de desaparición forzada, después de la época conocida como "la violencia" y como acción frente a la existencia del Frente Nacional, este intervalo coincide con la propuesta del Proyecto Colombia Nunca Mas según la cual las razones y condiciones de la experiencia de violencia en Colombia cambian y se determinan por las políticas de seguridad y la creación del enemigo interno.

- Con respecto a hijos ¿Cuándo te vinculas a la organización por qué que te vinculas a la organización? No hay un proceso de vinculación hay un proceso de maduración ahí de distintas personas, de distintas inquietudes más o menos alrededor del $2000 \ldots$ inicialmente alrededor del...

- (Otra) 2006.

- 2006, 2007. Hay una serie de reflexiones que nos van congregando, una serie de hechos de contexto que nos van juntando incluido el periodo del gobierno de Uribe, la reelección, la ley de justicia y paz, el paramilitarismo, el asesinato de varios compañeros del movimiento estudiantil y una emergencia en los escenarios de movimientos sociales del tema de memoria son los que nos van vinculando en una reflexión que luego ya se llamó movimiento de hijos e hijas entonces no hay como una vinculación. Ya 
formalmente el nombre aparece públicamente hace seis años, hace cinco años ... ¿2008?

(Otra) En el 2006 (Camilo, entrevista 18 de octubre de 2011).

Se reconoce como segunda generación a quienes conocieron durante su juventud y como periodo álgido de victimización, el gobierno de Álvaro Uribe Vélez y son descendientes de una persona desaparecida. Esta definición es artificial para el trabajo, teniendo en cuenta la observación del nacimiento de la organización de hijos e hijas por la memoria y contra la impunidad, me atrevería a decir haciendo eco a lo planteado por miembros de la organización, que se trata de una segunda generación que se expresó en medio del desarrollo de las políticas de represión y memoria de Álvaro Uribe Vélez. En conclusión, defino el intervalo desde el sentimiento generacional y el punto de vista del grupo con el que trabajo. No implica una ruptura en un proceso largo de represión ejercida por el estado sino del surgimiento de un discurso que se reconoce a si mismo de segunda generación en un contexto que podría llamarse de impunidad o manipulación institucional de la reconstrucción del pasado para sostener las formas de represión actualmente ejercidas.

Al igual que en Colombia, en Argentina el nacimiento de hijos se dio entonces en medio de un contexto adverso al de la construcción de las memorias de las organizaciones sociales ${ }^{36}$. Las nuevas generaciones parecen tener un lugar fundamental en la reconstrucción de memoria de estos pasados, su papel es bastante valorado y su trabajo depende de cómo a través de ciertas experiencias o relatos familiares, esos contenidos guardados por los grupos de pertenencia de sus padres o madres se volvieron privados o indecibles. La elaboración de los hechos queda en manos de los jóvenes que han recibido a través de la familia y los amigos estos relatos. $Y$ este es un procedimiento que puede reconocerse en organizaciones como HIJOS en Argentina, que es por otro lado la organización fundadora del carácter generacional de los organismos de derechos humanos a nivel internacional.

\footnotetext{
${ }^{36}$ Menem banalizó el pasado y negó las diferencias: "si miramos al pasado nos convertimos en estatua de sal". Acompañó su política de olvido con una propuesta de reconciliación y reformas neoliberales. Los indultos presidenciales de 19891990 beneficiaron a jefes militares condenados en 1985 justificados en que borrar la memoria resuelve los conflictos. Aquí surgen expresiones de memoria que intenta tramitar el sentimiento generado por la falta de justicia y se traduce en principio de acción simbólica y ritual. La práctica de los escraches quizás ejemplifique el punto expresando "Si no hay justicia, hay escrache" (Palermo,2004).
} 
Y hubo otro día en que HIJOS volvió a nacer. No fue un día exacto. Fue el día en el que HIJOS se hizo de otros hijos, de los hijos de quienes estuvieron presos y exiliados durante la dictadura. Compañeros que merced a la planificación represiva, fueron liberados. "Para que cuenten el horror, para hacerlos sentir culpables de que ellos si y los otros no". Compañeros, que nos contaron el horror, pero desde otro lugar, no como los milicos lo planificaron. Contaron la entereza, la dignidad, el amor profundo de todos los que estaban allí, de los que salieron y de los que no. Compañeros a los que admiramos, porque llevan viva la historia, porque nos han podido criar en la alegría de estar vivos y que siguen apostando a seguir....Sus hijos, los hijos de presos, hicieron nacer a hijos de nuevo. $Y$ también los hijos de los exiliados, los que sufrieron el castigo de los pueblos: el destierro (Cueto, 2008:88).

Este fragmento demuestra un segundo momento en la elaboración de la historia que se nutrió de la vida política de los padres gracias a la existencia y participación de hijos que no perdieron a sus padres y su relación con los grupos políticos de los que hicieron parte, que son cruciales por su coparticipación en actividades militantes. La transformación del pasado reconstruido por la vinculación de otras voces y otras experiencias.

Esa reconstrucción es muy evidente en hijos e hijas de militantes colombianos por varias razones: el perfil del desaparecido o asesinado no es una referencia simbólica fuerte como en Argentina. Los grupos de militancia en muchos casos existen aún o han resurgido después de ciertos momentos de represión fuerte como en el caso de la Unión Patriótica. Shaira, por ejemplo, reconstruye el pasado recuperando distintas dimensiones del padre pero también el móvil de la desaparición. Evidentemente la investigación sobre este hecho no parece dirigirse a ese punto y seguramente una reconstrucción política solo pueda lograrse desde una búsqueda sociológica e histórica que lo ubique en un marco amplio.

Sí, como decir ahí que es lo que estaba haciendo él y por qué le interesaba, qué era lo que estaba haciendo este man y por qué era tan importante. Yo creo que no me he acercado todavía lo suficiente, estoy indagando apenas con compañeros, compañeras, preguntando que era lo que estaban haciendo en ese momento cuando lo desparecen, además también eso dicen: "Si es por su trabajo". Pero qué estaba haciendo él tan importante para que esta gente estuviera interesada en desaparecerlo... entonces es como que si he charlado mucho con los amigos de él y ahí he ido conociendo distintos matices de su personalidad, pues que no yo no lo leía así antes, entonces es como muy loco así 
(Shaira, entrevista realizada el 26 de julio de 2011).

Pero no todo es pasado, el espacio de militancia como tal no ha desaparecido, pero eso a veces se convierte en una dificultad porque en tanto esa militancia no ha desaparecido la persecución contra grupos de izquierda radical es muy álgida y un hijo o hija que intente buscar o más aún difundir información sobre las historias de lucha de padres o madres encuentra grandes riesgos.

\subsection{Tipos de Memoria}

El principal elemento de organización de la memoria que presento en esta tesis tiene que ver con la memoria que se centra en la transformación del pasado. La posibilidad de recordar, reconstruir, replantear el pasado y el presente a través de la acción memorística para revelar las condiciones en las que se fue construyendo el recuerdo. La memoria que intenta abordar este trabajo es una memoria reflexionada y construida desde la modernidad para pensar la transformación y bajo ese primer principio comencé a tener en cuenta la manera como el recuerdo es abordado en cada forma de memoria, los sentimientos que genera y la intención consciente que cada persona imprime en el trabajo de recordar, el proceso o longitud temporal del trabajo de recordar, estos ejes dependen de las nociones de memoria que los y las participantes han venido construyendo en su propia práctica. He decidido organizar esas nociones como: Memoria traumática, memoria espontánea y familiar, memoria intencional colectiva, memoria clandestina.

La memoria traumática es una memoria relacionada directamente con el sufrimiento personal, con la fragmentación social y corporal, con el hecho violento y deviene con menos intencionalidad. De todas las memorias mencionadas parece la más fragmentada y menos colectivizada.

Para mí existe una diferencia entre memoria e historia en el sentido de que la historia es lo que se hace y se escribe y la memoria contribuye a ese proceso de escribir la historia... pero también hay otras memorias que... me metiste en una cosa que estoy viendo más desde el lado teórico. La diferencia entre 
la memoria como algo que estás reconstruyendo y que seleccionas pero también está ese otro aspecto de la memoria que simplemente emerge, son las evocaciones que surgen, los recuerdos instantáneos que se vienen a ti. Esa noción de memoria larga que tiene que ir acompañada de una visión crítica, para mi una memoria que no sea crítica... y en últimas no sé qué es memoria porque todo el mundo habla de memoria (Diana, entrevista realizada el 21 de septiembre de 2011)

La memoria familiar es espontánea o generada por organizaciones de familiares, es una memoria con frecuencia grata que se refiere y rescata el vínculo afectivo. La memoria colectiva es conscientemente construida desde matrices ideológicas más o menos discutidas y conscientes relacionadas con el indigenismo, el feminismo, la izquierda marxista, la ética y la jurisdicción de los derechos humanos. Finalmente, la memoria clandestina que circula por ciertos grupos, es una memoria que, por ahora, está desvinculada de la memoria colectiva de la nación o de memorias que están disputando la definición del pasado.

\subsection{Trabajadores de estas memorias}

Guillermo Tell no comprendió el empeño pues quién se iba a arriesgar al tiro de esa flecha y se asustó cuando dijo el pequeño: "Ahora le toca al padre la manzana en la cabeza". Guillermo Tell tu hijo creció, quiere tirar la flecha, le toca a él probar su valor usando tu ballesta (Carlos Varela).

Elizabeth Jelin creó una categoría llamada emprendedores de memoria. Al igual que en el contexto de Jelin es posible describir al grupo de "víctimas" como protagónico y de la siguiente manera:

No cabe duda del protagonismo privilegiado de un grupo especial, el de las víctimas o afectados directos.

En Francia podrán ser ex deportados o ex resistentes, podrán ser grupos de veteranos de guerras (de Vietnam o de Malvinas) o sobrevivientes de masacres. Sus frentes de demandas y de luchas varían. Pueden intentar influir y cambiar el sentido y el contenido de la historia oficial o dominante sobre un periodo con el fin de eliminar distorsiones históricas o hacer públicos y legítimos los relatos que habían estado en las <<catacumbas $>>$ (Jelin, 2002).

La categoría de emprendedores de memoria ubica en el mismo concepto el acto de construir y usar la memoria. Sin embargo, en el uso de la herramienta es claro que hay personas que la ponen en marcha y otras que consideran ser sus propietarias. Las relaciones de clase se 
establecen de una manera dinámica (Thompson, 1977). Por eso traigo la noción de trabajadores de la memoria. Trabajadores que intentan no sólo transformar y hurgar en la materia del recuerdo, sino también conservar de esa materia el conocimiento de su acción y el beneficio de su esfuerzo. No incluiría en este caso a miembros de instituciones que toman ese recuerdo recuperado de las organizaciones así como sus métodos de reconstrucción para hacerla capital del estado.

Hijos o hijas de personas desaparecidas que dan cuenta de procesos de memoria sobre sus padres desaparecidos, estas personas participan en la investigación gracias a la ayuda que me ofrecieron miembros de las organizaciones H.I.J.O.S. Colombia, el Movimiento Nacional de Víctimas de Crímenes de Estado, Asfaddes y el Movimiento Hijos e Hijas por la Memoria y contra la Impunidad. De esas organizaciones también pude conversar con otros miembros y familiares para reconstruir algunos decires sobre el trabajo de la memoria.

Las personas entrevistadas han tenido educación superior y el conocimiento o participación en el movimiento feminista, el campo artístico, las juventudes comunistas o los grupos estudiantiles camilistas, entre otros. Son miembros del movimiento social y defensores de derechos humanos. Tienen un vínculo permanente con su núcleo familiar. En todos los casos han sido participes de procesos de reconstrucción y difusión de la memoria.

Tengo 37 años. Vivo con Victoria mi compañera y con Manuela mi hija. Trabajo en la Fundación Nydia Erika Bautista en el área de comunicaciones y aparte estoy involucrado en algunos proyectos culturales y políticos en la ciudad como el movimiento de hip-hop... con algunos grupos de música... (Chico Bauti, entrevista realizada en Septiembre de 2011).

Hijo de Nidia Erika Bautista. Ella era Socióloga de la Universidad Nacional de Colombia, Economista de la Universidad Central, sindicalista y militante del M-19.

Todo comenzó o se trastocó un 30 de agosto, año de 1987 (...) Nuestra tradición cultural rodea esa fiesta religiosa de afectos y encuentros familiares y sociales. Hubo regalos y símbolos tiernos para colocar en las solapas de los vestidos. Los encantos de la infancia, nimbados con resplandores celestes, invitan a 
hacer derroche, en ese día de afectos y ternuras que saturan el ambiente. Por eso fue más brutal el episodio del atardecer: la madre, Nydia Erika Bautista de Arellana, fue raptada violentamente en un jeep de los servicios secretos del Estado e inmediatamente desaparecida (Javier Giraldo, Julio de 2011) ${ }^{37}$.

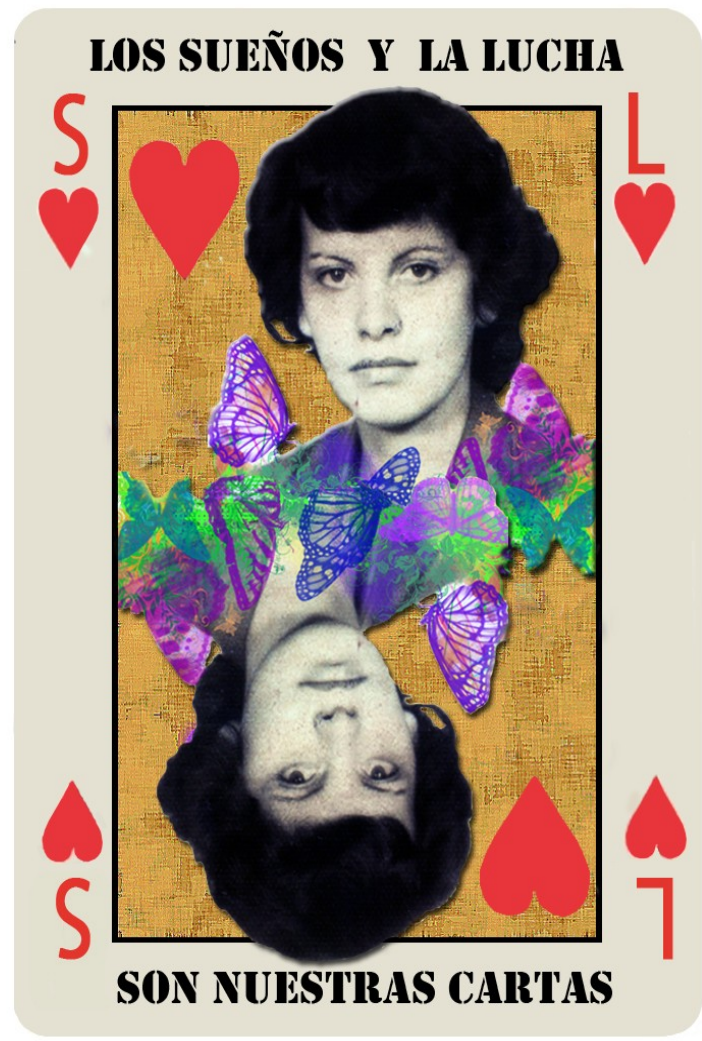

Imagen de la campaña organizada por la organización H.I.J.O.S: "La impunidad no puede ser la reina"

Ni nombre es Diana Gómez y estoy ahora estudiando en Estados Unidos un doctorado en antropología, tengo 33 años, creo que soy la mujer más viejita de hijos e hijas, soy antropóloga de pregrado, hice una maestría en historia. Yo empecé esa maestría en el 2003 y terminé materias en el 2005, me gradué en el 2009 porque fue en medio de lo de mi papá todo lo de la tesis en la nacional y ahora estoy aquí en la universidad de Carolina del Norte (Diana, entrevista realizada el 21 de septiembre de 2011).

Hija de Jaime Gómez. Él era líder sindical de la Empresa de Teléfonos de Bogotá y de la Central Unitaria de Trabajadores (CUT), graduado como historiador de la Pontificia Universidad Javeriana y Magister de la misma universidad en la Maestría de Ciencia Política. Desaparecido el 21 de marzo de 2006.

\footnotetext{
${ }^{37}$ Presentación del libro de poesía "Tránsitos de un hijo al alba" de Chico Bauti
} 
Jaime Gómez fue desaparecido el 21 de marzo de 2006, momento en el cual se desempeñaba como asesor de la senadora Piedad Córdoba. Sus restos aparecieron el 23 de abril del mismo año. Sobre su historia el sello de la impunidad ha sido estampado con la fuerza bruta que caracteriza el ejercicio del poder en Colombia, reproduciendo una lógica de terror y exterminio sobre dirigentes de oposición (Diana Gómez, 2007) $)^{38}$.

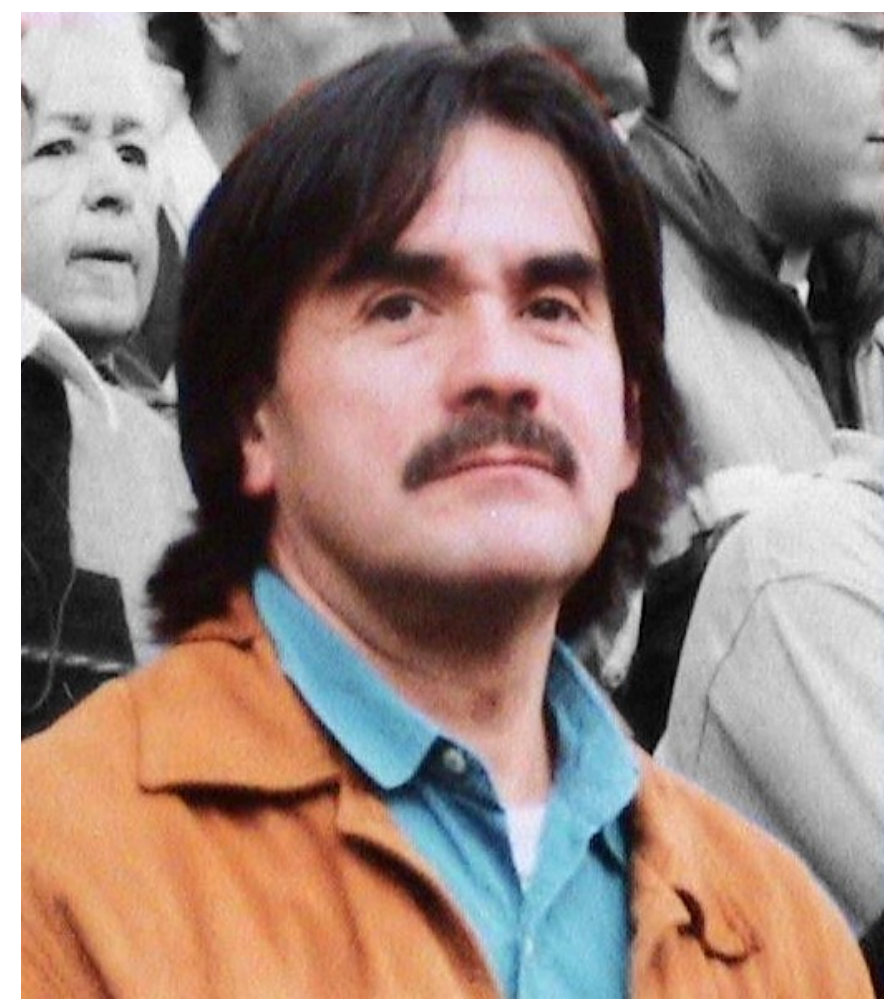

Jaime Gómez. Fotografía donada por Diana Gómez.

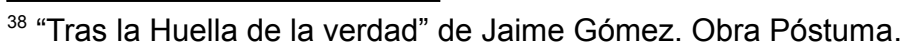


3.

Mi nombre es Shaira Rivera Gallo tengo 25 años, nací el 14 de enero del 86 en Cali pero me crié acá en Bogotá, estudié trabajo social y terminé hace dos años, no me he graduado porque quedó pendiente el tema de escribir la tesis y digamos que el tiempo en que terminé materias se cruzó con los hechos de la desaparición de mi papá (...) (Shaia, 2011).

Hija de Guillermo Rivera. Él era economista de la Universidad Autónoma y Magister de la Universidad Javeriana. Miembro del Partido Comunista, líder sindical de la Contraloría y de la CUT, sobreviviente de la UP. Desaparecido el 22 de abril de 2008.

Hace dos años mi padre trotaba por esta esquina, hace dos años iba tranquilamente a hacer ejercicio y la policía metropolitana lo interceptó en una patrulla, lo subió arbitrariamente y se lo llevó. Desde ese día no sé nada de él, desde ese día nadie responde, desde ese día el caso de mi padre está en la impunidad (Shaira Rivera, 22 de abril de 2010).

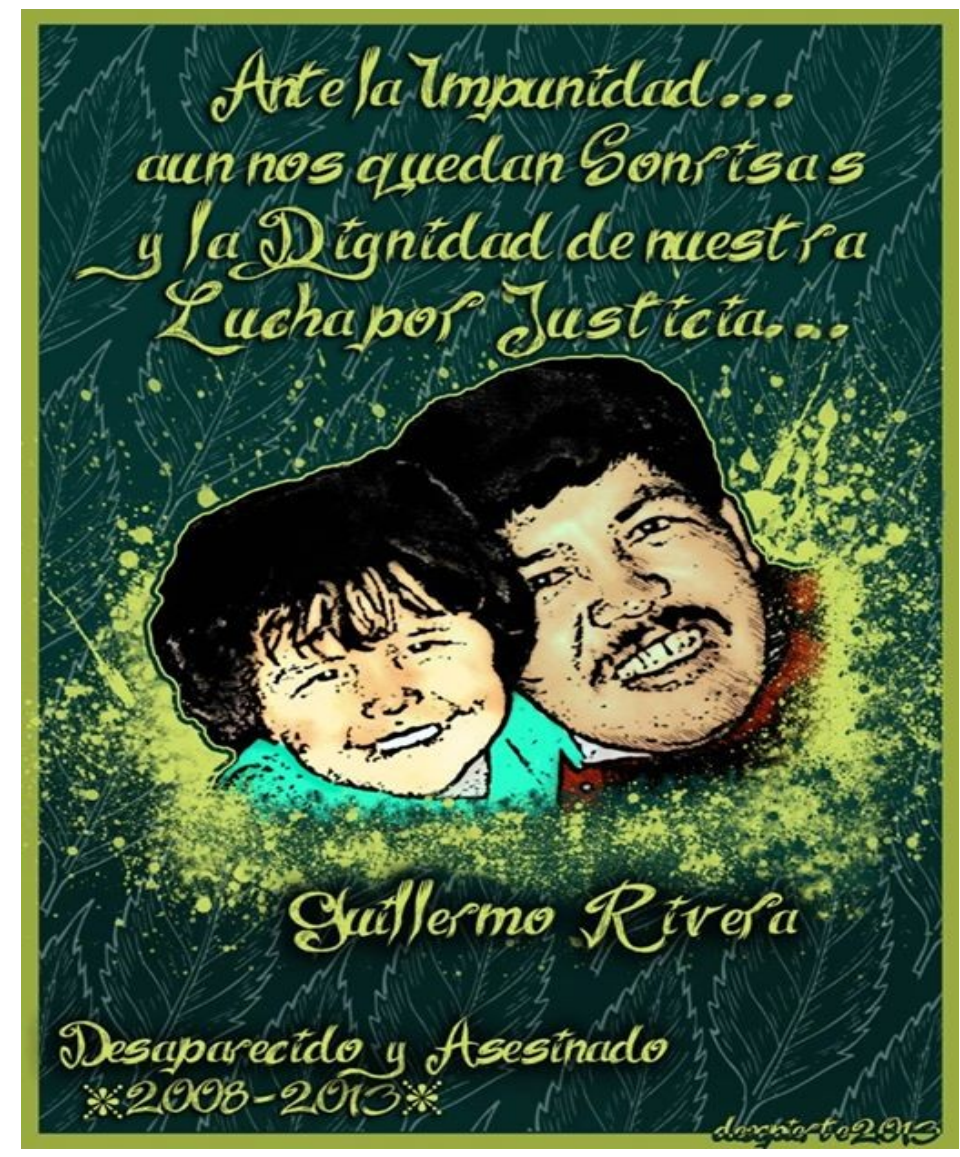

Fotografía del afiche conmemorativo.

Tomada de internet. 
4.

Yo me llamo Steffany Beltrán Navarrete. Tengo 30 años. Trabajo en el sector de banca y seguros de Bogotá hace más o menos unos ocho años. Soy tecnóloga, tengo dos hijos, que más te puedo contar ese es mi nombre y mi edad (Steffany, entrevista realizada el 20 de abril de 2013).

Hija de Héctor Jaime Beltrán. Él tenía veintiocho años. Estaba casado y tenía cuatro hijas con Pilar Navarrete. Trabajaba temporalmente como mesero en la cafetería del Palacio de Justicia. Fue desaparecido entre el 6 y 7 de noviembre de 1985 durante la retoma del Palacio de Justicia.

Al ver a la gordita y morena Steffany ambos sonrieron al saber que era una niña. Tenía los rasgos del papá; su tez, sus ojos, su pelo, todo. Steffany estuvo enfermita mucho tiempo, y Pilar piensa que su esposo le tomó más cariño por eso. Se la pasaba con ella en el hospital y casi nunca se soltaban. Precisamente el día de la toma, Jaime llevaba en el bolsillo de su camisa una fotografía de su hija y unas sobrinas (...) "Me imagino lo que debe haber estado sufriendo Jimmy, si aún estaba vivo, viendo el recuerdo insistente de su hogar" (Gómez, Herrera y Pinilla, 2010: 464).

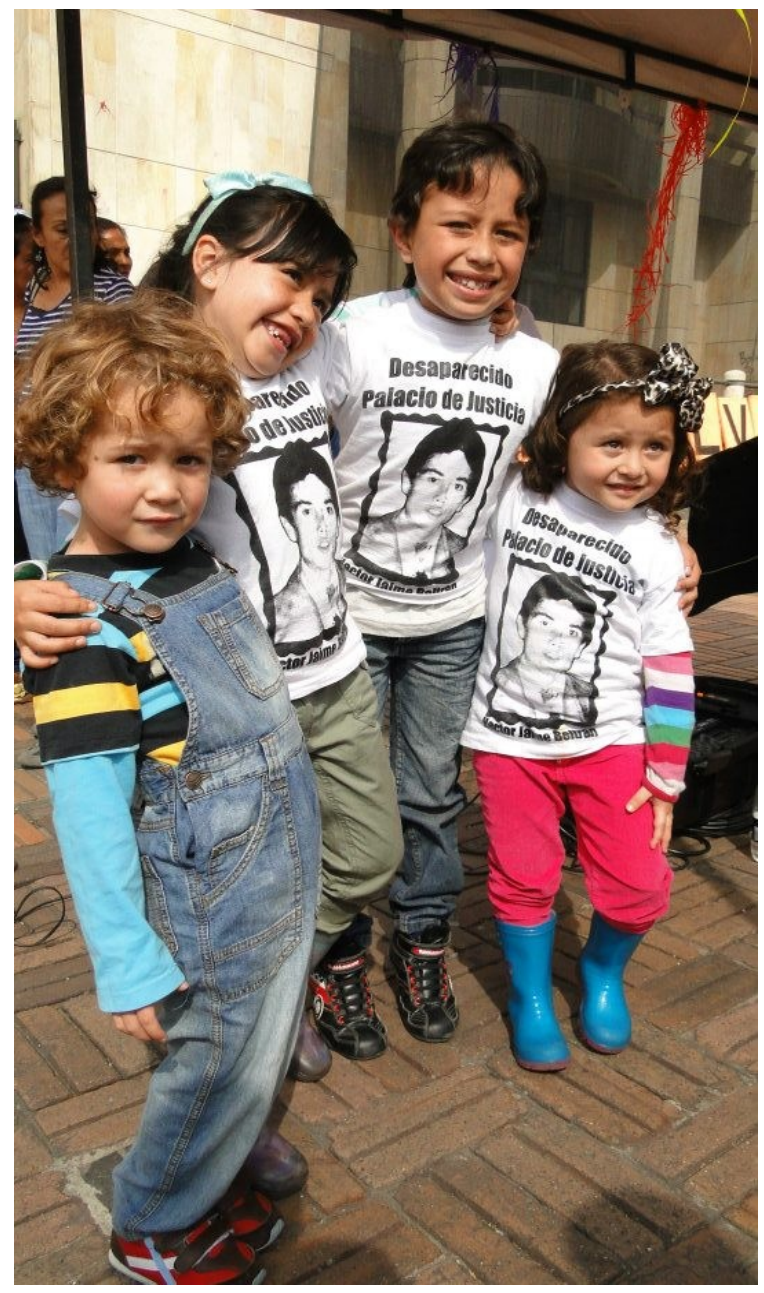

Nietos de Héctor Jaime Beltrán. Conmemoración de la toma del Palacio de Justicia. Bogotá. Noviembre 6 de 2011. Fotografía donada por Pilar Navarrete. 
Junto con su pertenencia a grupos dedicados a la exigencia de justicia o el trabajo político desde una apuesta generacional, tres de ellos participan en otros procesos y organizaciones: El movimiento feminista, grupos políticos que trabajan desde el arte, procesos barriales o diversas comunidades en el país, que en algunos casos se constituyen como referentes subjetivos, matrices de comprensión del mundo.

$\mathrm{Si}$, dos cosas, mi actividad política comenzó desde muy chiquita pues por mis papás estaba vinculada a la actividad política, pero conocer organizaciones políticas de víctimas comencé a conocerlas en 2002 cuando comencé a trabajar con Iniciativas de Mujeres Colombianas por la Paz. Entonces allí conocí muchas organizaciones de mujeres y viajé mucho por el país conociendo experiencias de este tipo y allí me familiaricé con los derechos de verdad, de justicia, reparación y con el proceso de desmovilización de los paramilitares. La iniciativa de mujeres por la paz, en ese entonces, fue de las pocas o la única organización que interlocutó el proceso de desmovilización de los paramilitares.

(Diana, entrevista realizada el 21 de septiembre de 2011).

También entrevisté a tres terapeutas que atendieron en distintos momentos a hijos e hijas de desaparecidos y que estuvieron integrados al Movimiento Hijos e Hijas por la Memoria y contra la Impunidad y a la Corporación de Atención en Salud Mental y Acompañamiento Psicosocial a Víctimas de Violencia Política. 


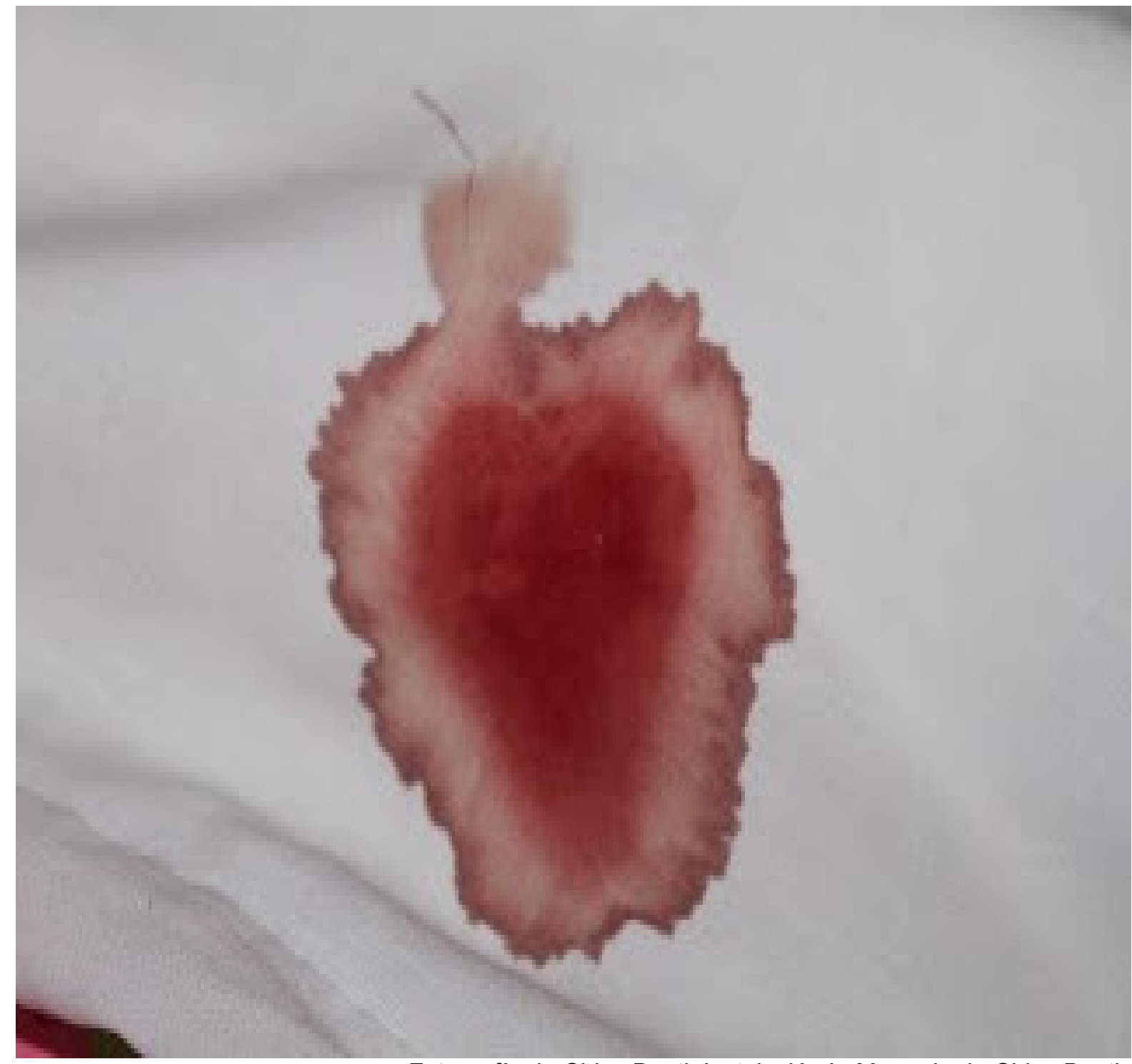

Fotografía de Chico Bauti. Instalación In Memoria de Chico Bauti. 


\section{Tercer Capítulo: Memoria traumática}

Se presume que la memoria es terapéutica, pero este capítulo es sobre un tipo de memoria a la que se puede considerar traumática. El estudio de la memoria constituye un campo de producción de diferentes disciplinas y tiene numerosos problemas epistemológicos. Uno fundamental es el de la relación entre la subjetividad ${ }^{39}$ y las ciencias sociales. La subjetividad fue definida por Freud a inicio del siglo XX y muchos de sus conceptos fueron usados por él mismo y otros autores en el análisis social. Mi interés más allá de trasladar los conceptos, es limitarlos, en el mejor uso de sus avances y nutrir el análisis con otras disciplinas.

La memoria es un campo de discusión heterogénea, para la psicología, es una capacidad cognitiva, función superior del hombre, acto inconsciente propio del aparato psíquico y motor del síntoma así como del proceso terapéutico individual ${ }^{40}$. Para psicólogos vinculados con la atención a víctimas la memoria es un campo de discusión nutrido por el análisis de otras disciplinas sociales y científicas, en tanto ubica al sujeto en su contexto.

Esta memoria a la que he llamado traumática es una memoria relacionada con el sufrimiento. La huella más clara de una imposición venida desde afuera a través de la violencia para generar tristeza y miedo. Con este planteamiento quiero limitar un poco el uso del término para referirme a la memoria qué es impuesta por la violencia y dejar para un análisis

\footnotetext{
${ }^{39}$ La noción de subjetividad tiene su origen en la comprensión del aparato psíquico de Freud (1898) que desde el primer momento es diferenciado del sistema inconsciente y por lo tanto se reconoce como un conjunto de procesos de relación entre el exterior y el cuerpo marcado por ese exterior. Atravesado y vinculado directamente con el mundo libidinal. En las elaboraciones más recientes la subjetividad está construida sobre el concepto del sujeto como sujeto del lenguaje y por lo tanto está constituida como matriz del sentido. Es entendida en el marco de la memoria como el sentido que tiene el acontecimiento para cada uno, producido por elementos heterogéneos que lo hacen eminentemente social y en permanente construcción (Coimbra, 2002). Está encargada de la elaboración psíquica de la cual depende, en gran parte la capacidad de entender y transformar las condiciones contextuales, y al tiempo adquiere recursos para esta tarea de contextos con recursos históricos, que permitan la ruptura del silencio, entre otros. A través de esa reflexión colectiva se genera una subjetividad, un nosotros "instancia productora de significaciones imaginarias sociales" (CINTRAS, EATIP, GTNM/RJ, SERSOC Ed., 2009: 357).

40 Joel Candau (2002) reconoce que en el análisis psicológico la memoria, se relaciona con otras funciones humanas que sólo se desarrollan de una manera específica en el ser humano. La especie humana tiene consciencia de su memoria con nociones de pasado y futuro, gracias a ello tiene intención, lenguaje, y se construye la representación del pasado. Esa memoria hace posible el mito y cualquier otra explicación de la realidad. Uno de los aportes más importantes de la psicología es el reconocimiento del vínculo entre la memoria y la vida emocional.
} 
posterior las otras formas de memoria intencional y crítica ${ }^{41}$. Esto para señalar que en la reconstrucción del pasado de violación de derechos humanos, al menos en el caso que estudié, todo lo que se intenta reconstruir del pasado no es el hecho horroroso sino otros muchos elementos.

Hay cosas que yo no quisiera recordar pero que se vienen a mí, la manera como vi a mi papá en la morgue, es algo que no estoy buscando pero que emerge, aparece (Diana, 21 de septiembre de 2011).

El efecto de la guerra sobre la subjetividad fue evidenciado desde el enfrentamiento ruso japones (Bekerman, 2002) y es usado de manera consciente e intencional, según los manuales mencionados en el capítulo de contexto de esta tesis. Ese uso intencional puede definirse desde la categoría de guerra psicológica y está destinada a influenciar la subjetividad con determinadas acciones que tienen ese fin, y esa influencia se da gracias a la violencia y a enunciados identificatorios que las acompañan. Los enunciados identificatorios incluyen las representaciones sociales y las reglas según las cuales esas representaciones se organizan (Bleichmar, 1991) La familia es un primer grupo de pertenencia que provee al sujeto de enunciados identificatorios, las instituciones, el estado, la clase social. Los enunciados en tanto referentes transmiten valoraciones sociales que intervienen en la moral y en los comportamientos.

- Las difíciles fueron las del dolor las de momentos de la tortura... cuando no sabíamos qué había pasado con ella porque uno ya sabía que habían hecho con las otras personas ya había ido a enterrarlas. Pero además era que los habían matado con sevicia y eso queda muy marcado digamos que era eso lo malo pero siempre sopesando con lo que habías visto con lo que te habían enseñado.

- Bueno. ¿Tú has leído los textos del CONADEP sobre Argentina sobre la desaparición?

- No, he leído lo de la ESMA.

- Son unos textos tremendos y hay una cosa interesante que es el prólogo. Sobre ese prólogo hay muchos debates -se reescribió después con Kirchner. Hay una disputa sobre cómo se lee el resto del texto. Hay una cosa muy interesante que me recordó algo que decías y es que estas cosas generan algún tipo de lección perversa, como una cuestión que a uno le quieren enseñar. ¿Te parece que hubo un

\footnotetext{
${ }^{41}$ Joel Candau (2002) afirma que la memoria a corto plazo es rápida, fiel, evanescente sin profundidad. A largo plazo permite el procesamiento de la información con profundidad o el trabajo de memoria: atribución de sentido producida por la categorización de las sensaciones y percepciones con el correr del tiempo.
} 
intento de enseñarte algo?

- Sí imagínate, en un país tan patriarcal, machista, la ofensa siempre ha sido el hijueputazo, que se metan con tu mamá es una gran ofensa y que se metan con tu madre es porque te están preparando para algo muy fuerte. Entonces pues a mí me fueron a preguntar directamente al colegio donde estaba estudiando para llevarme para torturar a Nydia. Pero bueno por suerte en el colegio eran un poco habidos de la historia que estaba pasando porque ya les habían desaparecido a un muchacho de ese colegio, a Antonio... y ellos me negaron y desde siempre pensaba que podían venir por mí y siempre ha sido así (Chico Bauti, entrevista realizada en Septiembre de 2011).

Tanto el conocimiento permanente sobre la realización de actos de sevicia, como el efecto que genera una frase previa como: "El que se mete con mi madre se mete conmigo" que tiene que ver con los sostenes de vínculos fundamentales, son muestra de cómo el miedo se mueve justamente por los lugares por los cuales se transmiten los vínculos y aprovecha para ello mandatos como los del patriarcado en cuanto a usar el cuerpo de la mujer para imponer sobre él todos los excesos. Estos están tan afincados que se enquistan como trampas para permitir la opresión de unos sobre otros, $u$ otras ${ }^{42}$.

Yo he reflexionado mucho sobre eso, yo encuentro cambios mucho mas profundos en mi vida en relación con lo de mi papá. Uno, es porque le tengo miedo a la soledad, a mi me angustia mucho la idea de que mi mamá se muera por ejemplo, y yo creo que este tipo de casos, de historias, afectan tu autoestima. A veces siento que hay un problema de autoestima y como que se alborota en un lugar en el que eres extranjero, eres extraño, eso también siento que me ha pasado. (...) En eso también he reflexionado mucho, qué significa perder la figura paterna, bueno también la materna porque también generaría cierto tipo de cosas, pero en una sociedad como la nuestra qué significa perder la figura paterna (Diana, 21 de septiembre de 2011).

En una sociedad como estás, es decir en una sociedad católica y conservadora en donde hay un control muy fuerte sobre el cuerpo de las mujeres y un comportamiento de exclusión con respecto a ellas. Esta pregunta de Diana sobre qué significa la desaparición en términos de género. ¿La necesidad de establecer por ejemplo rápidamente, un nuevo vínculo con una

${ }^{42}$ Esta idea está relacionada con el debate propuesto por Butler acerca de la diferencia entre una violencia primaria y una secundaria, y la pregunta sobre si la segunda es necesaria. Una violencia primaria que es la del nombre y otra secundaria que tiene que ver con mandatos sociales que legitiman expresiones de opresión. 
figura masculina?

Este tema se expresa en contradicciones al interior de propuestas de transformación como las que intentó o intenta aún adelantar la izquierda y que llevaron a la confusión entre la disciplina militante y las expresiones más básicas del patriarcado centradas en la imposibilidad del afecto.

- ... Cuando me voy a vivir sola empiezo a ser consciente de eso, del tipo de relación que tenia con mi papá, de esa forma que construí esa relación por sus miedos por los miedos de él, porque yo siento que él me amaba mucho y su forma de amar era sobre protegerme que me volviera fuerte, que no fuera vulnerable y era la forma que me podía demostrar que me amaba pero antes me conflictuaba eso que fuera tan exigente conmigo pero al irme sola y ser consciente de eso y también ser consciente que no podía hablarle, que quería decir muchas cosas que no podía hablarlo (Shaira, entrevista realizada el 26 de julio de 2011).

El lazo social es amarre y soporte, pero al mismo tiempo es un camino lastimado por el miedo de lo que ha ocurrido ante la impunidad sostenida por los representantes de la ley. Otras se suman: "si lo desaparecieron por algo sería", "vale más ser verdugo que víctima, se tiene más derechos", "reina la impunidad", "trabajar, trabajar y trabajar" por mandato presidencial, entre otros ${ }^{43}$.

El resultado de esto es que la subjetividad constituida en ese lazo social es lesionada. Ahora bien, ¿cómo se define la lesión? La primera definición es médica, e intenta rebelar las lesiones psíquicas con el uso de un instrumento diagnóstico llamado DSMIV que define el trastorno de estrés postraumático. En tal caso se supone que una persona estuvo expuesta a un acontecimiento traumático en el que "ha experimentado, presenciado o le han explicado uno (o más) acontecimientos caracterizados por muertes o amenazas para su integridad física o la de los demás; y la persona ha respondido con un temor, una desesperanza o un horror intensos" (DSMIV, 1994); el acontecimiento traumático es re experimentado con persistencia, es decir que el hecho se reactiva en recuerdos, sueños, juegos, o en la

${ }^{43}$ El terror es un objetivo esperado por parte de los perpetradores en el marco de la violencia de estado. Según... se produce en medio de climas de alienación que generan: la imposibilidad de pensar sobre los hechos y conceptualizar o reconocer el terror. Implican la promesa de que el sujeto violentado, puede al mismo tiempo violentar a otros que hacen parte de su conjunto social. Estos elementos que están vinculados con el terror se derivan de la lógica de la alienación. 
sensación de estar viviendo la situación de nuevo. Esta condición reiterativa genera la evitación de ideas, lugares, actividades, vínculos afectivos con elementos que estén asociados con la situación traumática. Este cuadro incluye síntomas de "aumento en la activación", nerviosismo, irritabilidad en otros momentos en donde no se experimenta la situación traumática.

La primera conclusión que se deriva de la descripción de este cuatro clínico es que no basta experimentar un hecho traumático para ser "portador" de un diagnóstico sino que se requiere una acción de remembranza y reminiscencia de esa experiencia. En segundo lugar, es importante reconocer que la idea de estrés pos traumático señala la existencia de un daño generado por una experiencia externa traumática que no requiere ninguna condición de personalidad previa y que, por lo tanto, señala la responsabilidad del daño, en el caso del estrés generado por una situación violenta, del perpetrador.

En el caso de la reminiscencia en el estrés pos traumático la memoria es intrusiva y hay muchas dificultades para que se reconstruya de manera intencional, puesto que se establecen mecanismos de evitación con respecto a la situación dolorosa.

La memoria traumática se refiere a una memoria que aparece por motivaciones inconscientes y no intencionales, que es la huella más horrorosa de un acontecimiento traumático y que no se puede equiparar con los recuerdos de los procesos de memoria adelantados por los familiares colectivamente por ejemplo, porque son intencionales e implican una primera toma de distancia con respecto al mandato de dolor y silencio de los hechos violentos.

En tanto hayan esfuerzos de rememoración de lo ocurrido, rememoración colectiva y difusión del hecho hay una acción en contra del cuadro patológico. Algunos autores afirman que en el acto de rememoración del familiar hay una repetición o memoria fijada que simboliza el nivel 
de traumatismo ${ }^{44}$, este acto estaría relacionado con expresiones como el escrache. Según este trabajo, esa idea se contradice pues el acercamiento al pasado demuestra o implica un proceso de elaboración. El escrache transmite una memoria no centrada en el sufrimiento, con un nivel importante de reflexión y socialización.

El concepto de estrés pos traumático nos ayuda a desmentir las apreciaciones o los usos que se hace del trauma o de la rememoración como extensión del trauma. La memoria traumática es la memoria vinculada con el relato horroroso, con la marca traumática de un acontecimiento que superó las condiciones de respuesta, elaboración y representación por parte del sujeto, el acto inicial de marcar, fragmentar, objetivar al cuerpo. Una memoria privatizada, individualizada, que dificulta la participación del sujeto en el grupo, que le genera un costo en esa participación y que con frecuencia se vincula con una imagen siniestra del efecto directo que la represión tiene sobre el cuerpo.

Sin embargo, para los familiares y sobrevivientes, el concepto de estrés postraumático no abarca la complejidad ni significación del impacto generado por las acciones violentas y por eso la psicología ha dado un vuelco y se ha alimentado de las reflexiones de otras disciplinas para limitar la categorización y medicalización de las personas afectadas directamente por acciones de terrorismo de Estado y para tener una comprensión más profunda del hecho. Según lo plantea Bekerman (2002) el estrés postraumático deja de lado:

- La condición natural o intencional del evento

- El contexto socio político en el cual éste se desarrolla

- La posibilidad de traumatización crónica y retraumatización

- El sentido particular que cobra el acontecimiento traumático para cada persona

\footnotetext{
${ }^{44}$ En este campo aparecen las aproximaciones de los historiadores Marcos Novaro, Vicente Palermo, quienes hablan de una forma peculiar de reunión del pasado y el presente que se denomina memoria fija que se aproxima en parte al de "memoria traumática". Esta se define por no ser verbalizable, es una especie de hiper memoria que determina el presente en donde los sujetos se relacionan entre sí y con el mundo a partir de un sentimiento originado en situaciones traumáticas. La memoria fijada se establece como principio de acción colectiva. Según Palermo (2004) ésta memoria fijada o traumática se traduce en "una acción expresiva de reiteración ritual" e idealización. También porque es la ritualidad la que hace posible la traducción de cualquier - enteramente comprensible - deseo personal en un principio de acción colectiva y repetible. Es efecto de la responsabilidad de hacer justicia frente a la impunidad y se traduce en un principio de acción simbólica y ritual.
} 
(subjetividad)

La autora plantea que el trauma generado por las experiencias violentas generadas por el estado requiere:

- La comprensión de las condiciones sociales es necesaria para prevenir la culpabilización de la víctimas desde la ciencia médica: en lugar de interpretar las manifestaciones psicológicas como respuesta a una situación traumática se las atribuyó como causa del trauma en tanto las experiencias ocurrían a personas con perfiles "dependientes" y "masoquistas". Esto fue fuente de estigmatización.

La memoria traumática es aparentemente más individualizada que otras expresiones de la memoria y se refiere al mundo emocional. Es la expresión más clara del impacto de la represión. Ahora bien si se deja en el ámbito privado y no tiene lugar en espacios públicos se ubica en el lugar de experiencia que contagia, tóxica, peligrosa y marginal ${ }^{45}$. Pero al contrario, la memoria traumática requiere un lugar, un esfuerzo de escucha y representación colectiva.

Finalizada la Segunda Guerra Mundial, Primo Levi habló, no dejó de contar lo que vio, en nombre de todos los que ya no podían hablar y que se fueron solos hasta el final del horror. El dolor estaba aún demasiado cerca y la gran mayoría se resistió a escucharlo. Comenzó inmediatamente a escribir ya que la "necesidad de contar a los demás, de hacer participar a los demás, había adquirido en nosotros, antes como después de nuestra liberación, la violencia de una impulsión inmediata, tan imperativa como las demás necesidades elementales (Fush, 2007).

Ha sido en muchos casos la única memoria reconocida o vinculada directamente con la condición de victimización y en algunos casos también ha sido el argumento para que historiadores como Enzo Traverso (2010) reduzcan la condición de la "víctima" de violaciones de derechos humanos a su situación de sufrimiento, planteando que "las víctimas no son sujetos, sufren. La noción de víctima eclipsa la noción de vencido, derrotado, la

${ }^{45}$ Esta idea del contagio puede relacionarse con dos elementos que pueden ser indagados en la literatura freudiana: el primero el de la idea del contagio de algo peligroso o tóxico a través de la muerte que es indagado en la relación entre el sujeto y el cadáver, o la sangre y que aparece claramente en las lecturas de tótem y tabú como expresión propia de culturas primitivas con creencias animistas. En segundo lugar, relacionado con la creación de un otro masivo a través de la experiencia de la identificación, dinámica que es explicada en el texto sobre psicología de las masas y análisis del yo. 
generalización es peligrosa y plantea equívocos.

Ante este evento, Silvia Bekerman (2002) plantea que es fundamental reconocer la definición del traumatismo para no estigmatizar por algún tipo de condición médica o psicológica específica a los sujetos y reconocer la responsabilidad del perpetrador y la potencialidad traumatizante de la experiencia. LaCapra (1998) iría más allá hasta decir que justamente esa comprensión de la red que constituye al trauma ubica en cada lugar lo siniestro, lo sublime y lo sagrado, la responsabilidad del victimario y las condiciones de humanidad y agencia de la víctima.

Es una memoria que podría ser definida en primer lugar por el sufrimiento pero que no define al sujeto que la nombra, sino a una dimensión de su experiencia. Como dice el párrafo anterior su imposibilidad de ser escuchada define más la intolerancia del otro ante narraciones para las cuales tal vez no está preparado pues esta memoria también está involucrada con el miedo permanente; la presencia de ideas e imágenes que son insoportables para el sujeto y que están vinculadas a la desaparición y los vejámenes vividos durante la detención: la tortura, los tratos crueles e inhumanos y otros actos de sevicia.

Esta memoria puede estar también vinculada con el surgimiento y la permanencia de enunciados identificatorios o mandatos que determinan el proceso de elaboración de la muerte.

Yo creo que para mí si ha sido algo difícil solucionar eso y es que él me decía: "Cuando uno se muere... a uno le tienen que decir las cosas en vida, le tienen que dar las cosas en vida, porque cuando uno muere deja de existir, somos materia y ya, entonces a mí nunca me vayan a hablar a la tumba". Porque él dice: "La gente hace eso por elaborar cosas que le quedan pendientes, más que pensar en la otra persona lo hacen es por uno por quitarse culpas, entonces van y le hablan a las tumbas" (Shaira, entrevista realizada el 26 de julio de 2011).

En el anterior apartado el material identificatorio transmitido por el padre se vuelve un enunciado fundamental para resolver la situación de duelo. Junto con este muchos 
pensamientos o principios familiares o sociales constituyen los recursos con los cuales las personas transitan esta experiencia. Es decir que además de que la experiencia tiene elementos o está determinada por un contexto social, es afrontada desde recursos que se construyen en la interacción y devuelve a la memoria a un plano colectivo.

La memoria traumática puede colectivizarse y eso es visible en diversas acciones: primero, en los esfuerzos de documentación desarrollados en distintos países. Me atrevería a decir que en cuanto a aclarar la responsabilidad del aparato represivo del Estado en Latinoamérica, el más efectivo fue el ejercicio de la CONADEP en Argentina. La investigación de CONADEP requirió varios elementos que afirmaron la claridad de la documentación, además de aportar una descripción exhaustiva de lo ocurrido:

- Fue posterior al cambio de la junta por un presidente constitucional.

- Se centró en un crimen que claramente se definía como crimen de terrorismo de Estado y no sumó otras actividades realizadas por grupos armados de izquierda a pesar de que estos cometieron delitos ${ }^{46}$. Se dedicó a desenmascarar el aparato represivo y sumó en la documentación la victimización de miembros de organizaciones armadas, prescindió de categorías como combatientes muertos o cosas parecidas, es decir que priorizó el principio de DDHH sobre el principio de DIH.

- Incluyó un reconocimiento de la criminalidad por parte de las juntas militares.

- Implicó la pedagogización para transmitir la nación de lo ocurrido y de la responsabilidad del Estado, así como la planeación de una forma de difusión en escuelas y televisión pública.

En términos de Emilio Crenzel (2008) la documentación llenó de representación algo que parecía no poder decirse, según el concepto de lo traumático, y llevó a una elaboración constante, que al día de hoy no ha terminado sobre los móviles, las víctimas, los responsables de la represión. En términos de Emilio Crenzel (2008) fue la construcción de un

\footnotetext{
${ }^{46}$ Sobre este tema y a razón del tiempo que ha pasado después de que algunos actores políticos optaran por la vía armada, sobre el reconocimiento de delitos o acciones revolucionarias por parte de las guerrillas hay numerosas reflexiones. Una muy nutrida puede verse en el texto "No Matarás" de El Barco.
} 
conjunto infinito de representaciones las que pusieron límite al horror en Argentina. La construcción del CONADEP, las denuncias, las pintas, el escrache, las bicicletas en la pared, las películas, las novelas, las canciones demostraron un esfuerzo hasta ahora inagotable por producir representaciones que bordeen el recuerdo horroroso que quiso quedar como huella en la sociedad.

La documentación permitió crear un marco social y jurídico y poner evidencia que lo que ocurrió tuvo lugar y por eso se centró en la descripción de los centros clandestinos de detención. No es en si mismo el proceso de elaboración. Solo creó un campo en el que fue permitido hablar de la desaparición como algo real. Pero la elaboración de las experiencias de violencia se dio en gran parte gracias al arte: la literatura, el cine, pinturas, canciones que retomaron la imagen de lo siniestro, el terror, la muerte, la fragmentación y cosificación del cuerpo a través de la tortura otorgándole a las víctimas identidad, imagen unificada, palabras.

Estas iniciativas también son llevadas a cabo en Colombia, con la gran diferencia de que el marco institucional no dio lugar aún al reconocimiento de la desaparición forzada y otros crímenes bajo la responsabilidad del estado.

\subsection{Procesos subjetivos frente a la desaparición forzada}

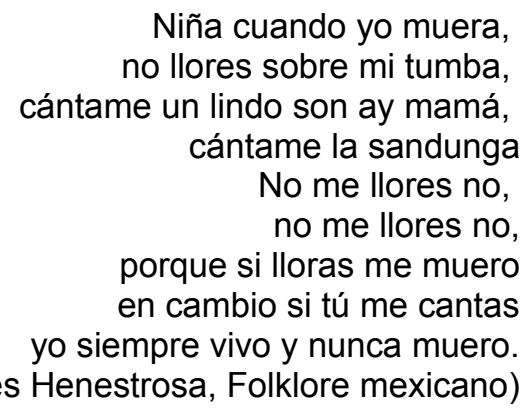

Esta memoria puede estar relacionada de manera más clara con los postulados psicológicos y ha servido como elemento diagnóstico para el reconocimiento del Estrés Postraumático. Centra sus reflexiones en el conocimiento y terminología propia de la psicología pues se supone que es una memoria de actos privatizados que en apariencia sólo afectan y sólo 
incumben al individuo. Se expresa a través de recuerdos o imágenes intrusas e ideas que debilitan anímicamente a quién las experimenta.

La investigación de Silvana Bekerman (2002), por ejemplo, ubica históricamente la noción de trauma en la investigación médica y el contexto histórico en el que se adelanta demostrando cómo el análisis científico está determinado, entre otras, por cuestiones socio políticas que sacan al individuo de su condición de singularidad y lo relacionan, en su síntoma y diagnóstico, con el clima de su época ${ }^{47}$. En cuanto al concepto de trauma es necesario decir que no señala solo condiciones psíquicas en quienes lo experimentan sino condiciones del medio.

\section{Gracias al estudio de las nociones de trauma psicosocial ${ }^{48}$ se puede nombrar un conjunto de}

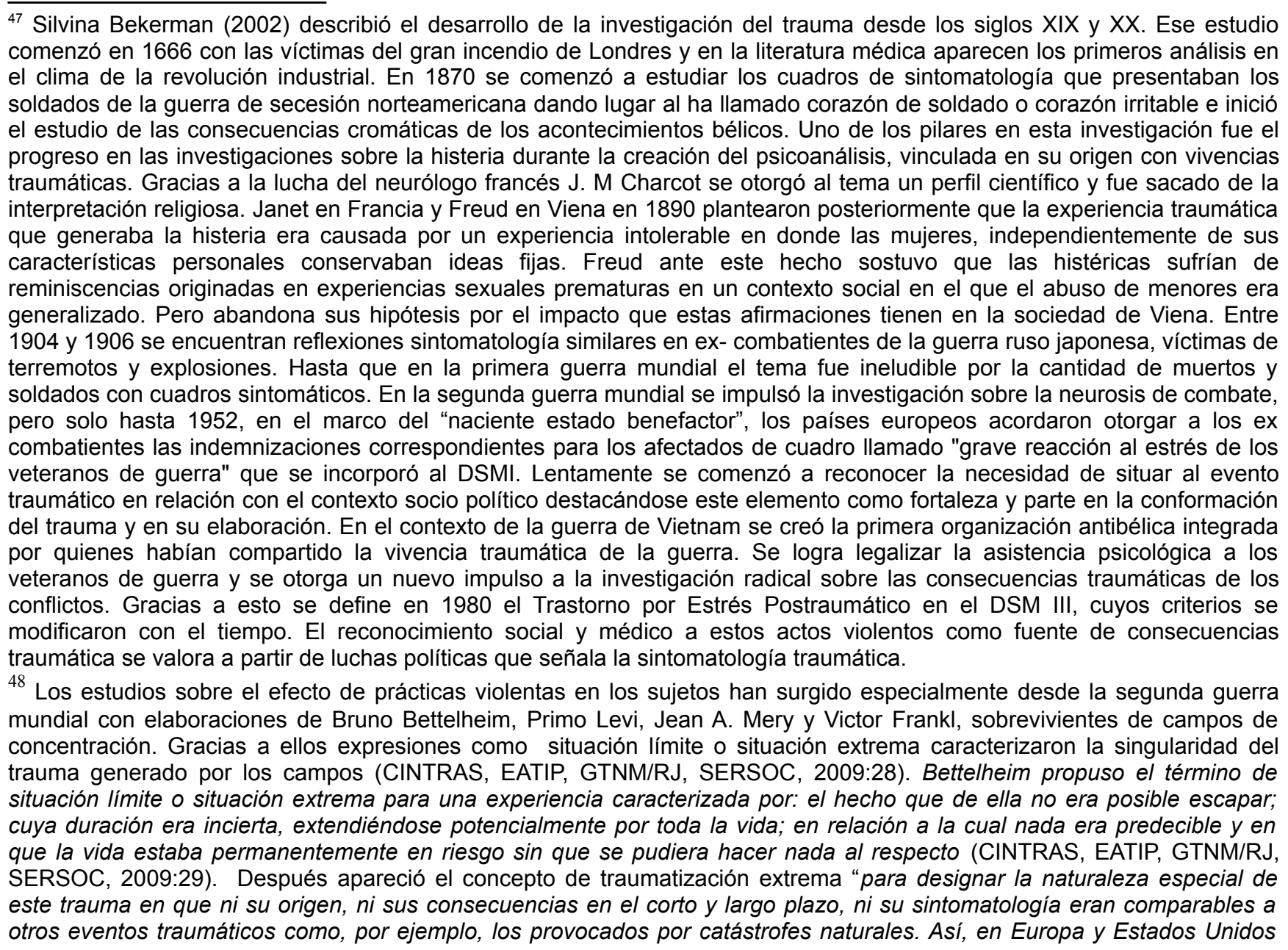


elementos que hacen de la desaparición un hecho particular que genera transformaciones en el sujeto, superando o dimensionando de otra manera el concepto de estrés postraumático, estos elementos que caracterizan la experiencia de la desaparición proporcionan nuevos criterios de análisis:

\title{
1. En primer lugar aquello que genera la condición pos traumática es una situación de la que
}

\author{
no se puede escapar o sobre la que no se tiene control; es sorpresiva, no es natural y, por lo
}

comenzó a hablarse de man-made disaster, desastres provocados por el propio ser humano" (CINTRAS, EATIP, GTNM/RJ, SERSOC, 2009:29). Otro investigador, Keilson concibió la traumatización secuencial o proceso desarrollado en el tiempo que contiene una serie de situaciones traumáticas que se intensifican mutuamente. (CINTRAS, EATIP, GTNM/RJ, SERSOC, 2009:29). también dio relevancia al periodo posterior a estos hechos, en tanto determina la elaboración y construcción de un proyecto de vida. Identificó de este modo uno de los factores determinantes para la persistencia del trauma y su posible manifestación a través de síntomas de diverso tipo incluso décadas después de haber sufrido el sujeto la primera experiencia traumática" (CINTRAS, EATIP, GTNM/RJ, SERSOC, 2009:30). El evento traumático "por su intensidad y cualidad es potencialmente patológico, según las capacidades defensivas y de elaboración psíquica". Entre sus peculiaridades cuenta con ser provocada por el propio ser humano, no constituirse como un hecho único sino como una serie de situaciones traumáticas que intensifican el daño, ser sorpresivo y con frecuencia culposo. El caso de la desaparición forzada se da inicio a procesos de duelo interminables. Bajo la perspectiva de Martín - Baró se propone la noción de experiencia traumática definida en tanto lo traumático es una producción social. Sus raíces no se encuentran en el individuo, sino en la sociedad y su naturaleza se alimenta y mantiene en la relación entre el individuo y la sociedad, a través de diversas mediaciones institucionales, grupales e incluso individuales. Lo cual tiene obvias e importantes consecuencias a la hora de determinar que debe hacerse para superar estos traumas (CINTRAS, EATIP, GTNM/RJ, SERSOC, 2009). La propuesta del Equipo Argentino de Trabajo e Investigación Psicosocial ha expuesto de manera contextual la "Situación traumática de origen social" definida como una situación represiva producida desde el Estado que invade violentamente la vida del sujeto. Estas situaciones pueden generar desestructuración psíquica y parálisis de acción y pensamiento, dificultando la adaptación activa a la realidad (CINTRAS, EATIP, GTNM/RJ, SERSOC, 2009:151). Esta última comprendida en términos de Riviéré como adaptación a través de acciones que transforman el contexto y no de aceptación o acomodación. Para Baró hay un trauma que se llama psicosocial o repercusión de momentos históricos como la guerra en aquellos que la viven. Hay un impacto en la población civil que puede ser llamado trauma psicosocial, que implica para otros autores una "marca en el psiquismo" . Esa marca es la huella, inscripción identitaria o rasgo caracterológico generado por la situación represiva que dice algo sobre el sujeto y su relación con los demás. El concepto de marca es un vinculo entre lo traumático y lo identitario (CINTRAS, EATIP, GTNM/RJ, SERSOC,. 2009:159). El contexto se considera un marco de análisis del trauma así como un elemento que modifica y se modifica. La experiencia traumática se elabora tanto individual como socialmente. ( CINTRAS, EATIP, GTNM/RJ, SERSOC, 2009, 35). Para el centro de salud mental y derechos humanos Cintras, las dictaduras del cono sur fueron una reacción a la intensificación de lucha en América y las responsables de instrumentar la doctrina de seguridad nacional, usando técnicas con objetivos como el castigo y la coerción para imponer ideologías ajenas y convertir al sujeto en un ser carente de personalidad, pensamientos, sentimientos y voluntad propia. La carga traumática opera con fuerza un conjunto de fenómenos políticos, sociales, culturales, morales y económicos en el marco histórico del neoliberalismo. En consecuencia ellos definen la desaparición forzada como una violación que buscaba la destrucción del sujeto opositor y del cuerpo social que lo sustentaba, y la producción de formas de subjetividad social acrítica y funcionales a formas extremas de dominación y control político (CINTRAS, EATIP, GTNM/RJ, SERSOC, 2009). Cintras se basa en Martín Baró y su construcción de la "Experiencia traumática" es la siguiente: "Hecho socio-histórico, como un proceso en el cual es posible distinguir ciertas etapas y en cuya génesis juegan un rol determinante las relaciones sociales, especialmente aquellas que surgen desde la formación económico-social propia de la sociedad concreta en la que se producen. Es un fenómeno que afecta globalmente a toda la sociedad, pero no en forma uniforme ni mecánica, sino condicionado por la extracción social y las características personales de cada individuo" (CINTRAS, EATIP, GTNM/RJ, SERSOC, 2009: 34). Pero por otro lado y desde otras perspectivas se afirma que el evento traumático no genera trauma sino transformaciones, a menos que las condiciones personales, y las acciones de retraumatización así lo definan. Los efectos de hechos violentos en el contexto del acompañamiento colombiano son leídos en términos de impactos. Así describe la corporación para el acompañamiento y rehabilitación emocional de víctimas AVRE, equipo encargado de este trabajo las familiares de personas desaparecidas en Colombia. "Se ven enfrentadas de manera abrupta a aceptar la idea de que esa ausencia pueda ser definitiva y se resisten a hacerlo. Además, se ven enfrentadas a la angustia que genera el sufrimiento por la situación que pueda estar pasando la persona ausente y la incertidumbre constante por su supervivencia 
tanto, no se puede comparar con una catástrofe "ni en su origen, ni en su intensidad, ni en sus consecuencias", entre otras cosas por la responsabilidad de un ser humano en su perpetración (CINTRAS, EATIP, GTNM/RJ, SERSOC, 2009).

A este momento de mi vida, la forma en que yo he elaborado el duelo de la muerte de mi mamá ha sido de una forma tan sana, además las circunstancias de su muerte tuvimos tiempo para vivir muchas cosas, ella sabía que se iba a morir entonces aprovechamos muchos momentos en los últimos meses, nos dijimos cosas, nos despedimos, nos abrazamos, ya en el momento de llegar: "Me voy a morir quiero decirte esto, agradezco esto, siento que me voy a ir con la sensación de no poder estar ahí en los momentos futuros". Y de llorar las dos así muy sano y despedirnos y entonces pienso que la forma que he elaborado el duelo con mi mamá ha sido muy sano puedo decir: "No está la extraño". Puedo sentir ese dolor, puedo hablarle a ella, puedo decirle: "Me pasa esto quisiera que estuvieras acá seria mas fácil que habláramos escucharte" (...) (Shaira, entrevista realizada el 26 de julio de 2011)

\section{En el caso de la desaparición la incertidumbre se constituye en una forma de tortura} psicológica, la ideación permanente y la gran posibilidad de que el familiar esté siendo objeto de tortura se conjugan en una experiencia en la que se pierde control.

Entonces cuando uno está dentro del proceso uno sabe muy en el fondo y tiene muy presente que lo que uno quiere es que le den una respuesta de dónde está. Pero también tiene muy presente que nunca la va

(... ) se presentan dificultades para elaborar el proceso de duelo que permite asimilar el dolor y comprender las causas que lo están generando (...) A estos impactos a nivel individual, se suman los del orden familiar. En ocasiones, la familia se niega la posibilidad de hablar sobre lo que ha significado la violencia socio política y la desaparición forzada; se niega la posibilidad de expresar los sentimientos que causa la desaparición forzada en cada uno de sus miembros (...) las víctimas continúan viviendo en un medio en el cual siguen sucediendo hechos que amenazan permanentemente la integridad individual y colectiva; o también, porque en ocasiones, las dimensiones del dolor y la incertidumbre que genera la desaparición forzada son tan grandes, que limitan las posibilidades de entender lo sucedido. Entonces, pareciera no haber respuesta a la pregunta: ¿por qué pasó?" (Chaparro, 2007:12). Se piensa a un sujeto que atraviesa una situación de crisis abre preguntas sobre el lugar del contexto como origen y fuente de explicación al sentimiento y sufrimiento vivido. El significado de la experiencia se afirma en el contexto social y en la razón social del hecho traumático y ese contexto social se amplía desde el registro de la psicología social la cual reconoce al sujeto como destinatario de una situación traumática y no como un sujeto traumatizado (CINTRAS, EATIP, GTNM/RJ, SERSOC, 2009). En efecto el sujeto no es evaluado como portador de una enfermedad con causas intra psíquicas sino como un sujeto vinculado (Riviere, 1985) atravesado por condiciones sociales que permiten o motivan la vulneración del sujeto y que por lo tanto le causan enfermedad. En consecuencia el sentido del malestar del sujeto se construye teniendo en cuenta que la situación que lo causó es social y en el caso de la desaparición es de origen político (CINTRAS, EATIP, GTNM/RJ, SERSOC, 2009). Al igual que SERSOC el equipo de AVRE no menciona la existencia de un trauma ni individual ni psicosocial como efecto directo de una acción violenta, y al igual que el Grupo Tortura Nunca Mais menciona la importancia del daño por el lugar que da también a la clarificación del hecho y las pérdidas que causa, teniendo en cuenta que acciones sociales como el acceso a la justicia y la reparación por parte de los responsables complementa las acciones que desde los escenarios terapéuticos se puedan adelantar. 
a encontrar. Entonces es muy agotador esa contradicción: "Bueno dígame qué hizo con él". Pero muy en el fondo sé que no lo voy a volver a ver porque no te lo van a decir. Entonces en el proceso de lo de mi papá eso ha sido muy agotador para nosotras, para mi mamá, para mí, para mis hermanas. El saber que nunca van a decir: "Está aquí, está allá, o está acá". Entonces es como ese dolor mental, como ese dolor del corazón de saber que nunca vas a encontrar una respuesta. Por eso es que uno trata de mantener la memoria viva porque si yo supiera que a mí me van a decir: "Ah no mire su papá está allí". Yo no vuelvo a decir nada más, no vuelvo a conmemoraciones, no vuelvo a decirle nada más a mi hijo, yo dejo eso así y ya. Pero el hecho de que la persona sea desaparecida hay que hacer memoria y esa memoria se hace para tener presente y no olvidar, porque tú sabes que nunca vas encontrar (Steffany, entrevista realizada el 20 de abril de 2013).

3. En algunos de los casos presentados las familias recibieron el cuerpo de sus familiares. En ningún caso ese cuerpo estaba en condiciones de ser reconocido a pesar de que hubiese aparecido antes del tiempo normal de descomposición, así que más que como base de una elaboración, era causa de un nuevo dolor, confirmaba todas las acciones cometidas por los perpetradores. En ese sentido el "duelo" es un proceso totalmente irregular.

Yo creo que no debo elaborar el duelo, que es más, yo creo que la no elaboración del duelo le lleva a uno a hacer más cosas en el caso y buscar la verdad. Yo no sé qué será eso de la elaboración del duelo, sólo se, y creo que no se terminará de hacer hasta que uno se encuentra al familiar. Pero el hecho de aceptar que está desaparecido, de que ya no se volverá a encontrar, es un poco de resignación y a mí no me gusta (Hermana Cali, 1995: 185) ${ }^{49}$.

4. La desaparición forzada hace parte de una sucesión de agresiones. No se define como una única experiencia sino como parte de una secuencia en donde pueden existir previamente amenazas, persecuciones o encarcelamientos. Después de la desaparición continúan las amenazas y los cambios de lugar.

${ }^{49}$ Extraído del libro Veinte años de historia y lucha. Asfaddes con todo el derecho (2003). 


\subsubsection{El duelo}

Como respuesta ante lo ocurrido y la ausencia de un ser querido comienza un proceso de elaboración que implica la reconfiguración de los vínculos de afecto. Esa reconfiguración se ve afectada por la expresión que otros y otras tengan de solidaridad y apoyo frente al sentimiento vivido. La respuesta que tienen los demás intervienen en la redefinición o reconfiguración de alianzas, espacios de contención y de confort y espacios que quedan desechados, en ese sentido hay una reorganización de los vínculos emocionales.

Incluso tuve una etapa en la que sentí mucha rabia con la familia de mi mamá porque son muy godos, muy conservadores y habían muchos uribistas y yo no podía entender cómo podían seguir respaldando a Uribe y a su política cuando había pasado algo tan cercano en mi vida, entonces si hubo un momento en el que contra casi toda la familia de mi mamá sentía rabia. Lo que hice fue volcarme más a la familia de mi papá, buscar compartir más con ellos... con muchas fragilidades emocionales, estaba muy sensible (Diana, 21 de septiembre de 2011).

En el párrafo anterior aparecen factores, que también influyen en la elaboración del hecho actual, relacionados con el pasado político. Viejas historias se reactivan porque no terminaron de ser expuestas, indagadas y memorizadas por la sociedad colombiana. 


\subsubsection{Cada vez que lo trae el pensamiento}

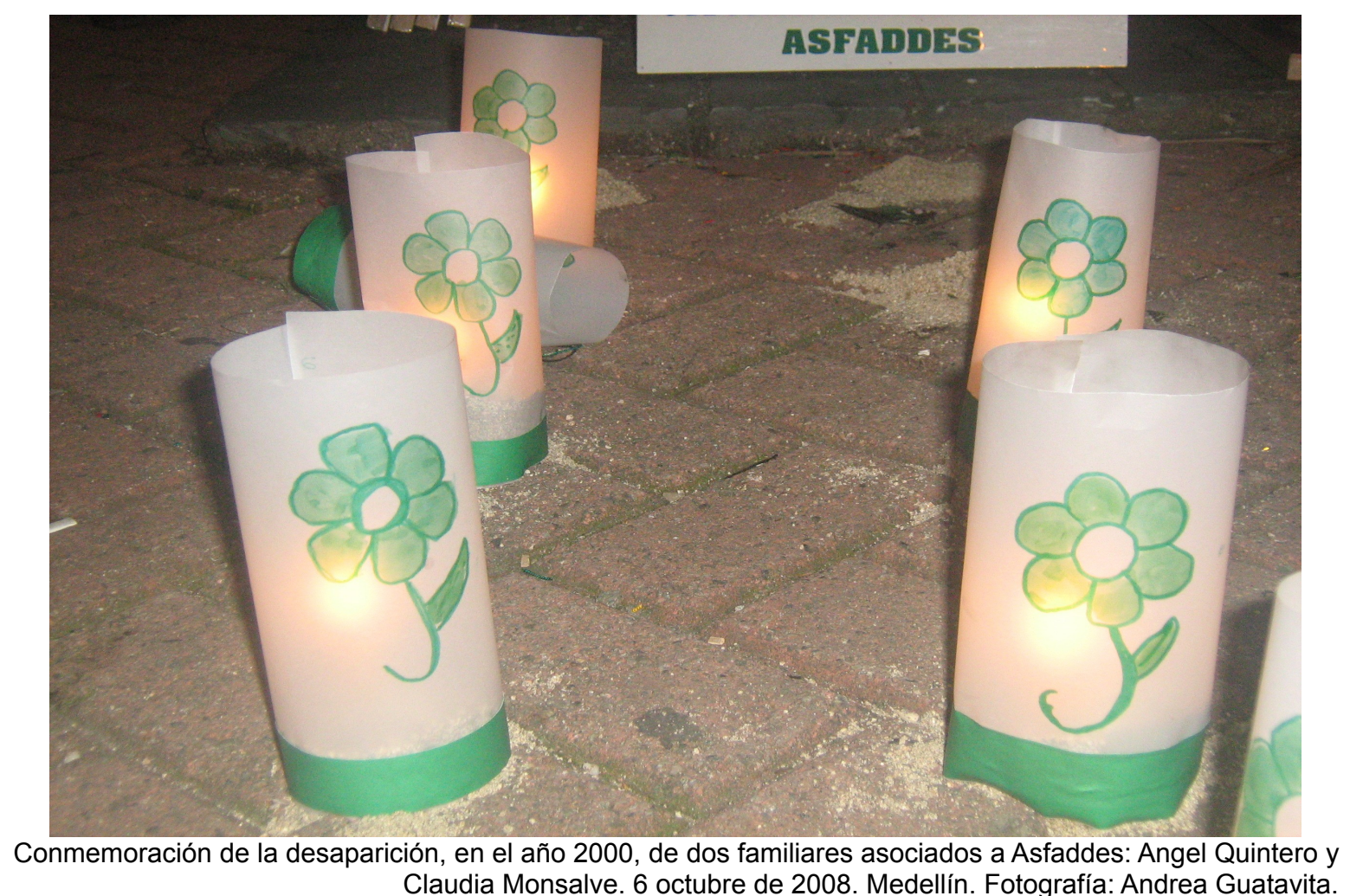

... cuando él me contó eso yo casi me muero yo duré una semana que lo veía sentarse en mi cama y no sabia si era que me hablaba, lo veía tal como era. Porque todas las mamás me contaban eso pero después de veinte años, hace seis años, durante veinte años nunca y yo le decía a la mamás y me decían: "Pero usted que hace si él aparece". Pero yo jamás me imaginaba ese encuentro pues lo duré viendo una semana (Pilar, entrevista realizada el 13 de abril de 2013).

Durante una práctica de trabajo guié un taller con una organización de mujeres familiares de 
desaparecidos y a la actividad asistieron dos niñas llevadas por su tía. Cuando las niñas salían nos dijeron a mi compañera y a mí que durante toda la actividad el padre asesinado y la madre desaparecida, estuvieron entre nosotros.

Cómo se veía el fantasma, qué rostro tenía, cuántos años, no lo supe nunca porque no volví a ver a las hermanas y no sabía si a su corta edad habían tenido una narración exacta de quiénes eran, cómo se veían sus padres, o qué hacían, si los sentían como una compañía o les explicaban y respondían inquietudes sobre su vida y su paradero. Cuando la madre desapareció ellas eran bebés y alguien tenía que responder esas preguntas o cómo se puede crecer sin saber con qué referentes construir el carácter, qué está mal o bien, en brazos de quién se llora o se resguarda, por qué hay cosas que pasan en la calle o qué significan las cosas que se dicen en las noticias, qué significa la desaparición.

En junio del 2008 mi papá todavía estaba desaparecido, entonces caminábamos a una ciudad descansábamos el resto de la tarde, la noche y al otro día arrancábamos bien temprano a caminar y los buses nos iban acompañando y resulta que, eso era para el día del padre, llegamos un sábado, el domingo era el día del padre, llegamos el sábado a lbagué entonces nos decían: "Mañana es el día del padre mañana no vamos a caminar sino que vamos a descansar acá y volvemos a arrancar el lunes para llegar el martes ya a Bogotá en la tarde". Ese día llegamos, nos duchamos, descansamos y los compañeros nos fueron a golpear en la habitación del hotel que si queríamos salir a tomar algo donde nos estábamos quedando pero yo estaba muy achantada porque era el día del padre entonces ellos me insistieron y salimos a dar una vuelta y ellos querían entrar y habían muchos compañeros y una que otra compañera y ellos: "Nosotros queremos celebrar el día del padre queremos entrar a una viejoteca". $Y$ yo me iba a ir y ellos: "No que entre". Pues yo entré con ellos pero yo estaba muy achantada y les dije: "No yo me quiero ir a dormir ya". Entonces me fui temprano con la compañera de mi papá ella se durmió y yo me quedé viendo televisión. Yo tengo la sensación todavía de... si fue un sueño o fue real pero me despierta como una luz me doy cuenta de que el televisor estaba prendido entonces lo apagó pero la luz seguía así cuando volteo a mirar mi papá estaba parado en la puerta entonces yo cierro los ojos y yo me asusté y como que no de él sino de estarlo viendo y al otro día me desperté y dije: “¿Qué pasó fue un sueño o estaba ahí?" Pero entonces comencé a tener la sensación de que él estaba muerto que si se me aparecía si era un sueño o era real estaba muerto, empecé a tener la seguridad. A pesar de todo lo que había pasado del testimonio de la testigo de todo eso que se lo había llevado la policía yo seguía guardando la esperanza pero desde ese día yo digo no, nada, y la mejor amiga de mi papá al 
otro día que ya estábamos en Girardot en un hostal chiquito para seguir la marcha al otro día, nos quedamos al otro lado hablando me dice: “¿Usted como hija tiene la sensación de que él está vivo o esta muerto?" Yo le cuento lo que me pasó la noche anterior y digo: "Yo desde anoche o desde esta mañana me quede pensando será que estaba ahí o es un sueño" (Shaira, entrevista realizada el 26 de julio de 2011).

Ante estas imágenes, sueños, presencias, la explicación psicológica de lo ocurrido tiene que ver con "la negación del duelo por parte del sujeto". Pero esta explicación no da cuenta de la elección específica ¿En qué momento el psicólogo decide pensar que el desaparecido ha muerto?¿Conciben las familias esa muerte de la misma manera? ¿Que significa la aparición de un fantasma que te cuida, te observa, te acompaña, te aclara su destino y guarda secretos sobre tu pasado? La desaparición tiene una carga fantasmática que para algunos resulta siniestra y para otros natural o hasta restauradora, pero esa carga fantasmática puede encontrarse con una respuesta limitada en lo racional e individual y sobre todo en el ámbito terapéutico que contradice la experiencia mística.

Traer a la «vida» a un fantasma es acabar con su existencia, con sus legados, con sus inyunciones. Porque es acabar con su secreto y éste, el secreto, es el lugar de donde surge el movimiento de diseminación de la herencia y la supervivencia del legado. El secreto es lo que se resiste al movimiento de reapropiación, ese deseo de canibalizar al otro, por ejemplo aquí, escribir lo que «Derrida» dijo, dejarlo sentado y establecido de una vez y para siempre, si tal cosa fuera posible, sería el fin de la herencia, el entierro y la lápida colocados como trofeo en el interior del «hermeneuta». El legado sobrevive al sustraerse, esta sobrevida le da su porvenir al no cerrar el trazo, la herencia está siempre por venir (Potel, 2010:7).

Traer al sueño al padre desaparecido puede incluir, como Shaira lo afirmó, un vínculo nuevo. Aborda el secreto de su destino. El sueño a Shaira le rebela qué ocurrió con su padre y en dónde, resistiendo a la acción de apropiación realizada por los perpetradores, al mismo hecho de la desaparición. A través de la sobre vivencia del fantasma se previene un olvido, un cierre.

Que para mí es muy difícil pensar que él se me haya aparecido porque yo no creo en nada entonces yo 
le decía, y mas cuando él era una persona que me decía: "Cuando uno deja de existir ya no pasa nada". Entonces yo decía como a mí me formaron de esa forma me resulta difícil que se me aparezca pero puede haber una conexión con él a través de los sueños. Si lo vi en un sueño él me estaba diciendo que ya no está, y yo siento eso él ya no esta vivo y a los veinte días de eso el 15 de julio es cuando nos dicen que él está enterrado en lbagué entonces la amiga de él me decía: "Si ve, él quería decirle que estaba ahí él de alguna forma se quería comunicar con usted". Entonces yo decía: "No que locura, es una casualidad". Pero yo pienso que sí como que yo pienso que hay una conexión ahí después de que ellos se van o no sé si hay una forma en que la mente busca solucionar cosas ahí pero si es raro yo a veces charlo con mi hermanita y también sale con unas cosas así muy ...

¿También ve o escucha a Guillermo? -

Ahorita si, pero como ella estaba tan chiquita en ese momento ella nunca decía: "Soñé con mi papá". Sino: "Mi papá vino anoche". Entonces era muy loco porque era yo siempre que soñaba con él soñaba que él regresaba nos decía: "Es que estuve secuestrado". Entonces era una idea que no se me iba de que ya había aparecido, ya lo habíamos enterrado y yo soñaba eso era como: "No es que me pasó esto" y llegaba sucio y yo lo abrazaba, y lo abrazaba y lo abrazaba. Entonces como que no podía aceptar eso y todo el tiempo mi subconsciente soñaba eso, soñaba seguido pero soñaba eso pero después dejé de soñar con él (Shaira, entrevista realizada el 26 de julio de 2011).

Los seres queridos son retenidos en un lugar irrecuperable, indecible, pueden llevarse al mismo lugar a aquellos y aquellas que los extrañan con el dolor más profundo y duro de la melancolía. Entonces en el sueño se acepta la herencia, y esa parte del ser que se va con el ser amado se expresa y se explica, se aclara, aparece como una luz que ilumina la incertidumbre, a veces para que esta no vuelva más. Por eso antes que nombrar a la locura tendríamos que decir:

«Ven» venido del otro, «Ven» que no viene más tarde, «Ven» que no es un programa teleológico, «Ven» que es ahora, aquí. "Ven» como respuesta imperiosa entonces también, «Ven» afirmativo y siempre plural. Un sí entonces en el origen. Un sí que antes de todo promete y compromete con el otro que está siempre antes - y del cual por tanto soy heredero - (Potel, 2010:7).

Los fantasmas son una resolución más que entre la vida y la muerte, entre el amor y la muerte, porque alguien que está ausente no puede ser recuperado de manera real, es el amor el que hace posible el reencuentro. Las dos fuerzas más importantes del mundo en juego. En tanto momento de resolución, el encuentro con el fantasma es importantísimo, 
puede ser escuchado, pero a veces atormenta, repite acciones o aclara, cuida, acompaña, o se despide. Todo esto toca directamente los elementos más amorosos de las personas que los extrañan y a través de sus sueños o sus vivencias los mantienen cerca, hasta que consideran necesario despedirse.

\subsubsection{El miedo}

El miedo también es un sentimiento importantísimo en este proceso, el miedo como una señal de alerta ante el peligro queda integrado a la cotidianidad de hijos e hijas que adelantan las denuncias y van reconstruyendo la desaparición, desenmascarando un sistema "oculto" que viene desapareciendo, en medio de la democracia, a miles de personas.

Después de lo de mi papá muchos sentimientos se me mezclaron. Uno, tenía miedo y el miedo determinaba algunas dinámicas de: hasta qué hora podía estar en la calle, cómo me movilizaba, si andaba sola o en compañía; por otra parte tenía mucha rabia y mucho dolor además de otros sentimientos, pero esos tres conjugados hacían que también buscara estar a veces sola y que le huyera a los espacios... de alegría (Diana, 21 de septiembre de 2011).

Ese miedo causa de manera efectiva la evitación a ciertas situaciones que pueden ser riesgosas, es válido en el contexto y puede generar respuestas de protección. Sin embargo, produce cambios físicos y en la percepción que le exigen mucho control y esfuerzo a quien lo experimenta.

El miedo siempre estuvo, las amenazas y todo eso, desde que mi papá desaparece, como viste en el video la historia fue supremamente irregular y presión siempre hubo, entonces yo identifico... no se cómo conceptualizarlo pero sé que he tenido distintas etapas del miedo. Hubo un miedo que de pronto acepté normal hubo otro miedo que internalicé y no era consciente de que lo tenía pero lo tenía y hubo un momento en el que lo hice consciente creo que fue cuando... no exactamente pero creo que un momento clave fue cuando recibí unas amenazas escritas de las águilas negras que dije: "No, yo no quiero seguir viviendo así yo soy consciente de que estoy sintiendo miedo esto no tiene sentido voy a tomar un receso". Cuando salí de Colombia aquí el miedo se alborotó, osea, a diferencia de sanarse se alborotó entonces no sé yo creo que aquí sentía mucho más miedo que en Colombia al menos era más consciente aquí... Eso fue muy chistoso es que también han sido como partes de mis etapas del miedo. 
Otras etapas del miedo es que cada vez que regreso a Colombia se me alborota pero esta última vez que estuve estuve más tranquila, pero a mí se me alborota es porque cada vez que voy también me amenazan, no es que no tenga una razón de ser, pero esta vez estuve mucho más tranquila. (Diana, 21 de septiembre de 2011).

Pero también se va convirtiendo en causa de desarticulación en los espacios más habituales porque quedan marcados como escenarios de memoria traumática, y genera grandes sensaciones de vulnerabilidad. El miedo puede ahuyentar las denuncias, silenciar, desunir, descomponer procesos sociales.

Después del video después de presentar el documental, al otro día, estábamos con Shaira y con Álvaro y él nos dejó en un taxi a Shaira y a mí y ella se bajó antes -esto no lo sabe Shaira- entonces ella se bajó antes que yo y el taxista me empezó a hacer preguntas ridículas como: "Y ella por qué se baja aquí" y “¿Ella para dónde va?” y “¿Esa ruta si le sirve?”. Entonces yo me empecé a poner muy nerviosa y el señor me hacía preguntas que a mí me parecían tontas, entonces yo empecé a sentirme mareada y yo le dije al señor: "Déjeme acá joríllese!". Pero yo abrí la puerta esa fue mi amenaza. Íbamos por la Caracas y el señor se orilló y yo me bajé en el éxito de la 53 y yo caminé y el señor me pitaba yo no sabía si... yo me estaba inventando la historia... porque yo lo que pensé es que me hubiesen querido poner escopolamina $^{50}$. Pedí ayuda en el éxito y por teléfono llamé a mi mamá pero cuando llegué a la casa llegué avergonzada porque yo por dentro decía será que me lo inventé... Fue muy loco pero tampoco es gratuito, porque el lunes presentamos el video y al otro día yo tenía cita en el colectivo de abogados para hablar del caso de mi papá, cuando yo salí del colectivo de abogados yo recibí una llamada pero era una llamada perdida, entonces yo sé que esas llamadas han sido formas de intimidarme, me marcan después de que me ven salir de algún sitio clave, pero yo les conté a Shaira y a Álvaro y me dijeron: "Ay no seas paranoica no le pongas cuidado". Claro entonces yo por la noche tenía eso en la cabeza y entonces me dio esa locura (Diana, entrevista realizada el 21 de septiembre de 2011).

En Colombia es sistemática la violación de derechos humanos. Una persona vive una desaparición o el asesinato de un familiar, después recibe amenazas por entrar en los procesos judiciales, y al final es acusada de "subversiva", (que para el estado es menos que nada) o narcotraficante ${ }^{51}$, acusaciones que justifican cualquier victimización. Hay un contexto

\footnotetext{
${ }^{50}$ La escopolamina o hioscina es una sustancia derivada del árbol de mandrágora o de borrachero. Es utilizada con frecuencia en Colombia para la comisión de delitos poniendo bajo su efecto a las víctimas, generándoles delirios, parálisis y sumisión.

51
} 
caótico en donde la ley parece no ser capaz de poner límite y en ese sentido la realidad es invasiva y desbordante.

\subsubsection{El Desarraigo}

En todos los casos de hijas e hijos que participaron en la tesis se dio un cambio de lugar. En algunos casos ese cambio se reconoce como positivo porque fue una forma de protegerse ante el peligro y la "mirada" del perpetrador.

-Quedó como un caso de la Unión Patriótica.

- Sí, como Reiniciar lleva los casos de la Unión Patriótica entonces también lo presenta así como parte del exterminio de la Unión Patriótica. Yo me tuve que ir de ahí porque yo vivía muy paranoica, porque me ocurrían cosas con la gente que todavía estaba ahí que me asustaba. Pero fue muy chistoso porque cuando ya me fui de ahí como que empezó a cambiarme un poquito, si seguía temerosa pero ya me sentía mas tranquila, ya no había esa paranoia, estar ahí. Yo me bajaba en ese paradero y en una ocasión una patrulla de la policía se hace adelante mío y un carro me sigue y un tipo así estilo militar baja la ventana me mira, pues claro yo no me podía mover ni gritar osea yo quede asustada yo dije: me van a llevar, yo me quede así y el tipo se rió, subió la ventana, la patrulla arrancó detrás de él. Pero pues fue eso que nosotros seguíamos insistiendo, en denunciar, entregar volantes, entregar afiches por todo el barrio, entonces eran como formas de amedrentarnos. A la esposa de mi papá varias veces la siguieron. La esposa de mi papá si acepta un esquema de seguridad del DAS ${ }^{52}$, yo no. Entonces yo pongo de

52 El estado cuenta con distintos sistemas de protección. Según el Informe Final de la evaluación de las políticas de prevención y protección a líderes sindicales y trabajadores sindicalizados del Estado colombiano, elaborado por el PNUD, estos sistemas han ido transformándose según el contexto y en el marco del conflicto armado interno. Aunque definir la amenaza contra sindicalistas como resultado del conflicto interno, ya que este implica una ganancia para empresas nacionales y transnacionales en la pérdida de derechos laborales y por lo tanto es efecto de avances del capitalismo y específicamente el neoliberalismo en Colombia. Retomo este estudio porque presenta un recorrido histórico de la construcción del programa de protección, según el cual la creación de estos sistemas se funda frente el ataque contra la UP. Después del éxito que este partido alcanzó en las elecciones populares para alcaldes realizadas en 1987. En respuesta el presidente Virgilio Barco ordenó proteger a los principales dirigentes de la UP con esquemas provistos por el Departamento Administrativo de Seguridad (DAS). Sin embargo, antes de 1991 habían sido asesinados 497 sindicalistas, y entre 1992 y 1997 la cifra ascendió a 923. Junto con estos, en 1997 se asesinó a una pareja de investigadores y defensores de derechos humanos y en consecuencia el gobierno de el presidente Ernesto Samper implementó un sistema de protección a víctimas y testigos del conflicto armado interno, el cual fue creado formalmente en la ley 417 de 1998 conocida como la Ley de Orden Público, la cual cambio sucesivamente hasta la declaración de la Ley 1106 de 2006 . En 1998 tras la continuación de atentados contra otros defensores de derechos humanos, docentes, miembros del partido comunista y activistas por la paz.

Se definió desde ese momento que el esquema de seguridad debía operar usando "escoltas de confianza", recomendados por las propias personas protegidas, una experiencia que fue valorada como exitosa y que contó con la participación de reinsertados de los procesos de paz de la década del noventa, provenientes de los grupos armados desmovilizados: M 19, PRT, ADO, EPL y Quintín Lame. La asignación del sistema fue dejada en manos del Ministerio del 
condición que me pongan un escolta del partido y paso hojas de vida de escoltas del partido pero no las aceptan, entonces yo decidí que yo no iba a tener esquema de seguridad pero entonces en ese proceso que conozco a hijos conozco a las organizaciones que hacen acompañamiento ${ }^{53}$, yo les cuento ese tipo de cosas y ellos dicen: "Si en algún momento necesitas que pasemos por tu casa, hagamos una ronda, avísanos como para que se den cuenta que estamos ahí" (...) Pero para mí lo más importante la decisión mas importante que tomé fue irme de ese barrio del Tunal en donde desparecieron a mi papá y ya donde me voy era el barrio donde yo había vivido la mayor parte de mi vida en donde había vivido con mi mamá, que fue un apartamento que me había dejado mi mamá y también y ahí otra vez empecé a darme un aire, empecé a sentirme tranquila, segura porque yo salía por ese barrio y era horrible. En otra ocasión salí también con mi hermanita sola y nos seguían y era muy fuerte muy tensionante todo el tiempo pensar que nos iba a suceder algo (...) (Shaira, entrevista realizada el 26 de julio de 2011).

\section{Irse como una forma de encontrar en soledad los miedos personales y hacer análisis de las}

Interior y de Justicia, en coordinación con el Departamento Administrativo de Seguridad y la Policía Nacional. La Ley $6^{a}$ de 1995, creó el Sistema de Protección de los Derechos Humanos, y le otorgó al Ministerio la competencia para desarrollar "un sistema de atención a las demandas de protección de los derechos ciudadanos" bajo amenaza, orientados a la "protección, preservación y restablecimiento" de los derechos de los denunciantes. Con la Ley 418 de 1997, se ordenó la creación de "un programa de protección a personas que se encuentren en situación de riesgo contra su vida, integridad, seguridad o libertad, por causas relacionadas con la violencia política o ideológica, o con el conflicto armado interno que padece el país, entre los cuales se incluyó a dirigentes y activistas de organizaciones sociales, cívicas y comunitarias, gremiales, sindicales, campesinas, de los grupos étnicos, defensores de derechos humanos, periodistas, dirigentes o activistas de organizaciones políticas, sobre evaluación de riesgos según las necesidades de diferentes grupos poblacionales específicos. Decreto 372 de 1996 para testigos y personas amenazadas, en el cual se incluye a los líderes sindicales, Decreto 978 de 2000 para ex integrantes de la Unión Patriótica y el Partido Comunista, Decreto 1592 de 2000 para periodistas y Decreto 1386 de 2002 para alcaldes y concejales. En 2006 se expidió el Decreto 2816, por medio del cual se "diseñó y reglamentó el Programa de Protección de Derechos Humanos del Ministerio del Interior y de Justicia". En él que se incluyó como población objeto a los dirigentes o activistas de organizaciones sociales, cívicas y comunales, gremiales y sindicales, campesinas y de grupos étnicos. Recientemente, se expidió el Decreto 1740 de 2010 que reglamentó la protección a los dirigentes o activistas de organizaciones sociales, cívicas comunales, gremiales, sindicales, campesinas y de grupos étnicos. El informe concluye que estos esquemas se han multiplicado al pasar de los años a causa de la desarticulación institucional. Y se puede afirmar que su eficacia es mínima teniendo en cuenta el alto número de sindicalistas asesinados, por lo cual se reconoce como un programa que no se iguala a una política pública y que es de carácter reactivo más que preventivo (PNUD, 2011) Este es un buen ejemplo, en tanto se propone un esquema de seguridad a las familiares de Guillermo Rivera Fuquene, después de haberse ejecutado su desaparición.

${ }_{53}$ Las organizaciones de acompañamiento son la alternativa del movimiento social para proveer protección a sus miembros sin hacer uso de los esquemas de seguridad del estado que implican con frecuencia, seguimiento del DAS o la policía, y cambio de residencia y desplazamiento. Es una experiencia solidaria creada gracias al apoyo de organizaciones como Brigadas Internacionales de Paz (Peace Internacional Brigades - PBI), el Movimiento de Reconciliación (F.O.R), el Observatorio Internacional de Paz (I.P.O) y Pax Christi, con mandato de neutralidad y apoyo diplomático que ha sido decisivo en situaciones de riesgo pasadas por distintas organizaciones y personas del movimiento social colombiano. Estas organizaciones se articulan a complejos programas de prevención y protección. La prevención según el Programa Somos Defensores consiste en un conjunto de "medidas tempranas que individual y colectivamente deben implementarse para evitar un peligro, disminuir un riesgo o los impactos de éste". Las medidas de protección o conjunto de "acciones que pueden desarrollar las organizaciones y las instituciones para resguardar la vida, libertad e integridad personal de los defensores y defensoras". Estas se refieren específicamente a: difusión, divulgación, incidencia y acompañamiento para disminuir la amenaza, dar acompañamiento integral en caso de ser necesario que el o la líder salgan de la región en la que adelantan su trabajo (Programa Somos Defensores, 2010). Más allá de estos programas algunas organizaciones proponen o han llevado acabo el abandono de todas las medidas de protección del estado para exigir "fórmulas de protección política" es decir la disminución de señalamientos y amenazas públicas recibidas por parte de altos funcionarios del ámbito ejecutivo o de las fuerzas militares. 
cosas que se han elaborado y las que no, en un contexto o un territorio contenido y contenedor puede ser un proceso de reflexión para elaborar las experiencias. Sobre todo si implica una ruptura necesaria o un corte con un lugar que está bajo el control de los perpetradores. Pero tiene todo el componente de un nuevo duelo, la necesidad de hacer algo sin un deseo previo, y las condiciones de estrés que puede generar un lugar nuevo.

En el caso de Chico Bauti el exilio se repitió recientemente. Él se fue del país desde junio de 2013 por haber sido objeto de seguimientos y después de que su casa fue allanada ilegalmente por miembros de seguridad vestidos de civil. Actualmente se encuentra en Alemania.

Tuve que cambiar siete veces de casa en una semana y esas cosas marcan muchísimo. Era muy triste porque pensaba que mi madre iba a regresar a la casa donde nosotros estábamos viviendo y entonces eso era como muy difícil de llevar (Chico Bauti, entrevista realizada en Septiembre de 2011).

El cambio de hogar y el exilio terminan de constituir al acontecimiento potencialmente traumático. Se desarrolla en una situación dual en la que hay que escoger entre la vida y los grupos de pertenencia, el territorio, la familia. Todos los lugares de transmisión que permiten recibir el legado de la familia, las luchas pasadas, la escolaridad, entre otros. Todo es nuevo, todo es un nuevo misterio. El miedo en estas circunstancias en donde el lugar ha cambiado y las condiciones de seguridad no son las mismas tiene que ver con la transformación de la realidad en cuanto a que, como dice el siguiente apartado: cambia el principio de realidad: "Un gato se convierte en león" 54 .

Si y a experimentar el miedo, aquí yo sentía mucho miedo en la calle, aquí es un ambiente completamente distinto, las calles son súper oscuras y súper solas y eso me hacía sentir muy insegura.

\footnotetext{
${ }^{54}$ Este proceso refleja con claridad las distintas dimensiones que puede tener el miedo como sentimiento propio del sujeto por su auto conservación, en una gama que puede llegar hasta la instalación de la angustia en momentos en los que se desconoce la razón de su activación. Freud analiza el tema y diferencia entre la inhibición, el síntoma y la angustia, y ubica al miedo como una expresión que se puede relacionar claramente con la realidad peligrosa y la necesidad de auto conservación. Esta lectura es útil en dos sentidos, por un lado puede explicar como se sustraen o limitan acciones o funciones del yo por cuenta de experiencias que resultan traumáticas, y entre estas aparece la de la experiencia de violencia sexual que evidencia una condición de objeto en aquel o aquella que la experimenta. Y por otro lado, la relación que existe entre sentirse en situación de invalidez y la efectividad de la angustia. Es decir la rememoración y conservación de un estado anterior de innermidad que se reactiva y posibilita o potencia el miedo en situaciones inexplicables (Freud, 1926).
} 
Por ejemplo, vivía en una casa muy grande yo solita solita y vivía con un gato y a mí los gatos no me gustan y entonces una vez el gato me arañó pero parece que me tenía mucho afecto entonces como yo no hacía más que rechazarlo me arañó y yo por la noche, te juro, estuve encerrada en una sala como media hora porque afuera estaba el gato y entonces la psicóloga me decía: "Uau estabas comparando un gato con un león, osea focalizaste todo tu miedo" (Diana, 21 de septiembre de 2011).

El exilio es un desprendimiento para vivir en un espacio que no dice nada, desconocido, que finalmente fue usado por aquellos que lo vivieron como lugar de aprendizaje, pero también de pérdidas incalculables. Es necesario mantener el control, intelectualizar, trabajar, denunciar, hablar. Entonces en una situación que reactiva el miedo no siempre se puede tener control y aparece el pánico. Se regresa a situaciones de miedo previas que aumentan la dimensión de peligro del momento presente. El gato es león porque el miedo sentido en el pasado fue generado por algo tan poderoso o peligroso como un león, y ese miedo se reactiva con intensidad aunque la situación no lo amerite. ¿Cuanto tiempo o con cuanta intensidad la angustia va a generar esta presión? Hasta el momento en que sea claro que el miedo es miedo de un león que se encuentra en el pasado. Es decir hasta cuando los perpetradores tengan límite, no puedan ejercer su dominio en el presente o en el futuro. El tiempo tiene que ver con la justicia y con la elaboración psicológica.

De esa situación de pánico es posible decir que el aparato psíquico posiblemente ha estado expuesto a un conjunto de cambios importantes generadores de estrés. Ante estos la necesidad de adaptación y control por parte de quién experimenta esta vivencia es desbordante y esa carga alta le genera una descompensación ${ }^{55}$.

En los dos casos es posible encontrar un elemento externo causante de la situación de vulnerabilidad en la que se ubica el sujeto atrapado por el miedo. El elemento externo

${ }^{55}$ El pánico o su expresión, el ataque de pánico está reconocido en el DSMIV como un trastorno de ansiedad y es definido como la aparición temporal y aislada de miedo o malestar intensos, acompañada de cuatro (o más) de los siguientes síntomas, que se inician bruscamente y alcanzan su máxima expresión en los primeros 10 minutos: 1.palpitaciones, sacudidas del corazón o elevación de la frecuencia cardiaca 2. sudoración 3. temblores o sacudidas 4.sensación de ahogo o falta de aliento 5. sensación de atragantarse 6.opresión o malestar torácico 7.náuseas o molestias abdominales 8.inestabilidad, mareo o desmayo 9. disociación (sensación de irrealidad) o despersonalización (estar separado de uno mismo) 10. miedo a perder el control o volverse loco 11. miedo a morir 12. parestesias (sensación de entumecimiento u hormigueo) 13. escalofríos o sofocaciones. 
además ha actuado, bien se conoce, ha violado, ha torturado, ha desaparecido. El miedo expresado en la situación clara de una nueva acción de ese otro, que en el caso del estado además contradice la función de protección que se le ha otorgado, es entonces justificado. Pero en el caso de aparecer como una rememoración de una situación en un momento en el que no podría ocurrir nada, aunque implique una reacción desmedida, también tiene un objeto, y se justifica en la introyección o asimilación del objeto peligroso para reactivarlo y poner su máscara sobre otro. Ahora bien, ¿si el miedo ya no tiene objeto y se convierte en angustia, en miedo a los sentimientos, a los estados internos?

Lo más interesante de estas reflexiones es que en la creación de la angustia como noción psicológica, es necesario, según Freud (1928), distinguir primero entre una inhibición, una represión una imposibilidad del yo para alcanzar algo en la realidad y su efecto, el síntoma. Esa inhibición puede ser causada porque el sujeto está dedicado a un proceso de elaboración, en este caso un proceso de duelo, por ejemplo y no puede dedicar su energía a la consecución de otras metas.

La angustia es un síntoma. Existe un sentimiento constituido por miedos internos que se reactivan. Creados por situaciones tal vez por situaciones de inermidad que generan una inhibición interna en la búsqueda de ciertas metas y que trae consigo un gran malestar ante ciertas situaciones aparentemente irracionales (Freud, 1926). La angustia que aparece tiene que ver con la necesidad de establecer esos vínculos y la imposibilidad de hacerlo. Es un problema vincular y en ese sentido no tiene que ver sólo con que la realidad en un escenario de miedo se desdibuje o se sobredimensione sino que la situación real reactiva sentimientos que son anteriores y más complejos que los del momento de la angustia. Es un sentimiento relacionado con la interacción e implica el borramiento del otro como apoyo, la soledad en un medio social que reactiva situaciones de inermidad y la posibilidad de defenderse.

Nosotros encontramos los restos en agosto del 90' y yo me gradúo en el 91', claro empiezo esos días a ir a hablar sólo porque con quién habla uno en el cementerio (risas). Ahí está el vínculo. Al principio como la idea de recuperar los huesos y todo lo que había significado. Eran intentos de diálogo en donde contaba que había hecho, que había pasado conmigo y también angustia de qué iba hacer de mi vida en 
adelante. Siempre cargué una carga de angustia bastante alta (Chico Bauti, entrevista realizada en Septiembre de 2011).

Una soledad que no se resuelve a causa de la desconfianza generada por las acciones de otros seres humanos. Después de situaciones así en quién se confía y qué se puede esperar.

- ¿Y con la angustia cómo hiciste?

- Ahí la tengo (risas). Hay momentos en que uno la tramita pero eso es difícil porque, por ejemplo, -estaba pensando hace poco- nosotros habíamos hecho una acción de pintar un mural. Me pareció muy bacano porque hubo participación de la familia y la fundación también apoyo con algunas cosas. Digamos que era una conciliación entre mi forma de decir las cosas y la forma que tiene la fundación, que es más formal. Lo mío va más en acciones en la calle hacia la gente y la fundación hace un trabajo más de incidencia política más directo con los familiares. Son dos que son como estrategias diferentes. Y hemos conseguido hacer un mural. Estuvimos los hijos, gente de la fundación, fue chévere. Después hubo otra organización que quiso pintar encima sin avisar nada y entonces a mí me contaron y, dije: "Cómo así que primero llaman a consultar y después quieren hacer otra cosa y ahí si no avisan". Pensaba que no había que ocupar los mismos espacios sino hacer más espacios pero para mí era una cuestión territorial. Para mí (el mural) era un logro del trabajo que hemos hecho durante años y borrarlo de alguna manera es echar para atrás - pensaba yo-. (Chico Bauti, entrevista realizada en Septiembre de 2011).

En el proceso de construcción de la subjetividad una experiencia de terror, de tortura y violencia extrema, puede ser asimilada y convertirse en una experiencia dolorosa que en algunos casos resulta "peligrosa" en el recuerdo. Genera falta de control o la sensación de estar inerme. Estos sentimientos están relacionados o emparentados con los que son generados por la tortura en víctimas directas.

La víctima de tortura es ubicada en el lugar de una cosa sobre la cual se puede desplegar todo el poder del perpetrador. La tortura intenta colocar a la persona en situación de estar a merced y produce efectos de despersonalización. Kordon, Edelman, Lagos y Kersner (2002) plantean que los ataques físicos tienen a producir vivencias de aniquilamiento y destrucción del esquema corporal. La experiencia de testimoniar o ver a otro torturado lleva la 
advertencia de que esto puede pasarle también a quién está mirando. Esta experiencia trae el fantasma de la muerte, la pérdida de autoestima y de los referentes de identificación que apuntalan el psiquismo: el cuerpo, los grupos de pertenencia, los grupos de referencia, la presencia de otros que puedan brindar una palabra y ayuda.

Cuáles de estos elementos son trasladados a los familiares de personas desaparecidas que suponen o confirman la tortura contra sus seres queridos es un trabajo a indagar. En algunas de las entrevistas realizadas al menos se presume que hay una identificación en la extensión de la violencia, cae sobre ellos la advertencia sobre que eso puede pasar a cualquiera, a sí mismos, o a otros seres queridos. Pero en muchos casos ocurre porque literalmente cae sobre las familias una advertencia de que "les va a ocurrir lo mismo".

A este nivel y teniendo en cuenta que uno de los objetivos de la tesis es entender el silencio sobre los hechos del pasado, es importante resaltar ciertas "hipótesis" que los autores plantean sobre las causas "psicológicas" del silencio después de vivir una experiencia de este tipo:

- Efectos del dolor en el sistema nervioso, que afectan o disminuyen la capacidad de memoria y producen episodios de amnesia y se convierten en fuente de angustia.

- La experiencia de dolor afecta al núcleo de identidad y la persona se encuentra indefensa ante la cual se produce una selección narcisista que no permite efectuar representaciones psíquica.

- Se produce una disociación en donde la representación del propio cuerpo se pone afuera, el cuerpo ya no le pertenece y la persona no es exactamente la misma.

- Los sentimientos de pudor, la vergüenza o la humillación, dificultan la comunicación de lo ocurrido y están vinculados a vivencias íntimas.

Según los mencionados autores es posible decir que de esa misma manera se pueden usar algunas de las herramientas que las víctimas de tortura usaron para sobrevivir a estas experiencias: El mantenimiento del ideal del yo y ese ideal puede estar relacionado con la 
ideología política o no. Tiene que que ver específicamente con la resistencia en ámbitos que las personas consideran fundamentales para el mantenimiento de su dignidad. Otros mecanismos psicológicos implementados como respuesta son: la intensificación de los sentimientos de pertenencia, la comprensión intelectual y la disociación mente cuerpo.

Ante una mirada tradicional de la psicología la intelectualización funciona como mecanismo de defensa porque tapona su encuentro con las contradicciones personales. Pero en el trabajo de personas que han pasado por esta experiencia esta lectura sería un error pues la intelectualización no opera como mecanismo defensivo. "Mediante la comprensión se tiene la seguridad de que no se está indefenso del todo y se puede salvaguardar la personalidad" ante la amenaza. Esta defensa pone en juego capacidades tales como la capacidad sintética, la anticipación y la discriminación. En la situación de tortura protege a la víctima de sentirse a disposición plena del perpetrador. Le permite no confundir el lugar de la víctima y el perpetrador es decir que la protege de la culpa (Kordon y Edelman, 1983).

Para los adultos o cuidadores la responsabilidad de la transmisión les es dada pero no les es única por la necesidad de curar sus propias heridas. En manos del colectivo está crear los escenarios en los que estas condiciones se comuniquen y se vuelvan una información pública y aceptada o soportada por las redes sociales.

Porque cuando a mi me entregan el cuerpo en la funeraria porque es en la única parte donde yo lo puedo ver entonces yo le digo a la persona que yo quiero entrar y corroborar que realmente era Eduardo, cuando yo entro y veo realmente cómo me lo entregaron que obviamente no tenía sólo los golpes, las señales de haber estado amarrado, los impactos de bala que no fueron uno sino varios en su cabeza. Lo más impresionante lo más impactante es cuando yo le cojo su cabeza, esta parte que se le abre, se baja y es cuando ahí se ve que le hacia falta, a él le quitaron un pedazo de lengua, eso no le dicen en ninguna parte en el acta de levantamiento ni nada. Eso es lo que yo le oculto a mi hija, yo sencillamente le dije: "a su papá lo asesinó la policía" y después de mucho tiempo, Angie tendría nueve años, cuando a alguien se le dio por hacer un libro con historias de vida de personas que hicieron parte del M19 tanto actores políticos como gente realmente armada que estuvieron combatiendo, entre esos el caso de mi compañero, él era combatiente (Esperanza, entrevista 22 de septiembre de 2011). 
Estas redes construidas desde la comprensión de los ideales anteriores o su conservación buscan superar la individualidad y la ruptura de solidaridad que genera la objetivación del otro, en el caso de Esperanza, del otro guerrillero. Esas redes compuestas también por investigadores avanzan en la recuperación de la memoria y movilizan la recuperación de aquellos recuerdos que no terminaron de ser compartidos. Tal vez para Esperanza en su percepción de la relación con la hija, el momento en que ella supo todo lo ocurrido con su padre fue inoportuno, por otro lado, es necesario decir que sólo hasta ese momento le fue posible desde otro lugar, desde el campo colectivo la transmisión porque en el ámbito familiar había quedado marcado por lo traumático.

Por otro lado, es necesario aclarar que este mecanismo de terror que se evita es posible porque el familiar siente lo que ocurre a su familiar como si le pasara a él mismo, desde su fantasía o cuando lo comprueba después de recibir huesos separados, cráneos con disparos. Pero el como no es el yo. Es decir que el familiar y el desaparecido no son la misma persona. La elaboración de un duelo puede llevar a que cada persona introduzca en su propio yo al cuerpo lastimado de su ser querido y este se convierte en un elemento fundamental. Por otro lado, la implementación de acciones de protección y denuncia son útiles porque le permiten poner límite al perpetrador. Ritualizar el cuerpo del otro y su ausencia para que no se mantenga una confusión entre el otro y el sí mismo son elementos fundamentales.

\subsection{El dispositivo clínico en esta reconstrucción}

Tras un análisis del contexto brasilero tras el cual se demostró que a pesar de que las violaciones de derechos humanos afectan al conjunto social, "los afectados fueron convertidos en los únicos receptores de los daños provocados por tales sucesos" (CINTRAS, EATIP, GTNM/RJ, SERSOC, 2009, 259), el Grupo Tortura Nunca Mais propuso dentro de sus objetivos contribuir a la desindividualización, desintimización, desprivatización y politización de los daños causados por la tortura. A través de lo anterior evita que la problemática se quede en el consultorio y los afectados sean empujados al silenciamiento (CINTRAS, EATIP, 
GTNM/RJ, SERSOC, 2009).

Para el grupo tortura nunca mais las formas de padecimiento de los afectados y la transmisión no se explican por acontecimientos restringidos a sus historias personales o disociadas en los modos de subjetivación y de objetivación de los sujetos contemporáneos (CINTRAS, EATIP, GTNM/RJ, SERSOC, 2009: 263). Este grupo se ubica en el análisis clínico y se preocupa por adoptar en este dispositivo "una perspectiva ético - estético política para producir agenciamientos capaces de operar desplazamientos intensivos para habitar el pasado de otra manera" (CINTRAS, EATIP, GTNM/RJ, SERSOC, 2009:264). EI grupo reconoce el componente político de la clínica y reconoce el inconsciente como un campo de luchas. Pero a su vez reconoce que aunque en sus escenarios mitigue el dolor y ayude a la producción de sentido no produce líneas de subjetivación y en consecuencia plantea la importancia del reconocimiento del daño. Es decir que reconoce que la clínica terapéutica tiene un papel auxiliar en este proceso y es el de respaldar al sujeto en esa lucha de significados para reducir el dolor y construir sentido dentro del caos de sentimientos y situaciones que se viven a causa de la represión (CINTRAS, EATIP, GTNM/RJ, SERSOC, 2009).

La clínica está limitada para producir contextos, marcos sociales con enunciaciones distintas a las que se transmiten en estos contextos y relacionadas con ideologías establecidas (CINTRAS, EATIP, GTNM/RJ, SERSOC, 2009). La clínica está destinada a ser un lugar para el reconocimiento y la expresión, por lo tanto la escucha de la subjetividad, no para su producción. Por eso es necesario que en medio de esos contextos se reconozcan daños y responsabilidades, porque la lucha del sujeto va a ser permanente y va a tener una búsqueda constante de sentido en distintos escenarios, en este caso el clínico, mientras la experiencia y los sentimientos sigan en contradicción con las experiencias narradas y los sentimientos promovidos desde el discurso hegemónico.

En este sentido las distintas elaboraciones de las personas entrevistadas evidenciaron dificultades en el escenario clínico: 
- ¿Y en todo ese proceso hay alguna ayuda terapéutica?

- No. Siempre me rehúse a hacerlo. Yaneth siempre me decía que venga que usted se está volviendo autista y yo le decía sí, de alguna manera, con algunas cosas, pero yo no quiero ir a que me interpreten y me... siempre tuve un rechazo...

- Sabes que es una cuestión común. Algunos fueron y llegaron a dos sesiones.

- Sí uno llega a la segunda. Sí yo lo intente hace poco en un momento de depresión que tuve cuando el primer congreso de exhumaciones y le dije a Yaneth: "Bueno listo vamos a intentar". Pero no sé. Yo supongo que puede ser una parte de miedo porque estos son temas que por más que uno los hable siempre le tocan a uno fibras muy sensibles uno puede que vaya acariciándolo pero puede ser que en cualquier momento presione algo que lo desestabilice. Entonces uno siempre habla de estas cosas como auto protegiéndose porque uno sabe hasta dónde puede llegar la depresión. Entonces trata de llevar por el humor, por lo bonito, por lo fuerte, por las cosas buenas que se han hecho pero eso tiene un matiz totalmente marcador de dolor (Chico Bauti, entrevista realizada en Septiembre de 2011).

Hay dos elementos importantes, uno tiene que ver con núcleos traumáticos que pueden aparecer en medio de la terapia y que pueden desestabilizar al que habla por el miedo que su contenido genera, entonces aparecen expresiones de resistencia o en otras palabras de "auto protección".

-Qué te ha servido, qué personas, qué sueños, qué lugares, qué cosas?

- Primero el feminismo, yo creo que sin el feminismo ese proceso no hubiese sido igual, en medio de todo ha sido bueno entre lo que se puede decir bueno. Hijos e hijas también me ha ayudado mucho y la posibilidad de compartir vivencias súper extrañas como la de los sueños, porque yo soñé mucho con mi papá, yo sentía que mi papá se comunicaba conmigo a través de los sueños y ahí encontraba eco en la gente de hijos. Qué más me ha ayudado... creo que tengo una capacidad analítica, de análisis de mi misma y de la situación que me ayudado. He tratado de ir a terapia y no ha funcionado, fui a AVRE una vez y no me gustó recién pasó lo de mi papá fui a psicoanálisis con una psicoanalista feminista y me iba volviendo loca entonces tampoco. Aquí en la universidad traté de ir pero la psicóloga sintió que era demasiado y me echó (risas). En otros momentos... yo no puedo contar la historia cien por ciento de mi papá porque el contexto colombiano no lo permite, eso creo que es lo mas problemático de todo. Tengo que tener silencios obligados, silencios que yo ni siquiera quisiera tener pero que siento que son obligados.

- Pero que puedes compartir con otros que comparten esa misma prohibición. 
- Con muy pocos, no lo comparto con mucha gente.

- Eso debe ser difícil para proponer la terapia por ejemplo.

- Si (risas) (Diana, 21 de septiembre de 2011).

Está en manos del terapeuta señalar con distintas herramientas el camino para superar la angustia y aceptar las dimensiones reales de aquello que causa temor. Pero por otro lado está el establecimiento de confianzas con una figura terapéutica que hace parte del mismo contexto que se percibe amenazante. Es necesaria la instauración de un espacio que no reactive las señales de desconfianza relacionadas con el estado autoritario para construir un lugar seguro para hablar. Pero para lograrlo puede ser necesario también que la terapeuta tenga en cuenta los mecanismos de reproducción de los enunciados justificatorios.

Con frecuencia es resultado del contexto de justificación e individuación: suponer culpa en el desaparecido porque desarrolló actividades políticas para elaborar lo injustificable, suponer que es necesaria una pronta elaboración del duelo y por lo tanto, la muerte del desaparecido, proteger a las familias de alguna información sobre la desaparición porque es traumática, priorizar lo individual y desactivar los escenarios colectivos porque no responden con inmediatez a necesidades de las personas, ignorando la importancia de los vínculos solidarios y el lugar del colectivo para la reconstrucción de nuevas representaciones sociales.

Por lo tanto, aquel o aquella que se acerque a guiar procesos clínicos no puede estar sólo formado en el ámbito psicológico, aunque debe estarlo muy bien, sino asumir que su inconsciente, que es colectivo, puede albergar también las imposiciones, las restricciones y los mandatos del estado y está obligado a ser crítico de su propia ideología.

En el caso de Colombia en donde la militancia de izquierda ha sido tan estigmatizada es necesario cuidar que el psicólogo sea consciente de la incidencia de los marcos ideológicos del contexto en su trabajo terapéutico. Es necesario también, tener en cuenta un elemento fundamental a la hora de hablar del dispositivo terapéutico: el rechazo casi generalizado al trabajo psicológico. Con frecuencia la intervención del psicólogo ha sido vista como un 
engaño, un escudriñamiento, un acto de pura individuación, una práctica burguesa, no como una cura; en algunos casos es más complejo porque las personas que participan de espacios organizativos reconocen el manejo ideológico del psicólogo y en la zona rural, con mucha frecuencia, lo relacionan con acciones destinadas a la manipulación. Hecho que puede ser similar al vivido por víctimas de tortura en Argentina cuando sentían desconfianza hacia el psicólogo a causa de que durante la dictadura los militares violentaron archivos y robaron información de los pacientes (Kersner, Lagos, Edelman y Kordon, 2002).

Esta desconfianza no puede ser vista como producto de ideaciones sin fundamento. El contexto actual da pie a opiniones de descrédito o desconfianza ante el papel de los profesionales en salud mental. Estos elementos son: La participación de profesionales de la salud mental en acciones cívico militares dentro de la línea de los Profesionales Oficiales de Reserva $(\mathrm{POR})^{56}$; la participación de profesionales del área en altos cargos dentro del gobierno de Álvaro Uribe Velez ${ }^{57}$; la creación de programas de atención en salud mental que

\footnotetext{
${ }^{56}$ El programa de Profesionales Oficiales de Reserva existe desde 1976 por orden del General Rafael Navas Pardo: (...) "quien vio la necesidad de fortalecer la integración del estamento militar y el civil, para lograr una proyección de la imagen positiva de las Instituciones legítimamente armadas. Es así como cientos de hombres y mujeres de diferentes profesiones se han hecho Oficiales de Reserva del Ejército Nacional, aportando y aunando sus conocimientos, sin ánimo de lucro, en la lucha por la paz del país. Siendo un cuerpo de apoyo de la Fuerza, los POR contribuyen en las actividades que realizan los soldados del Ejército para cumplir su misión constitucional, al tiempo que soportan las labores en las áreas administrativas, logísticas y de acción integral coordinada" (POR Brigada 4, 2013). Se trata de profesionales que se vinculan a las acciones cívico militares después de seis meses de entrenamiento y sin recibir ningún salario, con el objetivo de fortalecer las labores del ejército en distintas regiones del país. "Los Profesionales Oficiales de Reserva de las Fuerzas Armadas, fueron creados como un puente entre el personal de activos y la sociedad en su momento y coyuntura histórica. Los tiempos y la situación del país ha cambiado y la Reserva ha evolucionado. Los Profesionales Oficiales de Reserva ingresaron con la imagen de una disciplina y código de conducta ejemplar e intachable de la institución y con un FERVOR PATRIOTICO, por encima de cualquier horizonte: TODO POR LA PATRIA" (Ahmed Restrepo E.). (Esta cita aparece en la página web del POR y fue escrita a nombre de Ahmed Restrepo E., geógrafo proveniente de la ciudad de Medellín.

EI POR realiza un sin número de actividades que deberían ser adelantadas por instituciones civiles y entre esas actividades se cuentan la atención médica y psicológica, la asesoría jurídica, la entrega de medicamentos, el mejoramiento de infraestructuras, la entrega de útiles escolares, recreación, entre otras, acciones que se justifican o legitiman por las innumerables víctimas que ha dejado el "conflicto armado": "La población civil ha sido víctima inocente de los grupos armados al margen de la ley desde el inicio del conflicto. El Ejército Nacional que vela por cada uno de los colombianos, en cada rincón de la patria, ha reducido el accionar de estos grupos que han maltratado sin piedad el pueblo que dicen defender. En el marco de la protección de los colombianos, el Ejército y los POR, coordinamos con los diferentes entes gubernamentales, acciones cívico-militares en los distintos municipios que se encuentran bajo la jurisdicción de la Cuarta Brigada. Estas acciones están encaminadas a llevar calidad de vida y bienestar a quienes han sido víctimas inocentes del conflicto y a consolidar la institucionalidad del Estado en cada rincón del país. La calidad de vida sumada a la presencia del estado como garante de la seguridad y el bienestar de la población, disminuyen el riesgo del reclutamiento de nuevos miembros a estos grupos armados" (POR Brigada 4, 2013).

${ }^{57}$ Luis Carlos Restrepo, por ejemplo, apareció permanentemente en medios de comunicación, es autor del único texto de salud mental que se lee en secundaria en los colegios públicos: "El derecho a la ternura". Luis Carlos Restrepo participó en varias campañas por la tolerancia, entre ellas "viva la Ciudadanía" y en la campaña por la legalización de las drogas. Fue nombrado por Álvaro Uribe Velez como comisionado de paz en el proceso de "desmovilización" y negociación entre el Estado y los grupos paramilitares. Un proceso que tuvo la oposición de todo el sector de víctimas de crímenes de Estado
} 
no han sido regulados, débiles en su programa e infraestructura y que dieron fatales resultados $^{58}$, o de programas que a través de acciones con familiares victimizados movilizan su desarticulación a actividades de denuncia y movilización y promulgan el perdón. Profundizando en la necesidad o en la formación católica de las personas, bajo mandatos de neutralidad, cuando el trabajo con víctimas exige cierto nivel de compromiso en contra de las acciones perpetradas, porque es responsabilidad de las personas que se dedican a la atención de víctimas su acuerdo a la defensa de los derechos humanos y la protección de los afectados y porque es una condición de trabajo en términos subjetivos (Robben, 1989).

Por otro lado, fuera del estado hay organizaciones dedicadas a la atención de familiares de personas desaparecidas: Corporación AVRE, Tierra de Hombres, La Cátedra Ignacio Martín Baró, Vínculos, y Dos Mundos, Corfasol, la Comisión Intereclesial de Justicia y Paz, son las más conocidas. Estas organizaciones tienen que dedicar gran parte de su trabajo al establecimiento de confianzas entre ellas y las organizaciones de familiares. Pero la dificultad para hablar sobre el núcleo traumático o cuestiones políticas conflictivas es evidente.

Después fui a donde otra psicóloga pero también fui a un par de sesiones y dije no ella me dijo: cuando estés preparada y quieras volver vuelves.

- ¿Por qué?

- Porque sentí que estaba tocando cosas ahí.

- ¿Has tocado cosas difíciles a través del proceso de memoria?

- Si.

por la denegación por parte del Estado de su responsabilidad en la formación de dichos grupos. Paradójicamente la gente del común le llamó a ese proceso de paz un "diálogo esquizofrénico" del Estado consigo mismo, y a la Ley de Justicia y Paz que se instauró para regular el proceso bajo el nombre de "La ley de la ternura". En este momento hay una orden de captura contra Luis Carlos Restrepo después de ser acusado por apoyar la desmovilización "falsa" de paramilitares (El Espectador, 2012) y de un frente de las FARC - EP llamado Cacique Gaitana que era inexistente, formado por personas desempleadas y habitantes de calle que recibieron dinero por participar en el montaje (Noticias Caracol, 2013).

58 Por otro lado, gracias a las distintas legislaciones que se han creado en el proceso de negociación la presencia de psicólogos en los lugares de atención a víctimas se generalizó. Este es un tipo de participación y ejercicio distinto a los mencionados y está dirigido a la recuperación de las personas para su exigencia de justicia. Los resultados de este trabajo tienen un sin número de producciones escritas en forma de relatos de vida, videos o pinturas, gran parte de ellos realizados con hijos de personas victimizadas y retratando escenas de terror. Este trabajo es realizado por muy pocos profesionales, en un contexto de revictimización y altísimas condiciones de riesgo. Esto ha generado todo tipo de exabruptos: La falta de atención necesaria y acorde para la mayoría de las familias; el desgaste emocional de psicólogos y psicólogas, hasta la muerte de una de ellas en manos de un "desmovilizado" que tenía la casa por cárcel, como es el caso de Marjorie Kisner, psicóloga del programa de Paz y Reconciliación de la Alcaldía de Medellín asesinada el dos de diciembre de 2008 en la residencia del desmovilizado cuando ella, según los requerimientos de su trabajo, realizaba una visita domiciliaria (Semana, 2008). 
- ¿Y qué cosas has hecho para poder tocarlas?

- No las he tocado las he...

- Bordeado.

-Y les he hecho así como... (Shaira, entrevista realizada el 26 de julio de 2011).

Por otro lado está la particularidad del dolor. Un dolor infligido por otro ser humano que ha torturado y ser "objeto" aun de la tortura psicológica que genera la desaparición forzada de un ser querido. Un acercamiento a lo real de la existencia, a la fragilidad del cuerpo y sus posibilidades de fragmentación.

\begin{abstract}
Me parece que está cosa de la desaparición me ha generado muchas preguntas porque uno sabe hasta dónde pueden causar dolor a un ser humano... físicamente hasta matarlo otro mientras lo mantienen vivo porque es una forma de tortura psicológica que se trabaja muy poco. Lo que tú dices... la gente no quiere que la traten porque de alguna manera es el poco espacio de dignidad que le queda a uno. Ya cuando uno siente que le han escarbado por dentro y que sabe que ya no le queda nada porque le han violado el derecho el amor. Por ejemplo no se trabaja que uno tiene derecho a tener sus afectos... se miran más otras cuestiones (Chico Bauti, entrevista realizada en Septiembre de 2011).
\end{abstract}

\title{
3.4. Arte y Memoria
}

El nivel de politización de aquellos que han sido objeto de violación de derechos, antes de haber sido violentados, es un recurso que los ubica en un lugar distinto al de la vulnerabilidad. El miedo tiene efecto en tanto no se reconocen lugares de protección o límites en la acción del otro y eso solo es posible si el sujeto se ubica así mismo como vulnerable frente a esa acción. La participación en organizaciones como Hijos, las acciones de denuncia y búsqueda de justicia social, así como el señalamiento permanente del perpetrador ubicándolo en el lugar de infractor y señalándole un límite, es fundamental para la reubicación del sujeto y el manejo del miedo. Pero ese señalamiento en contextos como el nuestro ha buscado distintos caminos además del jurídico por las condiciones de impunidad y las posibilidades de revictimización. 
Por otro lado, así como los grupos de pertenencia generan marcos de comprensión e ideales distintos a los del perpetrador, distintas instituciones construyen contextos simbólicos diferentes que pueden soportar una subjetividad resistente a la tortura, física o psicológica: La academia, el arte, la escuela, la religión, las prácticas de memoria, funcionando como centros de análisis de las representaciones sociales no sólo como transmisores acríticos, pueden aportar en la creación de explicación de la realidad, palabras y formas de simbolización que prevengan la obturación del proceso de elaboración de estas experiencias de violencia extrema, y el silencio.

Chico Bauti al respecto hizo una instalación llamada In Memorian, con la ropa y los elementos que encontraron en la exhumación de la madre. Los usó y unió con un poema que escribió. Luego se unió con hijos surgiendo allí la propuesta de "la memoria crece", planteando que hubo desaparición pero que se sigue ejecutando y que a pesar de la intención depredadora hay un hilo que se conserva.

\section{La Memoria Crece}

He dejado atrás los cuerpos que ahora son semilla las miradas con sus voces en el grito

e infortunio, el desarraigo.

No es tiempo aún

de descomponerse en tierras olvidadas

no han vencido

estamos vivos gracias al destierro.

Si ha de ser esta una forma de vida

una nueva manera de fecundar los espacios que habitamos

los silencios en los que la arena

se divierte borrando nuestras huellas

bienvenido sea el transitar, seguir gritando, no acallar no dejarles actuar

con su obra trágica con muertos de verdad.

La memoria de sus luchas vive

en la invisibilidad del aire en el sabor de las aguas

en la tristeza del mar

en los ríos que transportan la libertad.

No, hoy no hay peces en el río

solo trozos de cuerpos fragmentados

por odios infundados

en la conducta de quien ejerce el poder

de las malditas armas y el martirio.

La madre tierra se desangra

hay libertades castradas

hay cuerpos flotando al servicio

de unos pocos con sus vicios.

Si ha de ser así

borremos y comencemos de nuevo

el vuelo del ave migratoria

abandonemos el complejo, la culpa

y construyamos con la calma que aún queda 
el día nuevo.

Hay que seguir en este combate

nuevo y proletario

con el brazo extendido del campesino

en el reclamo exigido por el indígena

en las otras tradiciones femeninas con el pecho nuevo y ansioso del niño.

Hay que seguir en este combate negro y rebelde

manchado de sangre y luto

por los paseos de la historia

continuar andando sin dañar

el fruto que calmará el hambre de hoy y de mañana.

\title{
Esas expresiones de memoria son formas de protección, denuncia, señalamiento y
} reivindicación de la existencia propia.

\begin{abstract}
Entonces tú si necesitas una ayuda muy grande porque el ser humano tiende a rechazar el dolor, y a sacarlo de su mente entonces si a mí me duele algo yo no lo recuerdo siempre. A mí me duele el día que me corté entonces yo prefiero no acordarme de que me corté porque se me olvida. Entonces una desaparición duele y va a doler siempre y el ser humano tiende a preferir olvidar qué sucedió y ahí se pierde la memoria entonces yo creo que la memoria y el trabajo que se ha hecho con nosotras, de dolor si, pero recordarlo en su mejor forma, de buscar la forma de encontrar soluciones, de siempre esperar y siempre anhelar que está persona llegue, ha hecho que mi memoria siempre esté viva (Steffany, entrevista realizada el 20 de abril de 2013$)^{59}$.
\end{abstract}

\section{En el anterior apartado Steffany expresa que la memoria trabajada con ellas a través de dibujos, narraciones, canciones y fotografías, no tiene solo una dimensión de dolor sino una dimensión de reconstrucción, reparación y persistencia.}

Paralelo a eso también estaba trabajando la urna, que me demore tres años haciendo, porque allí estaba yo botando toda mi angustia y cuando uno tiene rabia el barro tiene rabia, y si uno tiene angustia el barro tiene angustia y no te responde. Hice tres urnas en barro y las tres se me explotaron, la urna era una

\footnotetext{
${ }^{59}$ A propósito de la necesidad de olvidar los recuerdos dolorosos, han existido un sinnúmero de investigaciones neurológicas sobre esa posibilidad y la ética que la moviliza. En el artículo sobre los avances del científico de la neurología Anders Sandberg (2010) en cuanto a la posibilidad de borrar los recuerdos negativos a través de substancias químicas se reúnen posiciones encontradas: Por un lado el científico argumenta los elementos positivos en cuanto el estrés pos traumático imposibilita la vida normal de la gente y porque la memoria puede ser productora también de recuerdos ficticios. En contra de estos argumentos Emily Holmes, neuropsicóloga clínica de la Universidad de Oxford plantea que a pesar de que el dolor está vinculado a los recuerdos traumáticos. Esto no significa que todas las personas que vivieron este tipo de experiencias constituyan un cuadro psiquiátrico. En segundo lugar si fuera posible borrar parte de los recuerdos, la necesidad de comprender el pasado engendraría vacíos que la memoria empezaría a llenar con recuerdos falsos, es decir que estos aparecen justamente por la necesidad de entender y de saber. En tercer lugar los recuerdos juegan un rol en la vida de las personas que aún tiene un valor incalculable. Yerushalmi (1985) repite la pregunta sobre la necesidad de memorias absolutas y la posibilidad del olvido ante lo cual él dice convertirse en guarda absoluto del pasado, prefiriendo el exceso que la falta. Frente al ejemplo de Funes el Memorioso solo queda decir que así como el mismo decidió proveerse de todo lo memorable no está en manos del científico definir que recuerdo puede ser útil o no para la persona que lo experimenta.
} 
manera de tratar de entender la exhumación de Luis Fernando. Lo de la tortura había sido algo muy duro para mí, pero encontrar los restos desintegrados, regados por todas partes, no encontrar los huesos largos, ni todo el cuerpo junto fue como si después de muerto él hubiera sido sometido a otra tortura. Era como pretender desaparecer a Luis Fernando del todo, le quitan el nombre, desaparecen el cuerpo y luego desintegran los huesos. En la urna entonces yo trato de digerir todo eso y de armarlo, como de volverlo a hacer nuevamente persona. La urna se convierte para mí como en un símbolo, en una manera de "aceptar", de no volverme a derrumbar, porque el panorama era otra vez aterrador y desconcertante. Sumado a eso pasan cuatro años y medio mas para identificarlo, sin contar todas las penurias a través de ese proceso, donde trataron de hacer más chanchullos, más trampas. Es que yo no entiendo como hacen y cómo hicimos para aguantar. Todo lo que es mi elaboración donde yo acepto todo este país, a Luis Fernando en pedacitos, se concentra en la urna, que es lo que me permite no enterrarme con todo eso (Hermana, Medellín, 1984: 311) ${ }^{60}$.

La documentación no ha sido la única herramienta para abordar el elemento más traumático. La plástica permitiendo que entre la nada o el cuerpo convertido en un objeto en donde el otro depositó toda su sevicia y los seres queridos se construyan nuevos objetos simbólicos que representen todo el vínculo extraviado y problematizado por la violencia y la muerte. Objetos para separar, ordenar, expresar y mostrar que el otro o la otra desaparecida es más que esa marca que los perpetradores quisieron dejar, que es todo lo otro, la familia, la historia, el ritual, el símbolo, el afecto.

Otro de los caminos para poner límite a la acción excesiva del perpetrador es el humor que se burla de la cara más aterradora del miedo y logra caricaturizarla.

Pero también otra cosa loca que hice fue que en el 2006, yo hago parte de una organización que se llama Huitaca que es una organización de mujeres jóvenes feministas populares de ciudad bolívar, entonces nosotras teníamos... estábamos en el proceso de formación de teatro cuando pasó lo de mi papá, obviamente yo me tuve que salir de eso mientras que buscaba a mi papi. Después de lo que pasó que se encontraron los restos y todo eso ellas me dijeron... ellas se afectaron mucho psicológicamente pues todo el mundo se afectó mucho con lo de mi papá y entonces me propusieron... ellos querían hacer algo que fuera útil y entonces me propusieron que hiciéramos una obra de teatro sobre mi papá. Y entonces hicimos una obra de teatro que se llama la denuncia que ponía en debate de una manera tragicómica cuando se encontraron los restos de mi papá. Ahí yo actuaba como dos personajes, uno era

\footnotetext{
${ }^{60}$ Testimonio de Adriana Lalinde, Extraído del libro Veinte años de historia y lucha. Asfaddes con todo el derecho (2003).
} 
la mamá de un desaparecido y luego actuaba como yo misma lo cual era un ejercicio de memoria permanente que después de un rato me di cuenta que no era bueno, que me estaba afectando emocionalmente y entonces decidí no seguir actuando en la obra, pero ese fue otro ejercicio.

- De este proceso de memoria de todo esto que has estado reconstruyendo tú decías que se había presentado algo muy difícil en la obra de teatro. Yo supongo que habías tenido que presentar de una manera reiterativa el momento del encuentro del cuerpo de tu papá. ¿Hay otros elementos que hayan sido problemáticos o que te hayan generado dificultad en la reconstrucción de la memoria?

- Esa obra era tragicómica y la gente se reía y me molestaba cuando la gente se reía (Diana, 21 de septiembre de 2011).

Caricaturizar al perpetrador puede reducir su omnipotencia y sirve para que se desactive y tome una dimensión de pasado en la sensibilidad de quien habita el miedo, o el sufrimiento, no para que se banalice la situación traumática, como ocurrió en el caso de la obra de teatro narrada por Diana, porque se puede concluir que la memoria que promueve la risa frente al dolor, o el ser querido pone en duda el sentimiento de solidaridad del público. Es decir, en primer lugar, la experiencia estética que produce risa busca generar placer, por lo tanto tiene que pensar cuál es el generador de placer; en segundo lugar, puede decir una verdad oculta y lo ideal es que quien crea o dirige sea consciente de esa verdad; en tercer lugar, el humor ubica tres lugares, el de alguien que señala una verdad risible, el de alguien que es "burlado" y el de alguien que siente placer por ello. Entonces hay que decidir qué va a ser burlado ${ }^{61}$.

El criterio para definir qué va a ser burlado se basa en la separación entre perpetrador y víctima, pero también tiene que ver con principios políticos, con el amor y con la vida, estos son justamente los que se enfrentan con más eficacia al dolor, hacen que la gente, a pesar del miedo y de la violencia no dejé atrás la búsqueda de sus familiares, no deje de buscar la verdad fáctica, la claridad sobre lo ocurrido, que no deje de limpiar su nombre para decir que no merecía la desaparición, ni la tortura, ni la muerte. La recuperación después de vivir una situación de tortura psicológica viene del derecho a seguir, a amar el recuerdo de la persona

\footnotetext{
${ }^{61}$ Freud estudia el chiste para reconocer en él una expresión del humor y una forma de la felicidad propia de la neurosis. Reconoce en él una expresión de gusto por su expresión estética pero también la expresión de una verdad alcanzada en el deseo de un placer que está reprimido. Estudiando específicamente el chiste que no busca sólo el placer de la risa sino una intención, demostrar algo, burlarse de algo, encuentra la necesidad de que participen tres: quien lo dice, quien es objeto del chiste y una tercera que disfruta la intención creadora. Gracias a este análisis Freud plantea que el chiste : "Hace posible la satisfacción de un instinto (el instinto libidinoso y hostil) en contra de un obstáculo que se le opone y extrae de este modo placer de una fuente a la que el tal obstáculo impide el acceso" (Freud, 1905).
} 
desaparecida, a amar sus proyectos, y a odiar también y encontrarle un camino al odio que no sea el de destruirse a sí mismo. 


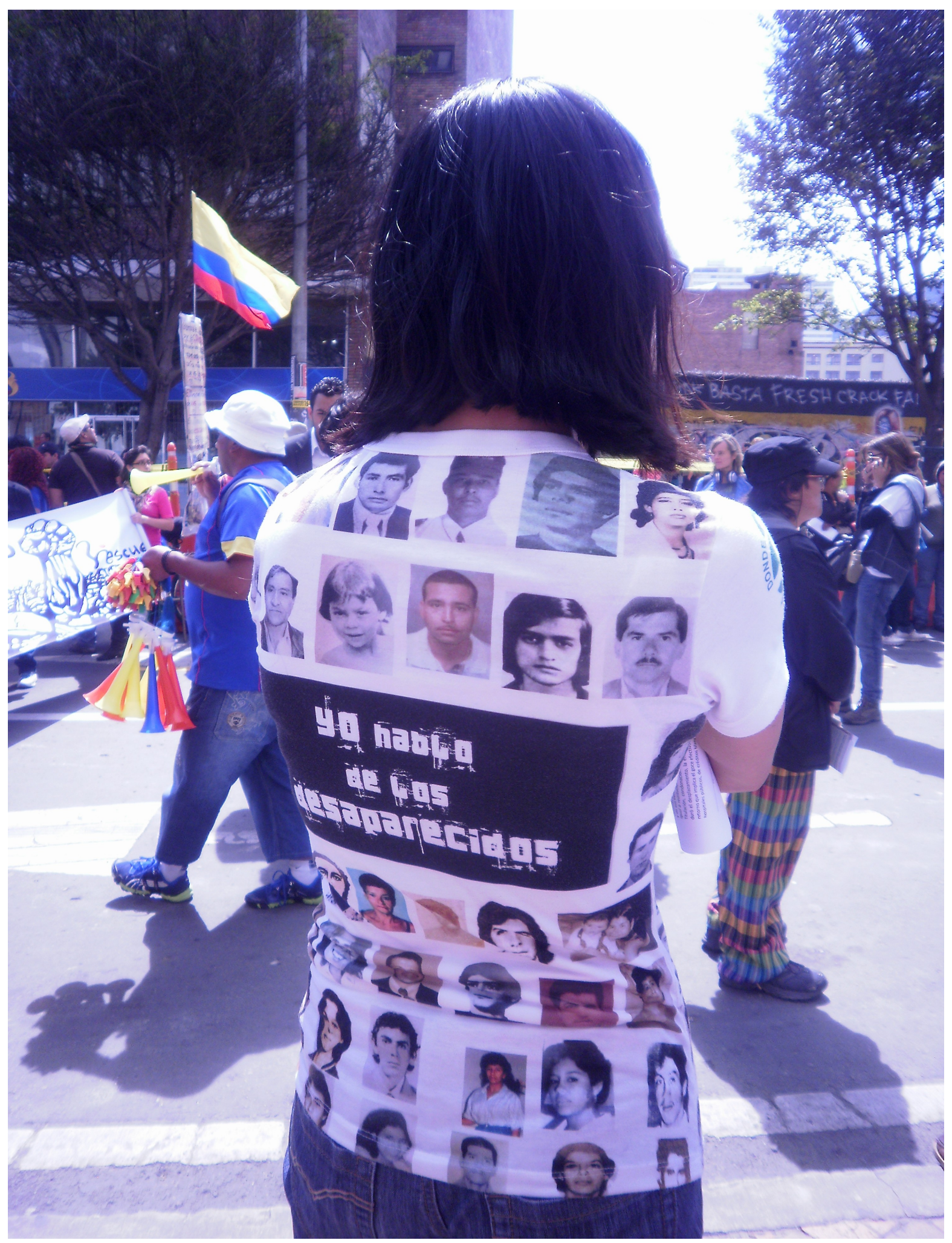

Esperanza. Marcha por la dignidad de las víctimas de crímenes de Estado. Bogotá. 2011.

Fotografía: Andrea Guatavita. 


\section{Cuarto Capítulo: Memoria familiar}

Cuando todo parecía oscuro y no encontraba nada tú emprendiste el camino y a todos nos llevaste como parte de tu cuerpo en tu mirada con horizonte.

Oh rosa púrpura invítanos a pasear mañana por paisajes claros donde vuelvan a estar los niños con sus mamás.

(Chico Bauti)

A diferencia del anterior apartado que se centraba en la memoria y el sufrimiento marcado en el cuerpo, este apartado habla de la memoria y el amor. Se trata de un recorrido por un tipo de memoria reivindicada por los familiares, para definir en dónde se reconstruye, qué recupera del pasado y quiénes lo nutren. Pero también, se trata de la transmisión transgeneracional y las experiencias que no se pudieron decir, que no se pueden recordar o que directamente se desconocen, porque quedaron fuera de la reconstrucción familiar y social de la memoria.

Hay que afrontarlo siempre con una clara visión del porqué esa persona es objeto de las atroces acciones. Pero lo que aprendimos en las detenciones, en las cárceles, en las guardadas en la Plaza de Toros... es que más allá del discurso político, allí prima el amor, sobre todo el amor de las madres, de los familiares, que los motiva a una búsqueda incansable, a no permitir que pase el tiempo, a enfrentar a los responsables (Vaca, entrevista 16 de marzo de 2013).

Para los y las familiares entrevistadas no hay nada que impida rescatar la memoria de una persona, a pesar de haber sido tachada y negada. Sobre todo si quienes la recuerdan son sus seres queridos. $Y$ no hay nada en esa memoria que sostenga que recordar a alguien amado sea una repetición dolorosa. Al contrario, es lo que queda para conservar y recuperar la humanidad que roba la violencia.

En un ejercicio espontáneo se vive se disfruta inclusive uno lo repite porque así se mitiga el dolor, se olvida el dolor, cuando yo hablo de Leonardo en ese momento estoy viviendo con él, lo traigo ahí, lo 
traigo con él y comparto con Esperanza y ella habla de Eduardo, el otro día nos estaba contando que le puso un cirio para celebrarle un cumpleaños y siempre que sentimos que está ahí estamos viviendo ese momento, que Eduardo está ahí, eso hace que nosotros olvidemos el dolor, es la única acción que valoramos. Qué hace que haya olvido: el dolor (...)

- Dentro de ese ejercicio algunos de esos especialistas han dicho que hay memorias que son dolorosas, yo por lo que he escuchado que hay un gusto en recordar entonces yo no sé si haya algo de eso.

- Lo que produce dolor no es vivir con ellos del recuerdo de los momentos eso nos produce deleite porque volvemos a compartir a estar con ellos ¿qué nos causa dolor? El momento en que no están en que se lo llevaron el hecho de la ausencia no es la vivencia con ellos. Pero es más cómodo decir que es dolor, inclusive ha habido momentos en que dicen: "Oiga pero es que ustedes deberían dejar de... ay que jartera volverlas a oír, es que siempre hablan de lo mismo y dolor". Pero si se ponen a escuchar un testimonio se podrían dar cuenta - y eso va también para los psicólogos y psicólogas - porque no se tiene en cuenta que cuando yo estoy hablando de ellos cambio, yo me divierto cuando estoy hablando que: "A Leonardo le encantaba comerse la pega, o que le gustaba comerse la nata de la leche". Y que fueron momentos que nunca se olvidarán y estarán en mi memoria, en mi pensamiento, en mi recuerdo (Gloria , entrevista realizada el 22 de septiembre de 2011).

Recodar se constituye, con frecuencia, en un momento de dicha, de orgullo o de sorpresa. Lo doloroso, dicen algunos familiares, es la ausencia. La memoria surge de la posibilidad de hablar y soportar el vacío, no sólo gracias a las condiciones o posibilidades de comunicación familiar, sino gracias a la superación de los pactos de silencio o los enunciados que marcan la relación entre las personas y su pasado.

Para todos estos expertos pues no es importante. Aquí, ayer y hoy y hace ya un buen tiempo cuando la memoria se volvió un tema de importancia, el tema de actualidad, la memoria se volvió conceptos. Ayer y hoy hemos oído tantos conceptos sobre memoria pero nadie habla de este ejercicio espontáneo simple como una manera de rescatarlos a ellos del olvido. Entonces qué es la memoria, la memoria para los familiares es mantenerlos vivos y buscar que esta sociedad los conozca, los reconozca y así mismo los respete y los valore porque si yo valoro un desaparecido como ese hijo tierno, amoroso, desorganizado en la habitación, muchas de las mamás de esta sociedad indiferente van a encontrar relación de similitud con su hijo y van a sentir: "Oiga pero si a mi hijo le pasara eso yo no podría sobrevivir o yo qué haría". Eso es lo que queremos. Que ellos vean que estos seres invisibles que queremos que sean visibles sientan que están en cada uno de los que si pueden hablar, de los que si pueden seguir viviendo, seguir sus proyectos, sus sueños, sus luchas y que esta sociedad finalmente se comprometa a que no se repita (Gloria, entrevista realizada el 22 de septiembre de 2011). 
Es justamente esta memoria una de las mas poderosas en términos de generar solidaridad e identidad ${ }^{62}$ porque dota a los desaparecidos y las desaparecidas de toda la humanidad de la que fueron despojadas, gracias a que fueron llamadas supuestas guerrilleras, colaboradoras y esa palabra enuncia a un otro susceptible a ser eliminado sin reparos. $\mathrm{O}$ su existencia o desaparición nunca fue reconocida.

Puede ser que los familiares hayan hecho mucho trabajo para decir que los desaparecidos no eran guerrilleros pero para quienes hayan sido guerrilleros tampoco es que sea... digamos que no hayan sido seres humanos. Creo que son cosas que hay que tener en cuenta algunas son las luchas políticas y otras las.... hay un autor colombiano que es Estanislao Zuleta que decía que: "Ninguna idea merece un cadáver". Pero ahí pareciera que sí que hay ideas que deben imponerse sobre los muertos. Es más o menos la lógica de lo que pasa en Colombia (Chico Bauti, entrevista realizada en Septiembre de 2011).

El amor fue el vehículo primario para la adopción de una identidad y un nombre ${ }^{63}$. A pesar de que en esas experiencias de violencia extrema se les impida el nombre y se declaren inexistentes o no identificados, porque se decía que estaban cometiendo un acto delictivo. La familia cumple un papel fundamental: Buscar y confirmar la existencia y la huella de esa existencia a través de los hijos y de las huellas en los hijos. Restituir el nombre, darle identidad al cuerpo, recomponer las distintas dimensiones de su humanidad demostrando a la sociedad que esos otros merecen ser llorados, que tiene parientes porque son seres humanos, sociales, familiares y políticos ${ }^{64}$.

\footnotetext{
${ }^{62}$ Para Cintras (2009) La identidad es un fenómeno que guarda relación con las vivencias del joven en relación a sí mismo y en relación con los otros, vivido en forma intrapersonal e inconsciente; es un proceso dialéctico entre sujeto y sociedad, que implica la estructuración intrapsíquica y el espejo de las opiniones de los pares. Para Kordon (2009) Hay realidades socio históricas que crean condiciones que favorecen o perjudican ese proceso. Aparece la necesidad de salir en busca de información y esta se convierte en una etapa de conmoción transitada de forma solitaria o con el acompañamiento de otros.

${ }^{63}$ En el contacto de quien cuida al niño devolviéndole con su mirada la imagen de unidad. Según Bernard (1991)en un proceso de más tiempo que ocurre gracias a la familia o "grupo primario" que permite la adquisición de identidad en el orden generacional y en la identidad sexual, es decir en el hacer parte de una familia gracias a todo lo que está le transmite y a su apoyo en el cuerpo biológico. Este grupo determina ciertos rasgos de identidad a partir de la inscripción histórico social y es el mediador del contrato social que garantiza a una persona el reconocimiento como miembro de una cultura (Lagos y Edelman,1995).

${ }^{64}$ Este acto es la restitución de los ejes fundamentales de constitución de los seres humanos, la inscripción en el cuerpo y en un grupo social, el vínculo."No tenemos en absoluto la opción de no ser puestos juntos en el agrupamiento, como no nos es dada la opción de tener o no un cuerpo: es así como venimos al mundo, por el cuerpo y por el grupo, y el mundo es cuerpo y grupo" (Käes, 1993).
} 
El trabajo de investigación, de búsqueda, de construcción del padre o madre desaparecidos, constituye una necesidad identificatoria. Es un trabajo intersubjetivo de construcción de memoria, que ocupa centralmente el interés del sujeto en ese período de la vida (Kordon y Edelman, 2007:60).

Todo esto por el vínculo de amor establecido pero también por lo que implica para hijos e hijas el pasado de sus padres, en cuanto a la propia construcción de la identidad.

Es muy difícil porque me acordaba mucho de mi mamá, qué quería -Estos días estuve hablando de esoMi mamá quería que me fuera estudiar ${ }^{3}$ a Cuba medicina. Entre el tipo de educación que recibí en la secundaria y lo que ella personalmente me hubiera podido dar hay una distancia muy fuerte porque mi madre era una lectora consumada y sabía muchísimo de muchos temas y la educación que tuve en la secundaria fue muy pobre. Pensando más en sobrevivir, en que no me pasara nada, en conseguir dinero. (...) yo empiezo a prepararme para meterme en la nacional a estudiar entonces era el reto (Chico Bauti, entrevista realizada en Septiembre de 2011).

Y por todos los elementos que están incluidos en el recuerdo y que hacen parte de la cotidianidad. Situaciones y características que superan las condiciones de militancia y vuelven carne un recuerdo que en ciertos marcos de reivindicación se convierten en puro discurso político.

\subsection{Organizaciones de familias de personas desaparecidas de manera forzosa}

La Asociación de Familiares de Detenidos Desaparecidos (ASFADDES) nació gracias al trabajo de los familiares de las siguientes personas desaparecidas que constituyeron el denominado colectivo 82 . 


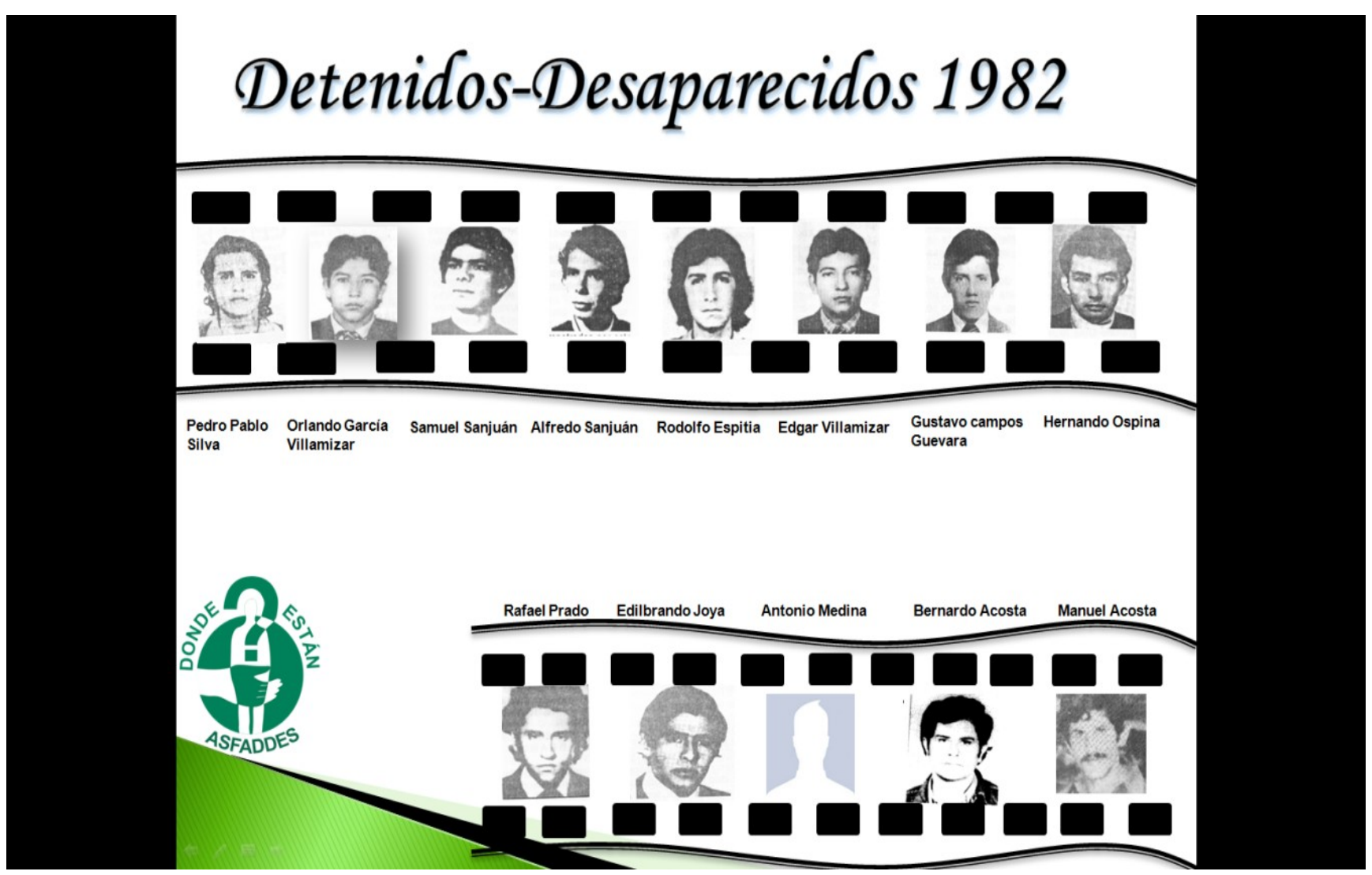

Fotografía: Archivo de Asfaddes. Leonardo Gómez, de diecinueve años de edad, era activista estudiantil del colegio Bravo Páez, había sido compañero de dos de los doce estudiantes desaparecidos en 1982. Por tal razón apoyaba a Asfaddes en sus marchas pacíficas y actividades denuncia. Fue desaparecido en noviembre de 1983 cuando salió de su casa para comprar materiales para su último examen de bachillerato. No regresó (Asfaddes, 2003: 326).

Gloria es hermana del desaparecido Leonardo Gómez. Ella es la coordinadora a nivel nacional de la Asociación de Familiares de Detenidos Desaparecidos- Asfaddes desde hace 27 años y sobre el sentido de la asociación comenta:

Nos hemos constituido en apoyo colectivo, creando un espacio para reconocernos y ayudar a otros en la denuncia, también para fortalecernos en la reconstrucción de la memoria como única manera de dignificar y rescatar el buen nombre de los detenidos desaparecidos y en exigencia por la erradicación de esta aberrante práctica (...) como organización contribuimos a superar el miedo y a enfrentar de una manera consciente la desaparición forzada de nuestros seres queridos (Gloria, 2007:16). 
Otra organización con idénticas características es la Fundación para los Derechos Humanos Nidia Erika Bautista - FNEB, fundada en honor a Nidia Erika Bautista, militante del M-19 desaparecida por miembros del estado. Fue gestada por Yaneth Bautista, Erick Arellana y otros familiares, durante el exilio obligado por la lucha contra la desaparición forzada.

Familiares de Desaparecidos Forzadamente por el Apoyo Mutuo - Familiares Colombia fundada en el 2005, suma a familiares con distintas filiaciones de personas desaparecidas en un sin número de episodios ocurridos bajo responsabilidad del estado colombiano. Esta organización es representada por José Daniel Álvarez y Gladys López.

José Daniel es hijo del desaparecido José del Carmen Álvarez Blanco y sobrino de Cristóbal Arroyo Blanco. Su desaparición ocurrió durante la "Masacre de Pueblo Bello" realizada, como su nombre lo indica, en el corregimiento de Pueblo Bello en la provincia de Córdoba (Región de la Costa Caribe de Colombia, subregión del Urabá) $)^{65}$, entre el 14 y 15 de enero de 1990.

${ }^{65}$ La Masacre de Pueblo Bello expresa la complejidad del contexto nacional y esto es evidente en el peritaje de Alfredo Molano presentado como prueba ante la Corte Interamericana de Derechos Humanos en el caso Pueblo Bello VS Colombia: Pueblo Bello es un caserío situado al noroeste de Turbo, en el Urabá antioqueño, y es frontera entre los departamentos de Antioquia y Córdoba. Gracias a la biodiversidad de la región, la selva ha sido entresacada y derribada intensamente lo cual ha dado lugar a enfrentamientos entre la población nativa y las empresas aserradoras. Los aserradores están protegidos por los paramilitares, mientras los campesinos son apoyados por las guerrillas. La explotación maderera se extendió hacia el sur. Dicha explotación ha abierto el camino a la colonización campesina y facilita la concentración de predios, los cuales son grandes ganaderías de propietarios antioqueños, respaldadas por el paramilitarismo.

La apertura de la carretera valorizó extraordinariamente las tierras. Los pueblos crecieron y se fundaron otros centros urbanos. A partir de los años sesenta la United Fruit Company, bajo su nueva sigla, Frutera Sevilla, apareció en Turbo y en pocos años, la vía entre Chigorodó y Turbo se convirtió en el muy rentable Eje Bananero. Los ganaderos que habían adquirido tierras en los años cincuenta se vieron en la alternativa de convertirse en empresarios agrícolas o migrar con sus reses a zonas limítrofes con el Eje. Las regiones periféricas al norte y al este de la carretera al mar se "ganaderizaron", generando conflictos de tierras y nuevos desplazamientos. El crecimiento de San Pedro de Urabá, el Totumo, Pueblo Bello y Valencia fue uno de los efectos demográficos más tangibles del período 1960-1990.

Las FARC y un nuevo partido comunista "marxista-leninista" ocuparon progresivamente las serranías de Abibe, San Jerónimo y Ayapel, y a sus filas ingresaron muchos de los campesinos que habían sido perseguidos por la Fuerza Pública en su intento por llevar a cabo la frustrada reforma agraria. Las demandas populares por servicios públicos, vivienda, salud, educación y tierra fueron respaldadas, y en cierta medida, envalentonadas por la aparición y fortalecimiento de los frentes militares de las FARC y del EPL.

En 1965 el gobierno nacional autorizó a las Fuerzas Militares por decreto a armar fuerzas civiles. A medida que el conflicto social era canalizado por la insurgencia guerrillera se fortalecía la tendencia a usar población civil para respaldar las acciones militares del Estado. Dado que la guerrilla se apoyaba también en la población civil, ésta se constituyó en uno de los objetivos centrales de la confrontación.

Con el desarrollo del narcotráfico se introdujo otro modelo: el paramilitarismo crudo asesorado por las fuerzas de inteligencia israelitas. Del Magdalena Medio la nueva versión de seguridad pasó con Fidel Castaño a las regiones de Urabá y Alto Sinú. Fidel Castaño se convirtió en un hacendado en el occidente de Córdoba, en el municipio de Valencia donde tenía su finca "Las Tangas". Esta región ganadera era una zona de gran importancia estratégica para las guerrillas.

En Turbo la actividad de la compañía Frutera de Sevilla así como la de los sindicatos, echaron raíces. En los años 80 se formaron fuerzas sociales y políticas que finalmente se enfrentarían a muerte en la década siguiente. Los elementos que 
Junto con los familiares de José Daniel las siguientes personas también fueron desaparecidas a manos de los paramilitares: Fermín Agresott Romero, Víctor Argel Hernández, Genor Arrieta Lora, Diómedes Barrera Orozco, Urías Barrera Orozco, Jorge Fermín Calle Hernández, Jorge Arturo Castro Galindo, Benito Genaro Calderón Ramos, Juan Miguel Cruz (o Cruz Ruiz), Ariel Dullis Díaz Delgado, Camilo Antonio Durango Moreno, César Augusto Espinoza Pulgarín, Wilson Uberto Fuentes Miramón, Andrés Manuel Flórez Altamiranda, Santiago Manuel González López, Carmelo Manuel Guerra Pestana, Miguel Ángel Gutiérrez Arrieta, Lucio Miguel Úrzola Sotelo, Ángel Benito Jiménez Julio, Miguel Ángel López Cuadro, Mario Melo Palacio, Carlos Antonio Melo Uribe, Juan Bautista Meza Salgado, Pedro Antonio Mercado Montes, Manuel de Jesús Montes Martínez, José Encarnación Barrera Orozco, Luis Carlos Ricardo Pérez, Miguel Antonio Pérez Ramos, Raúl Antonio Pérez Martínez, Benito José Pérez Pedroza, Elides Manuel Ricardo Pérez, José Manuel Petro Hernández, Luis Miguel Salgado Berrío, Célimo Arcadio Hurtado, Jesús Humberto Barbosa Vega (ColDH, 2006).

Gladys López es hija de Faustino López, dirigente agrario del Partido Comunista durante 40 años. Él fue desaparecido el 5 de septiembre de 1984 en el municipio de Puerto Boyacá, región del Magdalena Medio. Este hecho fue ejecutado por miembros del MAS y del DAS. En reacción a la búsqueda de verdad y justicia activada por Gladys su hijo León fue asesinado en el año 2000 (El Colombiano, 2007).

La siguiente organización es La Asociación Caminos de Esperanza Madres de la Candelaria, originada en el departamento de Antioquia por la unión de familiares de personas desaparecidas y secuestradas en el marco del conflicto armado. Madres de la Candelaria

contribuyen a entender el conflicto son las deplorables condiciones laborales de los bananeros; la represión de las invasiones en Córdoba y Sucre, que fomentó la colonización campesina de Abibe y la invasión de tierras dedicadas tanto a la ganadería extensiva como a las impulsadas por la economía empresarial; y la elección popular de alcaldes que amenazó a los partidos tradicionales con quitarles su poder tradicional a favor de nuevas fuerzas. La agitación social y política, la declaración de paros cívicos y laborales y la fuerza militar alcanzada en las guerrillas tanto de las FARC como del ELP fueron la justificación para que en 1988 el gobierno creara la Brigada XI en Montería, la Brigada Móvil Número Uno y la Jefatura Militar de Urabá.

Entre 1988 y 1990 hubo más de 20 masacres de campesinos y sindicalistas cometidas por los paramilitares con no menos de 200 muertos. Fidel Castaño llevó a cabo desde "Las Tangas", con la tolerancia y colaboración de la Fuerza Pública, las masacres de Currulao, Buenavista, Córdoba, Punta Coquitos, Turbo, Canalete, Córdoba, Pueblo Bello, Valencia, Apartadó y Tierralta. En abril de 1990 en "Las Tangas" aparecieron seis cadáveres de los presuntos desaparecidos en Pueblo Bello (Molano, 2006) Extraído de la Sentencia proferida por la Corte Interamericana de Derechos Humanos. 
Línea Fundadora, organización de mujeres creada en 1998 para reclamar la libertad de sus hijos secuestrados o desaparecidos también en el marco del conflicto armado ${ }^{66}$.

Junto con estas organizaciones a nivel nacional, hay varias de carácter regional como el grupo de "La Vereda la Esperanza" conformado por un grupo campesino de la zona rural del municipio Carmen del Viboral, provincia de Antioquia. Hombres, mujeres, ancianos, niñas y niños dedicados a las labores del campo y que son familiares de los siguientes desaparecidos durante una incursión de grupos militares y paramilitares entre junio y diciembre de 1996: Aníbal De Jesús Castaño Gallego, Oscar Hemel Zuluaga Marulanda, Juan Crisostomo Cardona Quintero, Miguel Ancizar Cardona Quintero y a otro joven sin identificar. "Fredy" y su esposa con un hijo de dos meses de nacido: Andrés Suárez Cordero. Elíseo Gallego, María Engracia Hernández, Juan Carlos Gallego Hernández, Irene De Jesús Gallego Quintero, Juan Carlos Gallego Hernández, Jaime Alonso Mejía Quintero, Javier Giraldo Giraldo, Hernando Castaño Castaño, Octavio De Jesús Gallego Hernández, Orlando De Jesús Muñoz Castaño, Hernando Castaño y Octavio Gallego Hernández, Leonidas Cardona Giraldo, Andrés Antonio Gallego Castaño (Corporación Jurídica Libertad, 2012).

Familiares del "16 de mayo" de 1998 es un grupo conformado para denunciar la desaparición de personas en la ciudad de Barrancabermeja. Este conjunto de desapariciones tenia por objeto crear el terror y desarticular el movimiento obrero de la empresa petrolera y su sindicato denominado Unión Sindical Obrera (USO) ${ }^{67}$. Los desaparecidos fueron: Orlando Martínez, Juan De Jesús Valdivieso, Riky Nelson García, Jaime Yesid Peña, José Octavio Osorio, Wilfrido Pérez Serna, Wilson Pacheco, José Milton Cañas, Diego Fernando Ochoa, Giovanny Herrera, Carlos A. Alaixt Prada, Oswaldo Enrique Vásquez, Ender González Baena, Libardo Londoño, Roberto Wells Gordillo, Jose Reinel Campo A., Fernando Ardila

\footnotetext{
${ }^{66}$ Las dos líneas de las Madres de la Candelaria, a diferencia de las otras organizaciones mencionadas no se centran en la reivindicación de las víctimas de desaparición forzada como víctimas de crímenes de estado. Suman en sus organizaciones a familiares de personas secuestradas y desaparecidas relacionándolas independientemente del perpetrador, por ello ubican su trabajo en el marco del conflicto armado y no señala específicamente la responsabilidad del estado.

${ }^{67}$ Acción desarrollada por las Autodefensas Unidas de Santander y sur del Cesar bajo el título de acción contra insurgente. Por estos hechos fueron denunciados el militar Rodrigo Pérez y como autor de todo el hecho al paramilitar conocido como el Panadero que involucró a otros catorce militares. En la investigación realizada por la Organización No Gubernamental Corporación Colectivo de Abogados José Alvear Restrepo (CCAJAR) se identificó la participación de Corporativo de Seguridad Física de Ecopetrol. El caso se encuentra actualmente en la Comisión Interamericana de Derechos Humanos y los demandantes viven bajo la amenaza por la continuación de las estructuras paramilitares en el país.
} 
Landinez, Daniel Campos Pérez, Gary De Jesus Pinedo, Oscar Leonel Barrera, Melquisedec Salamanca, Carlos E. Escobar, Juan Carlos Rodriguez y Luis Hernando Suarez y la desaparecida María Alejandra Ochoa (Familiares de desaparecidos del 16 de mayo, 1998).

La Corporación Reiniciar es una organización de derechos humanos que vincula a sobrevivientes del genocidio contra la Unión Patriótica, ejecutado a través de amenazas, torturas, desapariciones forzadas, asesinatos, exilio y desplazamiento forzado contra al menos dos mil de sus integrantes ${ }^{68}$. El Movimiento de Víctimas de Crímenes de Estado vincula a muchas de estas y otras organizaciones a nivel nacional.

Estos grupos se asientan en la exigencia por el cumplimiento de derechos internacionales a Verdad, Justicia, y Memoria (Chaparro, 2007:21), en la defensa a los derechos humanos, la denuncia y otras consignas que son generalizadas entre los familiares. "La lucha por la justicia se convierte en el objetivo fundamental de los familiares de los desaparecidos, tomando conciencia de la importancia que tienen los casos, en la lucha contra la impunidad en Colombia" (Cuesta, 2007:18); y fuera de las acciones por la memoria tienen estrategias de incidencia política en distintos niveles.

En esas acciones se involucran personas de distintas edades y vínculos familiares, laborales, ideológicos con las personas desaparecidas. Su presencia nos indica que aquellos "dolientes" o solidarios con la causa de preguntar por el paradero del desaparecido, la razón de su desaparición o los autores del hecho. Los sujetos que realizan estas acciones parecen ser heterogéneos, defensores de DDHH, miembros de organizaciones, familiares o artistas. Parte de las acciones que las familiares, o grupos sociales realizan se inscriben en el campo

\footnotetext{
${ }^{68}$ A pesar de que el concepto de genocidio político no fue reconocido en la noción general de este crimen después del genocidio nazi, los sobrevivientes de la Unión Patriótica lograron el reconocimiento de este hecho a través de la ley 589 de 2000, que incluye al genocidio político como delito en el código penal colombiano. El caso de la Unión Patriótica fue aceptado por la Comisión Interamericana de Derechos Humanos tal como lo explica Iván Cepeda, sintetizando la reducción de militantes del movimiento hasta llegar a la desaparición de su personería jurídica, la pérdida del poder electoral que logró después de su nacimiento y las fases en las que se desarrolló el genocidio: Debilitamiento de las estructuras organizativas, golpe de gracia y naturalización, y fase de exterminio que se extiende hasta ahora y en la cual se puede incluir la desaparición de Guillermo Rivera Fúquene (Cepeda, 2006). Recientemente entraron y fueron aceptados en la fiscalía de la Nación los archivos de ataques contra miembros de la UP como un sólo caso colectivo que corresponde por sus características a un genocidio político (Caracol, 2013), después de que fuera aceptado el año pasado por la magistratura de justicia y paz (verdad abierta, 2012).
} 
de la memoria y se concretan en galerías fotográficas, conmemoraciones, escraches, canciones, dibujos, entre otros. Ahora bien, estas experiencias pueden estar vinculadas con varios elementos: la denuncia, la generación de justicia social, simbólica, la dignificación de la imagen de los desaparecidos, la recuperación de sus vínculos sociales, la reivindicación de su humanidad.

-¿Cuáles matices?

- Yo a él lo leía como un persona muy política, yo lo admiraba cuando lo oía hablar en público pero esa era la visión que yo tenia de él como líder, de orador cuando yo lo veía. Pero escuchar a las compañeras decir: "Es que yo no perdí mi trabajo por él, él estaba pendiente de los compañeros y las compañeras a los que iban a despedir por razones injustas y ahí se metía a hablar". Y: "Él era tan afectuoso". Entonces como que yo no me lo imaginaba así con la gente, esos matices, cuando ya hablan de cosas muy personales, además porque mi papá era afectivo con nosotras pero no era un hombre súper cariñoso entonces yo digo: "Si él con sus hijas tenía un trato no tan .. él era si como en lo afectivo, pero no era de meloseria, abrazo, tenia otro tipo de detalles para expresar el amor, el afecto". Cuando me hablan las compañeras yo si no me lo imaginaba así con la gente, si no me lo imaginaba afectuoso con uno y obviamente no era así del abrazo con la gente pero si esa preocupación por la gente, verlo así como tan metido con los problemas de los demás (Shaira, entrevista realizada el 26 de julio de 2011).

\subsection{Testimonios y conmemoraciones}

Entre las prácticas más reconocidas de los familiares hay dos que han sido ampliamente debatidas: Ios testimonios y las conmemoraciones. Estos debates han estado relacionados con la necesidad o el valor que le dan a exponer la experiencia vivida, frente a la valoración de esta expresión en tanto "herramienta de memoria" y su uso político: la confirmación de la ejecución de la desaparición forzada en un contexto de orden "constitucional", la posibilidad de identificarse y organizarse, la recuperación de las banderas políticas de quien fue desaparecido. En primer lugar, el testimonio es un relato que puede extenderse a distintas situaciones de la vida relacionada con la víctima. La reconstrucción de su historia, de su proyecto, de la relación con sus familiares y el hecho del que fue víctima. Es decir que no se define por la exposición de un relato de violencia. 
Yo me sentía con la capacidad de poder hablar con los persona y de ir a hacerles un apoyo y contarles mi experiencia y así empezó mi camino con las víctimas y ayudándoles y ayudándome ellas a mi a entender el por qué de esta situación (Pilar, entrevista realizada el 13 de abril de 2013).

Puede implicar también la posibilidad de compartir la experiencia de dolor y los caminos escogidos para la lucha por los distintos ideales que tenga cada familiar y el apoyo psicológico que puede brindar a sus semejantes, al mismo tiempo que la oportunidad de identificarse y organizarse y construir una propuesta distinta a la de identificarse con la víctima directa. Con todas las consecuencias que tiene esto a nivel psicológico y a nivel social. Una de estas es la mencionada durante el análisis sobre la tortura, se trata de poder tomar distancia con el cuerpo y el ser que vivió la violencia física y los efectos que esa violencia genera.

Yo no sé, para mí es él porque él es el que se ha perdido todas las cosas en la vida. Nosotras seguimos nuestra vida y yo he sido muy feliz siendo abuela. Yo he sido sumamente feliz estando con mis hijas. Creo que él ha sido la víctima fue a él al que le pasó todo no a nosotros. Todo lo que está pasando lo que yo hago lo hago porque él se merece que yo lo busqué, que yo participe en las cosas y eso me ha dado la oportunidad de conocer cosas maravillosas (...) (Pilar, entrevista realizada el 13 de abril de 2013).

La posibilidad de separarse y señalar a la víctima directa y los vejámenes sufridos, está atravesada por el lazo filial y las identidades, pero también por las posibilidades de recuperación y de seguir la vida más allá del hecho violento. Podría parecer que esa posibilidad surge de la recuperación psicológica pero al parecer es un cículo que se alimenta. Si las personas tienen la posibilidad de vincularse con el resto de sus familiares y pueden llevar adelante sus proyectos en términos objetivos, la conciencia de la distancia entre el sí mismo y el ausente es mucho más clara. 
Por otro lado, el testimonio o la presencia de los familiares, especialmente de los hijos opera para muchos como una señal o un recuerdo del otro desaparecido que sirve como sostén de sus esperanzas. Pero también como herramienta de lucha para los familiares en cuanto que el marco social cambia su versión de lo ocurrido y mantiene la negación, la usa o la justifica.

Ha sido siempre la misma nosotros siempre nos hemos mantenido en lo mismo siempre hemos querido que la gente sepa quieres eran nuestros familiares, que importancia tenian. Y la del estado ha cambiado, a veces son guerrilleros, a veces son víctimas, a veces son malos, a veces son buenos, ha sido algo temporal me refiero a como le convenga al gobierno es la memoria que ellos quieren construir (...) en un ejercicio de trabajo que hizo la comisión de la verdad nuestros familiares comenzaron a aparecer como victimas, trabajadores de la cafeteria. Héctor Jaime Beltrán papá de cuatro hijas, empezó a hacerse memoria de los seres humanos que son. Cuando Plazas Vega salió condenado ellos pasaron a ser guerrilleros, desaparecidos que no son nadie o que son colaboradores de la guerrilla, esa es la memoria que ellos reproducen dependiendo como les parezca. Cuando sale el presidente y se conmemoran los veinti cinco años de nuestros familiares eran víctimas que merecían estar sentados con su familia y el presidente nos da un abrazo y una llama que representa la verdad y la respuesta de los desparecidos. Pero cuando se condena a Arias Cabrales entonces ya eramos los malos que no nos mereciamos perdón sino que nosotros le pidieramos perdón al ejercito por lo que pasaba y era un yo yo completo (Pilar, entrevista realizada el 13 de abril de 2013).

Ahora bien, el uso no es un tema de debate exclusivo para el estado. También dentro del movimiento de derechos humanos, en donde la experiencia violenta no pierde su carácter político comienza a tener un espacio privilegiado en cuanto a otras acciones de las familias. Privilegiado por su valor jurídico, por su condición de prueba frente a la negación permanente de la desaparición forzada. Pero cuestionado como elemento único en la reconstrucción de la memoria ${ }^{69}$ y conflictivo en algunas ocasiones con las reflexiones que están adelantando las

69 Todos los escenarios de reconstrucción de la memoria reciente han reconocido como herramienta fundamental la recopilación de los testimonios de testigos y sobrevivientes. Crenzel (2008) por ejemplo, afirma que estos dieron la posibilidad de construir una verdad general sobre las desapariciones en Argentina, para lo cual se necesitaba una amplia base de denuncias. En el genocidio Nazi los testimonios se convirtieron en expresión de resistencia y elaboración después del silencio, Los dueños de la memoria, aquellos que por haber tenido una experiencia directa pueden hablar con legitimidad de un hecho. El dolor y las marcas en ocasiones impiden que el dolor sea transmisible o elaborable. Las huellas traumáticas pueden también ser no escuchadas o negadas por decisión política o de un cuerpo social que las transmita. Esto puede glorificar o estigmatizar a las víctimas. En estos casos la disociación entre víctimas y sociedad se agudiza. En el caso de Elizabeth Jelin se expresan cuestionamientos muy profundos sobre la relación entre el testimonio y la constitución de 
familias. En ese proceso para algunos miembros de las organizaciones, participaron no solo entidades del estado sino también medios de comunicación, organizaciones o personas que quisieron ahondar en la condición de trauma de los familiares y priorizaron el relato del dolor por encima de sus propias elaboraciones sobre todos estos temas: el por qué, la política, la memoria, entre otros.

Yo estoy mamada de que me llamen para que hable del caso de mi papá osea siempre me invitan como miembro del movimiento pero siempre es para que hable como hija de Guillermo frente al caso de mi papá y lo hacen organizaciones amigas como para mostrar a organizaciones de derechos humanos de afuera: "Mire si hay familiares de víctimas recientes y mire por todo lo que están pasando y para reafirmar todo eso" (Shaira, entrevista realizada el 26 de julio de 2013).

Sin embargo, el testimonio no es solo una figura jurídica es un acto de reivindicación que surge por el marco de recolección de experiencias y de la necesidad de ser escuchado sobre la experiencia vivida y encontrar oídos atentos para validar la experiencia y reconocer su realidad. En términos de Dominick LaCapra en situaciones de violencia extrema "el testimonio es una condición necesaria de la acción y en ciertos casos es todo lo que cabe esperar de alguien que ha pasado por una experiencia límite" (LaCapra, 1998:25). Para algunos de los entrevistados el testimonio es necesario y es válido en tanto la experiencia personal permite la identificación con el otro víctimizado como un ser humano por el que se puede sentir dolor y porque es su mecanismo para dar a conocer lo que ha ocurrido.

Entonces yo le decía estoy mamada de eso pero cuando tenía la posibilidad en otros lugares y hablar desde otro tipo de lenguaje volvía y caía en lo mismo y yo decía: "Pero es que es muy complicado". Me

géneros de reconstrucción de la memoria y "actores privilegiados" y con autoridad para hablar, con el poder simbólico para decidir la forma y expresión de la memoria. Ante lo cual pregunta si hay memoriales adecuados, quiénes encarnan la memoria verdadera, y si pueden otros participar en la construcción de la memoria colectiva. Puesto que sin la participación del estado, el sufrimiento personal determina la legitimidad y la verdad. Si la autoridad simbólica se desliza a aquellos que sufrieron la verdad y la memoria se monopolizan. Esto lleva al aislamiento y la ritualización del dolor. Y no permite la re interpretación y resignificación del sentido de las experiencias transmitidas por parte de otros. Los dos peligros que se avecinan son el olvido y el vacío institucional y la repetición ritualizada del horror. Ante ello solo quiero resaltar en primer lugar la condición heterogénea de la memoria, la falsedad de generalizar la memoria de los familiares, sobrevivientes o testigos como testimoniantes del horror. Y las dificultades de esa generalización olvidando que se construye en un contexto como el de Argentina invadido por un proceso de institucionalización de la memoria que permite a los académicos, y en algunos casos les exime mostrarse descreídos ante la reconstrucción de la memoria, sirviendo en su análisis homogeneizante. En contra de esto es necesario decir, que no todos los testimonios son de horror, que los que lo son, son también expresiones políticas de poner limite y correrse del lugar de vulnerado y que la memoria como bien lo planteó Jelin en otro momento, no existe como única. 
invitaron a hablar en conversatorios así en universidades y como que arrancaba hablando de otra forma y siempre caía ahí, en volver a hablar desde ahí, desde lo que pasó, e inclusive en las entrevistas eso pasa pero entonces es como que replantearse todas esas cosas, replantearse el lenguaje y la forma de hablar de las cosas (Shaira, entrevista realizada el 26 de julio de 2011).

El replanteamiento sobre la construcción del testimonio es múltiple, requiere en primer lugar, la comprensión de que surge con una necesidad de escucha y reconocimiento de una experiencia. Que surge como un intento de elaboración de esa experiencia y la pérdida que conlleva, es decir, como parte de un duelo o del proceso de elaboración para asimilar la pérdida de un ser querido o de un ideal de manera que esa pérdida sea tolerable a través de la aceptación de su ausencia real, la valoración del objeto perdido y su ubicación en un lugar del recuerdo.

El examen de la realidad ha mostrado que el objeto amado no existe ya y demanda que la libido abandone todas sus ligaduras con el mismo. Contra esta demanda surge una oposición naturalísima, pues sabemos que el hombre no abandona gustoso ninguna de las posiciones de su libido, aun cuando les haya encontrado ya una sustitución. (...) Lo normal es que el respeto a la realidad obtenga la victoria. Pero su mandato no puede ser llevado a cabo inmediatamente, y sólo es realizado de un modo paulatino, con gran gasto de tiempo y de energía de carga, continuando mientras tanto la existencia psíquica del objeto perdido. Cada uno de los recuerdos y esperanzas que constituyen un punto de enlace de la libido con el objeto es sucesivamente despertado y sobrecargado, realizándose en él la sustracción de la libido. (...) Al final de la labor del duelo vuelve a quedar el yo libre y exento de toda inhibición (Freud, 1915).

La contradicción entre ese "examen de realidad" del que habla Freud (1915) y la dificultad real de confirmar que el desaparecido está muerto deriva de que en el caso de la muerte aparece el cadáver y se ejecuta el rito funerario y en el caso de la desaparición ese procedimiento no puede llevarse a cabo.

El testimonio hace parte de un proceso en el que quien ha tenido la experiencia de violencia comparte y recoge en ese compartir el daño que otros han vivido por esa experiencia y 
construyen conjuntamente una interpretación de ese hecho en términos colectivos. Este proceso aclara cuáles son los elementos sociales de la desaparición forzada y le recuerdan a quienes la narran que esto los pone en cierta condición pero que no son o no están definidos solo por ese hecho. De lo contrario el testimonio puede llevar a la formación de grupos de pertenencia en donde se dan dificultades para la elaboración de las diferencias de todo tipo y en donde ocurren con frecuencia procesos de cohesión y simbiosis, en donde la identidad se estanca porque es necesaria para la existencia de ese grupo.

(...) El uso político se vuelve perverso porque yo creo que todo lo que ahonde en tu condición de víctima no repara ni mierda, te marca.

- Revictimiza.

- Por más de que te eches el rollo de que: "No sí es que esto es para la reparación integral". Si tú lo que estás pidiendo todo el tiempo a la gente es... en la Esperanza dicen una cosa bonita y es: "Que el dolor se convierta en propuesta". Pues porque ya están mamados de que cada año les están diciendo: "Y cómo fue y qué pasó". Entonces aquí cómo vas a construir un sujeto desde ahí pero el debate incluso en hijos se dio es porque incluso... lo que pasa es que la gente... las versiones son las versiones por qué hijos no se cataloga como movimiento de víctimas y no es un problema solamente porque hay gente que no lo era sino porque es que cuando se habla en la nacional es en la idea de que ser víctima es una condición del sujeto pero no es el sujeto.

- Es una condición temporal desde un marco jurídico.

Puede que toda la vida... que una experiencia traumática te marque toda la vida (Camilo, entrevista realizada el 18 de octubre de 2011$)^{70}$.

Es necesario escuchar esos relatos con atención y devolverles la dimensión de dolor cuando aparece, y reconocer la realidad que tienen sin profundizar en la condición de victimización. Así se construyen espacios para decir y pensar, para reflexionar sobre lo ocurrido y definir los caminos de lucha contra la repetición de la desaparición de cualquier persona, o para lograr

\footnotetext{
${ }^{70}$ Según EATIP y organizaciones similares (2009) la diferencia entre hechos que actúan como segundo estimulo traumático de otras situaciones que atraviesan los hijos a lo largo de la vida es que si bien son dolorosas, pueden detonar afectos en las huellas traumáticas, movilizándolos. Pero al no recrear historias pasadas, no presentan características retraumatizantes. Sentimientos y vivencias de escepticismo e incertidumbre, temor a participar, de impotencia, también son consecuencias del terror impuesto. La práctica social en sus múltiples formas produce efectos de apuntalamiento para el psiquismo individual, genera un discurso social contra hegemónico, favorece la movilización de fuerzas des alienantes, construye representaciones sociales en el orden de lo transubjetivo y de lo transgeneracional ( CINTRAS, EATIP, GTNM/RJ, SERSOC, 2009:241).
} 
las transformaciones más amplias en términos de país. Es decir que para las organizaciones de derechos humanos, en un acto de respeto y de igualdad, deben reconocer a las familias en su capacidad de pensamiento y acción y no sólo en su dimensión sensible.

(...) cuando el estado construye una idea de discriminación positiva en donde tú vales más por ser mujer sin tener en cuenta variables como la de clase, como la historia del estado, variables como la constitución de las mismas regiones o de las comunidades pues te está fragmentando y yo creo que parte de lo que decía antes del límite de la noción de víctima es que cuando ahí te sustraen del territorio, de la comunidad, te sustraen de la organización comunitaria o política y te colocan por encima de ella lo que hacen es romper un tejido muy fuerte porque no te están ofreciendo nada en términos del proyecto político que podría representar tu comunidad sino que te lo están ofreciendo es por la vulneración de algún familiar tuyo ni siquiera por un líder es que si no tienes el primer grado de consanguinidad no... entonces ahí hay una fragmentación muy fuerte (Camilo, entrevista realizada el 18 de octubre de 2011).

De la misma manera implica un ejercicio de análisis que ayude a ubicar al testimonio en la historia y en un contexto amplio que no lo deje inerme en la condición de cosa única e impensable. Que no supere al relato histórico, que no se consuma en una memoria acrítica e incuestionable, y que sirva como fuente y guía de la construcción histórica. La memoria puede señalar qué hace falta en el relato histórico y qué tendría que ser conservado porque compete o defiende la existencia o la continuidad de un grupo social (La Capra, 1998).

Yo lo recuerdo y en mi memoria está siempre si. Pero fuera de eso yo alimento mi memoria y para alimentarla pues tengo que conocer, buscar procesos, saber, tratar. Porque para tu alimentar tu memoria tienes que tener mucha información. Para uno poder hablar de lo ocurrido y poder tenerlo presente de la mejor forma (Steffany, entrevista realizada el 20 de abril de 2013).

Este elemento de investigación equilibra las creencias sobre que la memoria de las víctimas se paraliza en el tiempo. No hay que dejar de lado la objetividad de la experiencia, hay alguien que no está y hay que buscarlo y esto requiere interrogar porque hay algo fundamental que se desconoce. Entonces es necesario revisar documentos, construir archivos, la búsqueda de "la verdad" que va más allá de la experiencia personal o subjetiva 
de los familiares y tiene que ver con la reconstrucción fáctica de la desaparición para saber "en dónde están los desaparecidos". Esto se refleja en expresiones como la de la señora Fabiola Lalinde cuando afirma que en la búsqueda de personas desaparecidas es necesario "aprender el rigor de la investigación", cortar y pegar archivos de prensa, guardar todos los documentos, leer, interpretar, "no superar la etapa del por qué".

Se busca para saber el destino del familiar, y la verdad sobre lo ocurrido. Cuando se está hablando de que las personas no aparecen, no se puede confirmar que se la llevaron porque no hay pruebas distintas a la sistematicidad del hecho a nivel nacional. Cuando la experiencia propia del familiar es desmentida y cuando se tiene una necesidad muy profunda de entender, los familiares se convierten en investigadores con todo el correlato subjetivo que esa investigación tiene ${ }^{71}$. Pero ese proceso de búsqueda de la verdad se ignora cuando se dice que las familias quieren imponer la verdad indiscutible, en esas expresiones hay un desconocimiento fundamental del centro de la demanda de los familiares: ¿dónde están los desaparecidos?

\begin{abstract}
Encontrar a Nidia fue un hecho histórico porque nos encuentran desaparecidos todos los días, y después de tantos años nosotros lo teníamos esperanzas pudimos hacer honores del cementerio, podemos devolver el nombre, devolverle la familia, la dignidad, porque la querían volver una cosa y nosotros no vimos un ser humano con derechos. Seis o la identificación de los restos, allí estaban las ropas, el zapato, el ariete, un Cristo, el saco, todo... Todo lo reconocimos, era Nidia (Hermana, Bogotá, $1987)^{72}$.
\end{abstract}

\footnotetext{
${ }^{71}$ Las películas que fueron realizadas por hijos e hijas en Argentina, se produjeron gracias a esfuerzos de reconstrucción e investigación, cargados emocionalmente por la identificación y diferenciación permanente con los progenitores. Según CINTRAS, EATIP, GTNM/RJ, SERSOC, 2009) hijos e hijas experimentan sentimientos de temor e incertidumbre al acercarse a familiares cercanos como fuentes. Porque interpelan los códigos de silencio sostenidos por las familias. Prefieren cuidar al otro del encuentro con recuerdos tristes y terroríficas. Al buscar información se involucran con la propia historia dando lugar a preguntas y decisiones complejas de auto preservación ¿Tiene sentido preguntar? ¿De que sirve saber? Preguntar a amigos y compañeros de militancia de los padres no se encuentra tan cargado del temor a dañar. La participación en grupos como hijos funciona como espacio de encuentro y mayor libertad para preguntar, preguntarse y procesar la información recogida y compartirla. En ese trabajo también identificaron preguntas difíciles: la participación especifica de los padres en actividades clandestinas. Esta etapa permite el encuentro con aspectos valiosos, característicos, emotivos tendientes a la elaboración. Otros que no la transitan tienen marcada sintomatología angustiosa. Esta etapa requiere tejer la posibilidad de reencuentro con los padres y la des idealización de las imágenes de padres y madres, dando lugar a nuevas adquisiciones identificatorias, ¿soy a partir de quien deseo ser? Se trata de un trabajo de construcción de psiquismo, llenado de un vacío. Se vive un proceso de encuentro y pérdida.

72 Testimonio de Janeth Bautista extraído del libro Veinte años de historia y lucha. Asfaddes con todo el derecho (2003).
} 
Las conmemoraciones por otro lado y según lo concibe Da Silva Catela en el caso de las actividades adelantadas por los hijos en Argentina en las facultades y las calles, se concibe como "un lugar de celebración que sobrepasa las fronteras familiares pero que no pierde su carácter íntimo, de conjunto y de permanencia. Es como un espacio de transición entre todo lo recordado y celebrado al interior de la familia y la construcción de la memoria del grupo político, o del grupo social y nacional ${ }^{73}$.

Una vez que los homenajes fueron inaugurados al público, su modelo de memoria objetivada dejó de ser "privada" para devenir pública y, como tal, consumible, traducible y reproducible libremente. En este sentido, en el encuentro frente a un público, la conmemoración pasó a cumplir un rol que excedió a la planificación racional del acto: pasó a ser pedagógico y a crear otros públicos potenciales (Da Silva Catela, 1997: cita on line).

Todos los familiares entrevistados han organizado y participado en conmemoraciones que han implicado distintas acciones académicas y artísticas nutridas por las expresiones propias del movimiento social: el graffiti, la música, la publicación de libros, las muestras de arte, las prácticas religiosas, entre otros. En dónde se realizan esas conmemoraciones, cómo, con qué objetivo, son todos elementos llenos de simbolismo.

Resulta un alto homenaje que estemos hoy acá, en la Universidad Nacional y en esta coyuntura interna de debate, en mi alma mater y en la Universidad de los sueños e ideales de mi padre, presentado su libro. Mi padre accedió a la Academia luego de los 40 años, después de pensionarse y haberse desempeñado como un reconocido dirigente sindical. Tránsito los pasillos de la Universidad Javeriana con la expectativa de encontrar en el saber nuevas puertas, intersticios y caminos para concretar sus proyectos. Desde allí, lo digo sin duda, aprendió nuevas miradas del mundo, de los proyectos políticos, de la sociedad y del cambio. Desde allí también comprendió desde otras dimensiones el sentido del poder y

\footnotetext{
73 Autores como Jelin, describieron la conmemoración como un escenario vinculado con experiencias traumáticas de represión como dedicadas a significar la pertenencia de la víctima a la comunidad política. "Las exclusiones, los silencios y las inclusiones a las que se refieren hacen a la reconstrucción de comunidades que fueron fuertemente fracturadas y fragmentadas en las dictaduras y los terrorismos de estado de la región" (Jelin, 2005:5). Esta autora plantea que los recuerdos no se dan de manera solitaria, están inmersos en narrativas colectivas reforzadas por el ritual y la conmemoración. Toda memoria es una reconstrucción y lo que no se ajusta al marco histórico es material para el olvido (Jelin, 2002). En este sentido no hay una contraposición de la memoria a los hitos construidos por la historia sino una vinculación de nuevos elementos, emocionales por ejemplo. Sin embargo la existencia de memorias que no se consolidan en el espacio público son muestra de que los marcos sociales son estrechos y los recuerdos superan la disposición de hitos históricos, no solo de sentidos del pasado.
} 
su relación con la historia (Diana Gómez, 2011).

Diana explica en este fragmento por qué escoge a la Universidad Nacional de Colombia para presentar el libro de su padre y el vínculo que existió entre él y el mundo académico. Entonces el lugar de este hecho de conmemoración no fue fortuito. De la misma manera Shaira describe la elección del lugar de la conmemoración por la desaparición de su padre después de dos años de desaparecido. Recordándole a las personas que habitan el barrio el Tunal que en ese lugar la policía se llevó a su padre como exorcisando a ese territorio del miedo y la necesidad de huir de él por el control de los perpetradores. Diana por su parte relaciona a la academia en la que conmemora, como a los otros espacios habitados por su padre, como lugares marcados por la búsqueda de transformación y afirma que esta sigue siendo una tarea sin término, tejiendo en sus palabras y en la asistencia a los mismos espacios, hilos entre sus decisiones actuales y el sentido que estas tienen al recordar el pasado de su padre.

Las conmemoraciones con frecuencia son relatadas por las personas entrevistadas como momentos de reivindicación y rememoración gratos en los que han podido sentirse acompañados y divulgar la memoria de los seres queridos. En algunos casos que conocí previos a esta tesis son momentos de ritualizar que le generan a las familias el sentimiento de haber cumplido con un deber con las personas desaparecidas.

Eso es recordar de buena forma. Yo sé que mi papá se desapareció y eso duele porque no lo tuve y no lo voy a tener y nunca va a volver. Pero saber que tú puedes buscar la manera de que te ayuden a recuperar esa verdad, de que te ayuden a saber qué fue lo que pasó, que te tranquilicen y esas personas permiten que tu memoria este activa siempre. Que no siempre sea un signo de dolor que no siempre sea un signo de tristeza aunque siempre sabes que ha estado ahí sino que tú sabes que por ejemplo hace ocho años hice la conmemoración en la Plaza de Bolívar de mi papá y fue tan bonito. Ese tipo de memoria te hace a ti recordar tranquilamente, saber que no estás solo y que las cosas se pueden hacer (Steffany, entrevista realizada el 20 de abril de 2013).

Pero además la conmemoración tienen el potencial de crear espacios de solidaridad social 
que fortalecen los lazos de afecto, de identidad y de cohesión entre personas de un grupo social y entre distintas generaciones.

\subsection{Transmisión entre generaciones y subjetividad}

El hombre bebió con avidez esa sopa tibia y espesa que le daba la madre y sintió cómo le volvía otra vez la vida

al cuerpo. Hacía varios días que no probaba bocado y había sentido el yerto terror de que no se estaba muriendo de la herida de bala sino del hambre. Era un milagro que ella hubiera encontrado algo para comer en ese paisaje de pedregales. La mujer después de darle de comer se recostó en una piedra que tenía forma de medialuna. El hombre se sorprendió al verla tan pálida y con las vistas como con fiebre. Quiso acercarse a ella pero la mujer lo detuvo con una señal de los ojos y dijo: "Me dejaría de llamar Emilia Sierra si dejara morir de hambre a mi hijo. No lo he parido ni lo he criado para que se acabe como un perro. Ese gusto no se lo voy a dar a los asesinos del gobierno". Arriba surgió un punto luminoso. Era un avión volando tan alto que parecía una pelusa desprendida del sol. La mujer se quedó mirando el avión hasta que se fue del cielo y agregó: "A usted lo necesitan los pobres de estas tierras para que siga la pelea hasta el final. Cuídese mucho. Ya ve que en un pequeño descuido la tropa nos inundó el rancho y tuvimos que agarrar lo primero que topamos a mano y salir

en estampida inventando caminos. Ahora regrese y siga al frente de nuestra gente. Me saluda a su tío Florentino y le dice que le entregue los dos caballos. Y dígale a Margarita que se meta con ustedes en el monte. Los ojos de la mujer se llenaron de lágrimas. Contempló amorosamente a su hijo y sonrió. Luego, poco a poco, se fue muriendo sobre la piedra en forma de medialuna. El hombre observó la cara transparente de la finada y luego vio la olla de peltre donde había hervido la sopa de color rojo, y vislumbró las dos profundas heridas que tenía la madre en las muñecas.

(Jairo Anibal Niño)

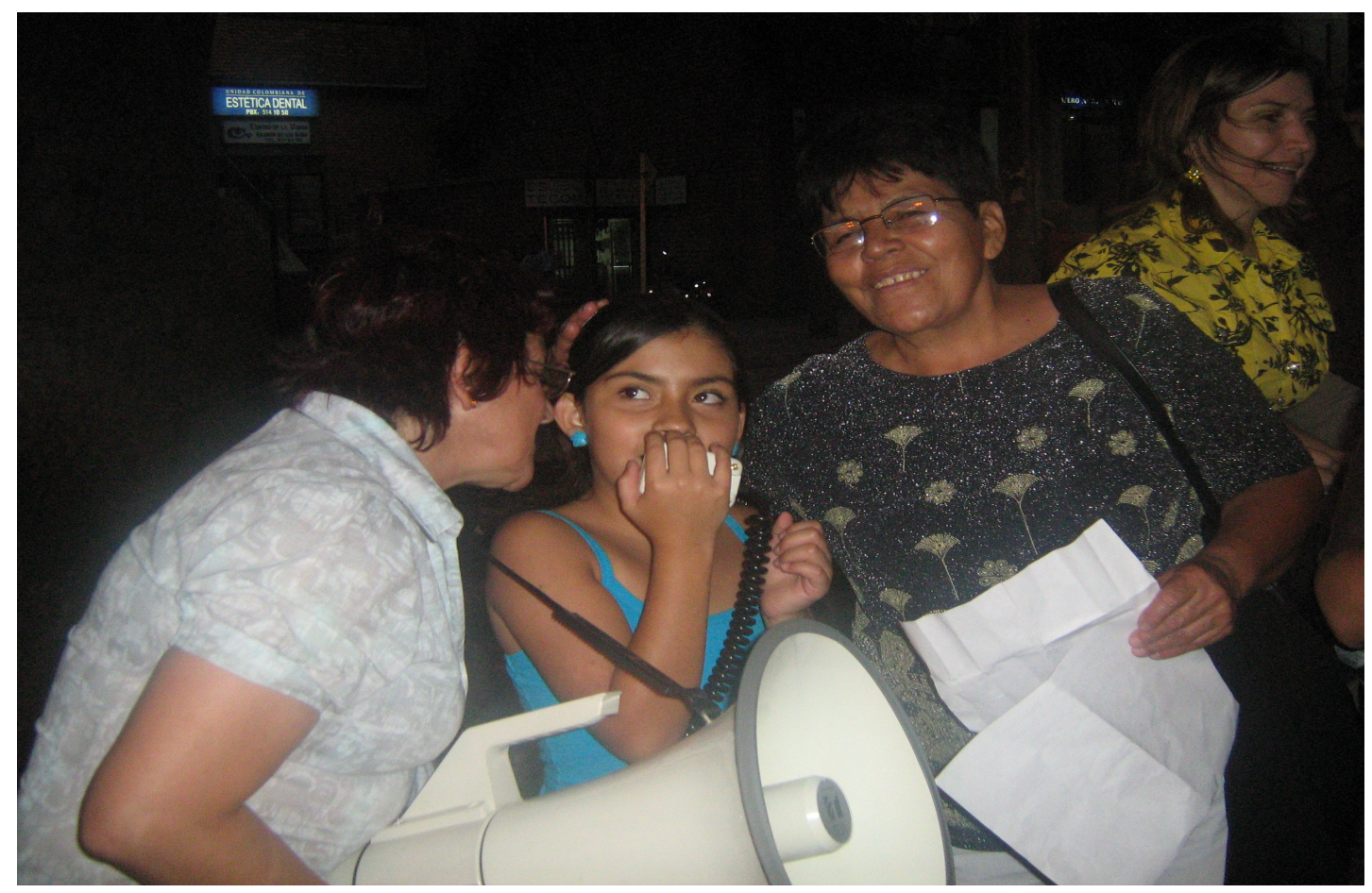

Fotografía: Andrea Guatavita. Conmemoración de la desaparición en el año2000 de dos familiares asociados a Asfaddes: Angel Quintero y Claudia Monsalve. 6 octubre de 2008. Medellín. 
En el campo del psicoanálisis específicamente uno de los debates más interesantes de las nuevas líneas de investigación tiene que ver con que se renuncia a la idea de la neurosis y la constitución pulsional como origen de la psique para plantear que no existe una transmisión generacional de la psique sino que su producción es intersubjetiva, es decir que se produce gracias al encuentro con otros de otras generaciones y la existencia de un cuerpo (Kaës, 1993).

Las preguntas sobre cuál es el efecto de la historia que pasa de una generación a la siguiente está vinculada directamente con esta disciplina y con los análisis de la historia. Estos postulados tienen implicaciones fuertes en el análisis que hasta ahora se realiza: Hay elementos de las experiencias violentas que pueden vivirse como traumáticos pues generan una percepción dividida del antes y el ahora, fracturan el vínculo, superan las posibilidades de elaboración, fragmentan la imagen del cuerpo, generan una situación de vulnerabilidad total a quién la experimenta. Esas experiencias violentas generan procesos de duelo para la elaboración de una ausencia en el vínculo de amor, y miedo.

Al inicio de este capítulo se evidenciaron múltiples esfuerzos por parte de las familias para enfrentar estos impactos a través de acciones para rescatar la imagen, el nombre, el cuerpo y la historia de las víctimas de la desaparición forzada. Es decir que las familias hacen un esfuerzo por elaborar y transmitir memorias para tomar distancia del hecho traumático y recomponer el vínculo social y familiar.

Sin embargo, es necesario preguntarse si estos elementos traumáticos participan en la constitución subjetiva y si esos impactos se transmiten en la familia a través de mecanismos que no son propiamente los ejercicios de reconstrucción de la memoria que han sido mencionados.

A través de la reconstrucción colectiva de la historia y el descubrimiento de que la privatización del daño es resultado de la marginación de una experiencia en el campo 
personal o familiar, comienza un proceso de elaboración en donde primero se intenta explicar lo que ocurrió en el encuentro entre las distintas generaciones.

Es decir que, en primer lugar, la pregunta se dirige a sí los hechos de violencia dificultan la transmisión o producen la transmisión de contenidos específicos. En términos generales la respuesta se divide entre quienes afirman desde las disciplinas sociales y la psicología que hay una transmisión de contenidos traumáticos, entre quienes reconocen la transmisión de tradiciones, valores, e identificaciones en términos generales, junto con esos elementos traumáticos y, finalmente, entre quienes plantean que hay una interrupción en la transmisión.

En el campo de la memoria esto ha sido estudiado por LaCapra (1998) quien afirma que la existencia, por ejemplo, de lugares de memoria como les expuestos por Nora y Claude Lanzmann llamados sitios del trauma, es la demostración de una no elaboración del pasado que pasa a ser otra cosa. Lo que se niega o se reprime en el lapsus de la memoria no desaparece, regresa de un modo transformado, un pasaje al acto, una repetición.

\begin{abstract}
La soledad y el aislamiento, las dificultades para establecer proyectos de vida y planes a futuro, estarían señalando las tendencias a la repetición, fruto de «nudos socio afectivos» complejos. ¿Pueden autorizarse a diferenciarse de sus padres, a veces severamente dañados, y emprender -sin culpas- una nueva vida? ¿Pueden salir del lugar estigmatizado al que los sometió la impunidad y el silencio oficial?” (CINTRAS, EATIP, GTNM/RJ, SERSOC, 2009:433).
\end{abstract}

Este apartado responde un poco a la pregunta diciendo que efectivamente hay otro tipo de transmisión no consciente que permite que los "daños" sufridos por los más grandes toquen a niños y niñas a través de la socialización. Un daño, por ejemplo, que tiene una intención política clara tiene que ver con vincular a lo político con el peligro, se identifica con los representantes de la administración, la corrupción y la impunidad.

(...) ahora uno puede decir ya estando en el ámbito privado el hecho de que tú en tu escenario más íntimo te sientas vulnerado es un problema fuertísimo en términos del existir, de vivir, que sientas que hay amenaza en tu núcleo más familiar lleva a que, por ejemplo, manteniendo la memoria de ese núcleo familiar que es imposible no tenerla te distancies de los escenarios organizativos, de movilización 
política, de acción política y sencillamente (...) (Camilo, entrevista 18 de octubre de 2011).

Puede llevar a una necesidad de cambiar procesos adelantados hasta ahora por el alejamiento total del sujeto a la dimensión política que lo atraviesa, no por opción, sino por miedo. $\mathrm{Y}$ este alejamiento puede ser visto como una falta con respecto al proceso histórico.

Claro... te distancias... o lo que yo llamo una de nuestras líneas de unidad generacional es si se quiere el aburguesamiento o el volvernos clase media que no tiene que ver con una línea de ascenso sino con una línea de protección es decir si yo hago que tus padres han estado en escenarios de lucha donde incluso la familia sabe que son escenarios de lucha y que el camino difícilmente es más libertad, o más apertura, pues sencillamente el acto reflejo es decir: "Yo prefiero que mis hijos crezcan en un espacio más seguro, más sano, menos pobre si se quiere, menos popular si se quiere, y eso genera distintas relaciones con el sujeto poblacional, con los sectores... generan distanciamientos con los sectores con los que luchaba mi propio padre (Camilo, entrevista 18 de octubre de 2011).

El escenario es complejo, puesto que depende o puede ser señalado en tanto reconocemos que el mundo es amplio y se puede ver desde distintos lugares e intereses. De la misma manera entendiendo que no todas las personas que fueron desaparecidas forzosamente en escenarios de fuerte lucha política estaban vinculadas a estos procesos. En este caso y como lo plantea Steffany, la política se muestra en su dimensión más ilógica y la impunidad que se impone sobre estos hechos, específicamente hablando de la toma y la retoma del palacio de Justicia, genera un desprecio total por los organismos y representantes del estado que son quienes aparentemente transitan por el escenario político.

En ese contexto como estaban en el proceso de paz con el M-19. Fuera de eso el ejército estaba en uno de sus puntos más fuertes porque estábamos en una opresión militar fuertísima. Adicional a esto teníamos un presidente que era manejado más por su grupo político. Todo esto dio para que la desaparición de mi papá se prestara con el fin de hacer un movimiento político más grande. Estos señores, toda la gente que estuvo vinculada en el momento de la toma del palacio de justicia, estamos hablando de una Noemí, estamos hablando de este señor que fue alcalde, no recuerdo el nombre. Aún están, aún siguen, son personas que no se les ha hecho ningún proceso, personas que estuvieron vinculadas, que hablaron, que dijeron y siguen ahí. Por eso el contexto político no es que me agrade 
mucho. No estoy de acuerdo con la política colombiana, no me gusta la política colombiana, porque el contexto de lo de mi papá fue muy ligado a esto muy amarrado a esto y a la fecha pues como nunca nos han dado respuesta entonces no me ha interesado nunca (Steffany, entrevista realizada el 20 de abril de $2013)^{74}$.

Los avances en el análisis de los daños vividos por la segunda generación y los procesos que genera a nivel subjetivo: el duelo, el miedo, los vínculos, la ausencia en la transmisión de la historia de los padres y madres, son protagonizados por equipos de acompañamiento psicosocial como el Equipo Argentino de Trabajo e Investigación Psicosocial (EATIP), CINTRAS de Chile, SERSOC de Uruguay y el Grupo Tortura Nunca Mais do Rio de Janerio en Brasil.

En la lectura de psicólogos sociales como Pau Pérez, Carlos Beristein, Ignacio Martín Baró, Maurice Gaborit, lo fundamental en la pesquisa ha sido pensar en la construcción de narrativas por parte de la segunda generación y en las facultades y las potencialidades de la memoria para aportar en estas. Estos equipos vinculan el ámbito psicológico y sus núcleos problemáticos con el origen social de ciertas prácticas que lo afectan.

Para la psicología, los hechos de represión de origen social generan un daño que se recuerda porque tiene una dimensión transgeneracional, es decir que la psicología plantea que hay algo que se transmite (CINTRAS, EATIP, GTNM/RJ, SERSOC, 2009), siguiendo una herencia de Freud (1901) que dicta que el silencio, el olvido o el error encubren huellas inconscientes.

En el campo histórico, autores como Yerushalmi (1985) hablan de la ausencia en la transmisión y la imposición del olvido, de falla en la representación (Crenzel, 2010). ¿Qué relación existe entre estas nociones y el daño?

\footnotetext{
${ }^{74}$ En Argentina, el EATIP reconoció que la afectación producida por el terrorismo de Estado no sólo produjo efectos a nivel individual, sino que tuvo importantes consecuencias en todo el conjunto social, incidiendo en la producción de subjetividad. Sentimientos y vivencias de escepticismo e incertidumbre, temor a participar, de impotencia, también son consecuencias del régimen de terror impuesto (CINTRAS, EATIP, GTNM/RJ, SERSOC, 2009).
} 
En todos los casos hablamos de que la transmisión a las nuevas generaciones es la herencia transformada por el receptor de la historia, es el pasado transformado en el presente y su esperanza, porque nada en la memoria es individual "concierne al sujeto singular y al grupo". Este trabajo permite a cada generación situarse en relación a las otras, inscribe a cada sujeto en una cadena y un grupo o grupos, funda su propia subjetividad, constituyendo su historia (...) es un trabajo de ligaduras y transformaciones (Granjon, 2009). "Alguna falta, alguna transgresión alguna muerte, algún delito, con su carga de culpabilidad y de vergüenza, no pueden ser abolidos, obligados a ser transmitidos e incluso con los impedimentos, las interdicciones, los mecanismos de defensa que ellos suscitan y que son utilizados para evitar que sea conocido, sabido o dicho lo que habría debido no ser, lo que fue traumático" (Granjon, 2009) y los silencios que se ponen sobre estos hechos son pactos que se sostienen fundamentalmente en la infancia. Para la psicología social, otros momentos fundamentales para la transmisión o el establecimiento de pactos de silencio son los momentos de transición de regímenes políticos, al menos son momentos en los que se indaga la existencia de ciertas memorias y se reconoce la transmisión de identidades políticas en los recambios generacionales (Pérez, 2006).

En resumen algunos elementos que podrían definir o asegurar que el daño o el impacto mencionado en el primer capítulo se transmita entre las generaciones y por tanto se instale a nivel familiar y social, son:

- Políticas de estado que no han sido reparatorias y que al contrario han promovido impunidad.

- Dificultad de elaboración colectiva de los efectos de la desaparición, la angustia, el silencio, el dolor y la impunidad que generó. La inexistencia de memorias sociales que superen el campo familiar y organizativo del desaparecido y que ayude en la construcción de subjetividades para explicar la angustia, romper el silencio, colectivizar el dolor.

- El mantenimiento de pactos de silencio o secretos familiares a nombre del dolor, que imposibiliten la transmisión consciente del relato de lo ocurrido y se traslada al campo del síntoma. 
- La transmisión de ideologías para relatar y nombrar el hecho traumático que apuntan a "revictimizar" o profundizar en el duelo, el miedo, la victimización. Los medios de comunicación, los espacios educativos, los centros de memoria institucional y otros aparatos son útiles a este propósito.

Esos daños son causados por la violación de derechos y continúan a través del vínculo porque las personas que fueron afectadas no han cambiado sus condiciones objetivas ni subjetivas de vida ${ }^{75}$. El daño generado a las nuevas generaciones tiene que ver con la ausencia del ser querido en momentos fundamentales. Constituye la ausencia de un referente sobre el cual dar un valor cultural, político, social a ciertas acciones o un centro de identificación para construir la propia imagen.

(...) cuando se graduó yo le decia: "Estás feliz". Yo la amo. "¿Estas feliz?". Y me decía: "Si mami hay un poquito de tristeza yo senti un poquito de tristeza". Eso me lo dijo en la noche cuando nos invitaron a comer unos amigos que la invitaron a comer en un hotel carisimo y yo: "Ay que rico lo que yo no puedo darle se lo dieron ellos y le dije que si estaba feliz. "Hay una cosa que me empaño un poquito el grado". Y le dije: "¿Qué pasó?" "Cuando el papá de Paola la recibió con su ramo de flores, cuando el papá de Milena la estaba abrazando cuando los papás de william porque yo siempre he querido que mi papá haya estado apoyándome y sintiéndose orgulloso de mi eso me ha dolido como me hubiera gustado que mi papá estuviera aquí para que me hubiera acompañado en mis quince años o cómo me hubiera gustado que mi papá estuviera acá no por respeto sino para que viera lo que somos como personas, porque yo siento mucho orgullo por mis hijas. Porque yo he sido una persona loquisima en la vida. He sido muy sensible. He hecho lo que he sentido. Pero mis niñas han sido unas niñas organizadas, juiciosas,

\footnotetext{
${ }^{75}$ CINTRAS encontró en sus investigaciones la existencia de mandatos paternos caracterizados por la cercanía, física o psicológica, y la exigencia de compartir creencias, valores, normas de comportamiento, sentimientos, haciéndole percibir al joven el menor alejamiento como una traición, generando los correspondientes sentimientos de culpa. Reconoció como motivos de consulta en los hijos e hijas: trastornos adaptativos, ansiosos y depresivos, baja en el rendimiento escolar, conductuales que se traducen en conflictos con la autoridad. Los jóvenes tienen una actitud ambivalente los admiran por luchas y sus ideales y sienten rabia al considerarse abandonados y se sobre involucran asumiendo role parentales (CINTRAS, EATIP, GTNM/RJ, SERSOC, 2009). Las causas de consulta, inseguridad, desinterés, consumo de drogas, no auto cuidado... son manifestaciones del sufrimiento vivido y resultantes de la instalación, en lo subjetivo, de bloque duros de identidad producidos pro el funcionamiento molar (CINTRAS, EATIP, GTNM/RJ, SERSOC, 2009). los procesos traumáticos en segunda generación interfieren la identidad y favorecen la irrupción de trastornos mentales. Se reafirma la aplicabilidad de lo indecible y lo innombrable. Las marcas psíquicas serían hitos identificatorios, con una incidencia importante en la constitución de la identidad del sujeto. Se comportan a la manera de organizadores de una serie de aspectos de la vida psíquica y, dado su funcionamiento como parte estructurante de la identidad, dirán algo acerca del sujeto en sí mismo y en relación con los demás (CINTRAS, EATIP, GTNM/RJ, SERSOC, 2009:160). Hay relación entre marca psíquica y huella mnémica, la diferencia es que la ultima no forma parte necesariamente de la identidad. A diferencia de las huellas, las marcas tienen un peso especifico a este nivel.
} 
responsables y el papá hubiera sido una persona muy orgullosa de ver lo que son (Pilar, entrevista realizada el 13 de abril de 2013).

Sin embargo, la flexibilidad de las mujeres u hombres que quedaron a cargo, su capacidad de comprender el hecho y su contexto, el acompañamiento que recibieron para lograrlo, y la posibilidad de reponerse de la ausencia o la transformación del rol que debía ejercer aquel que fue desaparecido para que no quede como lugar vacío de significación y marcado por el silencio, permite que las generaciones puedan continuar y cambiar el contenido traumático del hecho por otros contenidos.

Cuando estaba más pequeña a nosotros nos trabajaron mucho, nos hicieron mucho acompañamiento en el proceso de crecimiento, de siempre mantener presente qué era lo que había sucedido de una manera muy tranquila. Entonces siempre estuvimos presentes con el proceso de psicología, de información, de saber qué fue lo que sucedió. Tal vez la palabra que siempre he tenido yo presente es nunca olvidar. Entonces en Fasol nos hicieron un trabajo más bien de acompañamiento, de ayuda a mi mamá que se quedó muy solita con nosotras y de ayuda psicológica para que de pronto no se creara una imagen de rencor, sino una imagen de tranquilidad, un pensamiento de tranquilidad y de buscar siempre una solución a algo en el presente, que tuviéramos claro que mi papá era un desaparecido por x o y motivos que habían ocurrido (Steffany, entrevista realizada el 20 de abril de 2013).

Todas las personas entrevistadas vivieron una experiencia traumática directa y se vieron afectadas sobre todo en su vida adulta, excepto en dos casos, por los efectos de la desaparición. En los dos casos excepcionales es muy claro el papel que cumplen las personas que quedaron a cargo de la protección de los huérfanos por tanto terminan constituyéndose en padres y madres nuevos, en guías o compañías fundamentales como lo expresa Chico Bauti a su tía en el poema Rosa Púrpura.

La rosa púrpura realmente es la mamá que tuve después de la desaparición de mi mamá, mi madre putativa. Ella estuvo un tiempo muy enferma y estuvo seis semanas en coma... eso me dio muy duro y pensaba que no podía pensar en un futuro si ella ya no iba a estar ahí entonces la invitaba a seguir continuando el viaje y el poema se lo escribí a ella cuando estaba en coma... es todo lo que ella ha significado por encontrar a los desaparecidos desde lo que yo he visto en ella. Para que los niños puedan 
volver a estar con sus mamás (Chico Bauti, entrevista realizada en Septiembre de 2011).

Queda finalmente del lado de esos descendientes la relación entre la historia de sus padres y madres y su historia y en consecuencia qué otras cosas pueden vivir e inventar para su búsqueda de "felicidad" o "bienestar".

... O con la aprendido también porque uno no se puede desligar de lo que ha vivido... no sé tener como un derecho a la felicidad, lo que pasa es que la humanidad no se permite eso... por muchas cosas, por el sistema económico, por las cuestiones políticas digamos que tampoco... es muy difícil de conseguirlo (Chico Bauti, entrevista realizada en Septiembre de 2011).

\subsection{Transmisión y experiencia directa}

Tisseron (1997), en un análisis de la transmisión desde el psicoanálisis, recoge los planteamientos de Freud en cuanto a que "todo individuo está dividido en dos necesidades, ser para sí mismo su propio fin y ser el eslabón de una cadena". Esos planteamientos fueron abandonados, según el autor, por prevenir alguna hipótesis de determinismo psíquico, pero fueron retomados y desarrollados por autores como Nicolás Abraham y María Torok.

La diferencia entre el daño compartido por las generaciones o el transmitido por una generación a otra que no tuvo ningún contacto con una experiencia de manera directa aún se discute. Para el psicólogo Nicolas Abraham $^{76}$ la transmisión implica que sólo las terceras generaciones que no tienen ninguna relación con el hecho violento son el lugar en el que propiamente se reconoce el efecto transgeneracional.

Los duelos ancestrales se asemejan a los duelos patológicos en que, lo que no ha podido ligarse a la palabra son fundamentalmente los afectos provocados por la muerte de figuras significativas. Por otra parte, se diferencian de los mismos, en que la dificultad de tramitación no se refiere solo a una pérdida

\footnotetext{
${ }^{76}$ Nicolás Abraham y María Torok distinguen entre las influencias intergeneracional es y las influencias transgeneracionales. Las primeras que se producen entre generaciones adyacentes en situación en relación directa. La segunda se producen a través de la sucesión de las generaciones dos. Los contenidos psíquicos de los hijos están marcados por el funcionamiento psíquico y abuelos o de ancestros que no han conocido, pero cuya vida psíquica ha marcado sus propios Padres (Tisseron, 1997).
} 
propia, sino a una pérdida no elaborada, sufrida por un ascendiente, que produce efectos e impone un trabajo psíquico inconsciente plus a la descendencia. Cuando en primera generación se clausura el procesamiento de un duelo, las generaciones siguientes no reciben las condiciones para la nominación de las emociones asociadas a los efectos de dichas experiencias (Werba, 1997: 296).

Esa transmisión tiene que ver con el reconocimiento de que la familia es un grupo primario y su tarea es la prolongación de la especie y proporciona la identidad humana a las futuras generaciones. Sentimiento de pertenencia, estar dentro. Esto permite compartir metas y normas y leyes que el destino común. Desde lo imaginario, la pertenencia implica la ilusión de estar contenido en un ambiente amparador (Bernard, 1991). En medio de ese contexto la transmisión psíquica se determina a través de alianzas, pactos y contratos inconscientes. A su vez tiene distintas expresiones o mecanismos: el telescopaje, los pactos denegativos, la simbolización parcial, el proceso de encriptación.

El telescopaje se refiere a la transmisión de información que fue rechazada de la historia personal. El pacto denegativo se refiere al silencio pactado entre distintos miembros de un grupo familiar en el que la decisión hace eco y garantiza una complicidad inconsciente en donde la denegación parece prevenir la ruptura del vínculo. Hay cosas de las que no se habla.

El material con el que se construye la identidad está constituido por la enunciación o representación y por las reglas de la enunciación, las cuales definen la forma de relación entre esas representaciones. Las reglas de la enunciación preceden a la representación. Los padres aportan a veces la regla. No se trata entonces de lo que el otro dice directamente porque el sujeto puede formar nuevas combinaciones y éste es el factor creador que posee la fantasía del niño (Bleichmar, 1991).

La transmisión psíquica expone los intercambios entre las generaciones bajo un aspecto familiar, según el autor, el de los varones sin ningún cuestionamiento de la naturalización de 
esa definición desde el género ${ }^{77}$, con respecto a como se define la transmisión de las creencias y de las competencias que garantizan la continuidad familiar, grupal y cultura (Tisseron,1997). Los y las progenitoras consideran a sus descendientes, herederos de sus deseos y les heredan sus propias inhibiciones y prohibiciones.

\begin{abstract}
Yo digo que lo mío ha sido muy sencillo porque yo he visto casos de familiares en el mismo grupo al que yo pertenezco que son familiares del palacio de justicia y para ellos ha sido, para algunos ha sido más difícil acercar a sus hijas a lo que nos pasó a nosotros y llevarlos de la mano con esto de la desaparición y la búsqueda y estar metidos en este cuento por veintisiente años. Ha sido más difícil. Lo mío no yo como que lo hice sin pensar. A mí me tocó levantarme y irme para una reunión y salir corriendo o ír a acompañar a alguien porque tenía que ir a poner una denuncia y yo igual si estaba Karina la llevaba y las dejaba a las otras. Entonces fueron creciendo en medio de todo esto pero de una forma muy natural, sin rabia, sin rencores, más bien como que esto es algo de vivirlo todos los días, leer las mismas noticias, de preguntar porqué pasa esto: "Oye mamá cuidate un poquito". Pero algo muy natural. Yo no tuve problemas de tener que ocultarles durante todo el tiempo: "Su papá le pasó... lo desaparecieron". Nada. Todo se fue dando porque si, porque yo salía, porque me iba, porque llegaba con pancartas, porque salí en un noticiero o porque no salia, o porque hablaba o porque me la pasaba leyendo o por que compraba el periodico y cortaba cosas y para ellas fue natural (...) (Pilar, entrevista realizada el 13 de abril de 2011).
\end{abstract}

Sandor Ferenczi insistió en la transmisión de situaciones traumáticas, los adultos imponen contenidos psíquicos displacenteros en los niños. La imposibilidad de liquidar los aspectos de un traumatismo está en el origen de la psicopatología. Desde ese punto de vista la vida es una sucesión de momentos felices o desgraciados pero cada uno de ellos requiere una participación activa y consciente. En esa sucesión la infancia y la pubertad son momentos

\footnotetext{
77 Cuando el autor afirma que la transmisión se constituye como un mecanismo natural en donde se define que los intercambios culturales se realizan entre varones, expone un elemento patriarcal que no ha pasado por el tamiz del análisis en la teoría psicoanalítica tradicional, aunque si lo ha hecho en la literatura feminista. Para Molina Petit, Levi strauss creador de la estructura del parentesco representa lo que él considera es el principio de la organización de la sociedad. Se trata de un sistema simbólico indefinido por una alianza establecida en la que se intercambien categorías y estratos. Supone el paso de la naturaleza la cultura y se va a ser el concepto intercambio. El intercambio de mujeres significa en primer lugar que son los hombres los que realizan transacciones, jugando la mujer como objeto intercambio y no hubo como uno de los compañeros entre los cuales éste se lleva a cabo. Levi Strauss construyó implícitamente una "teoría de la opresión de la mujer" (Molina Petit, 1994:251). Sería necesario conocer las relaciones sociales por los cuales una mujer se convirtió en una mujer oprimida. La organización social que escribe Levi basada en alianzas matrimoniales es para Gayle Rubin, un sistema donde las organizadas realmente son las mujeres por los organizadores que son los hombres, desde ese momento la mujer no tiene derecho a disponer de sí (Molina Petit, 1994). En este texto sobre la herencia esa disposición tampoco aparece cuestionada.
} 
importantes. Existen muchas situaciones que necesitan re elaboración psíquica. La vida psíquica es un trabajo de auto elaboración siempre renovado.

Después de la tercera generación algunos traumatismos pueden subsistir sólo en forma y comportamientos o reacciones afectivas incongruentes. Estas actitudes tienen el valor de un signo de pertenencia familiar cuyos orígenes se han perdido. Otras veces la existencia de secretos desconocidos pero cuyos efectos se han extinguido, provoca la creación de secretos cuyo contenido desconocido cuya función esencial es dar sentido a las extravagancias del sujeto.

En ese sentido defino los duelos ancestrales como duelos no procesados, en los que los ancestros siguen teniendo presencia a través de los descendientes. Estos ancestros son personajes idealizados, cuya representación ha sido investida con una fuerte carga libidinal y/u hostil y que a modo de "muertos vivos", no han logrado, por diferentes razones, una verdadera sepultura psíquica en sus descendientes. Como tales siguen teniendo vigencia en las generaciones posteriores, capturando y alienando sectores del psiquismo de uno o varios de sus descendientes. Se plantea entonces, una situación en la que el proceso identificatorio no responde sólo a investiduras abandonadas desde el espacio intrasubjetivo y libidinal propio del sujeto. Se trata de un proceso inconsciente, por el cual uno o varios miembros de una familia, son identificados por el ascendiente, en relación a un tercero (el ancestro), e investidos con la carga libidinal y/u hostil destinada a éste (Werba).

Para Abraham las influencias entre generaciones no se operan en torno al contenido psíquico que estarían presentes en un hueco sino en torno a símbolos. Nachin completó este concepto, utilizando cuatro aspectos: representativo, afectivo, motor y verbal. Todo símbolo incluye la percepción, las imágenes que le están ligadas, los afectos y las potencialidades de acción del sujeto y el lenguaje verbal (Tisseron, 1997).

Cuando existe un fantasma en primera generación, siempre es simbolizado de alguna manera en las siguientes generaciones y esta preocupación se centra más que en los elementos pulsionales en las cuestiones del vínculo social. Estas teorías plantean también que la transmisión ocurre en distintos momentos y también atraviesa distintos caminos: 
1) Durante la gestación.

2) En la relación con el primer entorno, un mundo de significación que confronta a hjos e hijas con enigmas al igual que al adulto.

3) En la recepción de lo histórico de las personas más cercanas al niño y a través de los afectos que la Madre pone en juego durante los primeros intercambios con el hijo construyó su primera referencia y son más difícilmente reconocibles que los que resultan de las investiduras más tardías. Implica la fabricación de hábitos y a modelos de comportamiento.

4) Durante la organización de las identificaciones del niño con cada uno de sus Padres o con otros miembros de su entorno familiar. El niño puede identificarse con los deseos conscientes o inconscientes de cada uno de sus dos Padres respecto de él y también con sus objetos de deseo, o con sentimientos de dolor. Este mecanismo favorece en la repetición de una generación en otra de elecciones amorosas pero también de rasgos de carácter por personalidad. Este nivel de la influencias de generaciones es el que con más frecuencia se consideran hablar de la transmisión familia porque contiene los recuerdos más accesibles de la propia infancia ${ }^{78}$ (Tisseron, 1997).

5) En toda familia, los momentos del nacimiento de la muerte son también momentos privilegiados por los trastornos que los acompaña y permiten abrir espacios para integrar algunos acontecimientos separados de la vida familiar hasta el momento.

6) Toda las experiencias nuevas de una persona, de una familia o de un pueblo obligan a los sujetos y grupos interesados a un nuevo trabajo de elaboración.

7) Las transferencias de objeto de una generación a otra pueden ser portadores de formas de simbolización. Estos acontecimientos puede ser del orden de lo indecible ser un secreto vergonzoso de compartir por algunos miembros de la familia, del orden de lo innombrable ligado con un secreto de las generaciones presentes, ignorado por los descendientes o del orden de lo impensable aunque los descendientes experimenten sus efectos. Toda la realidad histórica familiar es una reconstrucción del secreto familiar. La realidad familiar nunca reside en el secreto mismo sino en las múltiples estrategias empleadas por las

\footnotetext{
${ }^{78}$ Esta teoría sin embargo, a la luz de los planteamientos de Bekerman (2002) resulta problemática pues se relaciona con la existencia del complejo de edipo que supone un deseo inconsciente del hijo al padre. La autora durante la reconstrucción de la historia del trauma refuta la hipótesis freudiana que postula la existencia de fantasías histéricas y afirma que las experiencias de violencia sexual precoz fueron reales. Para este tema es importante decir entonces que el adulto en la relación con el niño o la niña impone desde su comportamiento sexual una elección de objeto o lo transmite expresando sus propios afectos.
} 
generaciones sucesivas (Tisseron, 1997).

Pero hombre yo creo que nosotros nunca hemos sido y Samuel nunca ha sido: "Lo voy a recordar llorando, triste". No. Lo voy a recordar buscando una verdad y fuera de eso ayudando a las demás personas (...) Entonces lo que se ha trasmitido a Samuel es: memoria es ayudar, recordar a la gente, luchar, tener presente que pasó, por qué pasó y cómo puedo empezar a trabajar. Entonces Samuel tiene una reconstrucción de su proceso de recordar a mi papá muy bonita porque finalmente no lo conoció, él sabe que mi papá se desapareció y pues finalmente después de saber que se desapareció él trabaja los procesos de: "Yo voy a hacer un mural para recordarlo, podamos compartir acá". Él estuvo en la Guajira con mi mami.

- Para lo de Blanquita.

- Si. Dijo: "Quiero ir a la Guajira porque quiero conocer el proceso, porque quiero hacer..." Eso es hacer memoria. Memoria para mí no es sentarse a llorar y estar triste (...) Yo pienso que es es el tipo de memoria que se está reconstruyendo o que se está construyendo con Samuel, esa memoria bonita, agradable (Steffany, entrevista realizada el 20 de abril de 2013).

En este caso se expone la transmisión a la tercera generación: Recordar algo que no se conoció. Recordar gracias a una transmisión posterior a procesos de reinvindicación y terapéuticos de la madre y la abuela que dan lugar a la posibilidad de participar del niño en este y otros procesos para actuar, para entender y para reconstruir el lazo social. Por otro lado, es importante decir que según Kaës se pueden usar o no algunos elementos de lo heredado del núcleo familiar y cada ser humano puede ser lector y transformador de esa herencia. Aquello que es recibido no se recibe con pasividad y hay que hacer cosas para ganarlo (Kaës, 1993). Así es que Samuel desde pequeño se ha ido comprometiendo activamente a través de su participación, para recibir de sus familiares toda la información y los valores que le están heredando.

Otra dificultad de la memoria que en general se describe como grata está en la relación con la anterior generación y en asumir distancias o identidades en enunciaciones fundamentales sobre la vida y la muerte. La vida de los descendientes queda definida por la propuesta familiar, no sólo en este caso, en todos los casos. Y poco a poco cada quien busca caminos y alternativas para resolver el duelo desde sus propias necesidades, más allá de lo aprendido 
a través de los mandatos familiares. Gracias a aprendizajes externos, a la ayuda de los pares y a las propias reflexiones y deseos de preservarse.

Hay temas que caen bajo pactos de silencio y no son transmitidos. Según Gloria Gómez (2011) hay hijos e hijas que conocen las historia de sus antepasados pero "Hay otros que no sabían y que sólo conocen y viven el dolor de la ausencia del padre, pero que no dignifican sus militancias porque muchas mujeres o muchas mamás o muchas hermanas le ocultaron o le dijeron la verdad a medias (...)". En ese sentido reciben el sentimiento de tristeza, ese duelo interminable pero no lo significan con relatos históricos sobre lo ocurrido y pueden imaginar cualquier cosa. Por otro lado se hace efectiva una intención del perpetrador y es llevar al olvido la historia de militancia de padres y madres.

- ¿Ella no quiere socializar el tema?

- Creo que es más de este lado mio, no de ella, porque siempre hubo como ese temor a que ella, osea yo decía a mi el miedo a que ella, digamos no sé le pasara algo, que se yo en ese momento entonces dije: "Yo prefiero no llevarla tanto a Asfaddes" y mantenerla allá encerradita y es un error que con veinte años ella reclama (Esperanza, entrevista 22 de septiembre de 2011).

Estas dificultades se relacionan directamente con elementos muy claros que se repiten en distintas experiencias: El hecho marcado por la violencia y la cevicia o la historia de padres y madres.

Yo con la emoción ese día que fuimos al lanzamiento de ver la foto, uno dice: "Bueno al menos no sólo en las fotos con la galería de Asfaddes sino ver la historia de Eduardo en un libro pues eso es muy importante porque se está reconociendo a esa persona por lo que era (...) Él era un ser anónimo para muchos pero para nosotros los familiares era muy importante, entonces el saber que la foto iba a salir en eso y la hermana contando la historia de cómo fue de niño todo ese proceso de crecimiento y luego cómo él resulta en la lucha armada para la transformación, bueno toda esa ideología que el tenia en relación a un cambio social (Esperanza, entrevista 22 de septiembre de 2011).

Esperanza también está vinculada a ASFADDES y ha sido una miembro incansable. Su compañero Eduardo Ávila fue miembro del grupo insurgente M-19 y participó dentro del proceso de desmovilización del grupo. Este proceso estuvo marcado por unas condiciones 
muy dolorosas, porque le fue propuesto después de la desmovilización ser parte del DAS, a causa de ser reconocido como un combatiente porque "no podía dedicarse a otra cosa", según cuenta Esperanza él se negó por la conciencia que tenía de las prácticas del DAS y se dedicó a ser vendedor ambulante, tiempo después fue desaparecido, torturado, mutilado y posteriormente asesinado.

Se guardó su experiencia como un secreto que salió a la luz sin mucho tiempo de espera gracias a una investigación social de reconstrucción de memoria. El libro mencionado por Esperanza es uno de los pocos trabajos de memoria realizados sobre la memoria familiar de los militantes "anónimos" de un grupo insurgente en Colombia. Esto entre otras cosas tiene que ver con que el M-19 quedó en el pasado como movimiento armado y con que fue uno de los pocos grupos que después del tiempo mantuvo alta legitimidad y el apoyo popular que cultivó.

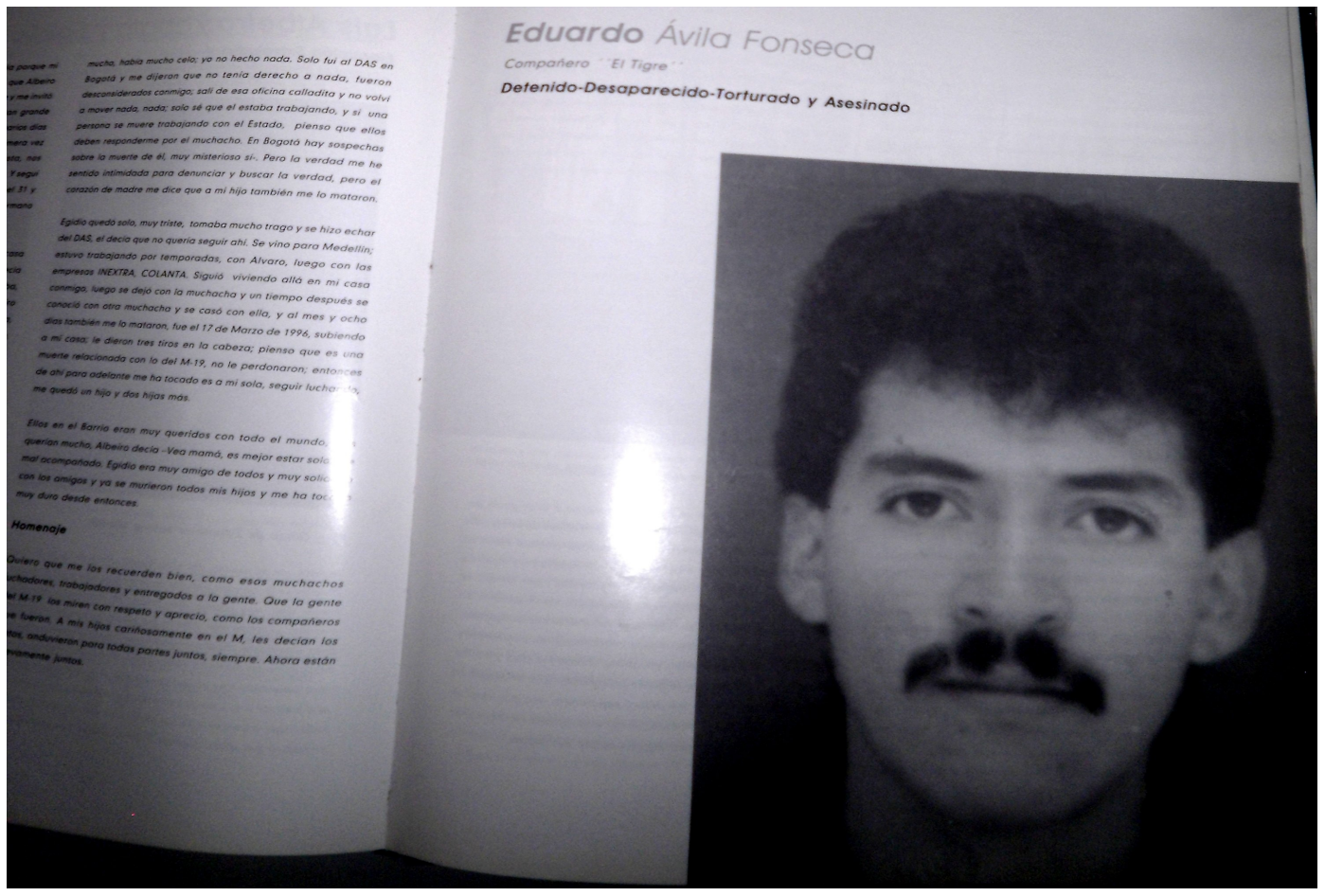

Eduardo Ávila. Libro Herencias de Paz. 2011. Fotografía: Andrea Guatavita 
En el caso de Eduardo la hermana mencionó como pasó de ser un ser un hombre "tímido" a un militante convencido de la defensa de los derechos de otros. Razón por la cual ella explica su elección de la vía armada.

Ella participa en el taller. Inclusive ahora eso la ha motivado mucho en los escenarios de la universidad, yo le estaba comentando inclusive a Gloria, que mi hija propuso un foro para hablar sobre el tema. Ella está en el semillero de la universidad para empezar a hacer ese trabajo de investigación sobre los crímenes de Estado. Y ella esta allá peleándose el espacio para que nosotros podamos ir a hablar y llevar la galería porque según los profesores dicen que eso es muy peligroso (...) Pero creo que se han abierto tres espaciaos donde yo he podido entender muchas cosas donde me equivoque y donde todavía hay tiempo de recuperar que esos espacios que también necesita donde ella escuche a los demás y también que los demás la escuchen de esa ausencia de su padre, de por qué no le permitieron crecer al lado de él, bueno, tantas preguntas que están sin respuesta en relación a su papá, pero si nunca lo que yo le oculté que Eduardo Ávida Fonseca fue militante de izquierda, perteneció al M-19 pues porque igual la fotografías y todo que eran la forma como uno relacionaba y uno le contaba las historias y digamos que es como eso (Esperanza, entrevista 22 de septiembre de 2011).

Obviar información a la hija sobre las violaciones de las que fue objeto Eduardo, causó sentimientos de culpa en Esperanza, y gracias a lo reconstruido en el apartado anterior sobre la memoria traumática, es necesario decir que Esperanza seguramente desde su dolor pero también desde la experiencia construida en el apoyo a otros familiares intuyó que el carácter de la información o la descripción de lo ocurrido en tanto relacionado con una acción mordaz sobre el cuerpo de Eduardo podría generar daños muy profundos a su hija. No tener toda la información puede ser un reclamo por información, pero puede ser también un reclamo de protección frente al dolor generado por la desaparición. Pero ni la desaparición, ni la manera como Eduardo fue objetivado por sus captores son responsabilidad real de Esperanza.

- Se puede hablar de que estos espacios de memoria compartidos entre las distintas generaciones son reparadores para el impacto sufrido por la familia.

- Son muy importantes porque eso permite afianzar y realmente dar la importancia que esa persona representaba para nosotros que a pesar que ella estaba muy pequeña, pero igual ella reivindica su papá y a ella no le da vergüenza (Esperanza, entrevista 22 de septiembre de 2011). 
La responsabilidad generada a padres y madres que quedan al cuidado de los hijos y la transmisión de lo ocurrido es muy alta porque se les pide que superen un mandato social en cuanto a que sobre la militancia política no se puede hablar, que pasen por encima de un marco establecido desde la represión para cuidar la memoria de sus padres, y al mismo tiempo están obligados a proteger y conservar la salud y la seguridad de sus hijos. Cada padre, madre, tío, tía, abuela, ha encontrado y ha creado un camino distinto para que esto ocurra.

Los grupos de familiares construyen un espacio de contención inicial, gracias a la identificación que permite la construcción de una organización que se moviliza por las familias y busca incidir a nivel político. Gracias a esos niveles les es posible servir de soporte, primero para escuchar, luego para el trabajo colectivo pero finalmente para avalar y proteger memorias como las que se menciona y debatir las reflexiones sobre el tema.

Mas allá de eso y teniendo en cuenta la politización de los familiares pero también su capacidad para reconocer y divulgar la militancia política de las personas desaparecidas, cuando tuvieron esa militancia y en medio de este contexto tan adverso, dar testimonio es resultado del amor y la valentía. ¿Cual es la dificultad entonces en este ejercicio? Que la experiencia del familiar se ve involucrada en acciones de incidencia independientemente de su estado emocional y el uso político que se da a su testimonio.

Entonces no es que dejé todavía de reprocharle eso pero por lo menos si como que el interés por reconstruir ahorita su proyecto de vida, su trayectoria de vida me ha ayudado a entender y sanar eso como decir: "Ey si lo compartía pero era el otro amor de su vida aparte de sus hijas también era su proyecto político y eso". Entonces en ese proceso me ha ayudado (Shaira, entrevista realizada el 26 de julio de 2011). 


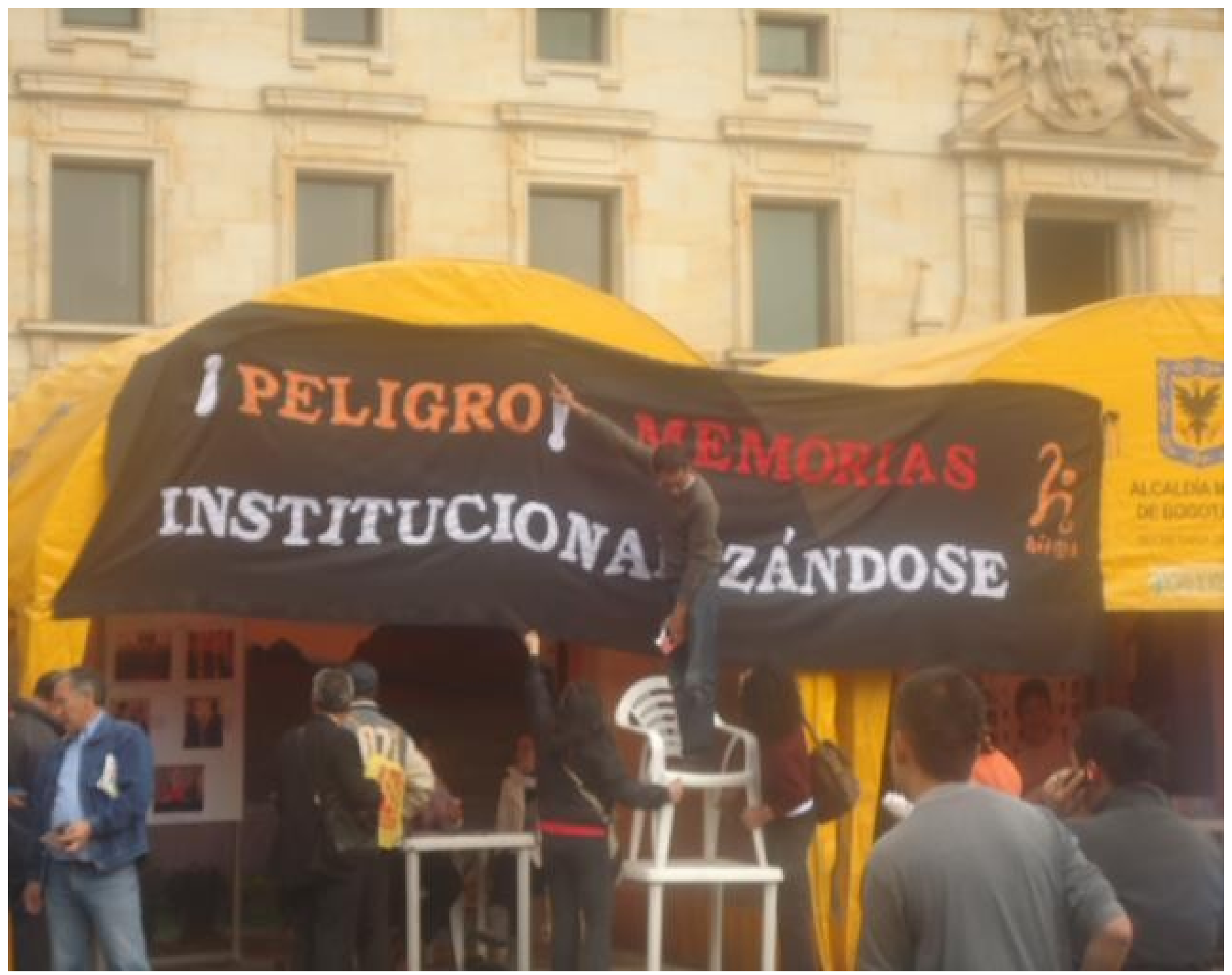

Conmemoración del día de las víctimas programada por la presidencia de la república en el marco de la ley 1408.

Fotografía: Movimiento de Hijos e Hijas por la memoria y contra la impunidad. Tomada de Internet. 


\section{Quinto Capítulo: Memoria intencional colectiva}

El coronel Aureliano Buendía promovió treinta y dos levantamientos armados y los perdió todos. Tuvo diecisiete hijos varones de diecisiete mujeres distintas, que fueron exterminados uno tras otro en una sola noche, antes de que el mayor cumpliera treinta y cinco años. Escapó a catorce atentados, a setenta y tres emboscadas y a un pelotón de fusilamiento. Sobrevivió a una carga de estricnina en el café que habría bastado para matar un caballo. Rechazó la Orden del Mérito que le otorgó el presidente de la república. Llegó a ser comandante general de las fuerzas revolucionarias, con jurisdicción y mando de una frontera a la otra, y el hombre más temido por el gobierno, pero nunca permitió que le tomaran una fotografía. Declinó la pensión vitalicia que le ofrecieron después de la guerra y vivió hasta la vejez de los pescaditos de oro que fabricaba en su taller de Macondo. Aunque peleó siempre al frente de sus hombres, la única herida que recibió se la produjo él mismo después de firmar la capitulación de Neerlandia que puso término a casi veinte años de guerras civiles. Se disparó un tiro de pistola en el pecho y el proyectil le salió por la espalda sin lastimar ningún centro vital. Lo único que quedó de todo eso fue una calle con su nombre en Macondo.

(Gabriel García Márquez, Cien años de Soledad)

Este capítulo recoge las reflexiones de la memoria afectada o construida desde marcos sociales que superan los elementos individuales y familiares. Aquellos elementos que devienen del momento histórico y la matriz ideológica que sirven de sustento a la construcción de la memoria. Esto no quiere decir que los anteriores capítulos no estén relacionados con estos elementos. Pero este capítulo se ocupa con mayor profundidad de la memoria que se construye conscientemente desde la preocupación por los usos políticos y las políticas que se instauran para definir el pasado.

\subsection{Memoria colectiva y pasado traumático}

Según Traverso (2010) el concepto de trauma ingresa en la historiografía, en medio de un cambio en el clima ideológico mundial como resultado del abandono, por parte de Europa, de la idea de la revolución y el siglo XXI inició con la caída de la utopía y la sombra de la derrota del comunismo. Una dinámica fruto de la influencia subjetiva sobre la reflexión crítica propia del historiador relacionada con la reivindicación de las "víctimas" y la evaluación del pasado por parte de antiguos revolucionarios, como creación de nuevas estrategias de lucha y ante la estrechez del campo histórico para recuperar o proteger del olvido expresiones sociales de 
grupos subalternos.

Traverso (2010) ve en su recorrido por la historia del siglo XX distintos traumatismos: Millones de jóvenes campesinos que vivían gracias a su relación con la tierra llegaron a la ciudad, se desarrollaron las guerras y las represiones políticas. El acontecimiento traumático recogería hechos de violencia y cambios en las formas de vida y producción. El hecho traumático no se limita a la muerte, sino que se expresa en cambios abruptos en el proceso social o el recorrido histórico y la pérdida de un ideal. Enmarcados en la visión de derrota que expresa el historiador a causa de la caída del muro y el socialismo utópico. Visión que no puede ser trasladada sin menor cuestionamiento al análisis de las disputas actuales en latinoamerica como la adopción directa de una mirada sobre Europa.

Para Lavabre (2006), la noción de acontecimiento traumático califica a la experiencia de violencia como elemento inicial, pero incluye a la memoria, al recuerdo traumático. Según Lvovich (2007), el carácter traumático de los sucesos depende de las políticas de represión de un régimen y el clima social, es decir, incluye como parte de lo traumático la reacción o el papel que cumple la sociedad durante la implementación de los planes de represión.

Arostegüi (2006), historiador español, afirma que el trauma es el resultado social y culturalmente comprobable de acontecimientos violentos, en sentido amplio, que afectan a un colectivo, (...) da lugar a la persistencia de una vivencia luctuosa, compartida y, en su momento y forma, también, en la que se refleja la ruptura abrupta y violenta de una cierta pauta histórica que adquiere un sentido perturbador para el desarrollo futuro de tal colectivo, son captados como críticos y violentos y son producidos por causas internas o externas, constituyen traumas sociales o históricos colectivos, son rupturas totales en el seno de una comunidad, tragedias colectivas entre las cuales están: La represión o exterminio sistemático, opresión política continuada, imposibilidad impuesta por la fuerza para construir identidades diferenciadas, y la guerra. Introduce el análisis de las causas, aplica el concepto de trauma a la noción de historia, se pregunta por el efecto que tiene en la identidad, en la cohesión, en el duelo, y lo ubica como el origen de la memoria. 
El hecho traumático a nivel histórico condensa según los distintos autores: un hecho violento con dimensiones colectivas o un hecho decisivo que cambia las condiciones de vida de un colectivo, sin ser siempre la guerra o un acto de violencia física. Incluye preguntas sobre el papel de la sociedad afectada por el acontecimiento y por las causas internas de los hechos. Si un hecho violento es traumático tanto o más por la participación o legitimación de la sociedad, claramente hay una preocupación por el relato y por entender el origen de los sistemas que dieron lugar a formas masivas de victimización.

Para diferenciar este concepto del que es usado en salud mental, sirve el siguiente ejemplo: No se busca al interior de la psique de un torturado condiciones previas para ser objeto de tortura. Esta acción se lee como un hecho externo que lo victimiza, y posteriormente, no se reduce su personalidad a esa condición psicológica, o al impacto que la tortura genera, pero ese impacto no se desconoce porque es nefasto y genera una condición traumática. La condición traumática también se vincula con frecuencia al silencio que se sostiene durante un tiempo para su elaboración, pero este tema también es particular en el ámbito social y será analizado más adelante. En cambio, una sociedad que engendra sistemas de exterminio -conceptualizados desde la historiografía como traumáticos- si puede analizar los núcleos económicos, políticos y sociales que la llevaron a estos, y sumar a ese análisis las causas exógenas relacionadas, por ejemplo: prácticas de colonialismo de los países "más desarrollados".

En la reconstrucción del pasado de un grupo social aplicar el término trauma requiere una resignificación del concepto, el reconocimiento de los procesos que al exterior y al interior de la colectividad hicieron surgir expresiones de violencia y dominación. La comprensión de estas cuestiones puede llevar al descubrimiento de la lucha de clases, los mecanismos ideológicos, los sistemas de coerción, entre otros. Pero con frecuencia deja de lado al proceso de resistencia.

Lo interesante es que el reconocimiento de un periodo "traumático" ha permitido crear marcos sociales de reflexión interna y externa sobre los límites sociales y las cosas que 
"Nunca Más" deben volver a pasar. Se trata de momentos en donde se define un mandato moral para toda la sociedad. Lo problemático es que se generan rupturas y extrañamientos frente a las expresiones de mayor "violencia" que crean esas sociedades con respecto a los procesos históricos anteriores. Ejemplifica Lvovich al rededor de la historia italiana:

... En efecto, por un largo tiempo los historiadores ignoraron el problema del fascismo y aceptaron como definitiva la imagen provista por las interpretaciones de la militancia antifascista. De acuerdo con esa imagen el fascismo no habría tenido vitalidad, ideología ni soporte de masas, y no habría significado más que una dictadura de clase, terrorista y demagógica (Lvovich, 2007:105).

Aunque en los apartados anteriores hablamos del recuerdo, traumático o amoroso de los familiares de personas desaparecidas, el elemento de la transmisión, la diferencia entre el pensamiento del pasado y este que se está engendrando, es fundamental para hablar de memoria colectiva del análisis, la interpretación y el establecimiento de morales, éticas o principios políticos colectivos. 


\subsection{Disputas por el establecimiento de la memoria}

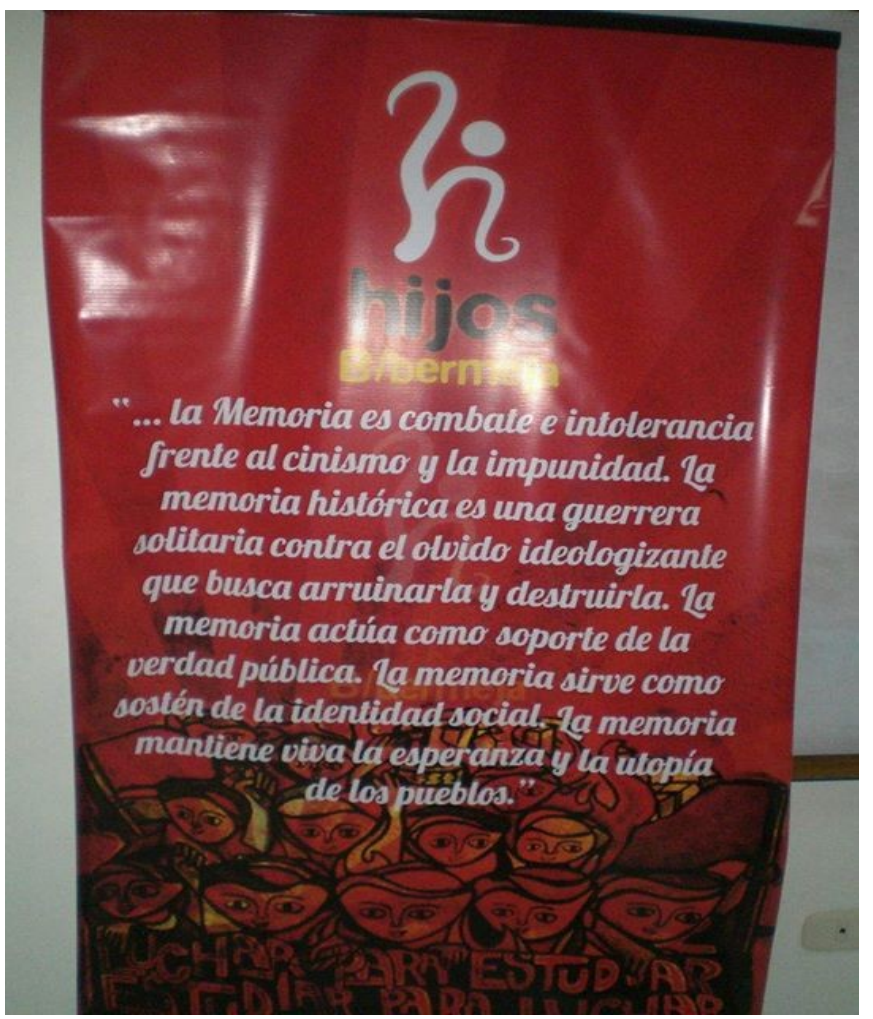

Fotografía: Movimiento de hijos e hijas por la memoria y contra la impunidad. Tomada de Internet.

Puede proponerse que es justamente en la memoria en donde ocurre el trauma colectivo. Es decir que el evento traumático se definiría como la imposibilidad de transmisión memorística a causa de unos hechos que atentan contra el colectivo y la ausencia de recuerdo en las siguientes generaciones.

Es decir, aquellos que hacen parte de los mismos grupos de pertenencia de los desaparecidos son portadores de una herencia con respecto al pasado y sus luchas y en consecuencia, los afectados seríamos hombres y mujeres desconocedores de ese pasado a causa de la selectividad del marco social represivo y de impunidad instalado en Colombia. Afectados teniendo en cuenta que lo olvidado tiene que ver con un repertorio de lucha común a nuestra propia condición social y su olvido es benéfico a los sectores que se mantienen en el poder, o en espacios de control que definen una limitada participación política de nuevos actores, una distribución desiguaa del capital,la marginación de amplios sectores de la población, la conversión de derechos básicos en servicios pagos, entre otros. 
En ese caso el rescate de la memoria es una nueva práctica de apropiación de un saber histórico y en consecuencia, una acción ideológica. La memoria reconstruida en la investigación del pasado con la participación especial de testigos, al rededor de periodos y escenarios vinculados con la lucha de los familiares. La memoria tendría su sentido entonces en la posibilidad que da de recordar otra vez, re interpretar y analizar la imagen que vuelve, no en establecerse, tiene sentido en su transmisión, contando con que quien la recibe no está pasivo, adelanta una práctica de reconstrucción que re estructura su forma de ver las cosas.

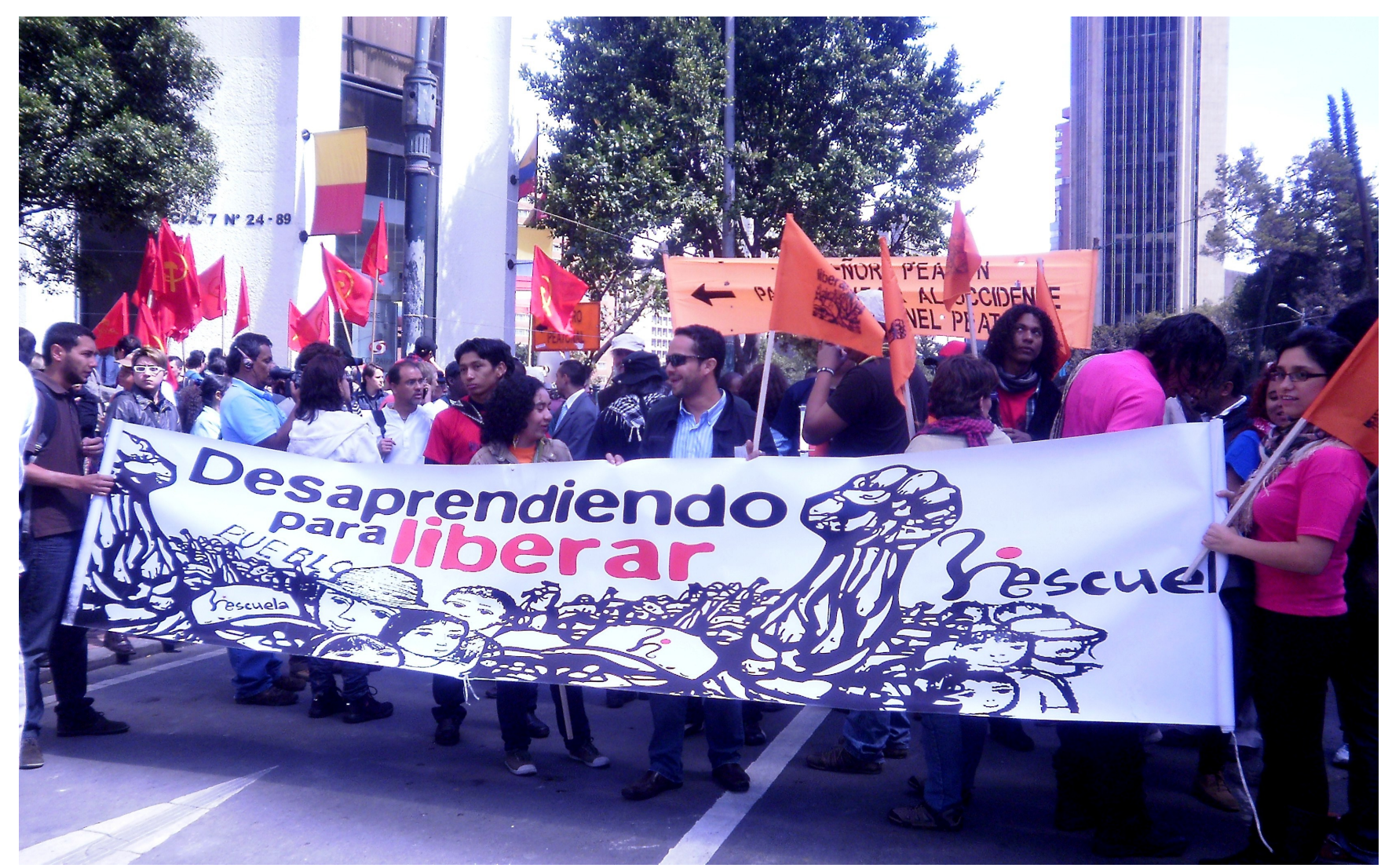

Hijos e Hijas por la memoria y contra la impunidad en la Marcha del Día Mundial de las Víctimas de Crímenes de Estado, por una restitución real e integral de las tierras en Colombia. Bogotá. 6 de marzo de 2012. Fotografía: Andrea Guatavita. 
El historiador Arostegüi (2006) afirma que si tiene realidad la memoria colectiva, la memoria generacional es una de sus formas, es la proyección de una anamnesis que tiene un sentimiento generacional. La memoria estaría relacionada con el sentido del que se provee al pasado y con la posibilidad de superarlo a través de una suerte de anamnesis contra el olvido. La memoria conflictiva es la de los hechos violentos, que dejan una huella trágica y duradera, por lo tanto llevan consigo un efecto de memoria. "Pero llevan en su seno la memoria de lucha, confrontación y tensión" (Arostegüi, 2006:70).

En las narraciones logradas a través de esta tesis es pertinente decir que existe una lucha al interior de la memoria de la nación, esa lucha se da porque los grupos de pertenencia de las personas desaparecidas, por ejemplo, son antagónicos y tienen relatos que se enfrentan al relato oficial. En consecuencia, busca romper las narrativas hegemónicas, es decir las narrativas instalas sobre el pasado a través de aparatos que se pusieron a funcionar durante los últimos diez años al rededor de: Las versiones libres de los paramilitares, las expresiones del ejecutivo por medios de comunicación y canales oficiales, programas de televisión y telenovelas y los alegatos que el estado presenta en las entidades de justicia tanto interna como internacional, a través de los cuales se determina no sólo la ejecución de la ley sino que se construye una verdad social.

Por otro lado, el enfrentamiento con las narrativas creadas para la impunidad, implica filtrar otras voces que intentan reconstruirse pero que ante las dificultades parecen más fragmentadas o se encuentran guardadas en archivos secretos, en álbumes de familia, y en la memoria viva de quienes sobreviven.

Parte de la sociedad se identifica con la lectura de los motivos de la desaparición como crimen de estado, es decir que asume o tiene un acuerdo ideológico, un acuerdo en cuanto a su forma de interpretar la desaparición como una realidad. Los valores que se asumen ante esta realidad y la conmoción que genera tienen consecuencia en las acciones.

Las memorias en tanto formas ideológicas están determinadas por las condiciones de los 
grupos sociales que las producen. El trabajo de la memoria no se aísla de esas condiciones $y$, en ese sentido, es coherente con la experiencia de cada sujeto dentro de su grupo social. Cuando los militares afirman que matar subversivos es una acción justa lo creen solemnemente, porque esto les permite reconciliar su acción con su moral, y porque les permite reproducir, a través de la formación de nuevos soldados, ejércitos que cumplan esta misma tarea. Esta idea se instaló durante el gobierno de Álvaro Uribe a través de los espacios institucionales, las alocuciones presidenciales, y las políticas de seguridad. Es decir que avanzó en cuanto al campo de control y generó cierta asfixia con respecto a otros discursos sociales.

Las personas desaparecidas se convirtieron para las instituciones del estado en cifras sin nombre. Sus políticas apuntaron a la acción jurídica y científica en medio de una gran contradicción entre lo que se propone en términos de reparación y lo que se hace con los familiares, durante los procesos de identificación, búsqueda del familiar y penalización de los responsables.

Una de las dificultades que están en el fondo de la selección de contenidos o de formas de tratar la desaparición tiene que ver con la ideología instaurada durante la última década con respecto a las razones y acciones del estado para violar los derechos humanos, justificación que deshumaniza y que permite o se hace efectiva en la transformación de los familiares en cifras.

Claro habían como posiciones encontradas, los medio de comunicación manejando los altos porcentajes de simpatía que tenía Uribe, la seguridad democrática que garantizaba supuestamente la paz pero además que la gente pudiera andar por las carreteras, organizaron unas caravanas para impulsar el turismo por carretera. Por supuesto una seguridad democrática que sólo beneficiaba y beneficia a quienes tienen y ostentan el poder desde la economía, la politiquería, fue concebida para eso. Claro a los pobres no nos beneficiaba porque no tenemos carro, no podemos ir a pasear, porque no tenemos salario. La economía que se fue fortaleciendo en "el día a día", cómo conseguir el día a día, bastante informal, bastante perseguida también por las autoridades. Entonces la gente ha tenido que salir a las calles a vender a revender para poder subsistir sin que haya garantías reales para tener un empleo con dignidad un salario acorde. Por supuesto los medios de comunicación nos pusieron a escuchar estadísticas de un 
pasado inmediato donde se negaban cifras porque decían que eso no era verdad, que aquí en Colombia no habían violaciones de derechos humanos, no habían desaparecidos no había nada, que eran inventos. Se pasó a mostrar grandes cifras. Si señor ellos en las versiones ya hablaron de diez, de cincuenta, de miles y empezaron a manejar cifras y estadísticas no solamente para la popularidad de Uribe sino estadísticas en todo sentido. Las estadísticas en la farándula si Juanes tenía más reiting de simpatía más que Shakira y por supuesto el involucramiento de toda las capas de la sociedad en la seguridad democrática y en la política de Uribe que no fue otra cosa que un fascismo puesto en marcha (...) (Gloria, entrevista realizada el 22 de septiembre de 2011).

Gloria se refiere a varios elementos del contexto: Una suma de encuestados apoyando a Uribe contra un gran número de muertos, las cifras de violaciones de derechos humanos pero también de popularidad. Las encuestas dijeron tres cosas: que en Colombia habían millones de víctimas, en algunos casos superando los datos obtenidos por las mismas

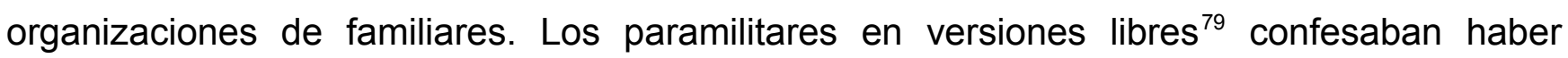
asesinado a miles de personas y sus confesiones amplias les proporcionaba beneficios de excarcelación; en otros casos, se dijo que las encuestas establecían que Uribe era el presidente más popular de la historia de Colombia, cifra que desapareció por completo la existencia de inconformidad u oposición y que se basaba en el aparente progreso de la seguridad democrática que quería decir, seguridad en manos de todos, todos vinculados con los planes del estado: la delación, el paramilitarismo, la estigmatización del otro.

Colombia, a pesar de la pobreza y la violencia se presentaba así mismo como un país inmensamente feliz ${ }^{80}$. Los familiares frente a esa afirmación tan homogeneizante se veían

${ }^{79}$ Las versiones libres

${ }^{80}$ Recientemente en un encuentro organizado por la Asamblea de Vecinos de Dorrego en Santelmo escuché a una representante de Costarica contándonos que los medios de comunicación difunden que su país es el país más feliz del mundo. Es decir que la estrategia ideológica para hacernos creer que en Colombia o hay autistas o la violencia y la pobreza son insignificantes no es única. La prensa de los dos países en el 2013 señala al mismo tiempo el mismo galardón para los dos países. En primer lugar RCN (Canalrcn, 2013) titula su nota de mayo del 2013: Nuevamente Colombia es el país más feliz del mundo según encuestas (...) La alegría de los colombianos tiene ese toque que los hace sobresalir en cualquier lugar del mundo, pese a la violencia y a los problemas económicos. La agencia Gallup publicó el listado de los países más felices, y entre las 54 naciones analizadas, Colombia ocupó el primer lugar. El 77 por ciento de los colombianos encuestados dijo que es feliz (...) La encuesta midió diferentes variables: la expectativa de vida y el bienestar. (...) En el ranking del 2013 le siguen a Colombia Malasia, Brasil y Arabia Saudí. (...) Juan Manuel Santos escribió en su cuenta en Twitter: "Golpe a los pesimistas: según última encuesta de Gallup Internacional los colombianos somos los más felices de todo el mundo ¿Qué tal?". Por su parte el diario la Nación de Costarica (Nación, 2013) publicó: San José (Redacción). Costa Rica nuevamente es catalogado como el país más feliz del mundo. El Happy Planet, que cada dos años marca el nivel de felicidad de los países del mundo nombró esta mañana a Costa Rica en primer lugar por segunda vez consecutiva, seguido de Vietnam y de Colombia. 
invitados a privatizar su dolor.

(...) la ley de justicia y paz que tiene que ver con los beneficios para los perpetradores, para los responsables y por supuesto una puesta en marcha del gobierno de Uribe Vélez de poner la situación de los afectados, de las víctimas en las versiones en ese boom publicitario de los versionados. Uribe meses antes había traído al congreso de la república -estamos hablando del 2005- a los paramilitares, llegaron casi como héroes, con alfombra roja, hubo mucha publicidad, inclusive artículos completos de cómo venían vestidos, la marca de los zapatos, la camisa y querer mostrarlos como estos seres humanos que no habían querido delinquir, que no habían querido causar daño pero que habían sido obligados porque se habían visto hostigados por la insurgencia por la subversión (...) Un ambiente de mucho manejo mediático para resaltar el arrepentimiento y la posibilidad de que desde ese arrepentimiento contaran la verdad, por supuesto un contexto donde las víctimas y los (las) afectadas estaban en la ansiedad de saber si servía o no servía, si voy o no voy a esa versión, y si me dicen que lo mataron en el caso de las desapariciones qué voy a hacer, si será verdad (...) Un juego perverso por supuesto desde los medios de comunicación al servicio de Uribe de hablar de la reparación desde una cifra irrisoria para callar a las víctimas. Una negociación perversa "si te doy plata no molestas más", pero además teniendo en cuenta que la mayoría de familias tienen necesidad, precariedad, sin posibilidades de vida digna (...)

Otro elemento importante de ese proceso fue el doble discurso con respecto a la solución del "conflicto armado". Por un lado se inició un proceso de desmovilización de los paramilitares, como si estos se adscribieran a ese concepto. Ese proceso no implicó el desmantelamiento de las estructuras paramilitares pero si el borramiento de sus estructuras de mando después de que fueron tan claras con la articulación de las Autodefensas Unidas de Colombia, dirigidas por Carlos Castaño.

Ese es el contexto en donde se movía Jaime Gómez, era asesor de Piedad Córdoba, pero además Piedad Córdoba había asumido una posición muy crítica con relación a esta ley de justicia y paz, por ende Jaime Gómez al ser asesor tenía una posición crítica a esta ley (...) Eso hizo que personas como Jaime Gómez que venían de un proceso de sindicalismo, militancia de izquierda, posiciones demócratas, quien también tuvo sus etapas de ser sindicalista radical, militante de izquierda, lograran golpear a Piedad, llevándose a Jaime golpearon a Piedad que empezaba a ser bastante señalada por el gobierno (Gloria, entrevista realizada el 22 de septiembre de 2011).

El programa de Álvaro Uribe, que se mantiene con el gobierno actual a pesar de algunos cambios y las disputas que esos cambios evidenciaron al interior de la derecha colombiana, 
tuvo como otro elemento central la ley de justicia y paz. En esa desmovilización habían varios elementos en juego: los desmovilizados pasaron por un proceso judicial que blanqueó por pocas penas su historial delincuencial. Les dio acceso a un conjunto importante de beneficios institucionales (empleo, salud y trabajo) y a presupuestos del Estado. Se centró en las versiones libres. Este hecho tocó muy fuertemente la sensibilidad de los familiares. Madres de hijos desaparecidos visitando y pidiendo a los paramilitares que contaran el paradero de sus hijos y asistiendo a numerosas exhumaciones en muchos casos sin obtener ningún resultado. Familiares que perdieron sus bienes y actividades de sostenimiento. Acciones denunciadas por las organizaciones de familiares, rechazadas como política de reparación por el conjunto de las organizaciones de derechos humanos y señaladas como un elemento más dentro de la cadena de victimización contra los afectados para debilitarlos más que para repararlos.

Por otro lado, la guerra declarada a los grupos guerrilleros que pasaba por negar la existencia de estos como grupos beligerantes y negarles su estatus político para impedir el retorno a la mesa de negociación política. Este elemento es fundamental para entender por qué el rechazo a la política de desmovilización en medio del terrorismo de Estado, la insistencia de personas como Piedad Córdoba en la liberación de los secuestrados y el reconocimiento del derecho a la rebelión.

Piedad Córdoba y su asesor, el desaparecido Jaime Gómez estuvieron empecinados en oponerse a las propuestas de Álvaro Uribe Vélez. La tarea de aclarar los hechos contra Jaime está inserta en este complejo panorama y no es de extrañar que los familiares vivan las consecuencias de esa problemática también en su seguridad y por lo tanto, en las posibilidades de reconstruir su memoria. Pero ante eso surge la organización de hijos e hijas herederos de la izquierda colombiana.

La aparición de hijos e hijas que recuerdan y discuten la historia de antiguos militantes permite la aparición de un discurso en medio de las organizaciones de familiares que interroga la política de impunidad de la Ley de Justicia y Paz. 
- ¿Tu papá fue del Partido Comunista?

- No primero empezó en el MOIR ${ }^{81}$ y después empezó a migrar a un montonón de cosas, después fue parte del sindicato de la empresa de teléfonos de Bogotá, de Sintrateléfonos, luego estuvo cercano a Antonio Galán y luego empezó a trabajar con Piedad.

- Cuando vi el documental me quedé con una pregunta a propósito de sus aportes y su posición política, tú decías que él era un hombre amigo del pluralismo político y dijiste: "A pesar de que leía a Marx era un hombre amigo del pluralismo político" ¿Cuál era la mirada ideológica que tenías con respecto a su posición política? ¿cuál es la posibilidad de distanciarse, crear otras, conservar otra posición política, como funciona eso para ti?

- Pues yo fui siempre muy critica de mi papá incluso estando vivo y teníamos diferencias políticas grandes, pero siempre reconocí en él una persona que fue más allá del marxismo ortodoxo, por eso la referencia a Marx y a la izquierda clásica. Mi papá creció formado en esa izquierda de Marx, Mao, Lenin, etc, pero tenía una visión crítica sobre ellos y había incluso en su perspectiva política otros debates importantes. Entonces mi papá incluía y sabía la importancia de la lucha feminista, de la necesidad de reconocer a los afros, sin querer decir con eso que era el hombre mas avanzado en esas discusiones pero las reconocía y reconocía otras dimensiones, la dimensión latinoamericana de la lucha o ese era su deseo. Y había leído muchos otros autores que me parecía le hacían tener una visión crítica de la izquierda y del marxismo y yo le escuchaba a mi papá hacerle críticas a la izquierda de que era muy sectaria o que no era tan abierta para abordar los debates, pero en otras cosas también mi papá resultó muy... bueno, teníamos posiciones distintas (Diana, 21 de septiembre de 2011).

\section{La aparición de hijos e hijas promovió ubicar a las personas desaparecidas, por ejemplo, como personas que fueron objeto de una violación de derechos. Pero las vinculó a ciertos hechos políticos con una interpretación y una finalidad.}

Al conocer a los hijos me aterrizó un poco escuchar las historias de vida de ellos, aterrizarme que si podía ser por razones políticas y empezar a hacerme a la idea de que no lo iba a encontrar con vida porque cuando los conocí él estaba desaparecido, entonces digamos que fue bueno estar con ellos porque era como que mucha gente me decía: "No lo va encontrar vivo, tenemos que comenzar a buscarlo en estos lugares". Pero yo me negaba a aceptar eso, y estar acompañada en ese proceso con ellos decir: "Ey, mira cuando a mi papá lo asesinaron, lo desaparecieron, nosotros teníamos que buscar en los basureros, en estos sitios". Me sentía, sentía que las personas que estaban diciendo eso podían

81 Movimiento Obrero Independiente Revolucionario de ideología marxista leninista. Fundado en 1970 hace parte fundamental del Partido Político Polo Democrático Alternativo. 
entender lo que yo estaba sintiendo, los hijos y las hijas, porque ya habían pasado por eso y porque estaban metidos en todo ese cuento. Entonces fue importante para mi para aterrizarme de que si había sido por razones políticas las que habían desaparecido a mi papá y saber que no lo iba a encontrar con vida. Y saber que todo este tiempo hubo muchos cambios en mi vida, entender también por qué mi papá dedicaba tanto tiempo a esa lucha de los derechos humanos de los trabajadores y todo eso porque yo creo que si hubo un momento de mi vida en que le reproché la falta de tiempo en la casa (Shaira, entrevista realizada el 26 de julio de 2011).

En estos párrafos además de indicar que hijos e hijas son pares y se identifican, influyen en la comprensión del contexto de quienes escuchan y quienes comienzan a participar del grupo también es importante decir que aparece en todos los casos la idea de que hay una posibilidad y un riesgo que sigue oculto en medio de ese contexto tan estigmatizado. No es posible imaginar o aceptar, o entender hasta que punto las políticas de estado han llegado a actuar en contra de la población, y de los grupos de izquierda especialmente. Esa acción es invisible y, contradiciendo su invisibilidad, es legítima.

En segundo lugar, la memoria construida por hijos e hijas reivindica a los desaparecidos como miembros de la familia y la sociedad con un nombre, una pertenencia, una identidad y con dificultades y marcas culturales que los humaniza y los convierte nuevamente en gente del común. Dejando ver que las desapariciones le ocurren a gente como toda, que transita sus relaciones con diferencias, dificultades e incoherencias. Sobre todo cuando la desaparición ocurre después de que entre la primera y la segunda generación se establecieron relaciones de convivencia.

Hijos significó una posibilidad de hacer un duelo o una etapa del duelo más en compañía, hacer el ejercicio de exigir verdad, justicia y reparación no sola sino reconociendo que habían otros que habían pasado por mi misma situación y me acompañaban en esa demanda de verdad y justicia; y también ha significado reconocer otras historias similares y en esas historias similares aprender a reconocer la particularidad de mi propia historia. Digamos que al principio estaba muy vinculada a hijos por lo organizativo básicamente, obviamente habían sentimientos, emociones y afectos que me ligaban a la gente de hijos pero estaba en un momento de mi vida, después de lo de mi papá, muy bloqueada también emocionalmente y muchas veces evitaba los espacios de socialización. Y la cosa con hijos es que cada vez que te encuentras... por ejemplo, con Shaira he compartido mucho el hablar de nuestros 
papás y con Shaira ha pasado algo bonito y es que hemos hablado de nuestros papás de manera crítica, diciendo las cosas que no nos gustaban de ellos, las cosas que nos hirieron y eso también ha sido importante. $\mathrm{O}$ ha habido momentos en que he recordado a mi papá con rabia, pero bueno, creo que ya pasé ese momento de recordarlo con rabia.

- ¿Y porque?

- Porque él como todos los hombres no dejó de ser machista y era machista en sus relaciones, fui siempre muy crítica con él en sus relaciones de pareja pero también sentía que a veces era muy duro conmigo por el hecho de yo ser mujer, creo que ahí replicaba una forma patriarcal y esas formas a veces duelen mucho en las mujeres. $Y$ también molesta porque era un papá de izquierda, bueno no necesariamente por ser de izquierda, pero era un papá que en algunos momentos estuvo ausente (Diana, 21 de septiembre de 2011).

Las personas desaparecidas son ubicadas también, en un proceso histórico marcado por distintos momentos y formas de pensamiento que se han venido transformando, con los costos personales que esa ubicación implica cuando trae consigo los efectos de la desaparición pero también la conciencia de la afectación a nivel social.

Por ejemplo -yo pensaba- la primera vez que hice un documental de Nydia además eso fue muy curioso -he pensado: “¿Por qué en Alemania tenía que pensar en hacer una documental sobre Nydia, sobre los desaparecidos y esa historia si ya supuestamente estaba lejos? Era que quiero contar esta historia y quiero vivir otra diferente". Pero nada, fue engancharse más. Ha sido lo mismo que con el libro dije: "He vivido estas cosas y de alguna manera tengo que tramitarlas para poder mirar hacia otro lado también". Pero es sumergirse otra vez, es abrir una nueva puerta donde uno encuentra diálogos sobre lo que escribe sobre lo que hace y a veces lo que quisiera es ver otro paisaje. Lo que tú me dices los sueños (Chico Bauti, entrevista realizada en Septiembre de 2011).

Gracias a la labor de investigación sobre las personas desaparecidas, se conocen su vida, sus relaciones y su trabajo, desde distintas preguntas guía. Con la transformación de la imagen del ser querido a través de la comprensión y el conocimiento de su acción en otros escenarios cambia o influye en el proceso subjetivo.

- La idea de hacer reconstrucción de la vida política ¿de dónde surgió?

- Pues es que yo no sé yo tengo presente un momento que mencionaba en el documental, el momento del velorio de él, ver la cantidad de gente que estaba ahí acompañándonos de organizaciones políticas, 
del movimiento social y la gente se acercaba, preguntaban dónde estaba yo y se acercaban y me decían que yo tenía que sentirme orgullosa de él, que mi papá era una persona muy importante para la organización sindical, para el movimiento, porque les había ayudado desinteresadamente, porque salía de su trabajo y lo llamaban para que les ayudara a solucionar algún problema y él siempre estaba ahí. Entonces yo ahí fue que empecé a entender por qué mi papá no llegaba temprano y eso y que él siempre vivía pensando en función de esas cosas, siempre llegaba a hablar de los problemas del sindicato, de la situación del país, entonces yo digo: "Lo que mi papá estaba haciendo era importante". Como que yo no dimensionaba que eso era tan importante para él y para otras personas hasta que yo no veo tanta gente hablándome y agradeciéndome y diciéndome que debía sentirme orgullosa (Shaira, entrevista realizada el 26 de julio de 2011).

A pesar de la vinculación temprana a otras organizaciones, los hijos y e hijas se suman a procesos que les compete mas directamente y que constituyen movimientos a nivel nacional.

- ¿Has tenido vinculación con otras organizaciones de víctimas?

- Desde muy pequeño la vinculación con Asfaddes hasta el tiempo en el que nos exiliamos... 97'...96' y pues estando en el exilio con muchas organizaciones de trabajo solidario con Colombia, la Coordinación Colombia Europa, tenemos un grupo de solidaridad e intercambio cultural con Latinoamérica y empezamos desde que yo llegué a trabajar con Colombia. Cuando regresé a Colombia empecé a trabajar con vivo arte que es un colectivo de jóvenes - éramos jóvenes en aquel entonces (risas) trabajábamos con jóvenes y aún existe. Y el Movimiento de Hijos e Hijas por la Memoria y contra la Impunidad hasta hace poco su separación. Ahora se llama la organización en donde estoy yo Hijos por la Identidad y la Justicia contra el Olvido y el Silencio.

- Te vinculas a Asfaddes desde muy pequeño, me puedes contar un poco porque se dio esa vinculación.

- Cuando mis tías comenzaron a preguntar por mi madre unos compañeros de Nydia que aún están vivos porque ya después no, les dijeron de la existencia de Asfaddes. Entonces mi tía se empezó a acercar a Asfaddes y después yo - tenía doce años- y en las primeras marchas salíamos con Asfaddes -desde los trece años-. Ahí empecé a conocer, por ejemplo, a la gente que luchaba por la objeción de conciencia y después cuando me tocó el turno estuve en el Colectivo Objeción de Conciencia impulsando la ley de objeción para la constitución del 91. Desde entonces (risas) (Chico Bauti, entrevista realizada en Septiembre de 2011).

Lo interesante en la separación del proceso familiar y la lucha de las madres desaparecidas es el nivel o la posibilidad de separación de los criterios o los caminos decididos por el padre o la madre para poder continuar la articulación de hijos e hijas como sujetos históricos, pero 
también teniendo en cuenta que al interior de la organización hay rupturas y diferencias.

Hago parte del movimiento de hijos e hijas por la memoria y contra la impunidad hace ya tres años exactos. Conocí el movimiento durante el tiempo que mi papá estuvo desaparecido, busqué a Iván Cepeda en el momento que el estaba desaparecido para que me ayudara a contactar a unas personas que hicieran presión en la ONU para que se agilizara la búsqueda de mi papá, él me puso una cita días después y ahí conozco al movimiento (Shaira, entrevista realizada el 26 de julio de 2011).

La articulación al movimiento de hijos e hijas va de la mano con adelantar la búsqueda más allá de la reivindicación de la memoria personal. Eso demuestra un panorama que es diferencial entre miembros de organizaciones de hijos e hijas en Argentina y miembros de organizaciones en Colombia. El paso o en algunos casos el desarrollo de las tareas de búsqueda, experiencia de duelo, exigencia de justicia, protección frente a la persecución, reivindicación de la memoria y desarrollo de procesos políticos que hagan ruptura con el legado anterior se dan todas al mismo tiempo.

Frente a esto un problema recurrente es el de por qué hacer memoria en este momento en Colombia. Tal vez es tiempo de buscar, reivindicar, denunciar y movilizarse. Si esta fuera la primera vez, o durante el gobierno de Álvaro Uribe fuera la primera vez que se desarrolla o se ejecuta la desaparición forzada por primera vez. Pero no, y los hijos e hijas que vienen vinculados hace más tiempo le recuerdan treinta o veinte años después o le cuentan por primera vez al resto de la sociedad que sus familiares fueron victimizados. Este proceso que influye también el trabajo de organizaciones o entidades educativas ha dado lugar a todo tipo de situaciones.

No sé si haya tenido escenas de pánico y eso, bueno una vez si, creo que identifico una y es que recién pasó lo de mi papá yo conocí a Erick y a Hada Luz y entonces Claudia Girón nos invitó a hablar de nuestras historias de vida y habían pasado quince días después de lo de mi papá, entonces ese día yo escucho la historia de Hada Luz y la historia de Hada Luz es muy terrible porque perdió a su papá y a su mamá y entonces esa noche mi mamá no llegaba a la casa, yo estaba histérica estaba tan histérica que cogí el control del televisor y se lo tiré al televisor y dije: "Auxilio, qué está pasando aquí" (Diana, 21 de septiembre de 2011). 
En algunos casos se crearon escenarios completamente desafortunados con respecto a la situación emocional de los familiares confundiendo la denuncia con un aparente proceso de memoria, sin tener en cuenta que cada una de estas acciones implica necesidades diferentes. Una de ellas afortunadamente generó por otro lado, la acción y la solidaridad que en las personas que la escucharon.

(...) hijos se ha metido en la academia de hecho fue ahí que yo me conecté con hijos en la universidad. Ellos llegan a contar y yo digo: "Cómo es esto yo no sabía esto".

- ¿En donde estudiaste?

- En la Javeriana (...) Entonces de ahí ya nos conectamos, entonces ahí se han metido a la academia ese ha sido un espacio, eso es clave, la academia, a través del fútbol ahí se hicieron varias propuestas de lo que se iba moviendo por parchecitos nos íbamos organizando ahí tratando de organizar. Ahí sí estuvimos mucho tiempo organizándonos.

- ¿Quiénes fueron a esa clase en la que tú estuviste escuchando esas historias?

- Yo escuché a Hada Luz, escuché a Diana Gómez recién desaparecido el papá que lo desaparecieron al lado de la universidad ella hablaba así como: "Aquí al lado de la universidad..." (Paula, entrevista realizada el 5 de octubre de 2011).

Este es el contexto de creación de hijos e hijas, un espacio al que se van articulando personas que recién están siendo victimizadas.

- ¿Inicias en el movimiento en el 2008?

- A mi papá lo desaparecen el 22 de abril del 2008 y yo conozco a los hijos y a las hijas en la marcha del 1 de mayo de ese año (Shaira, entrevista realizada el 26 de julio de 2011).

Aunque la organización de hijos e hijas se crea recientemente los casos que acumula de militantes victimizados o que pertenecieron a la lucha social tienen un espectro temporal muy amplio. Lo interesante es que en muchos casos todos hicieron parte de procesos paralelos y que cuando la organización nace parece fundar o cortar con la generación que venía prolongándose desde la resistencia contra el frente nacional hasta el comienzo del gobierno de Álvaro Uribe, es decir que adelanta su lucha durante más de treinta años y marca un 
corte. El movimiento de hijos e hijas dice: "Esta es una nueva generación". Qué es particular en esta nueva generación. ¿De qué elementos se ha dotado o qué cosas nuevas reivindica?

Nosotros queremos una historia crítica de la izquierda colombiana en la medida que sea una memoria para la transformación, es decir, queremos tener un recuento del pasado pero que no sea por contarlo y no más sino que nos permita un proceso de identidad con luchas del pasado y nos permita generar luchas nuevas. También la entendemos como una memoria larga en el sentido de que entendemos que se necesitan procesos de larga duración para entender lo que ocurre en Colombia (Diana, 21 de septiembre de 2011).

Con respecto al contexto hay muchas cosas que quedaron instauradas y que el movimiento de hijos e hijas discute.

\subsection{Matrices ideológicas}

-Cuando hablas de esa primera etapa, cuando dices que hay un primer momento en donde la gente se encuentra porque hay matrices ideológicas que les permite encontrarse y hablar, a qué matrices de estás refiriendo.

- Aquí es sencillo la... parte de la herencia de la izquierda moderna, de la izquierda occidental pues devino en cuatro matrices fuertes en términos ideológicos: Una es la del Partido Comunista, la del Partido Comunista Marxista Leninista, las experiencias de liberación nacional y diría que hay experiencias nacionales que pueden vincular experiencias socialistas, demócratas. Uno podría decir que son más pero digamos que son más las experiencias mismas que se van engendrando acá. Entonces cuando uno dice a qué matriz ideológica hace parte no quiere decir las estructuras aunque si pasa como que se está situado (...) en alguna de las estructuras pero también tiene que ver con todo el sentido de lo que podría llamar el campo de izquierda o el campo democrático que tiene una visión del mundo, unos objetivos, unos alcances, unos valores que están allí. Por eso difícilmente en hijos que fue un debate al comienzo, son los hijos de todas las víctimas, nunca pretendimos ese asunto sino hijos de...

- De marcarse en alguna matriz ideológica específica.

- De izquierda democrática nosotros nunca nos dedicamos a hacer un trabajo organizativo con hijos de secuestrados o con hijos de no sé... sino que estaba marcado por una visión de mundo, por una matriz ideológica con distintas entradas, a eso es a lo que me refiero (Camilo, entrevista 18 de octubre de 2011). 
Esas matrices se transmiten por espacios familiares y de formación política a las nuevas generaciones, se encuentran y se confrontan dando lugar a una memoria definida por estos paradigmas pero influenciada por la incidencia del feminismo, las miradas sobre las diferencias étnicas.

Una de las razones de esa confluencia no es sólo la existencia de diversos grupos auto reconocidos sino su inclusión en el marco jurídico de la nación. La constitución de 1991 integra en sus distintas normas a grupos étnicos con territorios colectivos y su participación obligatoria en las instituciones del estado. Esto a consecuencia de la participación de estos grupos en todas las formas de lucha del movimiento social colombiano que en el último proceso de negociación de la década del 80' abrió paso a la constituyente.

(...) pero en términos de lo que se mueve desde la estructuración del sujeto es difícil que yo me planteé un proyecto de nación distinta al alcance de la restitución de los derechos de las víctimas eso me parece volver a caer en una trampa que el estado ha puesto todo el tiempo: "Pelee por mujeres, pelee por niños, pelee por desplazados, pelee por indigentes". Entonces nos van variando la noción de sujeto.

-Pero ahí hay una discusión compleja porque tú estás diciendo que la pelea por los niños, por las mujeres... dices que es una trampa en la que cae el movimiento y que pone el estado y no por que sea una propuesta de reivindicación del movimiento social hablar de las mujeres en ese espacio.

-No porque sea la política pública... el movimiento social de izquierda crítico tiene propuestas muy fuertes y reivindicativas con nociones de sujeto desde las diferentes manifestaciones de los sujetos, todos, pero la política de estado social demócrata que está basada en una política garantista, en un asunto asistencial y en un asunto de discriminación positiva, lo que hace es fragmentar al sujeto. Yo no estoy diciendo que sea un problema de las feministas, estoy diciendo es que cuando el estado construye una idea de discriminación positiva en donde tú vales más por ser mujer sin tener en cuenta variables como la de clase, como la historia del estado, variables como la constitución de las mismas regiones o de las comunidades pues te está fragmentando y yo creo que parte de lo que decía antes del límite de la noción de víctima es que cuando ahí te sustraen del territorio, de la comunidad, te sustraen de la organización comunitaria o política y te colocan por encima de ella lo que hacen es romper un tejido muy fuerte porque no te están ofreciendo nada en términos del proyecto político que podría representar tu comunidad sino que te lo están ofreciendo es por la vulneración de algún familiar tuyo ni siquiera por un líder es que si no tienes el primer grado de consanguinidad no... entonces ahí hay una fragmentación muy fuerte (Camilo, entrevista 18 de octubre de 2011). 
La memoria de hijos e hijas como su nombre lo indica es reivindicativa de luchas políticas heredadas con una lectura crítica de esas cuestiones diferenciales. Se enfrenta a un concepto de estado en donde la "discriminación" separa a los sujetos en distintas categorías y con distintas necesidades, con el propósito de que se consolide en una agenda común un conjunto de propuestas de país. Es una memoria con un objetivo de transformación y recuperación de las luchas comunes.

-(...) en terminología de desplazamiento forzado intentan llenar de contenido ese vacío político que llaman el socialismo o democracia real, como le quiera llamar. Yo pienso que aquí pasa lo mismo en la noción de víctima hablando de reparación integral o hablando de justicia en sus versiones, es intentar vaciar ese proyecto y llenarlo ahí entonces casi que el debate no se vuelve... el debate es perverso porque cuando uno dice: "El problema es que estamos abordando la noción de justicia con las herramientas de justicia y con los sistemas de justicia del victimario". Y casi que la respuesta es: "Es que estamos llenando de contenido esa justicia". El problema no es llenar de contenido el problema es recuperar la matriz ideológica que habla de una justicia popular o de una noción de justicia comunitaria si se quiere (Camilo, entrevista 18 de octubre de 2011).

El movimiento de víctimas reunió algunos de esos elementos comunes en cuanto reconoció que había una estructura común de victimización y supero la división de perfiles que proponía el estado en donde el análisis se centraba en los impactos de cada víctima y no en la estructura y la lógica que la violentaba. Ese señalamiento surge durante el gobierno de Álvaro Uribe Vélez y se mantiene durante el de Juan Manuel Santos, reconociendo al mismo tiempo la impunidad en el proceso de negociación a través del cual el estado negaba su participación en la formación, conservación y uso de grupos paramilitares.

Y la tercera que es más frente al boom que hubo aquí de justicia y paz de paramilitarismo y toda esta emergencia del movimiento de víctimas en términos de la opinión pública, una serie de gente que asume esa bandera y se vuelve parte de hijos pero también de otro montón de escenarios del Movice, de Asfaddes, pero que tiene un pico histórico digamos... Asfaddes existe hace un montón de tiempo y yo creo que ha habido muy pocos momentos donde... esa emergencia de lo que fue la coyuntura del gobierno de Uribe pasó que mucha gente diga yo, pues que tengamos pasantes, que haya voluntarios, que haya gente que ofrece sus esfuerzos y corresponde sobre todo al escenario histórico y al desarrollo 
de la misma capacidad de propuesta organizativa que haya (Camilo, entrevista 18 de octubre de 2011).

La organización de Hijos e hijas surgió en esa coyuntura pero con la idea de no perder la lucha política que muchas de las víctimas mantenían antes de ser desaparecidas, asesinadas, exiliadas, perseguidas, retomaron las banderas y comenzaron a reivindicar la historia de sus familiares. Hijos e hijas construyen una propuesta de país. Muchos y muchas continúan, sin embargo, en la exigencia de sus derechos como víctimas porque la encuentran necesaria para su propio proceso y como una estrategia importante en la lucha contra la impunidad.

\subsection{La memoria y su incidencia en el Estado}

La memoria es reconstruida por hijos e hijas quienes proponen, al mismo tiempo, acciones institucionales a través de las brechas que se abrieron en el estado gracias, principalmente, a las entidades distritales dedicadas al trabajo con víctimas.

Nosotros hicimos un proyecto con la alcaldía de cartografía de la memoria y ahí se contaba la historia de Nydia Erika y en estos días le estaba diciendo a quién coordina eso - José Antequera ${ }^{82}$-: "Oiga yo quiero poner la placa porque me dijeron que ya estaba lista”. Y me dice: “¿Tú quieres poner una placa?” . "Para mí eso sí es importante sabes". "Pues la mandamos a hacer y la ponemos y no le pedimos permiso a nadie". "No pues yo lo hubiera hecho ya hace mucho tiempo es más yo he hecho muchos graffitis en la ciudad y no tengo que pedirle permiso a nadie, pero es el acto de que la institución y la alcaldía reconozcan que ahí hay una cosa". Eso es lo que a mí me parece que sería la acción porque de qué me sirve si hacemos unos mapas mandamos hacer cinco mil ejemplares y después viene otro afiche más bonito y lo cambian. El trabajo es realmente ponerlo donde pasan las cosas y que no se olvide. Porque cuál es el rollo de lo que ha sido con el Palacio de Justicia, que es la interpretación de una placa que cuentan una versión de la historia (Chico Bauti, entrevista realizada en Septiembre de 2011).

\footnotetext{
${ }^{82}$ Miembro de la organización H.I.J.O.S Colombia y miembro actual del Centro de Memoria Histórica Distrital. Hijo de José Antequera quien fue secretario general de la Juventud Comunista Colombiana, JUCO, y presidente de la Unión Nacional de Estudiantes de Colombia, UNEC. Dirigente nacional de la Unión Patriótica y secretario nacional de organización del Partido Comunista Colombiano. Asesinado el 3 de marzo de 1989.
} 


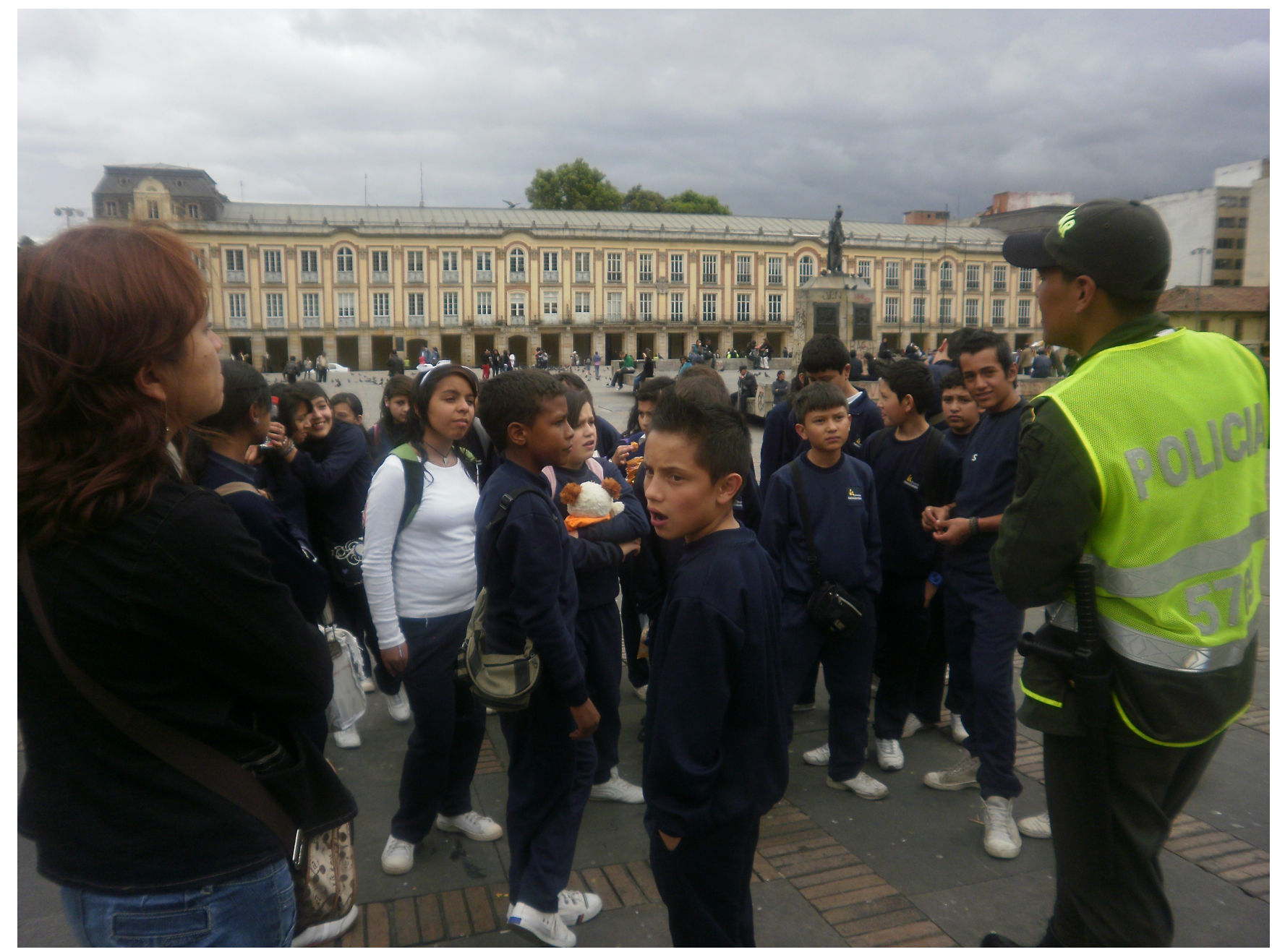

Auxiliar de policía sirve de guía a niños y niñas de un colegio Distrital y les enseña la historia de la Toma del Palacio de Justicia. Bogotá. 2011.Fotografía: Andrea Guatavita.

Las acciones institucionales sin embargo, todavía dejan mucho que desear. Pues persisten las estructuras clandestinas para estatales y quedan por adelantar investigaciones que apunten a acabar definitivamente la práctica de la desaparición forzada.

En la actualidad conocer el proceso desarrollado en Argentina nos da algunas pistas para eso y voy a resaltar solo dos puntos: El primero tiene que ver con el reconocimiento y la investigación a profundidad de los centros clandestinos de detención, las estructuras de mando y las acciones de inteligencia. El segundo tiene que ver con la necesidad de adelantar paulatinamente el desmonte de estos centros, inhabilitar a los funcionarios involucrados y 
desmontar las estructuras de inteligencia ${ }^{83}$.

Pero aún así una diferencia sin resolver en este escenario es reivindicar por un lado la lucha por la justicia jurídica y social y la representación de la memoria y por otro lado, la continuación de las banderas de lucha.

Hay para quienes optar por la lucha, por la eliminación de las desigualdades, por el ejercicio de la oposición, por la verdad, les cuesta la vida. En esa fatal realidad, mi padre fue desaparecido el 21 de marzo de 2006, y otra historia comenzó a relatarse para nuestras vidas desde que encontramos sus restos el 23 de abril del año pasado. Sin embargo, aunque su cuerpo no esta presente, sus ideas no han desaparecido, los cálidos lazos que tejió con su familia, sus amigos, amigas, copartidarios, siguen presentes, tejiendo otros puentes y extensiones de sus luchas y sus sueños (Diana Gómez, 2007) ${ }^{84}$.

Dentro de las entrevistas no encontré hijos o hijas de la izquierda desvinculados de proceso político, porque asumiendo el proceso jurídico o no, se vieron envueltos en debates sobre el lugar de la memoria en la disputa con el estado que no reconoce la desaparición forzada, y esa cuestión por el contexto actual está altamente politizada. En cambio si encontré diferencias con respecto a cómo se percibía ese proceso político.

Entonces ahí nosotros hablamos un poco de que esto necesitaría un nivel más profundo de reflexividad frente a tus acciones de vida como ser humano y frente a esa memoria de la cual eres puente, inevitablemente eres puente, inevitablemente para los que están organizados hoy porque hijos ya tiene una marca de reconocimiento que apela a que sabes de algo pero por otro lado a los que somos hijos de izquierda ese puente existe así uno reniegue cuando uno llega a las fiestas, a las marchas: "Ay el hijo de tal". Entonces tú eres puente (Camilo, entrevista 18 de octubre de 2011).

Un proceso marcado desde las luchas iniciadas por los padres, un proceso cuestionado o

\footnotetext{
${ }^{83}$ Jorge Julio López estuvo desaparecido durante la dictadura militar, entre los años 1976 y 1979. Miembro de la Asociación de ex detenidos hizo parte de los querellantes y su testimonio sirvió para el procesamiento de decenas de policías y militares entre ellos Miguel Etchecolatz. El 18 de septiembre de 2006, después de que se condena a Etchecolatz, Julio López fue desaparecido. Su desaparición puede interpretarse como una falla en el proceso de justicia en tanto los culpables de su anterior detención podían ejecutar una nueva desaparición es decir que mantuvieron vínculos de poder y un aparato de secuestro.

${ }^{84}$ Palabras en el lanzamiento del libro Tras las Huellas de la Verdad de Jaime Gómez leídas el 29 de junio de 2007.
} 
guiado por los distintos perfiles de la madre, un proceso marcado por los referentes construidos a través de la historia vital de la hija, o un proceso de relectura, comprensión y elección sobre la transmisión y el trabajo destinado al futuro.

La otra entrada para mí tiene que ver con una preocupación más en términos de como generación qué aporte se puede dar a la historia, a los movimientos sociales, a los diferentes escenarios de crisis que atraviesa el país, incluyendo las mismas organizaciones que luchan por transformarlo. Entonces incluida esa crisis pensar en qué podemos apostar generacionalmente para que transforme... (Camilo, entrevista 18 de octubre de 2011) 


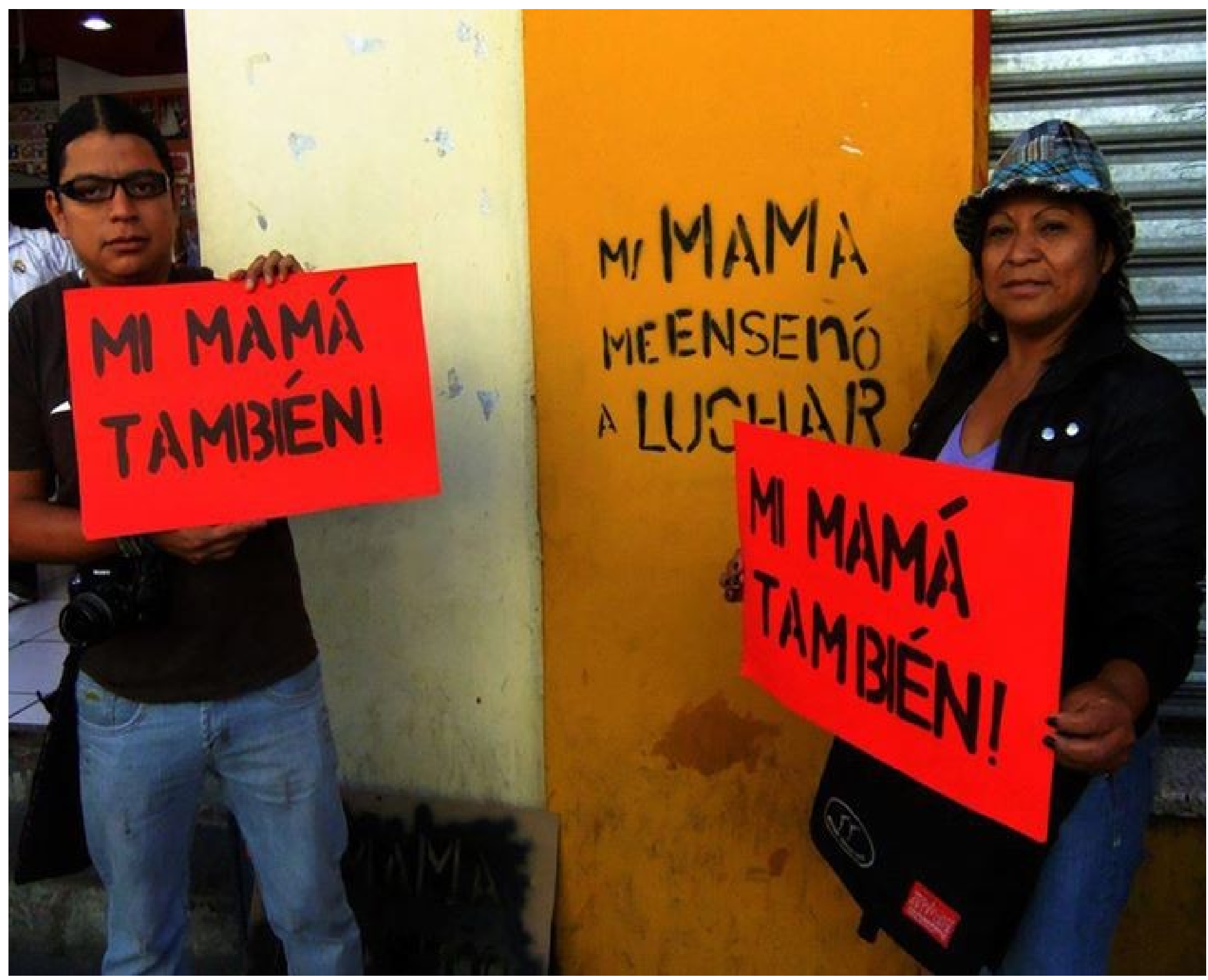

Fotografía: Movimiento de Hijos e Hijas por la memoria y contra la impunidad. Tomada de Internet. 


\section{Sexto Capítulo: Memoria clandestina}

Por eso no podemos decir que nos exportaron la mala yerba, que fue que nos la mandaron, que nos cayó como una de las siete plagas, los guerrilleros y guerrilleras son de nosotros, son producto de una sociedad excluyente

que asesina... es necesario dejar de pensar que el culpable de los problemas es otro, que aquí no hay problemas. El establecimiento no puede seguir buscando culpables pensando que quienes estamos descontentos que además abrazamos el derecho a la rebelión que está consagrado en el pacto de derechos

humanos (inaudible) tenemos derecho a la rebelión, es tal vez uno de los derechos más hermosos a que tiene derecho en la democracia cualquier ser humano, el derecho a rebelarse, el derecho a decir que no estamos contentas, el derecho a decir que señalamos esa pobreza y esa miseria producto de una nación que no es digna y no es capaz de defender sus recursos naturales... (Piedad Córdoba, 2008)

Esta es una memoria de reconstrucción directamente vinculada con la historia política de algunas personas desaparecidas. Es una memoria marcada por el secreto necesario al participar en organizaciones estigmatizadas, especialmente en organizaciones de izquierda radical. Sus escenarios de construcción son grupos cerrados y aún no hace parte de la memoria colectiva.

\subsection{Marcos de memoria y márgenes de omisión}

Fue Aureliano quien concibió la fórmula que había de defenderlos durante varias meses de las evasiones de la memoria (...) Cuando su padre le comunicó su alarma por haber olvidado hasta los hechos más impresionantes de su niñez, Aureliano le explicó su método, y José Arcadio Buendía lo puso en práctica en toda

la casa y más tarde la impuso a todo el pueblo. Con un hisopo entintado marcó cada cosa con su nombre: mesa, silla, reloj, puerta, pared, cama, cacerola. Fue al corral y marcó los animales y las plantas: vaca, chivo, puerca, gallina, yuca, malanga, guineo. Poca a poca, estudiando las infinitas posibilidades del olvido, se dio cuenta de que podía llegar un día en que se reconocieran las cosas por sus inscripciones, pero no se recordara su utilidad. Entonces fue más explícito. El letrero que colgó en la cerviz de la vaca era una muestra ejemplar de

la forma en que los habitantes de Macondo estaban dispuestas a luchar contra el olvido: Ésta es la vaca, hay que ordeñarla todas las mañanas para que produzca leche y a la leche hay que hervirla para mezclarla con el café y hacer café con leche. Así continuaron viviendo en una realidad escurridiza, momentáneamente capturada por las palabras, pero que había de fugarse sin remedio cuando olvidaran los valores de la letra escrita.

(Cien años de soledad. Gabriel García Márquez )

Como se ha venido exponiendo hay muchas razones por las cuales hay ciertas cosas que no se hablan. Como lo expondría Catela (2000) una de ellas tiene que ver con la autocensura de la militancia política o el exceso de violencia. Tienen que ver con las limitaciones en la acción de memoria que fueron mencionadas y que pertenecen a los distintos grupos que van 
construyendo la memoria y el desarrollo de sus reflexiones: la carga traumática, los pactos familiares, el contexto histórico y sus prioridades o censuras ideológicas, en general un conjunto de hechos que vinculan lo individual con un marco social. Este marco definido por cuestiones legales, comunicativas, morales, históricas.

Las políticas de olvido y de memoria trazan los límites de lo que puede o no ser objeto de la memoria (CINTRAS, EATIP, GTNM/RJ, SERSOC, 2009). Yerushalmi (1985) sería más específico al decir que en realidad lo que se enfrenta a la memoria colectiva no es el olvido sino la impunidad. Haciendo un paralelo entre la imagen de García Márquez y este texto se podría decir que la justicia mientras recuerda su papel permite la memoria y la organiza y no al revés.

El neoliberalismo que garantizó la impunidad le apostó a la cultura del miedo que legitima la tortura y el exterminio, con el silencio la banalización del daño, haciendo invisibles y deshumanizando a los y las afectadas.

En Brasil, según el Grupo de Tortura Nunca Mais Rio do Janeiro, el miedo se diseminó en la década del '60 y durante el '70 generó subjetividades que aceptaron las prácticas de excepción (CINTRAS, EATIP, GTNM/RJ, SERSOC, 2009:254).

La criminalización de la pobreza, la espectacularización de la violencia, la deshumanización de los considerados peligrosos y la gestión mediática del miedo y de la indiferencia crean las condiciones para que esos crímenes ocurran a la luz del día y coexistan con el orden constitucional (CINTRAS, EATIP, GTNM/RJ, SERSOC, 2009:256).

Según la psicoanalista Kolker (CINTRAS, EATIP, GTNM/RJ, SERSOC, 2009:257), la violencia institucional mata y produce subjetividades para justificarse, desaparece personas y niega las desapariciones. Estos hechos provocan catástrofes privadas y sociales, políticas, jurídicas incluso lingüísticas autorizando territorios sin derechos, legitimando políticas genocidas de control social, naturalizando formas de tratamiento degradantes y forzando a la lengua a convivir con las violaciones. Trabajar con una concepción de poder que toma en 
cuenta su función represiva y sus múltiples efectos productivos teniendo en vista los dispositivo de control para neutralizar focos de resistencia y deshacer posibles alianzas entre los distintos afectados (CINTRAS, EATIP, GTNM/RJ, SERSOC, 2009:258). Cuando revisan las causas de estas prácticas en el colectivo, Diana Kordon y Lucila Edelman (2007) hablan de mecanismos conscientes para la manipulación y describen las campañas de inducción psicológica de la dictadura de la siguiente manera:

Estas campañas comprometían a los miembros del conjunto, a su aceptación sobre la base de la amenaza no sólo a la vida, sino a la necesidad de cada uno de ser reconocido y reconocerse en la sociedad a la que se pertenecía. El manejo del poder era el garante de la eficacia porque universalizaba en forma simultánea la operatoria alienante (Kordon y Edelman, 2007:165).

Estas campañas proponían distintos modelos de conducta que Kordon y Edelman reconocieron de la siguiente manera:

1. "Inducción a guardar silencio".

Ella un día me comentó que en el colegio ella estaba cursando en quinto de primaria y hablaron de la relación con la familia, "que el papá en qué trabajaba que no sé qué..." pues obviamente los niños a esa edad son tan espontáneos que pues ella obviamente dijo: "No pues mi papá no trabajaba el fue guerrillero" así de una. Claro la reacción de los otros niños más la del profesor porque a mi me llamaron después al colegio y me dijeron "usted debería tratar de manejarle a la niña que hay en unos espacios donde ella no podría referirse a su papá así". Entonces en la tarde cuando yo llegué del colegio hablamos y yo le dije a Angie: "Angie y a usted no le da pena decir que su papa era guerrillero y dijo: "Mami y por qué si eso no tiene nada de malo". Y entonces yo ahí empecé a preguntarle por la reacción de los niños y claro que unos le habían dicho: "Terrible, esos son los que matan a la gente". Todo un conjunto de ideas que tenían los niños pero creo que eso a mi me sirvió porque afortunadamente esa parte yo no se la negué (Esperanza, entrevista 22 de septiembre de 2011).

2. "Inducción de sentimientos de culpa". A través de propagandas de televisión que intentan revertir la responsabilidad del victimario sobre la víctima. En Colombia al igual que en Argentina se divulgó a través de estos medios la pregunta: "¿Sabe usted qué está haciendo su hijo en este momento?", cuestionando como lo expresan las autoras 
el cuidado de los hijos por parte de sus padres y madres y sugiriendo la desatención y falta de control en sus actividades.

3. "Inducción a dar por muerto al desaparecido". En Colombia al igual que en Argentina se pide al familiar firmar la muerte presunta para resolver problemas jurídicos y económicos. Esa es una figura jurídica que cambia la definición del crimen con el riesgo de que se detenga el proceso de búsqueda. En el año 2009 la Unidad de Justicia y Paz de la Fiscalía General de la Nación propuso aplicar esta medida al total de las víctimas reconocidas en las versiones libres de los paramilitares. Las organizaciones de familiares no aceptan esta posibilidad y en consecuencia, lograron que en el 2012 el Congreso decretara la Ley 1531 "por medio de la cual se crea la acción de declaración de ausencia por desaparición forzada y otras formas de desaparición involuntaria y sus efectos civiles " (Congreso de la República, 2012).

4. "Inducción a considerar la disidencia política como una falta de adaptación social y, por lo tanto, como campo de la enfermedad mental". En el caso de algunas mujeres como las madres de plaza de mayo llamadas locas pero en general en la mirada de invalidez que se promueve con respecto a los familiares que por su "afectación" pueden estar cambiando la explicación o descripción de ciertos hechos.

5. "Inducción en la población del mecanismo por el cual la sola desaparición de una persona sería prueba de su culpabilidad". A través de la frase "En algo andaría" que legitima el sistema de represión y que llega en Colombia a expresiones sin sentido como "lo mataron porque ponía sobrenombres" 85 es decir que la acción represora es incuestionable y la sociedad se dedica a llenar de sentido con expresiones cada vez más insólitas, la victimización de una persona.

6. "Inducción al olvido". "Hay que olvidar el pasado para reconciliar la nación". Esto implica que la lucha por la memoria y la verdad con respecto a los crímenes de estado está en contra de la paz, un valor que es fundamental en Colombia y ubica en el lugar de enemigos de la nación a aquellos que se involucran con esa tarea. A nombre de la reconciliación se equipara a víctimas y victimarios en actividades psicosociales de

\footnotetext{
${ }^{85}$ En un desplazamiento que realicé en un bus público que iba de Florencia al Municipio de San Vicente del Caguán, un par de personas me comentaron el asesinato de un miembro de la comunidad y afirmaron esto: "Seguramente lo hicieron porque él ponía muchos sobrenombres"
} 
"abrazos" y en programas políticos para la rehabilitación y la reintegración.

7. "Inducción a la dilución de responsabilidades ". A través de referencias a que "Todos somos culpables", evidentes en Colombia por ejemplo, en los programas de atención psicosocial a víctimas en donde una de las premisas es inducir el perdón porque las víctimas, por el dolor sufrido, pueden llegar a violentar o legitimar violencia sobre el perpetrador. Entonces su sentimiento de dolor o resentimiento puede ser un riesgo para el proceso de pacificación.

Según Kordon y Edelman (2007), las modalidades de respuesta a estos mecanismos psicológicos se pueden comprender no sólo desde la dinámica de procesos individuales, sino tras el reconocimiento de toda la realidad social vivida en la que cada quien iba tomando una posición. Ante los modelos propuestos por la dictadura hubo dos tipos de respuesta: acatamiento - sometimiento o discriminación-resistencia. Estas posiciones se concretaron en distintos niveles de silencio, de lucha y de culpa. Silencio sobre la desaparición, o reconocimiento del hecho y aislamiento, o silencio en algunos lugares y en otros no. Pero las personas que se dedicaron a resistir generaron espacios de identificación y lazos filiales que les fueron más benéficos.

El análisis sobre el daño y la transmisión se ubica en la transformación que el relato tiene en las siguientes generaciones. El terrorismo de estado en Argentina no afectó solo a los "subversivos" sino a la sociedad como un todo. Tenía el objetivo de neutralizar opositores y capturar la potencia de los colectivos y producir un tipo de subjetividad sujetada, individualizada y despolitizada, funcional al régimen. Dispuesta a aceptar violaciones sin resistir (CINTRAS, EATIP, GTNM/RJ, SERSOC, 2009:254).

\subsection{Olvido, silencio o impunidad}

- ¿Y qué es agotador de la memoria?

- La indiferencia, a veces mas allá de la indiferencia el conformismo en el que uno a veces se estrella en esa lucha por la memoria, a veces pensaba es la indiferencia, a veces es que la gente no es que sea 
indiferente es que es conformista también se deja llenar de una sensación de impotencia como que cree que no tiene las capacidades para enfrentarse a lo que los oprime, prefieren quedarse en la comodidad de decir soy indiferente soy conformista entonces la gente cree que no se puede pelear contra ese poder no tenemos las herramientas no tenemos las oportunidades (Shaira, entrevista realizada el 26 de julio de 2011 ).

Es muy interesante que esta sea la dificultad de la memoria, la inmovilidad, ver que efectivamente hay una desarticulación del proceso social. Es decir, la limitación se encuentra más allá de la situación emocional. Se encuentra en la imposibilidad de movilización, de escucha de la memoria y de participación de la sociedad en un proceso de transformación del país.

El uso de la memoria por parte del estado y sus instituciones. La institucionalización de la memoria que de alguna manera la inmoviliza, en el caso de Colombia la hace confusa pues desdibuja las responsabilidades del estado y la generaliza como resultado de una violencia sin nombres. Y el uso en cuanto a "momificar" estrategias nacidas del movimiento popular de Colombia y de otros países para vaciarlos de sentido. Esto se enfrenta con la necesidad de que el estado establezca sus responsabilidades y asuma la tarea de enseñar y de insertar en sus propios aparatos distintas características del proceso histórico nacional para que se conviertan en relatos extendidos con contenidos que complejicen la comprensión de la realidad del país.

(...) La izquierda tiende a sentarse solamente en el personaje y no dar cuenta del escenario. Ese es uno de los puntos que hay y el otro es frente a los mismos usos políticos de la memoria que influyen en que permanente se estén creando y recreando mitos fundacionales, o sea las génesis de la historia, de quién posee la verdad, quién es el sujeto, o el actor, la vanguardia si se quiere, pero que en términos reales es el mismo valor que le da más prelación a un tipo de sujeto y no a todos, donde privilegian a los sujetos y no a las relaciones entre los sujetos entonces casi que nosotros en ese debate que no está saldado decimos: "Bueno habría que construir más que una visión subalterna, una versión compleja de la historia, una visión más de subversiones que se tejen, que se mezclan, de hecho ahí hay un personaje -No sé si es Octavio Paz porque ya se me olvidó- que dice que no hay nada más mentiroso que la verdad, la verdad es una versión sobre una serie de hechos que pueden ser narrados de distinta manera, el reto sería construir nociones complejas de las verdades, de las realidades, donde también... el uso que ha 
hecho la clase hegemónica de la historia es un uso de acuerdo a sus intereses, eso sí es claro y de acuerdo a sus intereses tiene que ver no necesariamente con que sea malo en sí mismo, es decir, cuando la historia oficial necesitó para la constitución del 91' que se hablara de diversidad se incluyeron en los textos los cimarrón, los raizales, los gitanos, entonces se supone que hay un avance pero realmente es porque el uso político necesitaba esa diversidad (...) Sí existe un uso, un uso que si no está ligado a valores, a ideologías, a periodos históricos concretos... tú puedes decir que es un avance en términos de memoria y de verdad lo que están haciendo en la ley de justicia y paz pero hay una noción de verdad que en el fondo a lo que contribuye a más impunidad entonces ahí esas dos diferencias: El uso político donde uno debería preguntarse por los intereses, por los objetivos de quién cuenta la versión de la historia y el problema de la complejidad de la verdad y la memoria que ya son dos cosas (Camilo, entrevista 18 de octubre de 2011).

Esta realidad compleja en donde también es difícil asegurar que las transformaciones del estado no se dan justamente porque devora propuestas del movimiento social para cambiar sus modelos y practicas nos dejan preguntas sobre si todo es realizado por el estado o han existido brechas eficaces en donde algunas cosas se han logrado. En este contexto hay pesimismo.

Existe una insistencia por sumar un elemento crítico de ubicación histórica de la memoria para repensar al país y una preocupación muy fuerte porque estos elementos que se rememoran sean también estrategias, modos de resistencia que se vinculen con prácticas en el presente. Una preocupación permanente por sumar o hacer también un uso de la memoria para cumplir con objetivos específicos dictados por la propia ideología del movimiento social, abriendo una pregunta fundamental o la necesidad de aclarar si la memoria es un camino de transmisión ideológica o una ideología por si misma, que por definición se relaciona directamente con las condiciones que la determinan y en medio de las cuales se produce, para configurar la reproducción de subjetividades específicas.

Y la tercera es que el ejercicio de memoria no puede ser netamente simbólico, lo simbólico es fundamental porque es el pegamiento que hay en términos de valores pero el ejercicio de memoria no puede ser solamente las galerías, solamente los monumentos, solamente las batucadas, o solamente los actos de rememoración, osea creo que hay que en los ejercicios de memoria uno de los elementos fundamentales del pensamiento crítico que debe estar instalado en todos los ejercicios y debe ser 
instalado en todos los sujetos sociales, es decir, el escenario de memoria no es un campo que defina sujetos en sí mismo pero debe ser un campo que todos los sujetos deben tener dentro (Camilo, entrevista 18 de octubre de 2011).

La memoria no es un campo puro del recuerdo, es una producción propia del grupo que la construye y que ejemplifica el pensamiento y las prácticas propias de estos herederos de la historia de Colombia. Si una de las hipótesis de este trabajo es que a través de las prácticas del terrorismo de estado se obliga al olvido de esos procesos, hay un vaciamiento ideológico y la imposición de nuevas subjetividades vinculadas con el estado actual de cosas.

Fundamentalmente esa es la primera apuesta, fundamentalmente esa es tal vez la que puede eclipsar las otras dos, la que puede incluir no eclipsar, la que puede incluir tanto los casos individuales traumáticos si quiere, la noción de víctima pero no tanto como noción de víctima sino como hijo de la izquierda (Camilo, entrevista 18 de octubre de 2011).

Ahora bien, desde el desconocimiento de lo logrado o lo parcialmente logrado, es esperable que lo que quede sea la desesperanza y también es muy inquietante que lo que genere motivación siga siendo la posibilidad de continuar a pesar de los golpes recibidos. La memoria colectiva está desprovista de un inventario de luchas y logros de grupos que ya no son recordados.

A ver si recuerdo algo: estábamos los de Alborada Comunista, el Frente Popular, la Juventud Comunista - JUCO, el PCC M L, ADO (Auto Defensa Obrera), el ELN, el Partido Socialista de los Trabajadores, el M19, el Ejército Popular de Liberación, el partido Comunista, la Asociación Nacional de Profesionales, los sindicatos; y claro, la ANUC Línea Sincelejo, que logró arrebatar la organización campesina del control corporativo de Lleras (Vaca, entrevista 16 de marzo de 2013).

La movilización está marcada por la señal de la violencia y la dificultad, pero también del descrédito de las instituciones democráticas y del olvido de los momentos de unidad en donde se obligó al estado a recomponer sus estructuras. Prácticas, valores y recuerdos atravesados por sentimientos muy profundos de tristeza y de rabia que contradicen los imaginarios más extendidos sobre nuestra idiosincracia. 
-Pues eres un puente de la memoria, eres una herramienta de...

-De memoria

-Casi que un instrumento es decir cuando la persona no está, cuando el militante de antaño no está y uno llega y lo ven quienes acompañaron uno es puente así no esté organizado.

- Lo ven en mí a través de mis ojos...

-Sí claro entonces es una cosa muy fuerte yo creo que por eso parte de la aceptación que tuvo hijos porque no es una aceptación tanto como la propuesta política de lo que estamos diciendo sino por el vacío porque somos algo que ayuda a llenar un vacío.

-Es muy fuerte lo que estás diciendo, que lo que estén viendo ahí sea el depósito en una ausencia como el registro de algo que se perdió y que no se quería dejar perder.

-Pero al mismo tiempo no es un problema solamente de culpa porque lo terrible sería pensar que es culpa sino que sobre todo se ve la probabilidad de una nueva relación que pueda ayudar a llenar ese vacío y yo no lo veo tanto como el vacío de carga si no como...

-Como de la nostalgia.

-No pero es que todo recuerdo es nostálgico es decir qué es lo que uno escucha: "Ustedes se unieron ustedes nos llenan de esperanza porque si se puede o si se podría hacia delante hacer una cosa que nosotros no hemos podido hacer hasta ahora". Y hay una relación temporal que está ahí y que sí está mediada por un vacío así uno no...

- Pero eso qué estás diciendo plantea que de parte de esos que dicen eso que son de una generación anterior hay como una sensación de... de retraso: "Lo que nosotros no pudimos hacer de pronto ustedes..."

- Yo creo que hay una generación... dos generaciones arriba de nosotros hay resignación muchísima yo diría conformismo aunque hay un montón de conformes y de acomodados pero creo que hay mucha resignación. El otro día esta hace poquito en el oriente antioqueño me decía uno de los viejitos de allá ya nadie habla de victoria y es un problema de la meta, incluso hablar de la utopía, de la revolución, de la victoria, yo si creo que hay una carga osea esa es una manera de medir la resignación la gente dice: "Podemos lograr ciertos derechos, ciertas cositas, lo que se puede, yo creo que si hay esa carga independientemente de que uno resiste. Porque resiste (Camilo, entrevista 18 de octubre de 2011).

Los hijos e hijas quieren reconstruir con criterio la memoria del país y juntarla con otras para construir un relato interesante y revelador del por qué ocurre en Colombia lo que ocurre y de cómo el país puede ser transformado. 


\subsection{Políticas de Memoria}

Para entender por qué se mantienen los daños o se transmiten, y si hay un marco que busque conservar formas de resistencia y deseos de transformación política, es necesario señalar los límites de la clínica como espacio de investigación primario de la psicología y hablar, por ejemplo, del papel de políticas de memoria y olvido incidiendo en el escenario del sufrimiento (CINTRAS, EATIP, GTNM/RJ, SERSOC, 2009:258).

El terrorismo de estado ${ }^{86}$ fue sustentado por la doctrina de seguridad nacional promovida a través de la escuela de las Américas y dirigida a desarticular a la sociedad e implantar su modelo totalitario. El Servicio de rehabilitación social Sersoc de Uruguay, encuentra que la desaparición, en ese contexto, buscó aniquilar la identidad militante, todo aquello que apuntala su psiquismo, cuerpo, vínculos, ideales. Modificó la cultura y los sistemas de convivencia característicos del país. A través del miedo se atacó la expresión, el pensamiento y funciones de producción de sentido y comunicativas del conjunto social. La lección para la sociedad y las nuevas generaciones fue el fin de la utopía y la "aceptación pasiva y resignada de un estado totalitario donde la disidencia se prohíbe". Estas consecuencias sociales o daños han sido definidas como un efecto intencional de la violación sistemática de derechos para generar subjetividades proclives a sistemas políticos y económicos injustos, ante los cuales $y$ en situaciones normales, se levantarian las personas en acciones colectivas (CINTRAS, EATIP, GTNM/RJ, SERSOC, 2009:341).

Más adelante se introducirá la pregunta sobre cuáles serían esas condiciones normales y si no son justamente estas condiciones las que requieren levantamientos de oposición ¿No sería más natural que justamente cuando las acciones de violencia se dan esos levantamientos ocurran?

\footnotetext{
${ }^{86}$ Este término es definido como el "conjunto de modalidades operacionales que se dieron en las dictaduras del cono sur en la década de los años 70 para la neutralización, represión, persecución, y aniquilamiento de aquellas personas y grupos considerados "subversivos" y "enemigos de la patria" (CINTRAS, EATIP, GTNM/RJ, SERSOC, 2009:339).
} 
Pilar Calveiro (1998) y Naomi Klain (2007) realizan una lectura desde otras disciplinas sobre "el daño" pensado como la transformación de un grupo social y sus sujetos, a costa de experiencias violentas. En el caso de Naomy Klain (2007) más claramente en la introducción de un modelo económico que contradice las necesidades de la población y en el caso de Pilar Calveiro (1998), con una descripción más exhaustiva de las estrategias y el proceso de establecimiento de poder a través de la desaparición.

En Colombia esto se puede comprobar en la medida en que a nivel internacional ha sido reconocida la conflictividad del país y la perpetuación de violación de derechos por parte del estado, como condición para la reproducción de la expropiación, la explotación extranjera, la venta de armas y la ruptura de la organización social. Así lo confirma la Sentencia Final del Tribunal Permanente de los Pueblos logrado gracias a la recopilación de investigaciones y testimonios de sindicalistas, indígenas y trabajadores del agro en todo el territorio nacional.

Colombia parece presentarse, en este sentido, como un verdadero laboratorio político institucional donde los intereses de los actores económicos nacionales e internacionales son plenamente defendidos a través del abandono por el Estado de sus funciones y de su deber constitucional de defensa de la dignidad y de la vida de una gran parte de la población, a la cual se aplica, como si de un enemigo se tratara, la doctrina de la seguridad nacional, en su versión colombiana (...)

5.3. a la vista de los hechos probados, el tribunal condena: 5.3.1. al gobierno de Colombia:

- Por establecer un marco legislativo que permite la violación del derecho al trabajo, que la Constitución política de Colombia de 1991 reconoce, así como de los derechos laborales reconocidos en diversas convenciones internacionales adoptadas en el marco de la OIT, como la $n^{\circ} 87$ y la $n^{\circ} 98$ (...).

- Por la vulneración de los derechos colectivos a la tierra, a los recursos naturales, al autogobierno, a los derechos de participación y al desarrollo propio de los pueblos originarios (...).

- Por su participación directa e indirecta, por acción y por omisión, en la comisión de prácticas genocidas, en sus modalidades de: matanza de miembros del grupo; lesión grave a la integridad física o mental de los miembros del grupo; y sometimiento intencional del grupo a condiciones de existencia que hayan de acarrear su destrucción física, total o parcial. Estas prácticas se concretan especialmente en el proceso de extinción de 28 comunidades indígenas, en el proceso de aniquilación del movimiento sindical colombiano y en el exterminio del grupo político Unión Patriótica (...) (TPP, 2008) $)^{87 .}$

${ }^{87}$ Las empresas examinadas en este juicio fueron Coca cola, Nestlé, Chiquita Brands, Drummond, Cemex, Holcim, Muriel MminingCcorporation, Glencore-Xtrata, Anglo American, Bhp Billington, Anglo Gold Ashanti, Kedhada, Smurfit Kapa - Cartón de Colombia, Pizano S.A. y su filial Maderas del Darién, Urapalma S.A., Monsanto, Dyncorp, Multifruit S.A. filial de la 
Esta sentencia demuestra que a través de las estrategias de terror adelantadas con la participación del estado y las transnacionales, se transformaron las condiciones de vida de la población y ese proceso puede ser reconocido como trasfondo de todo el proceso de represión y lucha que se ha ido reconstruyendo en esta tesis, pero también en el trasfondo de la historia compartida de Latinoamérica, afectada por la historia de los países más desarrollados ${ }^{88}$.

Sin embargo, hay un elemento aún más interesante y es pensar que esas estrategias de terror no tienen incidencia por sí mismas sino por el relato que se implementa para explicarlas. Ese relato en el caso de Colombia tiene un marco legal muy minucioso, determinado por la propuesta de negociación con grupos paramilitares y lo que era necesario

transnacional Del Monte, Occidental Petroleum Corporation, British Petroleum, Repsol YPF, Unión Fenosa, Endesa, Aguas de Barcelona, Telefónica, Canal Isabel II, Canal de Suez, Ecopetrol, Petrominerales, Gran Tierra Energy, Brisa S.A., Empresas Públicas de Medellín, B2 Gold - cobre y oro de Colombia S.A. Las audiencias públicas de esta sesión del TPP se desarrollaron según el programa adjunto en el anexo 1, en los días 21 y 22 . El dictamen fue presentado en el Auditorio León de Greiff de la Universidad Nacional de Colombia, a las $4 \mathrm{pm}$ del día 23. Con un Jurado integrado por: Adolfo Pérez Esquivel; Dalmo de Abreu Dallari; Marcelo Ferreira; Francois Houtart; Franco Ippolito; Lorenzo Muelas Hurtado; Juana Manquecura Aillapàn; Vilma Núñez de Escorcia; Antoni Pigrau Solé; Bruno Rütsche; Philippe Texier; Gianni Tognoni.

88 En 1978 la liberación de importaciones adoptada por Alfonso López y el fin de la bonanza cafetera llevaron al deterioro económico que azotó la economía desde 1979. A nivel general la solución a la deuda, para los países dependientes, fue la privatización y el mantenimiento de economías primarias, no tenían como pagar la deuda, disminuyeron la importación y abrieron los países al capital financiero internacional. En 1982 México suspendió los pagos. En 1984 la conferencia económica latinoamericana propuso la concertación de la deuda con los países subdesarrollados, desarrollados y la banca privada. No se logró el objetivo de concertación. Se culpó a los gobiernos latinos por el aumento de la deuda a causa de la industrialización y la disminución de importación priorizando la economía interna entonces se propuso a América Latina un modelo de acumulación siguiendo las fuerzas del mercado y orientado a fortalecer las reservas del exterior. Los nuevos gobiernos democráticos terminaron legitimando la deuda a través de la negociación.

Colombia jamás interrumpió el pago de la deuda. En 1982 esta se multiplicó por siete y las exportaciones cayeron en una cuarta parte (Gómez, 2007). La apertura menos los ingresos redujeron la demanda interna y afectaron la producción local mientras las empresas multinacionales como Coca - Cola, Nestlé y Chiquita Brands, por ejemplo, lograron una acumulación sin límites. Coca-cola y Nestlé rediseñaron sus patrones de inversión y utilidad desde 1980, cerrando fábricas y evaporando su responsabilidad con los trabajadores (Tribunal Permanente de los Pueblos, 2008). La tasa de crecimiento económico descendió del $8.9 \%$ al $2.0 \%$ y la inflación era de un $30 \%$, el FMI y la banca internacional presionaron la reducción del déficit para obtener excedentes que garantizaran el pago de la deuda (Gómez, 2007). El mercado de capitales que concentró la liquidez en intermediarios financieros en la década del 70' se fue abajo y entró en crisis al sector financiero. Los mayores afectados fueron los pobladores de la zona rural que sumaban a las históricas formas de explotación del trabajo de la tierra un abandono importante del Estado por su política centralista.

Múltiples empresas nacionales se vieron acusadas de corrupción, se generó un desacuerdo interno por la política liberal y el ingreso del narcotráfico para la época se había hecho bastante significativo, al punto que igualaba la tercera parte de la cifra de exportación de café e irrigó el sistema monetario, la industria, el comercio, la política y las obras sociales (Gómez, 2007). La nueva política económica subordinó el crecimiento nacional a la dinámica internacional. Se realizaron ajustes presupuestales, fiscales, en el régimen pensional y aumentó el subempleo en toda la región. Los sistemas partidarios posteriores a las dictaduras o en países con sistemas democráticos más antiguos, se debilitaron por su vinculación con las políticas neoliberales, así como que se abrió una brecha más amplia entre el Estado oligárquico y la sociedad. En 1982 ya se habían organizado más de diez grupos insurreccionales, se habían librado dieciocho años de conflicto armado y la militarización del Estado se fortalecía lentamente bajo un sistema caracterizado según el Proyecto Colombia Nunca Más por el desarrollo y la transformación de distintos Modelos de Represión para mantener el estatus quo. 
de memoria para que ese proceso se diera: la negación del vínculo entre el estado y estos grupos. La Ley de víctimas que parecía intentar reconocer los principios internacionales pero se sirvió de ellos para definir cuestiones políticas y económicas muy estratégicas como la negación de la beligerancia a grupos armados o su reconocimiento como víctimas jurídicas en caso de ser desaparecidos. Y finalmente la Ley de Homenaje que define cómo se da lugar a todo el proceso de ritualizacion de una persona desaparecida.

\subsection{Marco Jurídico}

Gracias a la insistencia a nivel nacional e internacional la desaparición forzada fue definida a través de la Ley 599 de 2000 como una acción distinta a la del secuestro, de la siguiente manera: Art. 165. "El particular que perteneciendo a un grupo armado al margen de la ley someta a otra persona a privación de su libertad cualquiera que sea la forma, seguida de su ocultamiento y de la negativa a reconocer dicha privación o de dar información sobre su paradero, sustrayéndola del amparo de la ley ". La parte resaltada fue después declarada Inexequible por la corte Constitucional.

La Ley 975 de 2005 dispuso el proceso de desmovilización de grupos paramilitares, reconocidos estos como grupos independientes a la acción del Estado, con el objeto de crear condiciones para la finalización del conflicto interno y, en consecuencia, la implementación de un proceso de transición política.

La implementación de estas medidas de transición responde a la reglamentación internacional sobre el acceso por parte de las víctimas a la verdad, la justicia y la reparación, así como al uso de herramientas jurídicas que las proteja de la impunidad. Hay dos cuerpos básicos a nivel internacional para delimitar los derechos de las víctimas y en consecuencia el acceso a la memoria como parte del concepto de reparación integral: el Conjunto de principios para la protección y promoción de los derechos humanos mediante la lucha contra la impunidad y los Principios y directrices básicos sobre el derecho de las víctimas de 
violaciones manifiestas de las normas internacionales de derechos humanos y de violaciones graves del derecho internacional humanitario a interponer recursos y obtener reparaciones.

Esta ley fue demandada por novecientas personas y organizaciones del Movimiento Nacional de Víctimas de Crímenes de Estado (Movice, 2009:11) por el incumplimiento en la garantía de dar acceso a los derechos de las víctimas y por la forma y contenido de las versiones difundidas de los victimarios en las audiencias libres que se han adelantado en los procesos penales.

A pesar de lo anterior la Ley 975 de 2005 se implementó y tuvo como resultado entre otros: la continuación de acciones paramilitares bajo el nombre de crímenes producidos por "Bandas Criminales Emergentes". Parte de los comandantes regionales fueron extraditados por sus vínculos con el narcotráfico dificultando reconstruir la investigación penal y los que fueron procesados recibieron penas que oscilan entre cinco y ocho años por crímenes de Lesa Humanidad. Su pena disminuyó porque su relato o versión libre reconocía un mayor número de crímenes. Hoy están saliendo los primeros sentenciados.

En el contexto jurídico de la Ley de Justicia y Paz o reglamentación de la desmovilización de grupos armados y de los derechos de las víctimas se establece un marco social que condiciona el cumplimiento o restitución de derechos y fundamentalmente la reconstrucción y difusión la memoria a través del establecimiento dentro de la Comisión Nacional de Reparación y Reconciliación (CNRR) y del grupo de memoria histórica que se define de la siguiente manera:

Memoria Histórica $(\mathrm{MH})$ es un grupo de investigación de la Comisión Nacional de Reparación y Reconciliación (CNRR) que tiene como misión elaborar una narrativa integradora e incluyente sobre las razones para el surgimiento y la evolución de los grupos armados ilegales (Artículo 52.2, Ley 975 de 2005), así como sobre las memorias que se han gestado en medio del conflicto armado, con opción preferencial por las de las víctimas y por las que han sido suprimidas o silenciadas.

En cumplimiento del mandato de la Ley 975 de 2005, la plenaria de la Comisión Nacional de Reparación 
y Reconciliación CNRR delegó a Memoria Histórica la elaboración de una narrativa que de cuenta del rol de los actores armados entre 1964 hasta la actualidad. Por la naturaleza misma de este mandato, le otorgó autonomía académica, metodológica y operativa.

Las labores del equipo se fundan en la convicción de que existe un vínculo indisoluble entre la reconstrucción de la memoria y el fortalecimiento democrático. Siguiendo criterios de independencia académica, rigor científico y veracidad, $\mathrm{MH}$ reconoce:

- El carácter político de la memoria.

- El papel fundamental de la memoria histórica en los procesos de democratización en situaciones de conflicto.

- La memoria histórica como un escenario para el diálogo, la negociación y el reconocimiento de las diferencias con miras a un proyecto incluyente.

- La memoria en sí misma como una forma de justicia.

- La memoria histórica como una forma de reparación que complementa pero no sustituye las obligaciones de reparación del Estado y la sociedad.

- La memoria como un mecanismo de empoderamiento de las víctimas.

- El derecho a la memoria y el reconocimiento de la verdad como derechos inalienables de las víctimas y de la sociedad" (CNRR).

Con respecto a esos principios vale resaltar que la memoria y la justicia no va una como elemento fundamental para que la otra pueda reconstruirse, o la primera como condición para que las personas conozcan lo ocurrido y exijan rendición de cuentas y sanciones a los responsables.

El grupo de Memoria histórica presentó varias investigaciones sobre violaciones de derechos humanos y ha contado con la participación de figuras primordiales en el campo de la historia, la antropología, el trabajo social y la psicología, entre las que se cuentan: Gonzalo Sánchez, María Victoria Uribe, Marta Nubia Bello y Pilar Riaño. Después de estos años de trabajo por parte de los investigadores el último informe recoge los costos del "conflicto armado interno" en un documento detallado que se titula "Basta ya". Su nombre se sugiere como la respuesta popular que la Comisión Nacional de Memoria Histórica comunica a través de su trabajo. El "Nunca Más" ya se había expresado por parte de los organismos independientes y era un 
Nunca Más frente a los crímenes de estado. Esto indica que hay una escisión fundamental entre la propuesta de las organizaciones de derechos humanos y la investigación desarrollada desde el estado.

La Comisión de Memoria se dedicó a trabajar sobre los "actores del conflicto" surgidos por cuestiones económicas y a los que se enfrentan casi en una línea lógica, los grupos paramilitares. Sus informes son firmados por representantes del estado entre los que se cuentan Francisco Santos, vicepresidente durante el mandato de Álvaro Uribe Vélez, acusado por paramilitares extraditados de haber impulsado la creación de un Bloque Capital de las AUC (Grupo paramilitar) en la ciudad de Bogotá (El Espectador, 2012). Esta reconstrucción no ha incluido la apertura de los archivos secretos del Estado para construir un relato sobre su responsabilidad y sobre su propia demarcación del otro insurgente, para darle lugar y credibilidad a su relato.

Con dificultades como haber nacido en un proceso de paz en donde se desconoció la relación entre paramilitarismo y estado, dejando de lado que sus crímenes eran responsabilidad de la estructura estatal.

Una verdad sabida: en Colombia, más allá de los debates jurídico-políticos, existe un conflicto armado interno en el que los grupos armados al margen dela ley -guerrillas y paramilitares-, se enfrentan a la fuerza pública, algunos de cuyos agentes actuaron en connivencia o colaboraron con las denominadas autodefensas, las cuales ejercieron dominio territorial en amplias zonas del país y asumieron, respaldadas por agentes estatales, especialmente pertenecientes a la fuerza pública y al órgano legislativo, funciones a cargo del estado, a través de estructuras en las que si bien no siempre se corroboró de manera nítida la existencia de una organización jerárquica, especialmente en el caso de los paramilitares (...) (Centro de Memoria Histórica, 2012:679). 


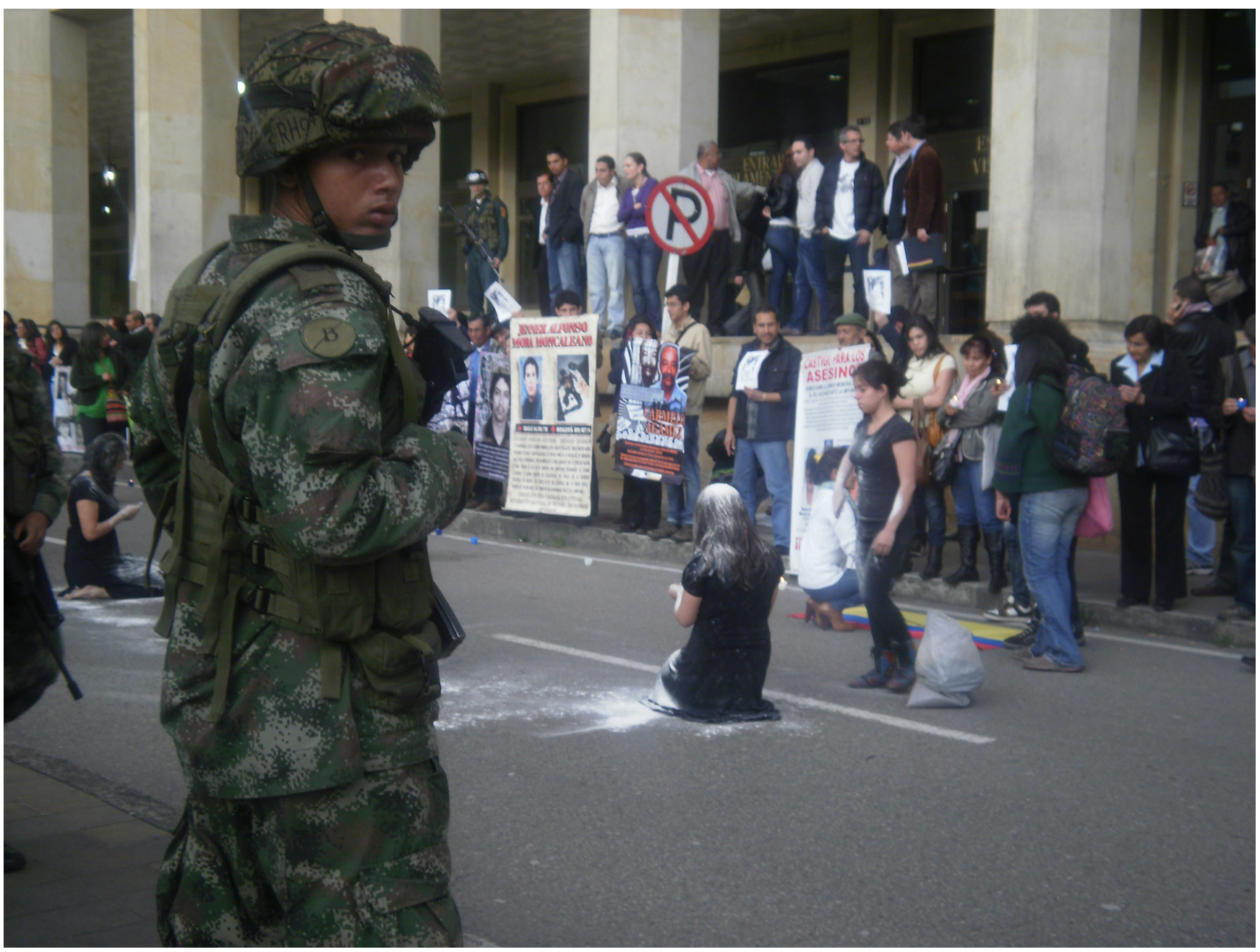

Plantón del Movimiento Nacional de Víctimas de Crímenes de Estado durante el lanzamiento de La Ley de Víctimas. Palacio de Nariño. Bogotá. Septiembre 27 de 2010. Fotografía: Andrea Guatavita.

En el anterior párrafo que es un párrafo concluyente de un análisis jurídico y político de la implementación de la ley de justicia y paz, además de afirmar que la definición del escenario de violencia en Colombia supera el marco de la investigación, el Centro de Memoria expresa cómo la responsabilidad de la participación en el paramilitarismo es de algunos agentes pero no una estrategia de estado. $Y$ lo expresa en uno de sus informes en el marco de la $V$ Semana de la Memoria.

En ese proceso se documentan algunas masacres o "casos emblemáticos", la figura del 
secuestro como un crimen ejecutado por "todos los actores armados ilegales" y por delincuencia común, distintas propuestas de reconstrucción de memoria, procesos de resistencia popular y la historia de las FARC y su relación con la población civil.

Posteriormente aparece la Ley de víctimas y restitución de tierras. Ley 1448 del 10 de junio de 2011. Por la cual se dictan medidas de atención, asistencia y reparación integral a las víctimas del conflicto armado interno y se dictan otras disposiciones. Esta ley se centra en el tema territorial, y define cómo se soluciona el despojo de más de cinco millones de personas en el país, sin haber solucionado las causas de su migración y por lo tanto las posibilidades por parte de minifundistas de retornar a sus tierras. Aclara varios elementos con respecto a quienes se dirige el estado cuando habla de víctimas en todos este proceso.

Para la Ley 1448 de 2011 los miembros de la fuerza pública son reconocidos como víctimas y tienen una jurisdicción especial. Los miembros de los grupos armados organizados al margen de la ley no son reconocidos como actores en beligerancia. No serán considerados víctimas, a menos que se hubiesen vinculado antes de cumplir 18 años. Sus familiares serán considerados víctimas directas. Por lo cual, no se les aplicará la Ley de Homenaje 1408 ni cualquier otro reconocimiento de victimización directa en caso de haber sido desaparecidos forzadamente.

Finalmente en la ley se reconocen violaciones del DIH y del DIDH pero en distintos apartados tanto por el reconocimiento de la víctima como por la "reparación solidaria" del estado no se reconoce su responsabilidad en violación alguna.

Esa misma Ley reconoce en el Artículo 139, ciertas medidas de satisfacción que definen algunas condiciones o lineamientos para la política de memoria del estado. Reconoce como compromiso del estado realizar acciones tenientes "a restablecer la dignidad de la víctima y difundir la verdad" que busquen proporcionar bienestar y mitigar el dolor de la víctima. Algunas de esas actividades serían: 
- Reconocimiento público del carácter de víctima, su dignidad nombre y honor, ante la comunidad y el ofensor.

- Realización de actos conmemorativos, reconocimientos y homenajes públicos.

- Construcción de monumentos: apoyo para la "reconstrucción del movimiento y tejido social de las comunidades campesinas, especialmente de las mujeres.

- Difusión del relato de las víctimas sobre el hecho, "siempre que no provoque más daños innecesarios ni genere peligros de seguridad".

- "Contribuir" en la búsqueda de los desaparecidos y colaborar en el proceso forense y ritual según las tradiciones de la familia y la comunidad.

- Reconocimiento, difusión de las disculpas y aceptaciones de responsabilidad hechas por los victimarios (Congreso de la República, 2011).

En cuanto a la desaparición se creó la Ley 1408 o Ley de homenaje, esta reglamenta la inhumación de personas no identificadas y los procesos para su ubicación, la creación del banco genético, condiciones de la entrega digna y define algunas condiciones para el establecimiento de la memoria en el apartado sobre "Santuarios de la Memoria":

Artículo 13. Previo acuerdo con los familiares de las víctimas que resulten identificadas, las autoridades municipales ubicarán una placa conmemorativa con el encabezado "Víctima(s) de Desaparición Forzada", el nombre de la persona, y en caso de estar disponible, la edad aproximada, el oficio, el número de hijos y el nombre del grupo armado al que se le impute el hecho. Para los cuerpos o restos que no puedan ser identificados, aparecerá la leyenda "Persona no Identificada". Estas placas terminarán con la frase "Nunca Más", deberán situarse dentro del año siguiente a la promulgación de esta ley y se entregaran en el marco de una ceremonia pública con participación de las víctimas(Congreso de la República, 2010).

\subsection{El periodo de latencia en la historia}

Pero esta guerra, mortal para Colombia, no es tan mortal para los dueños de Colombia: la guerra multiplica el miedo, y el miedo convierte la injusticia en fatalidad del destino; la guerra multiplica la pobreza, y la pobreza ofrece brazos que trabajan por poco o por nada; la guerra expulsa a los campesinos de sus tierras, que por poco o nada se venden; la guerra otorga dinerales a los traficantes de armas y a los secuestradores de civiles, y otorga santuarios a 
los traficantes de drogas, para que la cocaína siga siendo un negocio donde los norteamericanos ponen la nariz y los colombianos los muertos; la guerra asesina a los militantes de los sindicatos, y los sindicatos organizan más entierros que huelgas y se deja de molestar a las empresas Chiquita Brands, Coca-Cola, Nestlé, Del Monte o Drummond Limited; y la guerra asesina a los que denuncian las causas de la guerra, para que la guerra sea tan inexplicable como inevitable. Los expertos violentólogos dicen que Colombia es un país enamorado de la muerte.

Está en los genes, dicen.

(Eduardo Galeano, Guerras Disfrazadas, En Espejos. Una Historia casi Universal)

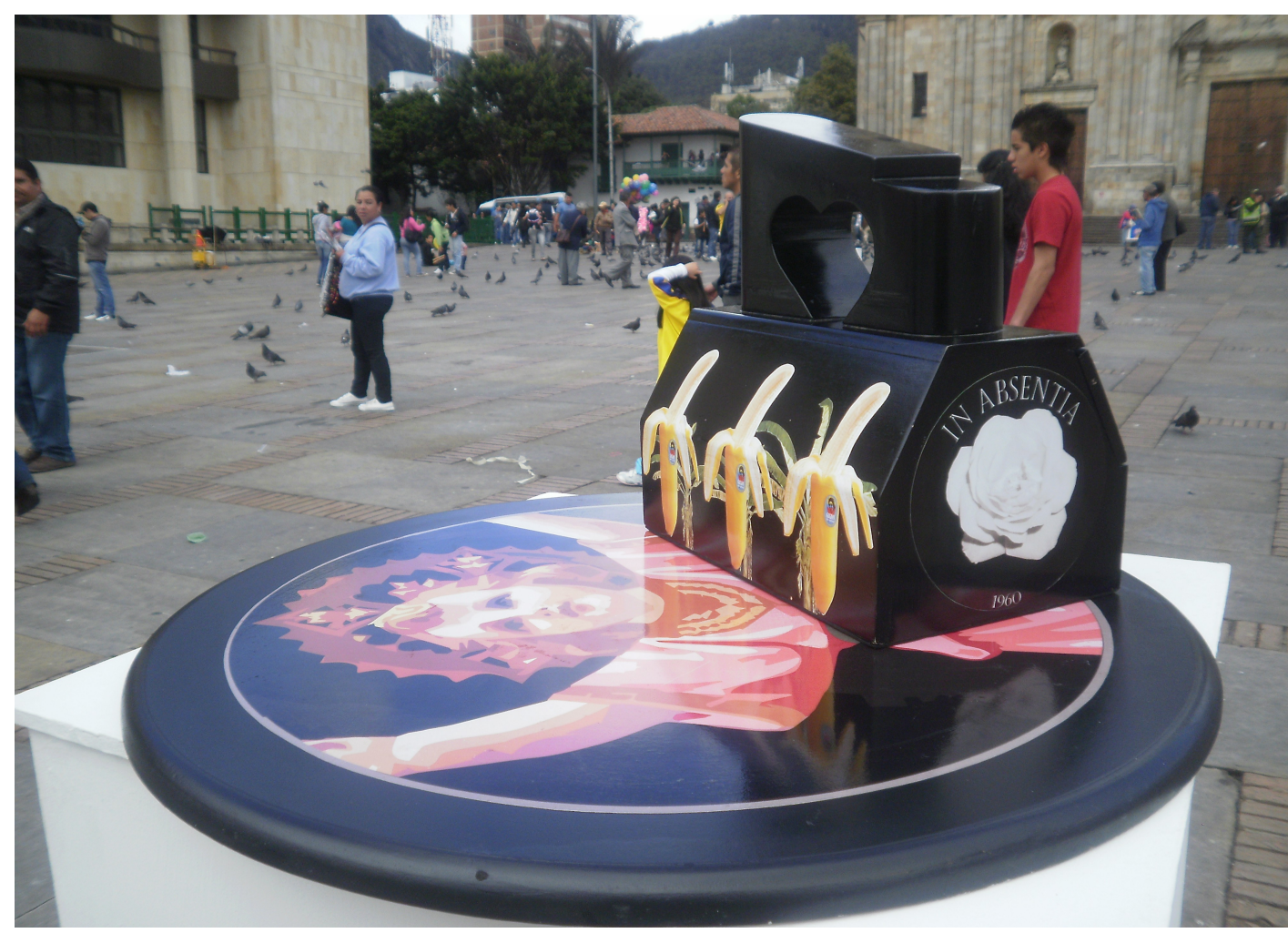

Sexta conmemoración de la muerte de Jaime Garzón, periodista, humorista y político colombiano. Plaza de Bolívar de Bogotá. 2011. Fotografía: Andrea Guatavita.

La comisión histórica planteó elementos económicos que dispararon la violencia política. No aclara la participación del estado en el mantenimiento de estructuras para el mantenimiento del estatus quo, sólo como respuesta a la violencia generada por las FARC- EP.

Con respecto a esos hechos económicos es posible recordar a la empresa bananera Chiquita Brands, Ilamada en el pasado United Fruit Company, y reconocida por inaugurar el siglo XX con el exterminio del movimiento sindical colombiano. La masacre de las bananeras fue realizada por el ejército que protegía el enclave bananero norteamericano y se sumaba a un 
conjunto de conflictos internacionales que Estados Unidos causaba en su intervención en el negocio de las frutas tropicales y la extensión de su mercado a través de la empresa del ferrocarril.

Años después, cuando Estados unidos se debilitó por el gasto militar en la guerra fría, y por derrotas políticas como la guerra de Vietnam, la devaluación del dólar y la crisis petrolera (Hobsbawm, 1995). La liquidez internacional no encontraba rentabilidad en el centro financiero y lo encontró en el tercer mundo. A los estados de esta región se les obligó a hacer uso de créditos sin responder a necesidades internas, y estos créditos fueron aprovechados por los grupos económicos dominantes que no contaban con buenas fuentes de financiación. Estados Unidos se convirtió en la primera economía deudora del mundo y chupó los capitales latinoamericanos (Acosta, 2002). Finalizando la década del 70' Estados Unidos intentó equilibrar su déficit aumentando el enfrentamiento con la URSS a través de los otros países y fortaleciendo sus sistemas de seguridad. En el 73' fue intervenido Chile, con la participación de una nueva estructura de gobierno dictatorial y la aplicación de técnicas de la universidad de Chicago el gobierno chileno incorporó una política de ajuste, caída de salarios y desocupación. Bajo las condiciones de represión fueron posibles políticas neoliberales que pusieron en marcha mecanismos de integración económica como la zona de libre comercio que no establecía barreras arancelarias (Klein, 2007). La relación entre las políticas de contención norteamericanas y la dinámica económica se tradujo en la represión al sector obrero por parte de miembros del estado ${ }^{89}$.

Hasta la década del 70' los estados promovieron sistemas de bienestar, pero al final de la década endurecieron el mercado y vino la des regulación de la economía. La capitalización de la deuda significaba la descapitalización de los países. La lógica del sistema era neoliberal. En aquellos países en donde existían regímenes dictatoriales, comenzó la transición a la democracia y la consolidación de los sistemas partidistas. Estos fueron

\footnotetext{
${ }^{89}$ En Argentina, por ejemplo, antes y durante la dictadura se reconocieron acciones como la detención de obreros y líderes sindicales, la militarización de las fábricas. ASTARSA, Acindar Industria Argentina de Aceros S.R.L., Dálmine Siderca, Ford Motors Argentina, Ingenio Ledesma, Mercedes Benz (Basualdo, 2006) se vieron involucradas en la represión y el gobierno en la implementación de medidas económicas impopulares en pro de la acumulación del capital. Lo anterior cuestionó la explicación única de que la dictadura fue una acción exclusiva contra las estructuras guerrilleras y hace eco en su intención económica. En este nivel la dictadura tuvo una nueva interpretación como un ataque clasista para configurar un sistema laboral propicio para la acumulación y la desestabilización del sector proletario.
} 
fortalecidos por la intención de participación de sociedades recién controladas, con menos capacidad de movilización por las acciones de represión.

Pero en ese marco surge una nueva burguesía proveniente del narcotrafico. A esa gran burguesía proveniente del narcotrafico en ese entonces estorbaba el movimiento popular y las clases tradicionales por eso ellos decían por favor seamos más libre mercado porque eso sirve para lavar dólares. Para lavar dólares qué hay que hacer, comprar huevonadas. Por eso les estorba y por eso aquellos fueron los promotores de la apertura económica por eso César Gaviria promueve la apertura económica. Claro el neoliberalismo es decirle a la gente seamos libre mercado dejemos que el que tenga más capacidad de monopolio nos venga (inaudible) (Vaca, entrevista 16 de marzo de 2013).

En Colombia ese movimiento internacional se reflejaba en el malestar social. Como lo reconociera el desaparecido historiador Jaime Gómez (2007) en su libro Tras la Huella de la Verdad. En 1974 el presidente fue un liberal llamado Alfonso López Michelsen y su gobierno conoció un movimiento huelguístico sin precedentes que culminó en el paro cívico nacional de septiembre de 1977 al que se integraron las cuatro centrales obreras de corte conservador, liberal, comunista y demócrata cristiano y el sindicalismo independiente con participación de la población y el apoyo de la ANAPO (Jaime Gómez, 2007) .

La respuesta a ese proceso de movilización contra el sistema socio político, fue una fuerte ola de represión, protagonizada por el mencionado gobierno y por quien lo continuó: Julio César Turbay Ayala. De esas expresiones de represión de estado se dice poco.

(...) es decir es el mismo Estado el que necesita depurarse, hacer su metabolismo mientras el modelo económico se sigue consolidando, y yo he dicho uno de los principales problemas es que el ejercicio de memoria en sí mismo no te forma políticamente y la memoria sin un ejercicio político de formación que vea críticamente esas matrices de pensamiento frente a lo democrático o de izquierda en un alcance más amplio puede ser contraproducente osea puede ser tergiversado, osea uno se pone a ver la mayoría de experiencias de transición cuando hay mayor boom de memoria hay mayor consolidación del modelo que rige el capital porque usan figuras simbólicas que antes fueron víctimas: Mandela, Bacheller, los hijos de las Hermanas Mirabal, incluso Dilma Rousseff que fue (...) hay una cosa muy fuerte y que la memoria lo puede ver como victoria o lo puede ver como un avance, pero que si se pierde esa matriz de pensamiento 
crítico pues termina siendo funcional al capital (Camilo, entrevista 18 de octubre de 2011).

Pero en otros países la memoria de la represión contra personas específicas de la izquierda ha dado lugar a la legitimación de algunas figuras políticas por su victimización y la reivindicación de sus luchas pasadas después de que sus propuestas de cambio con respecto al sistema capitalista fueron transformadas, el proceso de represión parece separarse de las condiciones objetivas que constituían un centro en las subjetividades de quienes se movilizaron, según lo menciona Camilo.

Tras esta rememoración la pregunta es cómo se construyen subjetividades que puedan olvidar estos cambios objetivos aunque han sido generados durante la historia más reciente del país. La idea de la transformación subjetiva que acompaña estos fenómenos históricos complejiza la noción de las experiencias límite o traumáticas pues al parecer conducen al olvido colectivo.

El Nuevo Orden Económico mundial, incluye en la gobernanza global corporativa, un alimento ideológico que apunta a fortalecer el ego, el concepto del individuo que se inserta en el sistema como ser exitoso, desarticula la organicidad. Creo que algo importantísimo es que los chicos y las chicas han venido respondiendo con nuevas formas de organización. Sería lindo alimentar eso con más comprensión política, más capacidad de análisis no académico, popular, local, construir su poder local sobre la base del reconocimiento de sí mismos (...) (Vaca, entrevista 16 de marzo de 2013).

Cuando las expresiones sociales se suman como "respuesta" de resistencia a impactos de los hechos violentos, se presume que existen capacidades para anteponer acciones en contra de actos de exterminio o similares. La parálisis puede explicarse como efecto de acciones por parte de representantes del Estado, por ejemplo, para legitimarse, o como acciones en donde el individuo decide no actuar.

Para algunos autores de las disciplinas psicológicas y sociales, la falta de solidaridad o la legitimación de hechos traumáticos se comprenden como consecuencia de actos generados desde arriba a través de aparatos ideológicos. Ante estas interpretaciones aparecen preguntas históricas que ponen la lupa sobre distintas experiencias nacionales y cuestionan 
el nivel de consenso o el apoyo de distintos sectores a los regímenes que generaron prácticas deshumanizantes.

En esa diferencia están en juego dos cosas elementales: el efecto del miedo frente a acciones reales de intimidación y coerción, y el valor y el lugar de la responsabilidad de cada individuo dentro del grupo social. Las dos aplican una noción de sujeto vinculado socialmente, la primera como afectado del vínculo u opositor y la segunda como parte del proceso social que genera la represión.

La primera perspectiva está más cercana al concepto de daño, la segunda requeriría más un trabajo sobre la participación o la responsabilidad. Pero son las nuevas generaciones quienes indagan sobre lo que les fue heredado del dolor vivido por los antecesores, y quienes al mismo tiempo preguntan: "qué hacías tú mientras todo esto ocurría".

Estas preguntas parecen ser dos lados de la misma moneda. Una inquietud por el pasado para saber lo que ocurrió y cómo la transitaron, aquellos quienes vivieron esa experiencia, por la necesidad de entender y de actuar. Puede ser que al conocer la segunda respuesta se hallen efectivamente omisiones o miedos que dejen sin pasado a los que preguntan. Sin embargo hay una tercera opción y es la de reconocer el contexto de represión y sus consecuencias pero también la participación de padres y madres en actividades "ilegales" pero legítimas en su momento histórico. Puede que se conozcan respuestas con las que poco se puede hacer, de las que poco se puede decir y tengan que seguir circulando en un espacio oculto.

¿Pero y si en este caso no se trata del olvido sino de una selección del recuerdo? Las preguntas o silencios sobre ciertos hechos son explicados por los historiadores usando nociones psicológicas como el periodo de latencia, así como lo hizo Freud (1926) en sus hipótesis sobre el tiempo en el que se mantuvo en el olvido el verdadero origen de la religión judía y de Moisés $^{90}$. Para hablar de aquellas cosas guardadas bajo los límites de lo

${ }_{90}$ Una vez establecida la combinación de horda fraterna, matriarcado, exogamia y totemismo, comenzó un desarrollo que podemos describir como un lento «retorno de lo reprimido». El término «lo reprimido» es aplicado aquí en una significación 
comunicable, Freud usó conceptos como represión y latencia, pero aclara que el uso de los términos no es el mismo que tienen en el estudio de la neurosis.

\begin{abstract}
Ahora podemos explicar el fenómeno de la latencia en la historia de la religión judía, que aquí nos ocupa, aceptando que los hechos y los temas deliberadamente negados por la historiografía, que podría calificarse de oficial, jamás se perdieron en realidad, sino que las noticias de los mismos subsistieron en tradiciones conservadas por el pueblo (Freud, 1926:38).
\end{abstract}

Estos mismos términos fueron usados por otros autores. Hay algo que queda grabado y algo selectivamente olvidado: Para Aguilar (2002), hablando de España se olvidó la guerra civil, para Yerushalmi (1985) el olvido de una parte de la cultura que no es resguardado porque no es "fundamental". En este camino se puede seguir definiendo cuál es el efecto de un momento histórico de riesgo en la memoria que es transmitida a las nuevas generaciones ${ }^{91}$.

- ¿Qué se perdió?

- Creo que profundidad política y capacidad de construcción de hechos populares. Creo que debemos trabajar entre todos, desmoronar la distancia generacional. Ahora han logrado enrolar a las juventudes en guetos de pinta, comportamiento y pose, pero necesitamos es menos aspecto externo y más amor a lo interno popular. (...) Hay que volver al trabajito de hormigas, al diario, a la organicidad. Hay que romper los guetos (...) La autogestión, la construcción de alternativas vívidas, y la memoria de lo cotidiano. Es importante rescatar la memoria de esos esfuerzos organizativos, que aunque temporalmente fallidos, albergan un rico material para la construcción del futuro que haremos (Vaca, entrevista 16 de marzo de 2013).

Yerushalmi (1981) preocupado por la relación del pueblo judío con su pasado y el papel que en ese proceso juega el historiador, pregunta cómo ocurre el olvido colectivo para definirlo como la ruptura de la transmisión en dónde las nuevas generaciones dejan de ser receptoras del pasado. Entonces hay un lazo muy cercano entre el evento y la imposibilidad de

impropia, no en su sentido técnico. Tratase de algo pasado, desaparecido, superado en la vida de un pueblo, algo que me aventuro a equiparar a lo reprimido en la vida psíquica individual. Por ahora no podríamos decir en qué forma psicológica subsiste eso, lo pasado, durante el lapso de su latencia. No es fácil trasladar los conceptos de la psicología individual a la psicología de las masas, y por mi parte no creo que se adelantaría mucho adoptando el concepto de un inconsciente "colectivo». De por sí, el contenido del inconsciente es ya colectivo, es patrimonio universal de la Humanidad.

${ }^{91}$ Este planteamiento deriva de planteamientos tanto de Yerushalmi (1985) como de Benjamín (2007) en cuanto a que es en momentos de riesgo vividos por una comunidad que decide guardar lo que más necesita. Momentos en los que su existencia se está viendo comprometida. Esto quiere decir que la memoria no es resultado de un boom decidido desde arriba sino que es una estrategia de sobre vivencia de ciertos grupos, su historia e identidad. 
transmisión o memoria colectiva. Para Yerushalmi, "la memoria colectiva no tiene ninguna herencia vagamente genérica, ni una estructura psíquica innata análoga a los arquetipos junguianos" (Yerushalmi, 1981:XXXV) o una forma de psico - lamarckismo de Freud, que propone identidades esenciales de los grupos sociales. Él plantea que la memoria es posible gracias a la transmisión, siguiendo a Halbwachs (1950), porque toda la memoria esta atravesada por unos marcos y es una realidad transmitida a través de ciertas prácticas e instituciones.

La causa de estos procesos puede ser como lo dijimos antes, una cuestión emotiva o puede estar relacionada con un marco social. Lo interesante es que existen análisis que relacionan el marco social con el silencio y con la necesidad de guardar, ocultar acciones, pensamientos, recuerdos.

Aunque el periodo de latencia no es generalizable al análisis de Argentina y Colombia, por ejemplo, donde las acciones memorísticas se dan casi al tiempo que los hechos traumáticos generados por los regímenes promovidos por la doctrina de seguridad nacional. La latencia si es una noción frecuente en el análisis del nazismo, el franquismo y otros fenómenos en Europa. En el caso de España, según Paloma Aguilar (2002), el silencio es auto impuesto por el pueblo a causa de una "culpa colectiva" por la muerte de miles de personas en una guerra fratricida, la guerra civil anterior al franquismo. Esa culpa dejó miedo a hablar y a afrontar los hechos y se relacionó con que se aceptara una transición sin justicia y depuración institucional. El silencio estaría en este caso relacionado con la memoria traumática y el elemento de la culpa reflejaría comportamientos colectivos de negación y ocultamiento.

Lvovich por su parte afirma y con ello introduce nuevamente elementos de análisis de tipo histórico:

Es posible sostener que en los tres casos considerados, la potencia del trauma, la cercanía temporal, y las negaciones individuales y colectivas resultan factores que contribuyen a explicar la dificultosa conformación de las respectivas historiografías nacionales. Sin embargo, resultan factores determinantes en la explicación los consensos sobre los que se construyeron -en el marco genérico de la guerra fría- los 
regímenes democráticos en Italia, Francia y Alemania, ya que dificultaron la emergencia de una apropiación de sus pasados recientes demasiado distantes de esos cánones (Lvovich, 2007:115).

En el caso específico de los crímenes del nazismo, Novick sostiene que hasta comienzos de la década de 1960 el genocidio no fue mediatizado como consecuencia de los alineamientos mundiales. Con el desarrollo de la segunda guerra fría Alemania pasó a ser un aliado de los Estados Unidos y la Unión Soviética se convirtió en el enemigo totalitario. Hablar de los crímenes nazis podría poner en peligro la orientación de la opinión pública hacia el anticomunismo (Traverso, 2010).

En el marco colectivo dejar al silencio como un efecto natural de un hecho intempestivo y de la culpa, es superficial. Todos los estudios reseñados a través del artículo de Lvovich (2007) sobre casos nacionales exponen que hubo marcos sociales, contextos políticos específicos que hicieron posible o no ciertos desarrollos de la memoria.

La posibilidad de construir la historia, y la latencia tienen que ver con la existencia de condiciones políticas que permitan esa reconstrucción, nunca sin la presión colectiva y el deseo de rememoración. En el análisis de la historia y las condiciones sociales será posible reconstruir hasta los hilos más secretos y dolorosos de la participación de la sociedad en procesos de represión o sus acciones de resistencia.

Lvovich (2007) afirma que en la historización del nazismo fue posible una indagación más profunda porque "la nueva generación resultaba inequívocamente inocente de los crímenes del nazismo, por lo que estaba en condiciones de romper el silencio que cubría el tema, interrogar a la generación de sus padres por sus responsabilidades por acción u omisión en esta etapa" (Lvovich, 2007:112). Al respecto Sorgentini (2003) plantea: "Su restitución al objeto de la historia responde a la vez a un problema epistemológico y a un imperativo éticopolítico: no sólo testimonia la existencia de aspectos ininteligibles de las culturas del pasado, sino que da cuenta de una racionalidad alternativa que debe ser recuperada en vistas a dar cuenta de "una mutilación histórica de la que, en cierto sentido, nosotros mismos somos 
víctimas".

De este modo, la intención restaurativa del historiador se inscribe en la línea del postulado benjaminiano que sostiene que "«nada de lo que se verifica se pierde para la historia», [...] más "sólo la humanidad redenta toca plenamente su pasado»" (Sorgentini, 2003:119). Nuevamente cualquier fragmentación histórica es un acto que aparece en contra del colectivo, también que el cambio generacional hace posibles nuevas racionalidades que dan cuenta del pasado.

Lavabre (2006) propone que la historia critica puede constituir una fuente de ilusión sobre nuestra identidad, podríamos ser herederos de los acontecimientos. En ese sentido, parece necesario un proceso en el que la sociedad se asuma en su responsabilidad, y al tiempo implemente acciones de justicia para des proveerse de cuestiones que la lesionan, puede integrar a su memoria todas las características del lazo social que dio lugar al acontecimiento "traumático".

No es para menos el efecto que quieren llegar a tener en la reconstrucción de la memoria, aquellos implicados en acciones de represión, porque cuando se fragmenta, niega o silencia la memoria de un grupo explotado, según Benjamín, los poderosos aguantan mientras que los otros comienzan de cero y con muy poco, es decir sin el acumulado de sus experiencias, la humanidad se prepara para sobrevivir" (Benjamín, 1989:173); por ejemplo, no fue ventajoso para las "víctimas" el olvido sobre el carácter de despojo que tuvo el apartheid en África como lo recuerda Alejandro Castillejo (Barrera, 2010) y por lo tanto, las condiciones particulares de la adquisición de tierras por parte de ciertos actores. Ni fue ventajoso para Colombia el olvido de la violencia de Estado durante el Bogotazo, bajo la explicación de una violencia puramente bipartidista y, en consecuencia, el enquistamiento de esa práctica en las estructuras militares y paramilitares. Pero tal vez sea más imponente simbólicamente el recuerdo de este hecho como una tragedia y no como un levantamiento memorable. La valoración ya fue establecida y parece inamovible. 
- Hay algunas cosas que yo creo y es que en medio de ese sistema que ha intentado enseñarle a uno, uno se vuelve un autodidacta y hay algunas cosas que uno aprende y construye las cosas que quiere: El derecho al amor, la necesidad de ser felices... ¿qué cosas has aprendido y qué has desaprendido tú como autodidacta?

- Eso es de todos los días. Lo que uno cree que supera y que después se da cuenta que no. Al principio tenía que desaprender, que la venganza no iba a ser un método de hacer justicia por lo que te digo que para sobrevivir estaba peleando todo el rato como preparándome para un gran combate porque además había sido una promesa y un compromiso. Pero ya después cuando dices: "Es que no merecen....". A mi la poesía me salvó y creo que por eso también he vuelto a ella. Nadie merece que uno se convierta en un asesino. Ahí tenía que aprender eso que la guerra y las formas de hacer la guerra no me iban a ayudar a tramitar lo que había experimentado ni a reivindicar el nombre de mi madre. Tenía que aprender eso. Después aprender que todo lo que me habían enseñado en el colegio incluso hasta la constitución no me había servido de nada porque me tocaba aprender la otra historia que me estaban negando. Que no sólo había sido la gente del M sino que estaban matando a mis amigos de la UP y ese proceso incluso hasta el noventa y cuatro. Porque fueron siete años de locura hasta que mataron a Manuel Cepeda. Uno va creciendo por una apuesta civil pero ve que le matan a todo el mundo. Eso había que desaprender, el no a las armas y entender que había sido una opción para otras personas en otra generación que también era muy difícil de deslegitimar. Porque había momentos en los que uno decía: "Pero para que se metió a eso". Pero también las condiciones lo van llevando... van llevando a la gente a tomar opciones (Chico Bauti, entrevista realizada en Septiembre de 2011).

\section{Este apartado rebela la creación de una subjetividad como plantea Chico Bauti, en donde} hay que enfrentarse al hecho de que uno parece destinado a convertirse en un asesino, a asumir una historia útil para los perpetradores, pero al mismo tiempo analizar la negación de la lucha armada como una estrategia posible y válida en el contexto en el que su madre la desarrolló.

Una vez me compraron un avioncito y me lo robaron en frente al Gernika que queda en la séptima y yo me puse a llorar y el gamincito le dio tristeza de verme llorar y me devolvió el avioncito y entonces mi mamá me echó el discurso de la desigualdad social y me compró el libro ese de Puro Pueblo de Jairo Aníbal Niño y por ahí está un afiche con ese texto que dice que: "En ese momento no entiendo pero que más adelante voy a entender". Entonces uno se gasta toda la vida tratando de entender qué es lo que quiso decir. Que carretazo (Chico Bauti, entrevista realizada en Septiembre de 2011). 
Qué significa decir que la historia se pueda repetir. En palabras de Eduardo Galeano este acto es imposible. Pero entonces cual es la necesidad de transmitir a las nuevas generaciones lo que ocurrió. Con qué objetivo y qué significa la elaboración en ese campo. Producir lo nuevo o participar en la intención de nuevos procesos puede ser simplemente ayudar a hacer posibles nuevas comunidades y nuevas formas de cooperación (CINTRAS, EATIP, GTNM/RJ, SERSOC, 2009) y necesariamente transformar instituciones y estructuras encargadas de transmitir y perpetuar ciertas prácticas: cambiar los centros de detención, las estructuras de seguridad e inteligencia, etc.

Según Candau, el olvido total, es una sumisión absoluta al futuro y hay dos formas bien diferenciadas del olvido parcial: una es el olvido activo aceptado -que no hay que confundir con la falsificación orweliana de la memoria o con lo que primo Levi llamo la guerra del "Reich milenario" contra la memoria: destrucción de documentos púbicos, retoques de fotografía, autos de fe, etc.- que es una amnesia fundadora del futuro porque este olvido es asunción del pasado: el otro, el olvido pasivo, atenta contra la memoria de la víctimas (EI olvido culpable del que habla Rene Girard) es el signo de un encadenamiento con una historia reprimida, actitud exactamente simétrica de la repetición machacadora de la memoria que manifiesta el encarcelamiento a un "pasado obsesivo" (Candau, 2002).

Sin embargo esta expresión metafísica, se vale de la existencia de una historia reprimida que se repite místicamente. La historia no se repite místicamente, es construida a través de prácticas de personas, y es posible gracias a instituciones específicas. El aparente contenido del olvido puede resurgir y puede ser reconocido como un contenido que estuvo latente y la memoria será el marco en el que ese ejercicio se realice.

La trasmisión oral o escrita puede caracterizar con fuerza el uso y las formas de las memorias que en ambos casos sirven para "transmitir la herencia cultural, social, religiosa y política de una generación a otra". En ese proceso se reconocen tres aspectos: el traspaso de acervos materiales, pautas de comportamiento que son trasmitidos también por imitación directa y los "elementos más significativos de toda cultura": significados y actitudes que los 
miembros de cada sociedad asignan a sus símbolos verbales (Da Silva Catela, 2008), es decir que, el estudio de la transmisión supera por muchos motivos el estudio de la transmisión de un impacto, o mejor de las condiciones que hacen que el impacto se sume a ese acervo de cosas que las generaciones se transmiten.

No hay un olvido colectivo a causa de un fenómeno emocional indecible que no puede representarse. El olvido colectivo tiene que ver con el miedo que se impone desde imposibilidades externas. Así que hay un silencio colectivo por marcos que llevan al silencio y ese silencio refuerza el margen de exclusión.

Lo que ocurre es que ante memorias construidas institucionalmente quedan por fuera las memorias "clandestinas" o como lo mencionaría Pollak, subterráneas relacionadas con culturas minoritarias y dominadas que se oponen justamente al discurso oficial, de manera explícita, y de estas cual más si no la de la desaparición que dirige la mirada al Estado como perpetrador único del delito. Esas memorias siguen su "trabajo de subversión en el silencio y afloran en momentos de crisis a través de sobresaltos bruscos y exacerbados". Limitados por un proceso previo de encuadramiento de la memoria que los dejó aislados (Pollak, 2006).

Finalmente, la opción con frecuencia en Colombia ante todo el contexto descrito durante la tesis fue de movilización. A pesar de la represión en las distintas etapas del país. Muchas veces también fue la vinculación con actores armados. Fue y sigue siendo, con la particularidad de que estos actores armados no solo se mantuvieron sino que se fortalecieron después de la caída del muro. Lo que para algunos dejó sin piso ideológico u horizonte utópico a muchos movimientos, en Colombia fue una demostración de que los conflictos del "tercer mundo" no se podían ver sólo bajo la lente de la guerra fría y que a pesar de que esa transformación fundamental se estaba dando para los insurrectos, para ellos y ellas aún existen motivos para pensar que "la revolución" por esa vía es necesaria y posible.

Esa idea ha tenido costos que tienen incidencia directa en el tema trabajado. Pues así como lo planteaba en párrafos anteriores, aparece la responsabilidad de la población en este 
proceso de enfrentamiento o, siendo estrictos con la memoria del terrorismo de estado y violencia económica, en el sostenimiento de algunas prácticas del estado pero también en este proceso de defensa. El clima sostenido en el país durante seis décadas ha sido de conflicto permanente y ha hecho mella en el bienestar de la nación. En el presente la mayor parte de la responsabilidad ha sido adjudicada a "la guerrilla". Expresión que cada vez se reduce más a las Farc - EP, aunque actualmente existen otras dos organizaciones independientes de esta y aunque, al mismo tiempo, se desdibuja la memoria de otras diez organizaciones armadas que ya no existen.

En ese clima actual se reconstruyen estas memorias y, en consecuencia, si en ellas hay una parte que tiene que ver con estas opciones de acción política frente al estado, sabremos de ellas con mucha dificultad. En primer lugar, porque solo es posible acceder a alguna información sobre quienes pertenecieron a grupos que ya no existen como el M-19. Con la dificultad de que esa memoria en algunas ocasiones parece deshumanizar la imagen de quien fue desaparecido.

No de eso hablo con muy poca gente. Lo que pasa es que es el imaginario que se tiene en este país del guerrillero, del subversivo... por eso he tratado de reivindicar también los otros perfiles de Nydia como mujer como estudiante de un sector popular (Chico Bauti, entrevista realizada en Septiembre de 2011).

Con respecto a la reconstrucción de la historia de las FARC - EP, es particular ver la elaboración del documento publicado por el Centro Nacional de Memoria Histórica. Este está dirigido a explicar la relación entre la guerrilla y la población civil pero menciona que desde la Séptima Conferencia del 4 al 14 de mayo de 1982 y bajo la comandancia de Jacobo Arenas asumió el nombre de Fuerzas Armadas Revolucionarias de Colombia - Ejército del Pueblo. Pero no asume ese título en su documento, en ninguno de sus apartados. Quitándoles la evidencia de su carácter popular y sustrayéndole a la nación la responsabilidades de sostenimiento y adhesión a las acciones que adelantan durante décadas.

En tercer lugar, podríamos conocer esta memoria gracias a documentos que transitan con 
mucha dificultad y no son muy numerosos porque siguen siendo causa de persecución y judicialización. Ejemplos de estos riesgos son la muerte de Oscar Arcos investigador de la historia del $\mathrm{M}-19^{92}$.

\section{Para terminar este capítulo quiero agregar un apartado de la entrevista de Chico Bauti que} tuvo a su madre vinculada al M-19, grupo desmovilizado en la década del 90'. Le doy gracias en este documento por la posibilidad de reconstruir un pequeño fragmento de la vida clandestina de su madre.

... Yo conocía a la gente con la que andaba mi mamá y en lo que andaba. Por ejemplo, me contaban las historias del Batallón América ${ }^{93}$, ella me llevó a Cali, ella estaba encargada de la parte de sanidad de recoger a los heridos, de curarlos y esas son imágenes muy fuertes. Un muchacho que se le había explotado una granada en las manos conocí en uno de los viajes que hice a Cali con ella. Entonces digamos que de lo que pensaba... de los sueños pues para mí quedó muy claro -porque yo le dije a mi Madre que se quedara en Bogotá después de saber toda la persecución, después de saber que la han detenido en Cali y todo lo que le habían hecho a qué está expuesta-. Era un poco una especie de sueño mezclado con escenas de pesadilla porque desde muy pequeño mi madre me llevaba a la repartición de los camiones de leche del $\mathrm{M}^{94} \mathrm{o}$ a construir escuelas. Los sueños eran un poco que todos tuviéramos educación, una cosa mucho más digna para la gente. Esos eran como los sueños sin saber en esa época qué era dignidad porque después de lo de mi Madre (vino) una época de mucha violencia física, de golpes, de sobrevivir en el colegio y era eso sobrevivir, aprovechando para sacar mi rabia pero era supervivencia (...) Había un señor que sabía mucho y le preguntaban cualquier cosa y se demoraba cualquier tiempo respondiendo. Era muy inteligente el viejo (...) Cuando lo mataron en el $85^{\prime}$ nosotros

\footnotetext{
${ }^{92}$ Estudiante de 20 años que cursaba quinto semestre de Ciencias Sociales en la Universidad Nacional Pedagógica en Bogotá. Murió en marzo de 2012 junto con dos estudiantes más en su casa después de la explosión de una bomba. La fiscalía aseguró que la bomba era de fabricación casera y la explosión fue accidental. Al mismo tiempo expresó a la opinión pública que: "al lado de los tres muertos, fueron hallados panfletos alusivos a las Farc y a un grupo que se auto denomina como seguidor de Jaime Bateman, el desparecido dirigente del desmovilizado M-19". Según su maestro Renán Vega Cantor, ese material obedecía a que el estudiante realizaba múltiples entrevistas sobre el desaparecido grupo guerrillero M19. Estas afirmaciones y la lectura que del hecho hace el docente con respecto a las medidas y los cambios vividos en la universidad, al parecer dieron lugar a un conjunto de amenazas que lo llevaron a exiliarse en Argentina durante los últimos meses del 2012. http://www.herramienta.com.ar

${ }^{93}$ El Batallón América fue una columna guerrillera internacionalista de carácter bolivariano, integrada por miembros de dos grupos guerrilleros de Colombia: M-19, de Quintín Lame, dos grupos guerrilleros de Perú: Movimiento Revolucionario Túpac Amaru (MRTA), y el Movimiento de Izquierda Revolucionaria-Voz Rebelde (MIR-VR); y dos grupos ecuatorianos: Alfaro Vive Al Carajo y la Organización Político Militar (OPM). Según notas periodísticas esta organización desarrolló combates sólo en el territorio colombiano.

${ }^{94}$ El M-19 robaba camiones de leche en Bogotá y repartía su contenido en los barrios más deprimidos de la ciudad. En una de esas operaciones murieron algunos de sus integrantes por acción de agentes del estado y en consecuencia el estado recibió una amonestación por parte de la Comisión Interamericana de Derechos Humanos en 1997.
} 
fuimos al entierro y eso fue impresionante porque de ahí mi mamá se la pasaba cada dos semanas en un entierro y eran los compañeros con los que yo la había visto entonces a mí me daba mucho susto. Cuando pasó lo del Palacio de Justicia ella se va y pues ella estuvo muy vinculada con esa historia de lo del Palacio. Para nosotros era todo evidente lo que había hecho. La vimos llorar por el fracaso de que no hubo diálogo. Tenían unos textos que habían redactado de qué iban a discutir y cuando se quedan sólo en la cosa armada entonces mirábamos esos papeles y no servían de nada. Todo ese fracaso ${ }^{95}$.

Después cuando era clandestina porque ya no se llamaba Nydia sino que me tocaba decirle Natalia, no era mi mamá sino una señora. No, era duro porque yo tenía mi tarjeta de identidad (...) y ella se llamaba Natalia no sé qué y una vez estábamos viajando juntos por el Cauca (risas) -como desde pequeñito uno ya metido en esa historia de que ellos tienen otra identidad y bueno Natalia era una pero tenían muchas-. Cuando llegué a Cali como que todo era misterioso ya. Nosotros éramos unos niños tenía como siete, ocho años como en el ochenta y algo... no ya tenía diez años... (Chico Bauti, entrevista realizada en Septiembre de 2011).

${ }^{95}$ El M-19 tomó el Palacio de Justicia el 6 de noviembre de 1985 con el objetivo de hacer un juicio político al presidente Belisario Betancour por la ruptura de los diálogos de paz iniciados por Jaime Bateman en 1983, suspendidos y retomados hasta el incumplimiento del cese al fuego. 


\section{Conclusiones}

Cuando inicié el trabajo asumí, basándome en distintas fuentes, que la producción de memoria ayuda a aliviar el dolor y el sufrimiento generados por la desaparición. De la misma manera asumí que ayuda a reconstruir un relato útil para la construcción de subjetividades no subordinadas al contexto hegemónico.

Ahora planteo que la memoria en tanto diversa, puede servir para esto o no, es decir, puede tener funciones psicosociales y resultar liberadora, emancipadora y curativa, o no. La memoria, en tanto está relacionada con prácticas sociales que generan representaciones y está influida o mejor determinada por ciertas ideologías, es reproductora o es transformadora.

En las entrevistas encontré memorias que parecían apuntar a la creación de subjetividades nuevas, críticas frente a un sistema de alienación de tipo capitalista. Pero también encontré recuerdos que fijaban a aquellos que las vivían al miedo y al dolor.

Ahora bien, para definir la memoria fue necesario definir el tiempo o el intervalo de tiempo de la generación que recuerda. Ese intervalo se traza, arbitrariamente y por cuestiones de la investigación desde el surgimiento del movimiento de hijos e hijas por la memoria y contra la impunidad.

Así es posible construir ejes para comprender el relato del pasado y superar la imagen de que en Colombia hay una violencia constante e inexplicable. Esta organización permite refutar que el país ha sido siempre el mismo y ver las transformaciones, algunos momentos de movilización álgidos en la década del 70', por ejemplo, y la instalación de políticas de memoria en gobiernos específicos.

También es posible ubicar actores de oposición en el proceso, la acción de grupos y 
personas que participaron en movimientos de izquierda para intentar incidir en la política nacional que con el paso del tiempo no han visto reconstruido su proceso político o la victimización de la que han sido objeto: La Organización Popular Revolucionaria, la Alborada Comunista, el Frente Popular, la Juventud Comunista - JUCO, el PCC M L, ADO (Auto Defensa Obrera), el Partido Socialista de los Trabajadores, la Asociación Nacional de Profesionales, la ANUC, A Luchar, entre tantos otros.

Después de revisar los testimonios habían algunos hitos históricos, relacionados con movimientos y re acomodamientos del Estado que ha modificado los procesos de represión. Esos hitos están íntimamente relacionados con los procesos de negociación de paz. Con esta idea he vuelto a leer los testimonios y los manuales de historia y me encontré primero con que en los tres casos los desaparecidos estuvieron vinculados con todos los procesos de negociación infructuosos o "exitosos" pero limitados, y que esos procesos explicaron también la transformación de los modos de represión después de la confirmación de que el movimiento social seguía organizado y había demostrado capacidades de incidencia en el Estado.

Esas transformaciones siempre tuvieron consecuencias en el marco jurídico, la participación política y la dinámica económica. En ese sentido siempre fueron muestras de logros del movimiento social por la aceptación por parte del estado de nuevas reivindicaciones con la salvedad de que el aparato estatal se adaptó para su beneficio, con el fortalecimiento de las estructuras de seguridad para que los avances no tuvieran un correlato en la realidad de las poblaciones. Y me surgió la pregunta sobre el reconocimiento de los logros de ese movimiento social y las construcciones que alcanzó a realizar en medio de estos.

Después de la violencia generalizada de la década del 50' durante la cual estuvo vedado el poder para el partido liberal ¿no fue resultado del Bogotazo y lo que lo prosiguió que este partido se insertara en un esquema de poder planteado a través del Frente Nacional, gracias al apoyo de partidos de izquierda que también estaban proscritos? ¿Durante los años de administración de la UP, gracias a ganar el 30\% de la administración a nivel nacional y 
regional, cuantas reformas alcanzó a adelantar? ¿La creación de la constitución de 1991 en donde se reconoce la participación de distintos sectores, el estado laico, el genocidio político, entre otros, no fue resultado de una construcción en donde participaron guerrillas de todo tipo de formación y otros miembros de la izquierda?

Acerca de todas las dificultades que esos "avances" enfrentaron se han escrito miles de páginas pero en clave del reconocimiento de los pequeños pasos dados desde la articulación, poco se ha dicho. Se generalizó la memoria de la violencia, del poder casi ilimitado del estado, pero no de la insistencia y la existencia de los grupos movilizados, es decir que la reconstrucción de la historia priorizó a ciertos "actores" del proceso y no construyó un relato en términos dialécticos de luchas por el poder, expresiones de conservación del estatus quo y resistencias.

Con mi residencia en Argentina y la posibilidad de conocer el proceso de reparación del estado al rededor del terrorismo de la última dictadura escuché que el gobierno de Néstor Kitchner asumió las banderas del movimiento de derechos humanos. Con esa consigna evidencian que el proceso es resultado de la movilización social. Pero no estoy segura de que en Colombia tengamos la misma consciencia, a pesar de que ni siquiera tuvimos un periodo de populismo en la administración, durante el cual una figura nacional se subrogara la construcción de las universidades públicas, los hospitales, las políticas de bienestar. Es tal el desconocimiento que ante la deslegitimación del movimiento sindical por ejemplo, no existe una conciencia general sobre la importancia y el papel que cumplieron los organismos sindicales en lo que hasta antes de la legislación uribista se había logrado en el mundo del trabajo, por ejemplo.

Con respecto a la investigación de la desaparición forzada hay trabajos que se pueden adelantar. Por un lado la investigación sobre los niños y niñas que fueron desaparecidos, que son miles y es un tema del que no se ha hablado y el segundo la reconstrucción de los centros militares y policiales que se conservan y siguen desarrollando actividades. De estos se mencionaron en Bogotá: el Batallón Charry Solano, la Escuela de Caballería de Bogotá; 
las Cuevas de Sacromonte; junto con estaciones de policía y otros centros de las FFMM reconocidos en el informe de Amnistía Internacional. Aunque el PCNM construye su documentación dividiendo zonas a nivel nacional según la jurisdicción militar, no es visible o evidente el uso específico de estas instalaciones del estado para la desaparición de personas. Menos aún la intervención de estos centros, su suspensión e investigación.

Las prácticas de desaparición pueden ser leídas como en muchos casos se hizo como experiencias traumáticas para un colectivo y para las personas que las viven directamente. Sin embargo, para la elaboración del proceso traumático y la comprensión de sus implicaciones se planteó una diferenciación:

Una violación a los derechos humanos es un hecho externo que victimiza a una persona. Ella no queda reducida a la condición psicológica, o al impacto que esa violación genera, pero ese impacto no se desconoce porque es nefasto y genera una condición traumática. En cambio, una sociedad que engendra sistemas de exterminio -conceptualizados desde la historiografía como traumáticos- si puede analizar los núcleos económicos, políticos y sociales que la llevaron a estos, y sumar a ese análisis las causas exógenas relacionadas, por ejemplo: prácticas de colonialismo de los países "más desarrollados". En este sentido no se reconoce ninguna culpabilidad en la víctima como responsable de una violación pero si se reconocen elementos internos en los colectivos que han sufrido "periodos traumáticos".

Gracias a las entrevistas se planteó una tipología de la memoria ya que cada uno de los actores o autores leídos tenían una propia. Diferenciar distintas formas de entender y hacer memoria, teniendo en cuenta el tipo de recuerdos, los lugares dedicados a la memoria, el nivel de voluntad o intención en el hecho de recordar y el distanciamiento crítico del pasado, así se definió que en este caso se podía hablar de memoria traumática, familiar, intencional o colectiva y clandestina.

La memoria traumática se definió como una memoria marcada por la intrusión del recuerdo y la vinculación de este con escenas de terror, causadas por la cevicia ejercida sobre el cuerpo 
de los y las familiares. Esta memoria es la que se relaciona más directamente con el concepto de víctima. Depende o surge como respuesta a una acción de objetivación de una persona (Víctima) por parte de alguien que ejecuta un hecho sobre ella: desaparecer, torturar, manipular la búsqueda.

La memora traumática incluye en sí misma un esfuerzo de elaboración por parte de quienes la experimentan y ha sido abordada desde los procesos jurídicos y desde el arte. Finalmente es una memoria que requiere un contexto de justicia y limitación del poder del victimario para superar no solo el proceso de duelo sino los efectos del miedo. Es una memoria de difícil transmisión pero requiere espacios de escucha y legitimación para que sea posible el reconocimiento de un daño colectivo y para la ruptura del dolor individualizado.

La memoria familiar es un ejercicio de reconstrucción que se distancia del hecho traumático y decide voluntariamente retomar del ser querido elementos que lo alejan de esa acción de objetivación que experimentó. La memoria familiar trabaja con el recuerdo de la cotidianidad y del afecto. Es un ejercicio de reconstrucción dedicado a vincular a quienes no conocen a la persona desaparecida a su mundo personal y a su dimensión humana. Es una memoria de permanente transmisión. Se enfrenta con la estigmatización y la indiferencia social.

La memoria colectiva e intencional, es una memoria reconstruida en la lucha con marcos sociales específicos, tiene un uso y está definida por matrices ideológicas. En el caso de las personas que participaron en la investigación, se plantea como un proceso de lectura permanente, de reflexión y como práctica, no como representación sólida del pasado. Se ubica como herramienta para la transformación política de la nación gracias a que retoma el pasado bajo la luz de los nuevos procesos.

La memoria clandestina es una memoria reconstruida en espacios más cerrados por algunos familiares de personas que hicieron parte de grupos de izquierda radical. No es una memoria caída en el olvido sino que es guardada, conservada y cuidada porque es perseguida y está estigmatizada, su divulgación puede generar riesgos a quienes la promueven o la pérdida de 
luchas en el proceso jurídico. Esta memoria no es menos riesgosa que la mencionada al comienzo a cerca de procesos de resistencia del movimiento social o de los lugares que han servido para la desaparición de personas. Su particularidad es que guarda ideas y experiencias de personas de Colombia que aún viven y que continúan sus procesos. 


\section{Referencias}

Aguilar Fernández, Paloma (2002) "Justicia, política y memoria: los legado del franquismo en la transición española en las políticas hacia el pasado" en Juicios, depuraciones, perdón y olvido en las nuevas democracias. Alexandra Barahona de Brito, Paloma Aguilar Fernández, y Carmen González Enriquez (eds). Madrid: Ed.Istmo.

Alberto Acosta (2002) La deuda externa de América Latina: origen, evolución y alternativas. [Versión Electrónica) Recuperado en Mayo de 2011 del sitio web: www.oidido.org/IMG/pdf/ACOSTA01.pdf

Althusser, Louis (2003) “Ideología y aparatos ideológicos del estado" en Ideología. Un mapa de la cuestión [Comp.] Slavoj Zizek. Buenos Aires: Fondo de Cultura económica. pp. 115-155.

Arellana, Erik ( ) "Memoria Ancestral" en Geomalla. Laboratorio de Memorias. Recuperado en Mayo de 2011 del sitio web: www.geomalla.net

Arenas Jacobo (1989) Correspondencia secreta del proceso de paz. Recopilación, notas y comentarios. Colombia: Editorial La Abeja Negra. pp.40-52.

Arostegüi, Julio (2006) "Traumas colectivos y memorias generacionales: el caso de la guerra civil" en Guerra civil, mito y memoria [Comp.] Julio Arostegüi y Francois Godicheau. Madrid: Marcial Pons Ediciones de Historia, S.A. pp.57-95.

Asociación de Familiares de Detenidos - Desaparecidos (2003) Veinte años de historia y lucha. Asfaddes con todo el derecho. Bogotá: Quito Editores.

Barrero Cuellar, Edgar (2010) Memoria , silencio y acción psicosocial. Reflexiones sobre por qué recordar en Colombia [Comp] Bogotá:Ediciones Cátedra Libre.

Basualdo, Victoria (2006) "Complicidad patronal-militar en la última dictadura argentina: los casos de Acindar, Astarsa, Dálmine Siderca, Ford, Ledesma y Mercedes Benz". Revista Engranajes de la Federación de Trabajadores de la Industria y Afines (FETIA). № 5 (edición especial). Marzo.

Bekerman Silvana (2002) "Redescubriendo la historia del trauma psíquico" en Paisajes del dolor, senderos de esperanza. EATIP, GTNM/RJ, CINTRAS y SERSOC. Buenos Aires: Editorial Polemos.

Benjamín, Walter (2007) Conceptos de filosofía de la historia. La Plata:Ediciones Terramar.

Bernard, Marcos (1991) "Pertenencia y Configuraciones Vinculares". Revista de la Asociación Argentina de Psicología y Psicoterapia de Grupos. Buenos Aires:Asociación Argentina de Psicología y Psicoterapia de Grupo. 
Bisquert, Jaquelina y Lvovich, Daniel (2008) La cambiante memoria de la dictadura. Discursos públicos, movimientos sociales y legitimidad democrática. Argentina:Universidad Nacional General Sarmiento.

Bitár, Sebastián (2007) Los primeros pasos de los Derechos Humanos en Colombia, la adaptación estrategia del gobierno de César Turbay. Bogotá:Ediciones Uniandes.

Bleichmar, Hugo (1991) "La anunciación identificatoria" en El narcisismo: estudio sobre la enunciación y la gramática inconsciente. Buenos Aires: Nueva visión. pp. 56 - 73.

Bloch, Marc (1925) [1999] "Memoria colectiva, tradición y costumbre. A propósito de un libro reciente" en Historia e historiadores. Madrid: Akal.

Buttler (2010) "La pretención de la no violencia" en Marcos de la Guerra: Las vidas Iloradas. Madrid: Paidós. pp. 227-252.

Cairo, Carlos del y Jaramillo Marín, Jefferson (04 de febrero de 2008) "Clifford Geertz y el ensamble de un proyecto antropológico crítico". Revista Tabula Rasa de la Universidad Colegio Mayor de Cundinamarca. No.8, enero-junio. pp.15-41.

Calderón, Omer (1999) La Seguridad Estatal en Colombia. América Latina Hoy. No.23. Diciembre. Recuperado en Junio de 2013 del sitio web: www.academia.edu/1277195/La_seguridad_estatal_en_Colombia.

Calveiro, Pilar (1998) Poder y desaparición. Buenos Aires: Colihue.

Canal RCN (2013) Colombia el país más feliz del mundo. Recuperado en marzo de 2003 del sitio web: www.canalrcnmsn.com.

Canal Caracol (Diciembre 7 de 2008) Un ex presidiario implicado en la desaparición y muerte de psicóloga en Medellín. Recuperado en Mayo de 2013 del sitio web: www.caracol.com.co/noticias/judicial.

Castillejo Cuéllar, Alejandro (2006) "Voces desde el sepulcro: Terror, espacio y alteridad en la guerra colombiana” en (Des)territorialidades y (No)lugares. Procesos de configuración y transformación social del espacio [Comp.] Herrera Gómez, Diego/ Piazzini, Carlo Emilio. Medellín: La Carreta Editores/Universidad de Antioquia. pp. 173-183.

CCAJAR (17 de mayo de 2012) Familiares de 16 de mayo reclaman justicia. Recuperado en septiembre de 2012 del sitio web: www.colectivodeabogados.org/Familiares-del-16-de-Mayoreclaman.

CCAJAR (Septiembre de 2011) Caso colectivo 82. Desaparición forzada, impunidad y memoria. Recuperado en Febrero de 2012 del sitio web: http://www.colectivodeabogados.org. 
CCAJAR (2012) La Fiscalía debe Agilizar la investigación de 12 jóvenes, detenidos desaparecidos hoy hace 30años. http://www.colectivodeabogados.org.

Centro Nacional de Memoria Histórica (2013) Basta Ya. Informe General [Versión Digital] Bogotá. Recuperado en diciembre de 2013 del sitio web: www.centrodememoriahistorica.gov.co.

Cepeda, Iván (2006) "Genocidio político: El caso de la unión Patriótica en Colombia" en Revista Cetil, Año I, No. 2, septiembre de 2006, pp. 101-112. Recuperado en Diciembre de 2012 del sitio web: www.desaparecidos.org/colombia/fmcepeda/genocidio-up/cepeda.html.

Chaparro, Claudia (2007) "Efectos psicosociales de la impunidad: impactos individuales familiares y colectivos generados en las víctimas por los espacios derivados de la ley 975/05" en Memorias de la semana del Detenido Desaparecido. Medellín: Arfos Editores.

Chico Bauti (2011) Tránsitos de un hijo al alba. Bogota:Ediciones Recordis.

CIDH (30 junio 1981) Informe sobre la Situación de Derechos Humanos en Colombia. OEA /Ser.L N/II.53 doc. 22 [Versión Digital] Recuperado en Marzo de 2013 del sitio web:www.cidh.org.

Congreso de la República de Colombia (2000) "Desaparición forzada". Art. 165 de la Ley 599 de 2000 por el cual se expide el Código Penal Colombiano. Diario Oficial 44097 del 24 de julio de 2000.

Congreso de la República de Colombia (2005) Ley 975 de 2005. Por la cual se dictan disposiciones para la reincorporación de miembros de grupos armados organizados al margen de la ley, que contribuyan de manera efectiva a la consecución de la paz nacional y se dictan otras disposiciones para acuerdos humanitarios. Diario Oficial No. 45.980 de 25 de julio de 2005.

Congreso de la República de Colombia (2010) Ley 1408. Por la cual se rinde homenaje a las víctimas del delito de desaparición forzada y se dictan medidas para su localización e identificación. Diario Oficial No. 47.807 de 20 de agosto de 2010.

Congreso de la República de Colombia (2011) Ley 1448. Por la cual se dictan medidas de atención, asistencia y reparación integral a las víctimas del conflicto armado interno y se dictan otras disposiciones. Diario Oficial No. 48.096 de 10 de junio de 2011. 
Congreso de la República de Colombia (2011) Ley 1531. Por medio de la cual se crea la acción de declaración de ausencia por desaparición forzada y otras formas de desaparición involuntaria y sus efectos civiles [Versión Digital]. Recuperado en diciembre de 2013 del sitio web: wsp.presidencia.gov.co/.../ley153123052012.pdf.

Corporación Jurídica Libertad (2012) Caminando en la Esperanza. Por justicia y dignidad. Medellín: Litografía Nuevo Milenio. Recuperado en febrero de 2013 del sitio web: www.cjlibertad.org/files/Caminando\%20en\%20la\%20Esperanza.pdf

Corte Internacional de Derechos Humanos (31 de enero de 2006) Sentencia. Caso Pueblo Bello Vs Colombia [Versión Digital]

Crenzel, Emilio (2008) “Investigar el pasado. La CONADEP y la elaboración del Nunca Más" en La historia política del Nunca Más. La memoria de las desapariciones en la Argentina. Colección Historia y Cultura: el pasado presente- Buenos Aires: Siglo XXI Editores. pp. 53-104.

Crenzel, Emilio (2010) "Introducción" en Los desaparecidos en la Argentina. Memorias, representaciones e ideas (1983 - 2008). Editorial Biblos. Latitud Sur Colección. 11-23.

Cuesta, Juan (2007) ¿A dónde van los desaparecidos? Bogotá: Ed. Intermedio.

Cueto, Santiago (2008) Nacimos en su lucha viven en la nuestra. Identidad, justicia y memoria en la agrupación HIJOS - La Plata [Monografía] Universidad Nacional de La Plata. Recuperado en mayo de 2013 del sitio web:www.memoria.fahce.unlp.edu.ar/tesis/te.427/te.427.pdf.

Da Silva Catela (2000) "De eso no se habla. Cuestiones Metodológicas sobre los Límites y el Silencio en Entrevistas a Familiares de Desaparecidos Políticos" en Historia, antropología y fuentes orales. No.24. Barcelona. Recuperado en diciembre de 2012 del sitio web: arpa.ucv.cl/articulos/deesonosehabla.pdf

Da Silva Catela (1997) Lugares de la Memoria. Cultos, Monumentos y Homenajes a los Desaparecidos. V Congreso Argentino de Antropología Social. La Plata. Comisión de Trabajo: Antropología Política y Jurídica. Recuperado en diciembre de 2012 del sitio web: http://www.naya.org.ar. 
De Ípola, Emilio (2007). Las celadas de la ideología en Althusser, el infinito adiós. Buenos Aires: Siglo XXI.

El Colombiano (2007) Mujeres en la guerra. Recuperado en enero de 2013 del sitio web: http://www.elcolombiano.com.

El Tiempo (2012) “Nace la Alianza para el progreso”. En 100 años. Recuperado en febrero de 2013 del sitio web: www.eltiempo.com.

El Espectador (30 de octubre de 2012) Vuelven las acusaciones de los paramilitares contra Francisco Santos. Recuperado en Noviembre de 2013 del sitio web: www.elespectador.com.

Fush, Jack (2007) “El Poder de las Palabras” en Página 12. Argentina. Recuperado en diciembre de 2013 del sitio web: www.pagina12.com.ar.

Fals Borda, Orlando (1990) “El tercer mundo y la re orientación de las ciencias contemporáneas" en Nueva Sociedad. Mayo - Junio. pp. 170-181. Recuperado en diciembre de 2013 del sitio web: www.nuso.org/upload/articulos/3072_1.pdf.

Familiares 16 de Mayo (Mayo 28 de 1998) Carta a Samper por las desapariciones forzadas. En Barrancabermeja. Recuperado en febrero de 2013 del sitio web: www.desaparecidos.org/colombia/doc/cartas/barranca.html.

Foucault, Michael (Septiembre de 1997) "Des espaces autres” Conferencia pronunciada en el Centre d’Études architecturales el 14 de marzo de 1967 en Revista Astrágalo. No 7. Traducción al español por Luis Gayo Pérez Bueno [Versión Digital].

Freud, Sigmund (1926) Inhibición, síntoma y angustia. Buenos Aires: Amorrortu.

..........(1938) "Moisés y la Religión Monoteísta" en Tres Ensayos. Buenos Aires: Amorrortu.

..........(1898). "Lo inconsciente y la conciencia" en La Interpretación de los Sueños. Obras Completas, Buenos Aires: Amorrortu. pp 355 - 362.

......... (1905) El Chiste y su relación con lo inconsciente. Obras Completas, Buenos Aires: Amorrortu. ...........(1915) "Duelo y melancolía”. Obras Completas, Volumen XIV - Trabajos sobre metapsicología, y otras obras. 
Gaborit, Mauricio (2008) "Memoria histórica: relato desde las víctimas" en Subjetividad, participación e intervención comunitaria. Una visión crítica desde América Latina. Buenos Aire:Editorial Paidos.

Geertz, Clifford (1995) “La ideología como sistema cultural” en La Interpretación de las culturas. Barcelona: Gedisa. pp. 87-117.

Giraldo, M, Javier. S.J. (1988) Los modelos de la represión. Revista Solidaridad, Noviembre, Año X No 100. Recuperado en febrero de 2002 en el sitio web: www.javiergiraldo.org.

Giraldo, M, Javier. S.J. (2004) El paramilitarismo una criminal política de Estado que devora al país. En Desde los Márgenes. http://www.javiergiraldo.org/spip.php?article76.

Gómez Gallego Jorge Aníbal, Herrera Vergara José Roberto, Pinilla Nilson (2010) "Homenaje a la memoria de las personas desaparecidas en el Palacio de Justicia, realizado por sus familiares" en Informe Final. Comisión de la Verdad sobre los hechos del Palacio de Justicia. Bogotá:Ed. Universidad del Rosario. pp. $449-472$.

Gómez, Jaime (2007) Tras las Huellas de la Verdad (Obra Póstuma) Bogotá: Fundación para la Investigación y la Cultura.

Gonzalo Sánchez G. (2004) "La Violencia y la Supresión de la Política" En Antología del ensayo en Colombia (Comp) Oscar Torres Duque. Bogotá: Banco de la República.

Gonzalo Sánchez G. (2008) Trujillo una tragedia que no cesa. Primer Informe de Memoria Histórica de la Comisión Nacional de Reparación y Reconciliación. Área de Memoria Histórica, Editorial Planeta Colombiana S. A., Introducción. pp.13 -27.

Gramsci, Antonio (1948). Concepto de Ideología en Materialismo histórico y la filosofía de Benedetto Croce. Argentina.

Guatavita y Rozo (2003) Mapiripán. Masacres: Mapas de una deshumanización [Monográfía] Departamento de Psicología. Facultad de Ciencias Humanas. Universidad Nacional de Colombia. 
Gubert, Rosana (1991) El salvaje metropolitano. Reconstrucción del conocimiento social en el trabajo de Campo. Buenos Aires: Editorial Legasa.

Halbwachs, Maurice (1950) [1998] "La memoria colectiva y el tiempo". Traducción e introducción de Vicente Huici Hormeneta [Versión digital].

Halliday, Fred (1989) Cáp I "La vieja y la nueva Guerra Fría". Cáp. IV. "Un nuevo período de revoluciones en el Tercer Mundo" en Génesis de la Segunda Guerra Fría. México: FCE.

Henríquez Chacín , Nadiezhda (2000) "Apuntes de la problematización de la memoria como derecho humano" en De Nuestras voces: Memorias para un nuevo caminar. pp. 47-60. Bogotá: Impresol editores Itda.

Hobsbawm, Erik (1995) “Cáp VIII: La Guerra Fría” en Historia del Siglo XX. Barcelona:Crítica.

Huyssen, Andreas (2002) "Monumentos y memoria del holocausto en la era de los medios"en En busca del futuro perdido. Cultura y memoria en tiempos de globalización. FCE/Goethe Institut. México. pp. 146-164.

Jelin, Elizabeth (2002) Los trabajos de la memoria. Madrid: Siglo XXI Editores.

.........(2005) Exclusión, memorias y luchas políticas. En libro: Cultura, política y sociedad Perspectivas latinoamericanas. Daniel Mato. CLACSO, Consejo Latinoamericano de Ciencias Sociales, Ciudad Autónoma de Buenos Aires, Argentina. pp. 219-239. Recuperado en marzo de 2013 del sitio web:bibliotecavirtual.clacso.org.ar/ar/libros/grupos/mato/Jelin.rtf

El Espectador (30 Jul 2012) Juez ratificó orden de captura internacional contra Luis Carlos Restrepo. Recuperado en junio de 2013 del sitio web:www.elespectador.com.

Kené KAËS (1993)[1996] "Introducción: el sujeto de la herencia" en Transmisión de la vida psíquica entre generaciones. París: Amorrortu editores. 
Kersner, Daniel ( ) Consentimiento informado o informando con consentimiento [Versión Digital]

Klein, Naomi (2007) La doctrina del shock: el auge del capitalismo del desastre (en inglés The Shock Doctrine: The Rise of Disaster Capitalism). España: Paidós.

Kordon, Diana y Edelman, Lucila (1983) Efectos Psicológicos de la represión política. Argentina [Versión Digital]

Kordon, Diana y Edelman, Lucila.(2007) Por-venires de la memoria. Ediciones Madres de Plaza de Mayo. Buenos Aires.

Kordon, D.; Edelman, L.; Lagos, D.; Kersner, D (1995) La Impunidad. Una perspectiva psicosocial y clínica. Buenos Aires:Editorial Sudamericana.

CINTRAS, EATIP, GTNM/RJ, SERSOC (2009) Daño Transgeneracional: Consecuencias de la represión política en el cono sur. Santiago: Impresión gráfica LOM.

LaCapra Dominique (2009) A la Sombra del Holocausto. En Historia y memoria después de Auschwitz . Buenos Aires: Prometeo Libros. pp. $21-58$.

Lavabre , Marie Claire Sociología (2006) “La memoria y acontecimientos traumáticos”. Cap 1 en Guerra civil, mito y memoria [Comp.] Julio Arotegui y Francois Godicheau. Madrid: Marcial Pons Ediciones de Historia, S.A. pp. $31-55$.

Lvovich Daniel y Bisquert Jacqueline (2009) Discursos sociales y legitimidad democrática. Argentina: Universidad Nacional General Sarmiento.

Lvovich, Daniel (2007) "Historia reciente de pasados traumáticos: De los fascismos y colaboracionismos europeos a la historia de la última dictadura argentina" [Comps.] Marina Franco y Florencia Levín. pp. 97-124.

Martin-Baró Ignacio (1983) Acción e ideología. Psicología social desde Centroamérica. San salvador: Talleres Uca editores.

........(1998) "La violencia política y la guerra como causas del trauma psicosocial en El Salvador" en 
Revista de Psicología de El Salvador. pp. 123 -141.

Marx, Karl y Engels, Friedrich (1985) La Ideología Alemana. Buenos Aires: Ediciones Pueblos Unidos yago.

MTDF (2012) Desapariciones forzadas en Colombia. En Búsqueda de la justicia. Documento Temático No.6 del Observatorio de Derechos Humanos y Derecho Humanitario. Coordinación Colombia - Europa - Estados Unidos. Bogotá: Editorial Códice Ltda. Recuperado en enero de 2013 del sitio web:www.rebelion.org/docs/150986.pdf.

Molano, Alfredo (2006) "Peritaje”. Caso Pueblo Bello Vs Colombia. CIDH. Sentencia del 31 de enero de 2006 [Versión Digital].

Molina Petit Cristina(1994) Público y privado desde la perspectiva semiológico formal la valoración como código de referencia en Dialéctica feminista de la ilustración. Barcelona: Anthropos.

Nación (2013) Costa Rica es nuevamente el país más feliz del mundo, según índice 'Happy Planet. Recuperado en Marzo de 2013 del sitio web:www.nacion.com.

Noticias Caracol (19 de diciembre de 2011) La mentira de la desmovilización del bloque "Cacica la Gaitana" de las FARC. Recuperado en Marzo de 2013 del sitio web:www.noticiascaracol.com.

Palermo, Vicente (2004) "Entre la memoria y el olvido: represión, guerra y democracia en la Argentina" en La historia reciente de Argentina en democracia [Comp.] Marcos Novaro y Vicente Palermo. Buenos Aires:Edhasa.

Pérez-Sales Pau (2008) Repensar Experiencias. Evaluación (y diseño) de programas psicosociales. Metodologías y técnicas. Grupo de Acción Comunitaria . Recuperado en Marzo de 2013 del sitio web: www.psicosocial.net

Pizarro Leongomez (septiembre de 2006) "Marquetalia: El mito fundacional de las FARC" en UN Periódico. Recuperado en Octubre de 2013 del sitio web: historico.unperiodico.unal.edu.co/Ediciones/57/03.htm 
Polla, Michell (2006) "Memoria, Olvido, Silencio" en Memoria, Olvido, Silencio La producción social de identidades frente a situaciones límite. La Plata: Ed. Al Margen.

Potel Horacio (2010) "Cuestiones de herencia. Fantasma, duelo y melancolía en Jacques Derrida" en Los (con)fines del arte. Reflexiones desde el cine, el psicoanálisis y la filosofía. México, Universidad Nacional Autónoma de México. Recuperado en marzo de 2013 del sitio web: www.jacquesderrida.com.ar

Profesionales oficiales de Reserva (2013) Todo por la Patria. Recuperado en Mayo de 2013 del sitio web: porbr4.org/sitio/index.php/inicio.html.

Proyecto Colombia Nunca Más (2000) Colombia Nunca Más. Crímenes de Lesa Humanidad. Zona 7 ma 1966. Introducción General Zona Séptima. Recuperado Febrero de 2012 del sitio web: http://www.movimientodevictimas.org.

Proyecto Colombia Nunca Más (2008) Colombia Nunca Más. Crímenes de Lesa Humanidad. Zona 5ta 1966 - 1998 [CD-Rom].

Proyecto Colombia Nunca Más (2008) Mecanismos de Represión. Recuperado en Febrero de 2012 del sitio web: http://www.movimientodevictimas.org.

República de Colombia (1966) Decreto Legislativo 3398 De 1965. Diciembre 24. Diario Oficial No. 31.842, 25 de enero de 1966.

Revista Cambio/Agencia Voces (25 de mayo de 2009) Cambio conoció hornos crematorios que construyeron los paramilitares en Norte de Santander. Recuperado en marzo de 2012 del sitio web:www.lasvocesdelsecuestro.com/articulos_detalle.php?id=168.

Robben, Antonius C. G. M (1989) "Seducción Etnográfica, Transferencia, y Resistencia" en Diálogos sobre Terror y Violencia en Argentina. Recuperado en febrero de 2012 el sitio web: dialnet.unirioja.es/descarga/articulo/2725360.pdf

Romero, José Luis (1986): "La ciudad latinoamericana: continuidad europea y desarrollo autónomo", en Situaciones e ideologías en Latinoamérica, Buenos Aires:Sudamericana. pp. 213-219. 
Sánchez Torres, Carlos Ariel (2001) "Notas a la decisión judicial sobre la muerte de Gaitán" en Revista de Estudios socio jurídicos de la Universidad del Rosario. Vol 3. No1. Recuperado en diciembre de 2013 del sitio web: http://revistas.urosario.edu.co.

Sandberg, Anders (Octubre de 2010) “¿Debemos borrar nuestros recuerdos?” en BBC Focus.

Recuperado en Marzo de 2013 del sitio web:

www.bbc.co.uk/mundo/noticias/2010/10/101026_borrar_recuerdos.shtml.

Semana.com (29 septiembre 2009) Condenado asesino de psicóloga en Medellín. Recuperado en Febrero de 2013 del sitio web: www.semana.com/nacion/articulo/condenado-asesino-psicologamedellin/108081-3

Tisseron, Serge (1997) El psiquismo ante la prueba de las generaciones. Clínica del fantasma. Buenos Aires: Amorrortu.

Thompson, Edward Palmer (1977) "Introducción" en La formación histórica de la clase obrera. Inglaterra 1780-1832, Barcelona: Laia. pp. XIII - XVIII.

Sierra, Alejandro (2009) Saturno Sigue Devorando A Sus Hijos. El advenimiento de lo "monstruoso" en la lucha contra el terrorismo y los casos de falsos positivos en Colombia [Monografía] Universidad Nacional de Colombia Facultad de Ciencias Humanas. Bogotá.

Sorgentini, Hernán (2003) "Reflexión sobre la memoria y autorreflexión de la historia" en Revista Brasileira de Historia. vol. 23, n 45.pp. 103-128. Recuperado en febrero de 2013 del sitio web: www.redalyc.org.

Traverso, Enzo (2010) Historiografía y memoria: interpretar el siglo xx. Conferencia dictada en la Universidad Nacional de la Plata [Grabaciones de Audio].

Tribunal Permanente de Los Pueblos (1 - 2 de Abril de 2006) Primera Audiencia Bogotá Dictamen del Jurado. Sesión sobre empresas transnacionales y derechos de los pueblos en Colombia - 2006 -2008 [Versión Digital]. 
Unimedios (Septiembre de 2006) La Isla Maldita. Recuperada en mayo de 2013 del sitio web: historico.unperiodico.unal.edu.co

Uribe, Álvaro (20 de julio de 2010) Discurso de Álvaro Uribe en la Instalación del Congreso [Video]. Recuperado en febrero de2013 del sitio web: www.youtube.com/watch?v=09ezCsrRbXQ

Uribe, Álvaro (25 de julio de 2010) Discurso de Álvaro Uribe en la Macarena. Municipio de la Macarena, provincia del Meta [Video] Recuperado en febrero de 2013 del sitio web: www.youtube.com/watch?v=LYHkNpbEb9Y

Verdad Abierta (12 de diciembre de 2012) Exterminio de la UP fue un genocidio político. Recuperado en marzo de 2013 del sitio web: www.verdadabierta.com.

Visacovsky, Sergio E.(2007) "Cuando las sociedades conciben el pasado como"memoria”: Un análisis sobre verdad histórica, justicia y prácticas sociales de narración a partir de un caso argentino". En Antipoda. Revista de Antropología. Universidad de los Andes (Enero-Junio). Colombia. http://es.scribd.com/doc/101815959/Cuando-Las-Sociedades-Conciben-El-Pasado-VisacovskySergio-E-Author

Werba, Alicia ( ） Transmisión entre generaciones. Los secretos y los duelos ancestrales [Versión Digital]. Recuperado en marzo de 2013 del sitio web: www.apdeba.org/wpcontent/uploads/werba.pdf

Yerushalmi, Josef Hayim (1981) [2002] “Introducción” de Zajor. La Historia judía y la memoria judía. Barcelona: Antrophos, pp. XI - XXXVI.

Yerushalmi, Josef Hayim (1985) "Reflexiones sobre el olvido" en Usos del olvido. Buenos Aires: Ediciones Nueva Visión. Prologo de Eduardo Rabossi. pp. 13-26.

Zizek, Slavoj (2003). “Introducción. El espectro de la ideología” en Ideología. Un mapa de la cuestión [comp.] Buenos Aires: Fondo de Cultura económica. 
